\title{
ATRIBUTOS DOS LATOSSOLOS MAPEADOS EM CERRADOS (BRASIL CENTRAL) E FLORESTA AMAZÔNICA
}

\author{
ANTONIO ANTENOR TOGNON \\ Geólogo
}

Orientador: Prof. Dr. JOSÉ LUIZ IORIATTI DEMATTÊ

Tese apresentada à Escola Superior de Agricultura "Luiz de Queiroz", da Universidade de São Paulo, para obtenção do título de Doutor em Agronomia, Área de Concentração: Solos e Nutrição de Plantas.

P I R A C I C A B A

Estado de São Paulo - Brasil

Janeiro - 1997 
Dađos Internacionais de Catalogação na Publicação (CIP) DIVISĀo DE BIBLIOTECA E DOCUMENTAÇĀO - Campus "Luiz de Queiroz"/USP

Tognon, Antonio Antenor

Atributos dos latossolos mapeados em cerrados (Brasil Central) e floresta amazónica / Antonio Antenor Tognon. - - Piracicaba, 1997.

192 p. : II.

Tese (doutorado) -- Escola Superior de Agricultura Luiz de Queiroz, 1997.

Bibliografia.

1. Caracterização quimica 2. Cerrado 3. Floresta amazónica 4. Latossolo 5.1 Solo de cerrado 6. Solo florestal 7. Mapeamento I. Título. 


\title{
ATRIBUTOS DOS LATOSSOLOS MAPEADOS EM CERRADOS (BRASIL CENTRAL) E FLORESTA AMAZÔNICA
}

\author{
ANTONIO ANTENOR TOGNON
}

Aprovada em: $25 / 04 / 1997$

Comissão Julgadora:

Prof. Dr. José Luiz Ioriatti Demattê ESALQ/USP

Prof. Dr. Carlos Clemente Cerri

CENA/USP

Prof. Dr. Carlos Roberto Espíndola

FEAGRI - UNICAMP

Prof. Dr. Jairo Roberto Jimenez Rueda

UNESP

Prof. Dr. Celso Augusto Clemente

ESALQ/USP

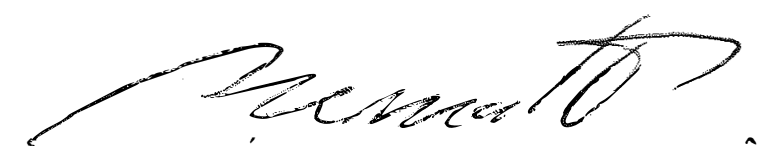

Prof. Dr. JOSÉ LUIZ IORIATTI DEMATTÊ

- Orientador - 


\section{AGRADECIMENTOS}

Sinceros agradecimentos a todos que colaboraram para que a presente pesquisa fosse realizada:

- À Escola Superior de Agricultura "Luiz de Queiroz" - ESALQ, pela possibilidade do desenvolvimento deste trabalho.

- Ao Professor Dr. José Luiz Ioriatti Demattê, orientador, o meu testemunho de gratidão pela orientação segura e eficiente, pelo a poio e incentivo em todos os momentos e pela amizade.

- Aos colegas Luiz Fernando Novello pelo apoio na formação do banco de dados e Marcelo Corrêa Alves pelo apoio no tratamento estatístico dos dados.

- A todos os docentes, funcionários e colegas do Departamento de Ciência do Solo que em muito colaboraram durante a realização do meu curso de pós-graduação e pela amizade.

- Aos membros da Comissão do Curso de Pós-Graduação em Solos e Nutrição de Plantas, especialmente ao coordenador Prof. Dr. Francisco Antonio Monteiro e ao Prof. Dr. Álvaro Pires da Silva pelo acompanhamento e orientação na etapa final do meu curso de pós-graduação.

- Aos pesquisadores Prof. Dr. Carlos Roberto Espíndola, Prof. Dr. Carlos Clemente Cerri, Prof. Dr. Celso Augusto Clemente e Prof. Dr. Jairo Roberto Jimenez Rueda, participantes da banca examinadora desta tese pelos importantes comentários e valiosas sugestões.

- Ao CNPq, pela bolsa de estudo. 


\section{SUMÁRIO}

Página

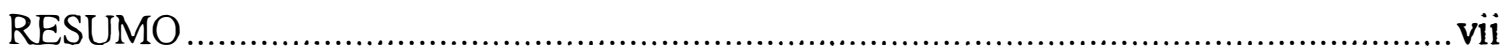

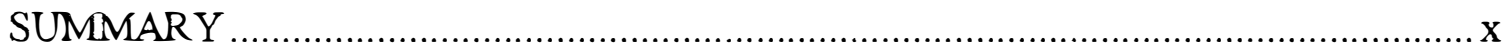

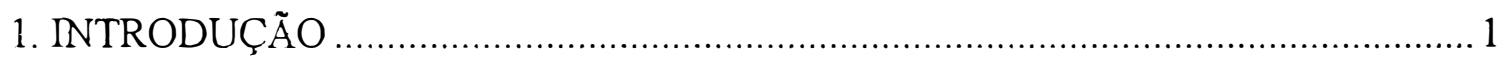

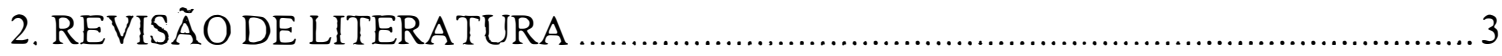

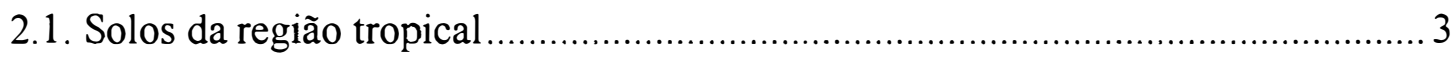

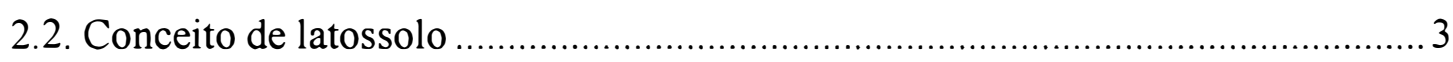

2.3. Latossolos da região amazônica e dos Cerrados ................................................... 5

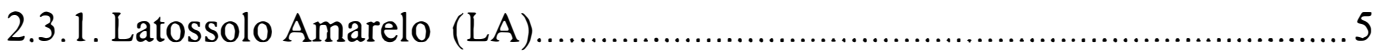

2.3.2. Latossolo Vermelho Amarelo (LV) _..................................................... 7

2.3.3. Latossolo Vermelho Escuro (LE) ..................................................... 7

2.3.4. Características mineralógicas da fração argila dos latossolos ..................... 8

2.3.5. Características químicas dos latossolos ............................................... 10

2.4. Ação dos fatores de formação: clima, vegetação e material de origem nas

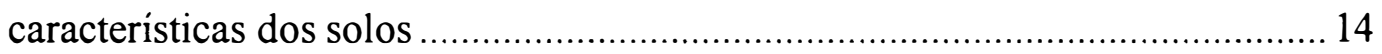

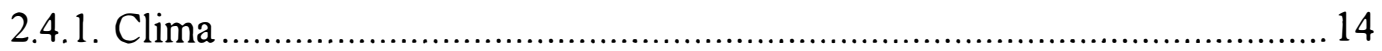

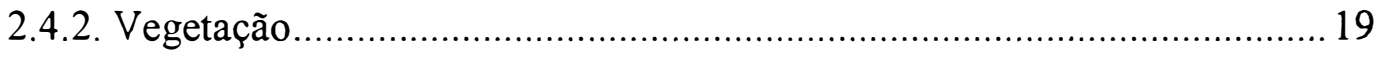

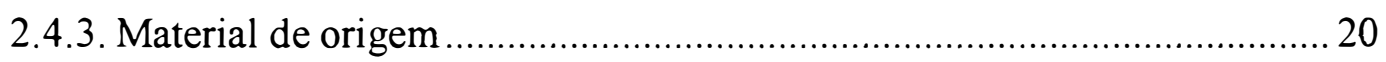

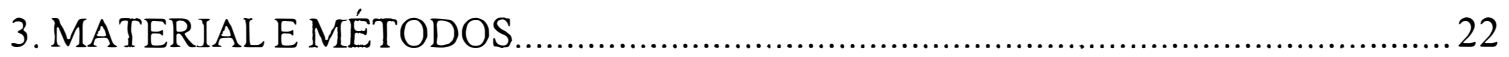

3.1. Descrição das áreas estudadas: Amazônia e Cerrados ...........................................22

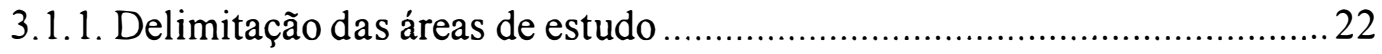

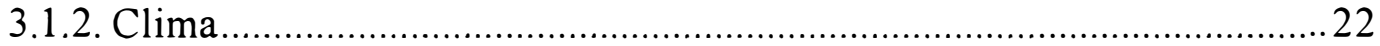

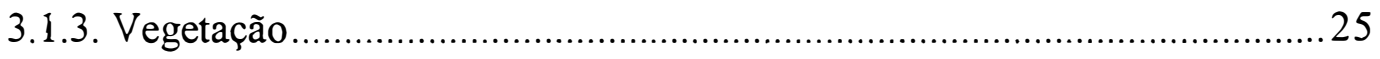

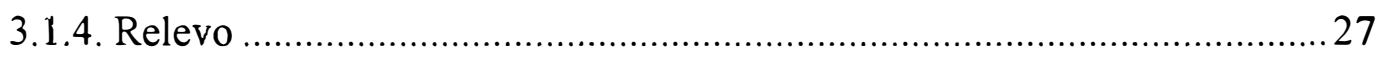

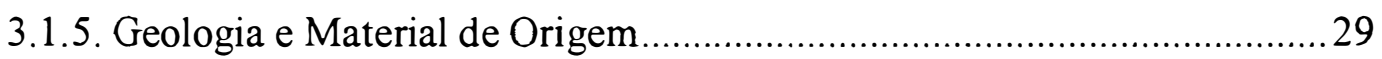




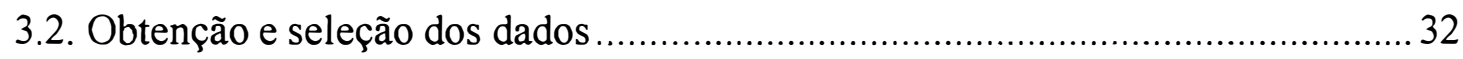

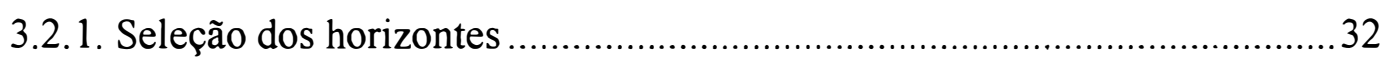

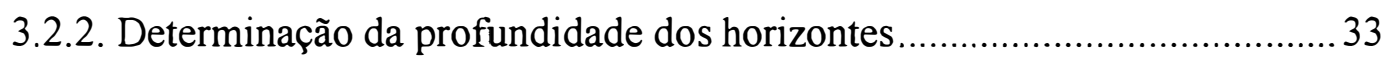

3.2.3. Seleção das características granulométricas e químicas.............................. 33

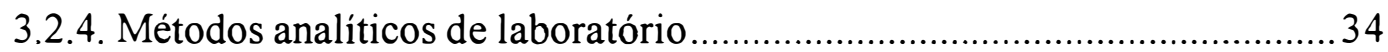

3.3. Métodos estatísticos empregados e tratamentos dos dados …..............................35

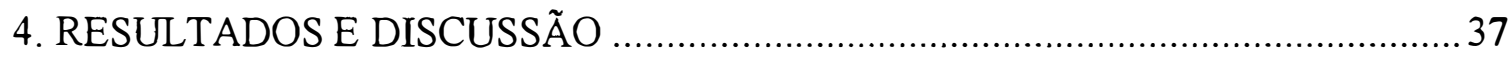

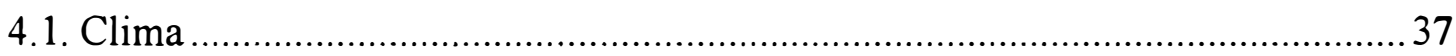

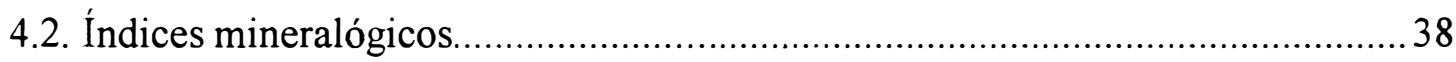

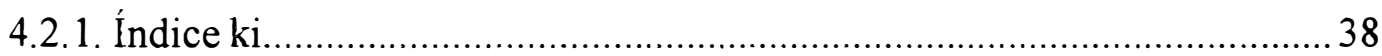

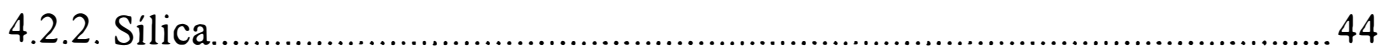

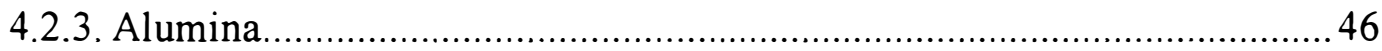

4.2.4. Teor de ferro total, extraído pelo ataque sulfúrico ...................................48

4.3. Propriedades morfológicas e granulométricas ................................................... 51

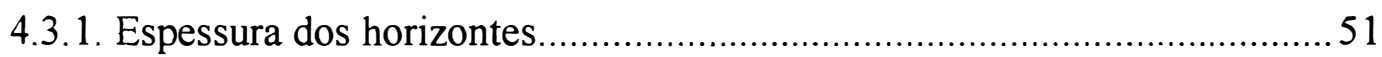

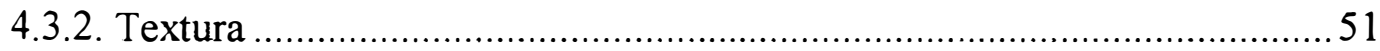

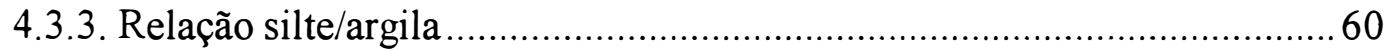

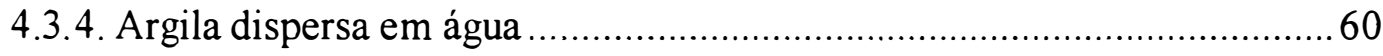

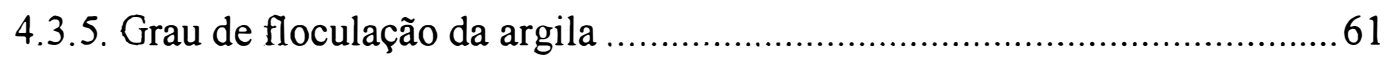

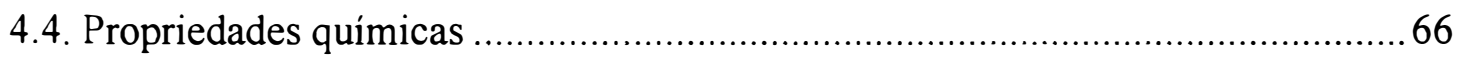

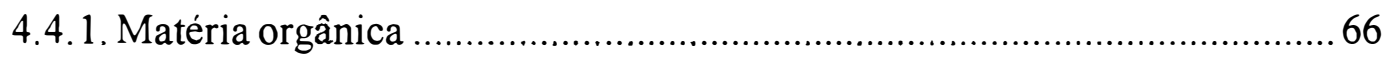

4.4.2. Relação $\mathrm{C} / \mathrm{N}$

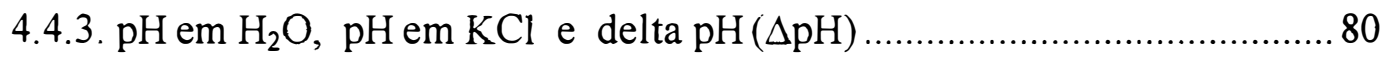

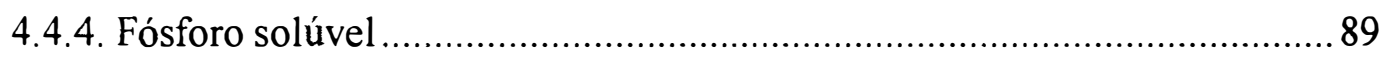

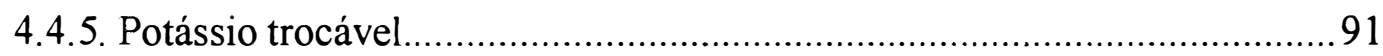

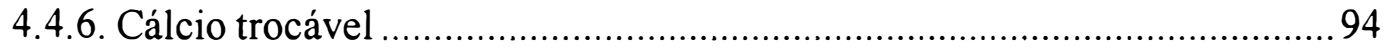

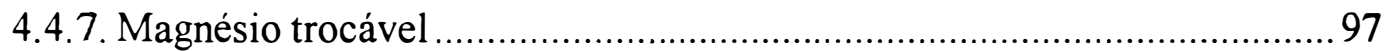

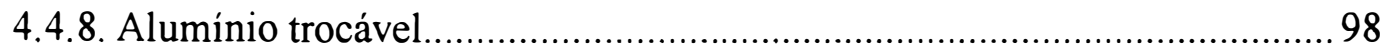

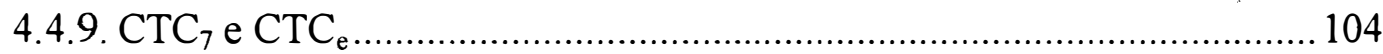

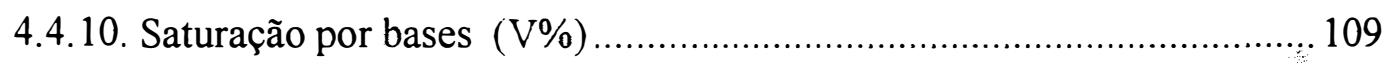

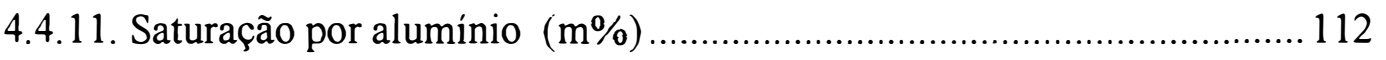




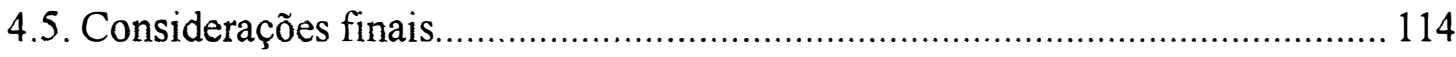

5. CONCLUSÕES

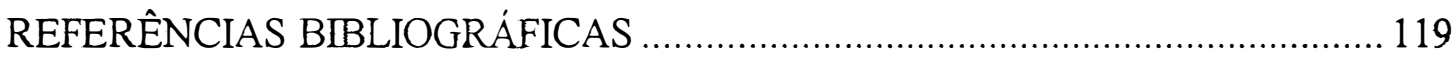

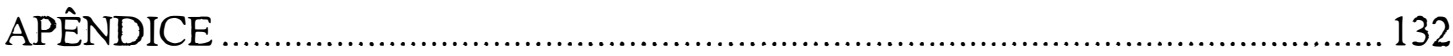




\title{
ATRIBUTOS DOS LATOSSOLOS MAPEADOS EM CERRADOS (BRASIL CENTRAL) E FLORESTA AMAZÔNICA
}

\author{
Autor: ANTONIO ANTENOR TOGNON \\ Orientador: Prof. Dr. José Luiz Ioriatti Demattê
}

\section{RESUMO}

Com o principal objetivo de caracterizar os latossolos da Amazônia e correlacioná-los com os dos Cerrados, foi desenvolvida esta pesquisa. Para isso foi delimitada, através dos mapas de solos, uma área compreendida entre os paralelos $04^{\circ} 00^{\prime} \mathrm{N}$ e $20^{\circ} 00^{\prime} \mathrm{S}$ e $48^{\circ} 00^{\prime} \mathrm{e} 75^{\circ} 00^{\prime} \mathrm{WGr}$., sendo que a área da Amazònia foi considerada até o paralelo $12^{\circ} 00^{\prime} \mathrm{S}$ abrangendo uma área de $3859730 \mathrm{~km}^{2}$ e a dos Cerrados até o paralelo $20^{\circ} 00^{\prime} \mathrm{S}$, abrangendo $1406342 \mathrm{~km}^{2}$. Ambas totalizam $5255072 \mathrm{~km}^{2}$. Nesta área foram selecionados 262 perfis de latossolos sendo, na região amazônica, 78 de Latossolo Amarelo e 184 de Latossolo Vermelho Amarelo e na região dos Cerrados, 123 perfis de Latossolo Vermelho Amarelo e 121 de Latossolo Vermelho Escuro. Tais perfis foram grupados de acordo com as características climáticas, de vegetação e de material de origem. Foram selecionadas 5 profundidades para o estudo dos atributos dos solos, a saber: $0-15: 15-35 ; 35-60 ; 60-100 ; 100-180 \mathrm{~cm}$. Os principais atributos dos solos analisados foram os seguintes: granulometria; $\mathrm{pH}$; teor de matéria orgânica, teor de fósforo; bases trocáveis; CTC a pH 7,0, saturação por bases e indice ki. As principais conclusões foram as seguintes: 
a. Quanto a metodologia das determinações analíticas: o coeficiente de variação da maioria dos atributos estudados esteve elevado refletindo a variabilidade da própria metodologia empregada.

b. Quanto ao aspecto granulométrico os latossolos da Amazônia são mais argilosos e siltosos do que os dos Cerrados. Dentre os latossolos da Amazônia o Latossolo Vermelho Amarelo é pouco mais siltoso do que o Latossolo Amarelo. A presença de um horizonte $\mathrm{A} / \mathrm{B}$ mais denso, principalmente no Latossolo Amarelo e com características de encharcamento temporário, reflete uma estrutura menos estável, quando comparada com os solos dos Cerrados. Neste particular, o menor teor de ferro no Latossolo Amarelo não deixa de ser um fator negativo na estabilidade da estrutura.

c. Quanto ao aspecto mineralógico, os solos da região amazônica são menos intemperizados do que os solos da região dos Cerrados, com índice ki na faixa de 1,8 a 2,1 , contra ki inferiores a 1,5 para a região dos Cerrados. Dentre os solos amazônicos, o Latossolo Amarelo apresenta maior valor de ki quando comparado com o Latossolo Vermelho Amarelo e conseqüentemente menos intemperizado. De acordo com tais valores, há dominância de caulinita com pequena contribuição de minerais 2:1 para a região amazônica contra a dominância de caulinta e óxidos para a região dos Cerrados.

d. Quanto aos aspectos de fertilidade:

- Os solos da Amazônia comparados com os dos Cerrados são mais ácidos, com maior teor de Al trocável e com maior valor de CTC a pH 7,0.

- Levando-se em consideração apenas os latossolos da Amazônia o Latossolo Vermelho Amarelo apresenta menor teor de alumínio trocável e menor valor de CTC a pH 7,0.

- Os teores de bases ( $\mathrm{Ca}$ e $\mathrm{Mg}$ ) e de P estão abaixo do nível crítico para a maioria das culturas para ambas regiões, sendo talvez os principais fatores limitantes à uma agricultura desenvolvida. 
- Na Amazônia há uma predominância de latossolos álicos, enquanto que nos Cerrados de latossolos distróficos.

- O teor de matéria orgânica é maior na região Amazônica nos horizontes superficiais. À medida que aumenta a profundidade do solo e o teor de argila, aumenta o teor de matéria orgânica na região dos Cerrados, ultrapassando os da Amazônia.

e. Quanto à influência do material de origem:

- Apesar da região amazônica ser caracterizada por apresentar condições bastante agressivas do clima atual para o intemperismo profundo, há fortes indícios da influência do material de origem nas propriedades do solo, tanto para o Latossolo Amarelo como para o Latossolo Vermelho Amarelo. O material de origem da Formação Solimões comparado com o da Formação Barreiras tende a originar solos mais argilosos, mais siltosos e com maior teor de alumínio.

f. Quanto ao potencial da região para a produção de alimentos:

- Tendo-se por base os elementos aqui examinados pode-se concluir que as diferenças básicas entre os solos da duas regiões se devem a uma melhor estrutura do solo para a região dos Cerrados e a um valor menor da CTC e do alumínio. Por outro lado, uma vez retirada a mata da região amazônica, os fatores limitantes dos solos para ambas as regiões são semelhantes, porém mais acentuados na Amazônia. 


\title{
ATTRIBUTES OF LATOSOLS MAPPED IN THE "CERRADO" (CENTRAL BRAZU) AND AMAZON FOREST
}

\author{
Author: ANTONIO ANTENOR TOGNON \\ Adviser: Prof. Dr. José Luiz Ioriatti Demattê
}

\section{SUMMARY}

The primary goal of this research was to characterize the amazonian latosols and correlate them to those of the 'cerrado'. An area comprised between parallels $04^{\circ} 00^{\prime} \mathrm{N}$ and $20^{\circ} 00^{\prime} \mathrm{S}$ and $48^{\circ} 00^{\prime}$ and $75^{\circ} 00^{\prime} \mathrm{Wgr}$ was delimited through soil maps, with the amazonian area considered as far as parallel $12^{\circ} 00^{\prime} \mathrm{S}$ and that of the 'cerrado' as far as parallel $20^{\circ} 00^{\prime} \mathrm{S}$, scoping an area estimated in 5,3 million $\mathrm{km}^{2} .262$ latosol profiles were selected in that area, with 78 Yellow Latosol and 184 Red-Yellow Latosol in the amazonian region, and 123 profiles of Red-Yellow Latosol and 121 DarkRed Latosol in the 'cerrado' region. These profiles were grouped according to climate, vegetation, and original material characteristics. Five depths were selected for the study of soil attribute: $0-15 ; 15-35 ; 35-60 ; 60-100 ; 100-180 \mathrm{~cm}$. The main attributes of soils were: granulometry; $\mathrm{pH}$; organic matter content; phosphorus content; changeable bases; $\mathrm{CTC}$ at $\mathrm{pH}$ 7.0, base saturation, and ki rates. The main conclusions were:

a. As to the methodology of analytic determinations: the variation coefficient of most studied attributes was high thus reflecting the variability of the methodology itself.

b. Regarding the granulometry aspect, amazonian latosols present more clay and silt than those of the "cerrado". Among amazonian latosols the Red-Yellow Latosol is slightly siltier than the Yellow Latosol. The presence of a denser horizon A/B - 
specially in Yellow Latosol and temporary waterlogging features - reflects a less stable structure when compared to 'Cerrado' soils. In that particular, the lowest iron content in Yellow Latosol could be considered as a negative feature in the stability of the structure.

c. As to the mineralogical aspect, soils in the amazonian region are less weather-beaten than those of the 'Cerrado' region, with ki rates ranging from 1.8 to 2.1 against ki lower than 1.5 for the 'Cerrado' region. Among amazonian soils the Yellow Latosol presents highest ki values when compared to the Red-Yellow Latosol and is therefore less weather-beaten. According to these values there is kaolinite dominance with a slight contribution of minerals of $2: 1$ for the amazonian region versus kaolinite and oxide dominance for the 'Cerrado' region.

d. Fertility aspects:

- Amazonian soils are more acid, have a higher exchangeable Al content, and higher CTC value at pH 7.0 in comparison with 'Cerrado' ones.

- By considering amazonian latosols alone, the Red-Yellow Latosol presents lower exchangeable aluminum content and lower CTC value at $\mathrm{pH}$ 7.0.

- Base ( $\mathrm{Ca}$ and $\mathrm{Mg}$ ) and $\mathrm{P}$ contents are below the critical level for most crops for both regions, and may be the main limiting factors in developed agriculture.

- Alic latosols prevail in the amazonian region while dystrophic ones are more common in the 'Cerrado' region.

- The organic matter content is higher in the amazonian region in superficial horizons. As soil depth and clay content increase the organic matter content increases at the 'Cerrado' region, and is higher than that in the Amazonia.

e. Influence of original material:

- Although the amazonian region is characterized by its quite hostile conditions towards the actual climate for a deep weathering, there are strong signs of influence of the original material on soil properties, both for Yellow Latosol and for Red- 
Yellow Latosol. When compared to the Formação Barreiras, the original material of the Formação Solimões tends to provide soils with more clay and silt, and with higher aluminum content.

f. Potential of the region as a food producer:

- Based on the elements examined here the primary differences between the soil of the both regions are found to be due to a better soil structure at the 'Cerrado' region and to a lower CTC and aluminum values. On the other hand, once the woods of the amazonian region are withdrawn the limiting factors of soils for both regions are similar, although more evident in Amazonia. 


\section{INTRODUÇÃO}

A região amazônica com aproximadamente 4,8 milhões de $\mathrm{km}^{2}$, apresenta cerca de $45 \%$ de latossolos sendo seguido pelos solos podzolizados com cerca de $35 \%$ (Demattê, 1988). Nos últimos 30 anos, cerca de $25 \%$ das áreas exploradas com pecuária nesta região foram degradadas e semi-abandonadas. As principais causas para a degradação são conseqüência do desconhecimento das reações do meio ambiente a esta atividade, da baixa fertilidade dos solos, da implantação de gramíneas inadequadas e do sistema de manejo das pastagens inapropriado (Serrão et al., 1979). Grande parte dos sistemas de agricultura, em larga escala, não estão tendo o sucesso esperado nesta região.

Por outro lado, a área dos Cerrados com cerca de 2,04 milhões de $\mathrm{km}^{2}$, representada pelas regiões central e centro-oeste do território nacional, produz atualmente $35 \%$ de grãos do pais (soja, milho e arroz) e com uma pecuária em franco desenvolvimento. Os solos desta região são predominantemente de baixa fertilidade. Os latossolos cobrem $48,8 \%$ da área, sendo seguidos pelos podzólicos e areias quartzosas que perfazem respectivamente 15,1 e 15,2\% (Macedo, 1996).

Os inúmeros êxitos alcançados com a agricultura e a pecuária na região dos Cerrados quando comparados com a região amazônica, se devem ao melhor conhecimento e desenvolvimento de práticas de manejo desenvolvidas principalmente pelo CPAC. Áreas consideradas infertéis e improdutivas no passado recente, hoje apresentam produtividades compatíveis ou até superiores às grandes regiões produtoras de paises do primeiro mundo. 
Com o intuito de melhor entender os dois ecossistemas em termos de seus solos foi proposta a execução desta pesquisa, tendo os seguintes objetivos:

a. Caracterizar os latossolos tanto da região amazônica como dos Cerrados quanto ao seu aspecto granulométrico, químico e mineralógico assim como, observar a variabilidade de tais atributos.

b. Estudar as possiveis semelhanças e diferenças nos atributos destas duas regiões para possibilitar um melhor entendimento de seu manejo, tendo-se como base o êxito alcançado pela agricultura na região dos Cerrados.

c. Fazer um adequado levantamento dos fatores limitantes ao uso agrícola, principalmente para os latossolos da amazônia, e verificar se tais fatores podem ser atenuados tendo em vista o êxito que tem sido alcançado na região dos Cerrados.

d. Caracterizar as possíveis relações entre os atributos dos latossolos, principalmente da Amazônia, com os fatores de formação, principalmente o material de origem. A hipótese para este caso supos-se que: "apesar dos latossolos da Amazônia e dos Cerrados serem solos muito lixiviados e profundos e terem sofrido ação climática anterior, seus atributos guardam ainda heranças com o material de origem".

Para tanto, foram utilizadas as informações contidas nos diferentes volumes do Projeto RADAMBRASI que abrangem tanto a região dos Cerrados como da Amazônia, e feitas tentativas de correlacioná-las. 


\section{REVISÃO DE LITERATURA}

\subsection{Solos da região tropical}

Os solos da região tropical úmida são conhecidos, em sua maioria, como altamente intemperizados e com argilo-mineral de baixa atividade.

Sánchez \& Buol (1974) relataram que os solos mais representativos dos trópicos úmidos possuem baixa soma de bases e são altamente lixiviados classificando-se como: Oxissol, Ultissol, alguns Inceptissol e Entissol. Estes solos abrangem aproximadamente $51 \%$ dos trópicos compreendendo vastas áreas da América do Sul, África Central e pequenas áreas do Sudeste da Ásia. Segundo Alvim (1973) mais de $90 \%$ dos solos dos trópicos da América Latina, são os latossolos florestados, denominados Oxissol ou Ferralsol, possuindo, na sua maioria, boas propriedades fisicas, mas, sendo quimicamente pobres. Nos trópicos úmidos sulamericanos, conforme pode-se observar na Folha IV-1 do Mapa Mundial de Solos da FAO/UNESCO (1971), destacam-se os Ferralsols Xânticos.

Os estudos em áreas tropicais ressaltaram a ocorrência mais ampla de solos menos evoluídos como os Ultissol (Buol et al., 1973; Mass, 1974) e inclusive Alfissol (Mohr et al., 1972; Alvim, 1973).

\subsection{Conceito de latossolo}

Kellogg (1949), ao propor o termo latossol atribuiu algumas propriedades que estão associadas com os solos dos trópicos, quais sejam: baixa relação sílica/sesquióxidos, baixa capacidade de troca, baixo conteúdo de minerais primários 
intemperizáveis, baixo conteúdo de constituintes solúveis e alto grau de estabilidade de agregados nos latossolos com matizes vermelhos ou avermelhados. Mais tarde, ao se referir especificamente aos latossolos do Brasil, Kellogg \& Orvedal (1969) mencionam a alta produtividade destes solos em resposta aos fertilizantes, onde as boas propriedades fisicas facilmente mantêm uma boa estrutura para os cultivos.

O conceito de latossolo na classificação brasileira está ligado ao conceito de horizonte B (Bennema et al., 1959; Brasil, 1960; Bennema 1963, 1966; Beek \& Bramão, 1969). Os latossolos caracterizam-se por serem muito profundos (freqüentemente superiores a $2 \mathrm{~m}$ ), bem drenados, e com seqüência de horizontes $\mathrm{A}, \mathrm{Bw}$ e C com limites difusos ou graduais. No horizonte B, os teores de argila são constantes ao longo do perfil, podendo aumentar pouco, sem contudo, configurar um B textural. São solos minerais em estágio avançado de intemperização, destituídos de minerais primários intemperizáveis, e sendo formados predominantemente por argilominerais 1:1 e óxidos hidratados de ferro e alumínio. Nos latossolos predominam as frações areia e argila. O silte apresenta-se na faixa de 10 a $20 \%$ e a relação silte/argila é inferior a 0,7 . A estrutura predominante apresenta-se sob a forma de blocos subangulares (fracamente desenvolvidos) muito pequena, granular ou maciça. As cores dos latossolos variam de vermelho muito escuro a amarelado. $\mathrm{Na}$ distinção dos grandes grupos de latossolos, vários estudos têm demonstrado que as cores dos diferentes latossolos estão mais relacionadas com o mineral de óxido de ferro: hematita e goetita do que com a quantidade de óxido de ferro (Weaver, 1974; Rodrigues, 1977; Volkolf, 1978; Souza, 1979). Os Latossolos Vermelho Escuro e Roxo apresentam predomínio de hematita, enquanto que nos demais latossolos ocorrem hematita e goetita. Há um predomínio da goetita e tendência de seu incremento, quanto mais amarelada for a cor do solo. Esta diferenciação na paisagem está condicionada ao regime hídrico e movimento de água no perfil do solo. 


\subsection{Latossolos da região amazônica e dos Cerrados}

Dentre os principais trabalhos referentes ao estudo de solos da Amazônia mencionam-se o levantamento de reconhecimento dos solos da região Bragantina (Vieira et al., 1967), da Colônia Agrícola de Tomé-Açú (Falesi et al., 1964); da Colônia Agrícola Paes de Carvalho (Falesi et al., 1970), da região fisiográfica do Xingu (Falesi, 1967), da Ilha de Marajó (Santos et al., 1964), do Estado do Pará (Vieira et al., 1971), da Rodovia Transamazônica (Falesi, 1972b), do distrito Agropecuário da SUFRAMA (Rodrigues et al., 1971), da Estrada de Ferro do Amapá (Falesi, 1964).

Falesi (1972a) relatou a existência de alguns levantamentos exploratórios e de reconhecimento dos solos de Benjamin Constant e Tefé no Estado do Amazonas, próximo à fronteira com a Colômbia. Desses relatórios, Falesi verificou que o Latossolo Amarelo com matizes 10YR e 7,5YR, cromas e valores altos, são distribuídos em grande extensão, em associação com Latossolos Vermelhos Amarelos, matiz $5 \mathrm{YR}$ e solos Podzólicos Vermelhos Amarelos.

A partir de 1973, toda a área em estudo foi alvo de levantamentos de recursos naturais pelo Projeto RADAMBRASIL, ao nivel de 1:1 000 000, achando-se os resultados consubstanciados na série de volumes editados. Os volumes de 4 a 27 proporcionam importantes subsídios para o estudo dos solos da Amazônia e dos Cerrados.

\subsubsection{Latossolo Amarelo (LA)}

O Grande Grupo Latossolo Amarelo apresenta as características fundamentais da subordem Latossolo, identificando-se por possuir horizonte B com coloração amarela com matizes 10YR e 7,5YR, com valores e cromas quase sempre altos, e são normalmente menos friáveis do que os vermelhos amarelos e os vermelhos escuros. Corresponde na classificação americana de solos (E.U.A., 1975) aos Grandes Grupos Hapludox, Acrudox, e mais raramente, aos Umbriudox e Acrusthox, todos pertencentes à Ordem Oxissol. 
De acordo com o sistema Brasileiro de Classificação de Solos (EMBRAPA, 1981a), os Latossolos Amarelos pertencem à Classe 8 que corresponde ao grupamento de solos com B latossólico. De acordo com o teor de argila no horizonte B, são subdivididos em classes texturais distintas, tais como: média, argilosa e muito argilosa (EMBRAPA, 1979).

De modo geral, os Latossolos Amarelos ocorrem em áreas geologicamente atribuídas ao Terciário, onde a Formação Barreiras aparece com maior representação geográfica (Oliveira \& Leonardos, 1943). Ocorrem na região Amazônica em relevo plano, suave ondulado e em alguns locais em relevo ondulado como nas áreas situadas entre Manaus e Itacoatiara (Brasil, 1969); Cacau Pirera-Manacapuru (Silva et al., 1970); e rodovia Belém-Brasília (Sombroek, 1962).

Segundo Falesi (1972a), o Latossolo Amarelo constitui a unidade pedogenética de maior representação geográfica da Amazônia Brasileira. A vegetação que normalmente o recobre é a floresta equatorial úmida, porém pode ser observado em cerrados, cerradão e campo cerrado (Pires, 1973).

Sombroek (1966), estudando algumas áreas da região amazônica, desenvolveu uma classificação do Latossolo Amarelo, combinando conceitos e definições de Baldwin et al. (1938), Thorp \& Smith (1949) e o Sistema Brasileiro. A classificação estabelece três níveis de categorias: Grande Grupo, Sub-Grupo e fases. As fases encontradas de Latossolos Amarelos na fronteira da Colombia com o Brasil foram denominadas como:

a) Latossolo Amarelo caulinítico de textura indiscriminada;

b) Latossolo Amarelo caulinítico de textura muito argilosa;

c) Latossolo Amarelo caulinítico de textura média.

Os Latossolos Amarelos cauliníticos são fortemente intemperizados, sendo solos bem drenados. O perfil tem uma seqüência $A-B-C$, pouco diferenciados. $O$ horizonte $\mathrm{B}$ corresponde às exigências do horizonte $\mathrm{B}$ latossólico, definido por Bennema (1966), mas com estrutura moderada para fracamente desenvolvida. 
Na região dos Cerrados o Latossolo Amarelo tem sua maior ocorrência na área de influência amazônica, ao norte do Estado de Mato Grosso.

\subsubsection{Latossolo Vermelho Amarelo (LV)}

As características morfológicas, físicas e químicas do Latossolo Vermelho Amarelo são semelhantes às do Latossolo Amarelo, diferindo porém na coloração que é mais avermelhada e pelos teores de óxidos de ferro ( 7 a $11 \%$ na textura argilosa) e relação molecular $\mathrm{Al}_{2} \mathrm{O}_{3} / \mathrm{Fe}_{2} \mathrm{O}_{3}$ maior que 3,14 (Bennema \& Camargo, 1964).

Na Amazônia o Latossolo Vermelho Amarelo recobre 19,7\% de sua área total e são originados de materiais de partida similares aos do Latossolo Amarelo. Rodrigues (1996) ressaltou, entretanto, que os localizados na parte sul da região, são mais evoluídos. São solos com textura mais fina que areia franca e com teores de argila variando de 15 até mais de $80 \%$. Possuem baixos teores de bases trocáveis, de micronutrientes, de fósforo e ainda alta concentração de alumínio, contudo, as propriedades fĩsicas são boas e o relevo, em sua maioria, é plano e suave ondulado. $\mathrm{Na}$ área dos Cerrados o Latossolo Vermelho Amarelo distribui-se predominantemente nas porções centro-norte, ao norte do paralelo $20^{\circ} \mathrm{S}$ (Macedo, 1996).

\subsubsection{Latossolo Vermelho Escuro (LE)}

O Latossolo Vermelho Escuro compreende solos muito profundos, porosos, bem drenados e de boa permeabilidade. A textura varia de média a muito argilosa. Segundo Rodrigues (1996), a boa resposta à aplicação de fertilizantes e corretivos, condições físicas boas para o preparo e manejo e, o relevo plano e suave ondulado, predominantes, são fatores determinantes ao uso intensivo e extensivo desses solos. Na Amazônia o Latossolo Vermelho Escuro perfaz 2,21\% de sua área e ocorre principalmente em regiões onde o tipo climático abrange um período seco de três a cinco meses, sendo encontrado no Tocantins, Mato Grosso, Maranhão, Pará, Rondônia e Acre. $\mathrm{Na}$ área dos Cerrados predomina na região Centro-Sul, situada ao sul do paralelo $13^{\circ} \mathrm{S}$, abrangendo as áreas do centro-sul e oeste de Goiás, centro-sul e sudoeste de 
Minas Gerais, oeste de Mato Grosso, centro e sul de Mato Grosso do Sul e Distrito Federal.

\subsubsection{Características mineralógicas da fração argila dos latossolos}

O estudo da composição mineralógica da fração argila é indispensável

para a gênese, classificação e manejo dos solos. Besoin (1985) considerou que a identificação qualitativa e quantitativa dos minerais e o conhecimento de suas estruturas permitem explicar razoavelmente as propriedades do solo e seu comportamento.

Vários autores como Sombroek (1966), Chiba (1970) e Iwasa (1976) estudaram os latossolos distribuídos na região amazônica e verificaram que a caulinita era o mineral predominante na fração desses solos. Kitagawa \& Moller (1979), constataram a predominância de caulinita, geralmente acompanhada de goetita, hematita e freqüentemente gibsita. Embora com alguma raridade, foi encontrada também a presença de minerais do tipo 2:1.

Lima (1980) estudando 12 perfis de Latossolo Amarelo da Amazônia, verificou uma variação quanto à dominância do mineral na fração argila, fato que o levou aos seguintes agrupamentos: a) latossolos com predominância de caulinita e gibsita; b) latossolos com predominância somente de caulinita; e c) latossolos com predominància de caulinita e presença de minerais do tipo 2:1. Resultado semelhante, foi encontrado por Moller \& Klamt (1982) em um perfil no Estado do Acre que apesar da predominância da caulinita, ocorria também argila 2:1.

Moller \& Araki (1984), pesquisando vários tipos de latossolos da região amazônica, constataram uma mistura de caulinita com diferentes graus de cristalinidade, tendo-se observado predominância de caulinita bem ordenada num Latossolo Vermelho Escuro e caulinita muito desordenada num Latossolo Amarelo.

Bennema (1977) ao se referir aos oxissolos, comentou que a maioria dos solos que está sobre os sedimentos na região amazônica tem relativamente baixo teor de óxido de ferro, normalmente entre 2,0 e $8,0 \%$ e apresentam freqüentemente coloração 
amarela. Lima (1980) comentou também que os teores de óxidos de ferro livre nestes solos são muito baixos, constatando, através de difratogramas de raios-X, ser a goetita $\mathrm{o}$ mineral de ferro dominante.

Melfi \& Pedro (1979) em trabalho sobre compostos minerais de ferro nas coberturas pedológicas superficiais do Brasil, enquadraram a grande maioria dos latossolos amarelos da Amazônia como solos unicamente com goetita, associando o predomínio deste mineral a clima equatorial super úmido. Os latossolos amarelos com goetita e hematita associadas em quantidades variáveis se distribuem mais restritamente nas planícies baixas do Médio e Baixo Amazonas e em áreas deprimidas do Alto Araguaia e Alto Xingu, onde o escoamento das águas pluviais tem sua velocidade diminuída. Nessas áreas o solo geralmente adquire característica plintica. A predominância de hematita e proporções variáveis de goetita associadas, foram atribuidas a solos mais envelhecidos que recobrem a borda guianense da Amazônia e a região do planalto central. Os solos unicamente com hematita ocorrem mais especificamente sobre rochas básicas da Bacia do Paraná, onde o meio é bem drenado.

De acordo com Bennema (1977), a relação molecular sílica/alumina (ki) é freqüentemente utilizada como uma indicação da composição mineralógica e do grau de intemperismo do solo; o valor de ki em torno de 2,0 indica predominância de caulinita na fração argila; ki maior que 2,0 indica contribuição de minerais 2:1, embora valores muito maiores do que 2,0 não sejam encontrados em latossolos; valores de ki bem abaixo de 2,0 indicam presença de óxido de alumínio livre, principalmente a gibsita. Dessa maneira, os valores de ki serão tanto menores quanto mais intemperizado for o solo. Dentre os óxidos de alumínio, a gibsita é o mineral mais comum dos solos, particularmente em solos tropicais submetidos a processos intensos de dessilicificação e desbasificação (Jackson, 1964; Fassbender, 1984).

Na área dos Cerrados, segundo Moniz \& Jackson (1967), Moura Filho \& Buol (1972), Weaver (1974), Mothchi (1977) e Souza (1977), a fração argila dos latossolos é constituída principalmente de caulinita, gibsita, óxidos de titânio e argilominerais $2: 2$, estes originados da precipitação de hidróxido de alumínio nas entre- 
camadas de argilo-minerais 2:1. A maior concentração de gibsita nesses latossolos reflete um maior estádio de intemperismo, quando comparados com os solos das regiões mais úmidas do Sul ou da Amazônia, onde predomina a caulinita. Por outro lado, os baixos valores de ki indicam maior dessilicificação e, portanto, maior tempo de atuação dos processos pedogenéticos, uma vez que as superfícies do Brasil Central são das mais estáveis e antigas do país.

\subsubsection{Características químicas dos latossolos}

Os latossolos da Amazônia apresentam, em condições naturais, uma baixa produtividade evidenciada pela saturação por bases e teores de soma de bases trocáveis muito baixos. Este fato deve-se principalmente à pobreza de seu material de origem e às condições de clima muito intensas na área (Falesi, 1969; Viana et al., 1976). Os poucos nutrientes disponíveis, em grande parte, foram concentrados pela biomassa através de sua ciclagem direta (Stark, 1971; Brinkmann \& Nascimento, 1973; Fittkau \& Klinge, 1973 e Volkoff \& Cerri, 1981).

Falesi (1972) verificou que os valores de soma de bases, capacidade de troca catiônica e saturação por bases são baixos, enquanto os teores de matéria orgânica variam de médios a altos no horizonte $\mathrm{A}$, e decrescem consideravelmente com a profundidade do solo.

De acordo com o trabalho da EMBRAPA (EMBRAPA, 1981), os valores mais baixos de $\mathrm{pH}$ e os teores mais elevados de alumínio, hidrogênio e soma de bases estão relacionados com os teores de matéria orgânica, os quais são mais elevados no horizonte superficial e decrescem com a profundidade. Volkoff \& Cerri (1981) estudando três perfis de solo na região do rio Madeira, constaram que teores elevados de carbono caracterizam somente o horizonte $\mathrm{Al}$, o qual, nos três solos, é muito pouco espesso $(5 \mathrm{~cm})$. Abaixo dessa camada o carbono decresce marcadamente. Condição semelhante foi relatada, ainda, por Volkoff et al. (1982), ao estudar três perfis de Latossolo Amarelo no Território de Roraima. Essa diferença nos teores de matéria orgânica entre os horizontes superficial e sub-superficial foi ressaltada também por 
Bennema (1974), quando na análise dos latossolos brasileiros, verificou um rápido decréscimo do teor de carbono a partir da superfície.

\section{Matéria Orgânica X Capacidade de Troca Catiônica}

Nos solos tropicais a matéria orgânica é um dos principais componentes responsável pela capacidade de troca de cátions na camada superfícial (Sánchez, 1976 ; Fassbender, 1984).

A matéria orgânica dos solos apresenta compostos de origem vegetal, animal e microbiana. Tem marcante influência sobre as propriedades físicas e químicas dos solos, sendo comumente responsável por grande parte da capacidade de troca de cátions (Raij, 1981).

McGeorge (1931) constatou que aumentos da CTC da matéria orgânica acompanhavam os sucessivos estágios de sua evolução no solo. A mesma conclusão pode ser tirada dos trabalhos de Broadbent (1953) que associou tais aumentos à capacidade de restos vegetais em reter bases no decorrer de sua decomposição. Wutke \& Camargo (1975) observaram que na matéria orgânica decomposta, as cargas negativas se originam da dissociação de radicais como $\mathrm{COOH}$ e $\mathrm{OH}$, o que talvez explicaria o aumento da sua atividade em função de sua evolução.

Bennema (1977) ressaltou que a contribuição da matéria orgânica para a CTC dos solos da Amazônia se torna ainda mais importante devido a CTC da fração argila desses solos ser muito baixa. Verificação semelhante foi feita por Verdade (1956) com relação aos solos do Estado de São Paulo, onde a predominância de argila é do tipo caulinita. Para a Amazônia ainda são poucos os trabalhos que quantificam a contribuição da matéria orgânica para a CTC dos solos.

Vieira et al. (1982), estudando alguns solos da zona Bragantina, Estado do Pará, observaram que a dominância das trocas catiônicas nos solos de terra-firme relacionava-se à matéria orgânica, sugerindo um domínio quase total na CTC para o caso das Areias Quartzosas e, na camada superficial do Podzol Hidromórfico. 
Alfaia \& Nogueira (1985), verificando as contribuições da matéria orgânica e da fração argila para a CTC do solos, constataram em um perfil de Latossolo Amarelo da região de Manaus que aproximadamente $71 \%$ da CTC no horizonte superficial (A1) e $24 \%$ no horizonte sub-superficial eram devidos à matéria orgânica, enquanto a fração argila contribuia com cerca de 29 e $76 \%$ para os referidos horizontes, respectivamente.

A capacidade de troca de cátions dos Latossolos Amarelos freqüentemente se encontra compreendida entre 3 e $15 \mathrm{cmol}_{\mathrm{c}} \mathrm{kg}^{-1}$ de solo, sendo que no horizonte A devido a contribuição de matéria orgânica, estes valores podem às vezes, serem superiores a $15 \mathrm{cmol}_{\mathrm{c}} \mathrm{kg}^{-1}$ (EMBRAPA, 1981).

Para Sánchez (1976) a CTC total é aquela determinada a pH 7,0 ou 8,2, dependendo do método (no Brasil, é usual a $\mathrm{pH} 7,0$ ), a qual reflete adequadamente a CTC dos solos com predominância de carga constante ou, ainda, quando o pH nas condições de campo está em torno desses valores. Contudo, para solos com pH menores do que 7,0 ou 8,2 , estes métodos superestimam os valores da CTC.

Nas regiões tropicais, onde a maioria dos solos é ácida, portanto com baixos valores de $\mathrm{pH}$, a CTC "efetiva" torna-se uma medida mais apropriada, pois, para sua determinação os solos estão em pH de campo. As estimativas da CTC "efetiva" apresentam valores muito menores quando comparada à CTC medida a pH 7,0 ou 8,2. Em geral, os valores da CTC "efetiva" maiores de 4,0 $\mathrm{cmol}_{\mathrm{c}} \mathrm{kg}^{-1}$ sugerem uma capacidade suficiente para evitar perdas por lixiviação (Sánchez, 1976).

De acordo com Raij (1969), a CTC da fração argila apresenta grande interesse, pois permite a comparação de dados obtidos para solos de textura diferente $\mathrm{e}$ material de origem também diferente, além de tornar possível a avaliação da argila em si, no que diz respeito às trocas catiônicas. 
$\triangle p H X$ Ponto de Carga Zero (PCZ)

De acordo com Mekaru \& Uehara (1972), no sistema oxídico, onde as cargas são dependentes de $\mathrm{pH}$, o estado de cargas pode ser avaliado através de $\Delta \mathrm{pH}$ que é definido como a diferença entre o pH em KCl e o pH em água. Para Sánchez (1981), enquanto em sistemas silicatados laminares o $\Delta \mathrm{pH}$ é sempre negativo, o mesmo não ocorre em sistemas de óxidos, onde o $\Delta \mathrm{pH}$ pode ser positivo, zero ou negativo.

Quando o $\Delta \mathrm{pH}$ de um solo é zero, diz-se que está no ponto de carga zero (PCZ) que é definido como $\mathrm{pH}$ da solução em equilíbrio com o solo no qual a carga líquida é zero. É um parâmetro importante em sistemas de carga variável, pois pode ser usado na determinação do sinal da carga líquida da superfície dos colóides. Assim, se o pH do solo é menor do que o PCZ, a superficie está com carga líquida positiva e, inversamente, se o pH for maior que o PCZ, a superfície está com carga líquida negativa (Raij \& Peech, 1972; Raij, 1973; Keng \& Uehara, 1974).

Uehara \& Gillman (1981), ao se referirem a solos de carga variável, relataram que o horizonte superficial apresenta valor de $\mathrm{PCZ}$ mais baixo do que o subsuperficial devido a seu maior teor de matéria orgânica.

De forma geral os óxidos de ferro e de alumínio, com valores de PCZ que variam usualmente entre 7,0 e 9,0, são responsáveis pela elevação do $\mathrm{PCZ}$ do solo, enquanto a matéria orgânica e minerais de argila concorrem para seu abaixamento (Parks, 1967; Raij, 1973; Uehara \& Gillman, 1981).

Raij (1986) verificou que os valores estimados de PCZ para os minerais de argila apresentaram razoável concordância com resultados experimentais. Para a caulinita, o valor experimental variou entre 3,3 e 4,9, enquanto para a montmorilonita foi inferior a 2,5 .

De acordo com Gallez et al. (1976), o PCZ do solo reflete seu grau de intemperismo ou dessilificação, tendo em vista seus resultados mostrarem que solos mais intemperizados apresentaram valor de $\mathrm{PCZ}$ superior àqueles menos intemperizados, na seguinte ordem: Oxissol > Ultissol $>$ Alfissol. Neste sentido, 
Velloso et al. (1977), ressaltaram a importância do PCZ no entendimento de muitas propriedades fĩsico-quimicas de solos tropicais, além de sua utilidade como critério importante na classificação dos latossolos.

pH X Saturação por Bases

Castro (1972), estudando várias amostras de solos dos horizontes superficial e sub-superficial de Latossolo Amarelo, verificou relação significativa entre pH e saturação por bases para todas as amostras estudadas do horizonte A, enquanto para o horizonte $\mathrm{B}$ o resultado foi significativo em uns casos e em outros não.

Raij (1968) encontrou correlação altamente significativa entre pH e grau de saturação por bases em amostras de horizontes superficiais e de horizonte B2 de perfis com $B$ latossólico e $B$ textural. Cita também que para um mesmo valor de saturação por bases, o pH mostrou-se mais elevado para as amostras do horizonte B2 de solos com B latossólico, mais baixo para o B2 de solos com B textural e intermediário para as amostras superficiais dos dois grupos de solos.

\subsection{Ação dos fatores de formação: clima, vegetação e material de origem nas características dos solos}

\subsubsection{Clima}

O clima na região amazônica e dos Cerrados constitui um dos mais ativos fatores de determinação das características dos latossolos. Dos diferentes aspectos do clima que controlam as propriedades do solo, destacam-se a temperatura e a precipitação pluviométrica (Jenny, 1980; Birkeland, 1984), esta, em termos tanto de quantidade como de distribuição ao longo do ano, o que propicia períodos diferenciados quanto à deficiência ou excedentes hídricos no solo.

Jenny (1941), ao sumarizar vários trabalhos que tratavam da relação entre a pluviometria total, na faixa de 380 a $890 \mathrm{~mm}$, e as propriedades do solo, concluiu que 
a concentração do íon hidrogênio no solo, a profundidade dos carbonatos, o conteúdo de nitrogênio e de argila se elevavam com o aumento da precipitação.

Por outro lado, a temperatura, componente do clima, exerce destacada influência nas reações que envolvem os processos de formação do solo, bem como na quantidade e qualidade da matéria orgânica produzida, uma vez que ela atua no tipo e quantidade de vegetação presente na região. Muitas propriedades do solo têm sido apresentadas como dependentes da temperatura. Assim, com o aumento da temperatura, a cor do solo torna-se menos cinza e mais avermelhada. De acordo com Jenny, as bases são quase que completamente lixiviadas em áreas quentes e chuvosas. Os conteúdos de nitrogênio e matéria orgânica diminuem com o aumento da temperatura.

Para os ambientes da Amazônia e dos Cerrados destacam-se entre as principais propriedades morfológicas e mineralógicas que se correlacionam com o clima o teor de matéria orgânica, conteúdo de argila, tipos de minerais de argila e de ferro, estabilidade dos agregados e cor.

\section{Matéria Orgânica}

Jenny (1941, 1961, 1980), através de estudos extensivos sobre relações do conteúdo de matéria orgânica com o clima, verificou que o nitrogênio aumenta logaritmicamente com o aumento da pluviometria e decresce exponencialmente com a elevação da temperatura. Isto significa que, para valores baixos de precipitação e temperatura, qualquer pequeno acréscimo na temperatura ou precipitação resulta num maior efeito na quantidade de carbono ou nitrogênio no solo do que com o mesmo incremento em valores elevados de precipitação e temperatura. Muito embora fosse de consenso comum que os solos tropicais continham conteúdos baixos de matéria orgânica, devido às altas temperaturas e rápidas taxas de decomposição, estudos posteriores não evidenciaram diferenças significativas entre o conteúdo de matéria orgânica dos solos tropicais e das zonas temperadas (Sánchez, 1976). Os próprios trabalhos de Jenny (Jenny et al., 1948) monstraram-se contraditórios ao se incluir os solos da Costa Rica e da Colombia. Estes solos continham teores mais elevados de 
matéria orgânica do que prediziam suas temperaturas médias anuais. Sánchez (1976) comentou que uma das explicações para o conteúdo de matéria orgânica nos solos tropicais ser bem maior do que se julgava, relacionava-se diretamente à cor do solo, pois, os oxissóis avermelhados aparentemente não revelando através da cor a existência de matéria orgânica, contêm mais matéria orgânica do que os vertissolos escuros. A propósito, Vageler, já em 1930, afirmou que o humus pode ser até incolor, e Volkoff \& Cerri (1981) ressaltaram que em solos da Amazônia, o apreciável teor de matéria orgânica em profundidade, é dificilmente percebida pela cor do solo.

Sánchez (1976) considerou nas avaliações do conteúdo do carbono orgânico de um solo em equilíbrio com a vegetação suas adições anuais e as constantes de decomposição em cada ecossistema florestal. A fórmula seguinte estabelece essas relações:

$$
\mathrm{C}=\mathrm{a} / \mathrm{k}
$$

sendo: $a=b m \quad e$,

onde:

$\mathrm{c}=$ porcentagem de carbono orgânico do solo em equilíbrio $\left(\mathrm{t} \mathrm{ha}^{-1}\right)$;

$\mathrm{b}=$ quantidade anual de matéria orgânica fresca agregada ao solo $\left(\mathrm{t} \mathrm{ha}^{-1}\right)$;

$m$ = taxa de conversão da matéria orgânica fresca para carbono orgânico do solo (\%);

$\mathrm{a}=$ adição anual de carbono orgânico do solo ( $\mathrm{t} \mathrm{ha}^{-1}$ );

$k$ = taxa anual de decomposição do carbono orgânico do solo.

É patente notar pois, através dessa fórmula, a atuação do clima no conteúdo da matéria orgânica do solo. A quantidade de matéria orgânica fresca (b) adicionada anualmente depende do tipo de vegetação (floresta tropical, floresta decidual, savana, pradarias, etc.) que por sua vez, em última análise, está intimamente relacionada ao clima. As taxas anuais de decomposição do cabono orgânico do solo (k) varia consideravelmente nos distintos ambientes em função das flutuações da temperatura. Novamente aqui, o clima, através da temperatura, exerce primordial importância, além do valor de k ser também reflexo do regime de umidade do solo, pois em ambientes ústicos a estação seca retarda a velocidade de decomposição do carbono orgânico como conseqüência da baixa umidade. Nota-se portanto, que o clima se faz 
atuante tanto em termos de regime hídrico como de temperatura do solo. Convém ainda lembrar que de acordo com regra empírica, a cada aumento de $10^{\circ} \mathrm{C}$ de temperatura a taxa de atividade biológica se duplica.

Conteúdo de argila

Embora Jenny (1935) tenha encontrado relação linear entre o conteúdo de argila e a precipitação e relação exponencial com a temperatura, em regiões dos Estados Unidos, nos diferentes tipos de climas da região amazônica e dos Cerrados é difícil de se estabelecer essas relações face à interferência de muitos outros fatores que também afetam a produção de argila no solo. Entretanto, há de se esperar que mantendo-se constantes os demais fatores, em ambientes quentes e húmidos a velocidade de produção de argila aumenta com o aumento da precipitação.

\section{Minerais de argila}

Os minerais formados no solo variam de acordo com a intensidade do intemperismo, e dessa forma com o clima. Rumo às maiores precipitações, os minerais de argila tendem a apresentar cada vez menos sílica, dessa forma, as regiões tropicais se caracterizam por apresentar produtos resultantes de intenso intemperismo (compostos de alumínio e ferro). Há uma tendência mineralógica bem definida de acordo com o clima. Montmorilonita comumente é formada em precipitações baixas, caulinita em mais elevadas e óxidos e hidróxidos de ferro e alumínio nas mais altas precipitações. No Havai, Sherman (1972) relatou que a montmorilonita predomina em regiões com precipitação abaixo de $1000 \mathrm{~mm}$, caulinita entre 1000 e $2000 \mathrm{~mm}$ e os compostos de ferro e alumínio acima de $2000 \mathrm{~mm}$. Por outro lado, convém observar que na formação dos argilo-minerais não só o clima, mas as condições de drenagem e o próprio material de origem exercem acentuada influência. 


\section{Estabilidade da estrutura}

Os latossolos argilosos, principalmente os dos Cerrados, apresentam estrutura com boa estabilidade, isto é, mantèm a estabilidade dos agregados depois de mudanças bruscas de umidade e sob ação de chuva intensa (Pereira, 1956). A estrutura desses solos consiste de grânulos formados por partículas primárias muito unidas entre si. Sua alta estabilidade foi atribuída inicialmente, ao elevado conteúdo de argila e à sua cimentação ou revestimento com óxidos amorfos de ferro e alumínio (Sánchez, 1976). Entretanto, Cagauan \& Uehara (1965), têm verificado que oxissóis com similares conteúdos de argila, matéria orgânica e composição mineralógica, possuiam comportamentos diferenciados quanto a estabilidade da estrutura, e constataram que essas diferenças associavam-se à orientação de partículas de argila nos agregados. Sánchez (1976) comentou que aparentemente os oxissóis de climas constantemente úmidos não retêm uma estrutura tão estável como os de climas que sofrem oscilações estacionais de umidade, como por exemplo, o ústico.

Em sintese, dos vários aspectos da atuação do clima nas propriedades dos solos, ressalta-se que em grande parte da Amazônia, a interação da elevada temperatura e a farta disponibilidade de água excedente, sem dúvida, favorece a efetivação das reações químicas que se processam no solo, a eliminação constante de compostos solúveis do perfil do solo através da lixiviação e a mineralização da matéria orgânica permanentemente adicionada à superficie dos solos densamente florestados, resultando em solos bastante intemperizados, profundos, essencialmente cauliniticos, quimicamente muito pobres e com reação bastante ácida.

Por outro lado, na região dos Cerrados as deficiências hídricas podem atingir períodos de até seis meses, o que propicia, neste período, uma lixiviação atenuada ou mesmo bloqueada, no caso dos períodos secos do regime ústico de umidade do solo. Entretanto, em ambas as regiões, os latossolos são igualmente intensamente intemperizados, o que pode ser explicado, no caso da região dos Cerrados, pela maior duração, em termos de idade, dos processos pedogenéticos na evolução do solo, fato este evidenciado pela posição e distribuição de grande parte de seus latossolos 
em extensas superfícies geomórficas estabilizadas e relativamente muito antigas (Feuer, 1956; Cline \& Buol, 1973; Rodrigues, 1977; Queiróz Neto, 1982). Nessas superficies os latossolos são profundos e caracterizados por uma estrutura granular fina, alta permeabilidade e quimicamente muito pobres, comportando como vegetação o cerrado, indicativo de baixa fertilidade.

Por outro lado, o clima tem efeito marcante na distribuição da vegetação. As formações vegetais guardam estreita relação com as condições climáticas, principalmente quanto ao aspecto do regime de umidade do solo, que por sua vez está intimamente relacionado ao clima atmosférico. Este fato levou inclusive, à adoção do tipo de vegetação primária como critério de fases de unidades de mapeamento, em levantamentos pedológicos de média e pequena escala, no Brasil, a partir de 1962 (Camargo et al., 1987).

\subsubsection{Vegetação}

Nas regiões da Amazônia e dos Cerrados a ação mais importante da vegetação reside nos fenômenos de adição, tanto na superfície, através dos resíduos vegetais aí depositados, como no interior do perfil do solo, mediante restos que se decompõem. Além da adição, fenômenos importantes de reciclagem de nutrientes são comuns nos ambientes vegetados. Há registros de valores de soma de bases variando mais de $20 \mathrm{cmol}_{\mathrm{c}} \mathrm{kg}^{-1}$ na camada superficial para menos de $2 \mathrm{cmol}_{\mathrm{c}} \mathrm{kg}^{-1}$ nas subsuperficiais (EMBRAPA, 1981). Esses transportes seletivos são importantes para as diferenciações dos horizontes e conseqüentemente das propriedades do solo.

Ao fator vegetação Jenny (1941) denominou fator biótico e atribuiu sua influência nas propriedades morfológicas e químicas do solo. Muitas propriedades do solo estão estreitamente relacionadas com as diferentes vegetações. A mais evidente é a distribuição de matéria orgânica. Embora os solos das regiões tropicais e temperadas têm igualmente teores elevados de matéria orgânica na superficie, a distribuição em profundidade varia com a vegetação. Horizontes A de regiões florestadas são relativamente pouco espessos, e o conteúdo de matéria orgânica decresce rapidamente 
com a profundidade, ao passo que em gramíneas, os horizontes A são mais espessos e o conteúdo de matéria orgânica se mantem por maiores profundidades. Estas diferenças ocorrem em função da maneira na qual a matéria orgânica é inserida ao solo. Nos solos de floresta a principal entrada da matéria orgânica é pela serrapilheira através da superfïcie do solo, ao passo que nas área de gramíneas, a entrada da matéria orgânica se faz tanto pela serrapilheira como pelo apodrecimento das raizes em profundidade. A saturação por bases tende a ser mais alta nas gramíneas do que nas florestas. Esta diferença pode ser função da maior lixiviação nas florestas com grande produção de biomassa e nas gramíneas pela maior reciclagem de cátions. Outra notável feição morfológica é a distribuição da argila em profundidade. As camadas superficiais dos solos com gramíneas contêm teores mais elevados de argila quando comparados com os de floresta, indicando que o ambiente florestal propicia translocação de partículas de argila em maior profundidade do que nas gramíneas.

Em sintese, as regiões florestadas comumente apresentam maior lixiviação de cátions, conseqüentemente menor $\mathrm{pH}$ e maior translocação de argilas do que as regiões de gramineas. Além disso, a matéria orgânica é menor em maiores profundidades. Estudos detalhados de química do solo em ambientes de florestas e de gramíneas revelam algumas tendências significantes. As gramíneas têm mais carbono, cerca de duas vezes mais que nitrogênio, e cerca de metade da relação $\mathrm{C} / \mathrm{N}$ em relação ao solos florestados. O ferro amorfo é mais alto nos solos de floresta. Por outro lado, a mineralogia de argila aparentemente não é afetada pela diferença de vegetação.

\subsubsection{Material de origem}

As condições da intemperização inerente ao ambiente tropical úmido e subúmido são notadamente agressivas, promovendo intensa alteração e decomposição dos constituintes iniciais e neoformações de outros. 
O material de origem tem primordial importância em muitos atributos dos solos, destacando-se entre eles a textura, a cor, a composição química e mineralógica.

A textura do solo depende intimamente da granulometria e constituição mineralógica do material de origem. Material de partícula arenoquartzoso (arenitos, coberturas superficiais arenosas) originam solos arenosos, porosos, com baixa capacidade de retenção de água, e freqüentemente, muito baixa fertilidade. Por outro lado, solos originados de produtos de decomposição de basalto, diabásios, dioritos, micaxistos, gnaísses, calcários, etc, em topografia suave, tendem a originar solos profundos e argilosos.

A cor do solo pode derivar diretamente de seu material de origem, ou dos produtos neoformados. Assim os óxidos de ferro como hematita e goetita, ou de manganês, quando em predominância, imprimem cores avermelhadas, brunadas, ou escuras, respectivamente.

A composição química e mineralógica dos solos depende da natureza do material de partida que quando bem provido em minerais ricos em cálcio, ferro, magnésio, fósforo, potássio e outros elementos propiciam condições para que o solo possa apresentar teores elevados desses elementos. Por outro lado, fontes pobres desses elementos, geram solos pobres.

A neoformação dos argilo-minerais, como a caulinita, esmectitas, gibsita, etc. está subordinada à existência de determinados elementos na solução do solo, os quais têm como fonte o material de origem. 


\section{MATERIAL E MÉTODOS}

\subsection{Descrição das áreas estudadas: Amazônia e Cerrados}

\subsubsection{Delimitação das áreas de estudo}

A área estudada, englobando a região amazônica e a maior parte da área dos Cerrados, situa-se entre os paralelos $04^{\circ} 00^{\prime} \mathrm{N}$ e $20^{\circ} 00^{\prime} \mathrm{S}$ e $48^{\circ} 00^{\prime}$ e $75^{\circ} 00^{\prime} \mathrm{WGr}$. do território nacional. A área da Amazônia foi considerada até o paralelo $12^{\circ} \mathrm{S}$ abrangendo uma área de $3859730 \mathrm{~km}^{2}$ e a dos Cerrados, até o paralelo $20^{\circ} 00^{\prime} \mathrm{S}$, abrangendo $1406342 \mathrm{~km}^{2}$. Ambas áreas estudadas totalizam $5266072 \mathrm{~km}^{2}$. Dentro da região dos Cerrados, avaliada em 2,04 milhões de km², conforme Adamoli et al. (1986), considerou-se a quase totalidade da região Centro-Oeste, incluindo parte dos Estados de Goiás, Minas Gerais, Mato Grosso do Sul e uma pequena parte do Distrito Federal (Figura 1).

\subsubsection{Clima}

Objetivando definir o clima da Amazônia e da área dos Cerrados, foi adotado, nesta pesquisa, o sistema de classificação de Köppen. De acordo com essa classificação, nas áreas estudadas dominam as condições de clima tropical chuvoso (Grupo A), sem estação fria, onde a temperatura do mês menos quente está acima de $18^{\circ} \mathrm{C}$. Abrange os tipos climáticos: Af, Am, Aw. Com relação à oscilação anual de temperatura, sendo inferior a $5^{\circ} \mathrm{C}$, pertence à variedade $\mathbf{i}$. 


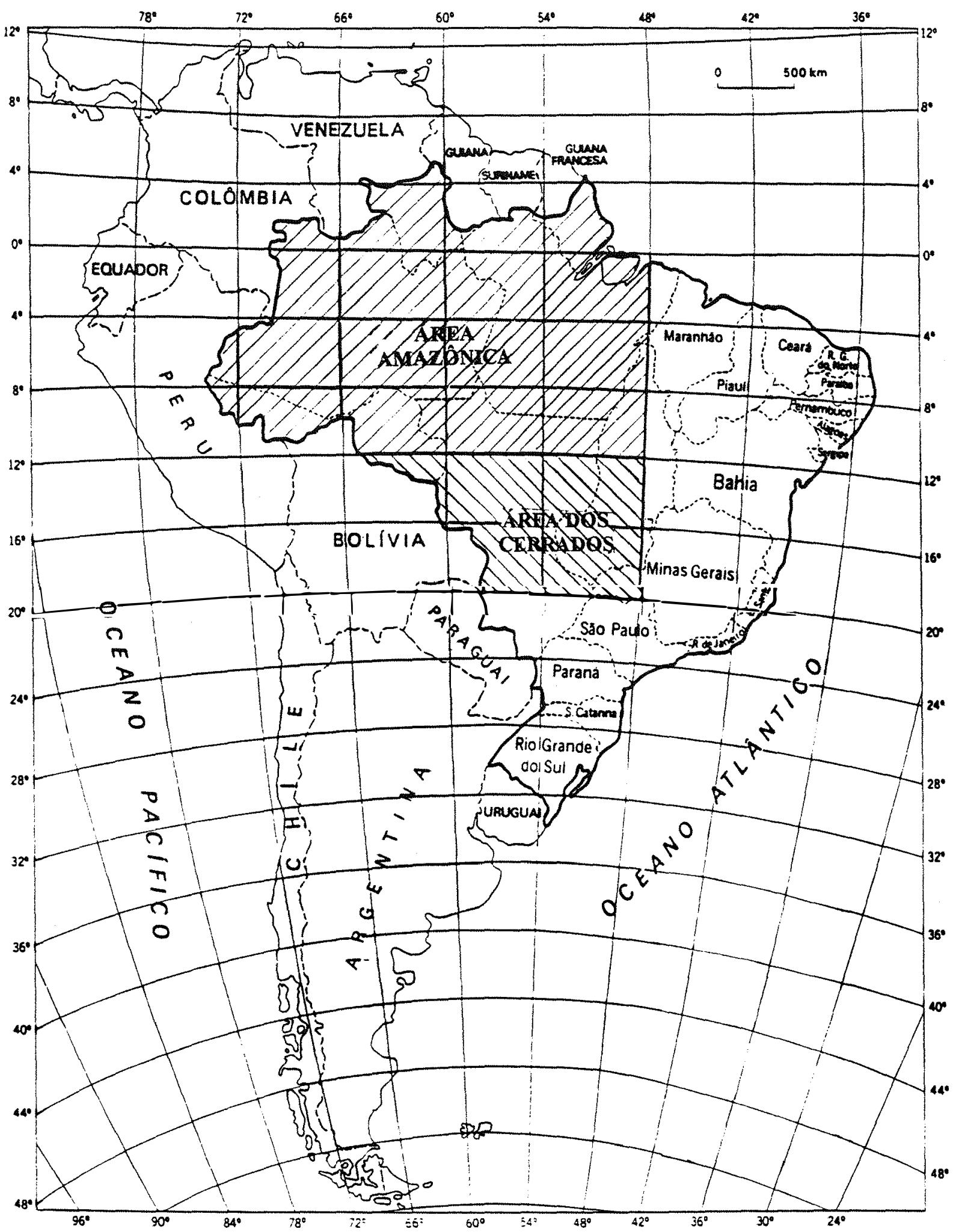

Figura 1. - Localização das áreas estudadas nas regiões da Amazônia e dos Cerrados. 
$\mathrm{Na}$ área amazônica, tem-se a seguinte distribuição dos tipos climáticos (Vieira \& Santos, 1988):

- Tipo Afi: é subdominante na área, onde abrange parte do estado do Amazonas e território de Roraima, além da região de Belém. Caracteriza- se por apresentar chuvas relativamente abundantes durante todo o ano e ausência de período seco;

- Tipo Ami: é o tipo climático dominante, abrangendo as partes correspondentes aos Estados do Acre, Rondônia e território do Amapá, além de partes dos Estados do Pará e Amazonas. Caracteriza-se por um regime pluviométrico anual que define um pequeno período seco, porém, com uma distribuição da precipitação total anual suficiente para manter este período;

- Tipo Awi: é o de menor abrangência na Amazônia, restringindo-se à pequena parte do Estado do Maranhão. Caracteriza-se por apresentar índice pluviométrico anual relativamente elevado, com nítida estação seca.

$\mathrm{Na}$ área dos Cerrados verifica-se um padrão de precipitação pluviométrica marcado por dois períodos distintos: seco e chuvoso, os quais variam temporalmente, de região para região. O tipo Aw é o predominante e o Am, subdominante. $\mathrm{Na}$ parte sul e sudeste dos Cerrados, em áreas mais restritas, ocorre o tipo $\mathrm{Cwb}$ que se caracteriza por apresentar clima temperado moderado chuvoso, sendo o inverno seco porém, não rigoroso, com chuvas periódicas e temperatura do mês mais quente inferior a $22^{\circ} \mathrm{C}$.

A Tabela 1 indica o número de perfis analisados em cada tipo climático.

Tabela 1 - Número de perfís analisados em cada tipo de clima.

\begin{tabular}{|c|c|c|c|c|}
\hline \multirow{3}{*}{$\begin{array}{c}\text { Tipo climático } \\
\text { (segundo Köppen) }\end{array}$} & \multicolumn{4}{|c|}{$N^{0}$ de perfis } \\
\hline & \multicolumn{2}{|c|}{ Amazônia } & \multicolumn{2}{|c|}{ Cerrado } \\
\hline & $L A$ & $L V$ & $L V$ & $L E$ \\
\hline Afi & 23 & 30 & - & - \\
\hline Ami & 48 & 57 & - & - \\
\hline Awi & 9 & 97 & 119 & 107 \\
\hline Cwb & - & - & 4 & 13 \\
\hline
\end{tabular}


Além da classificação de Köppen, na análise do clima, utilizaram-se também os parâmetros da pluviometria da Amazônia e da área dos Cerrados, em termos de precipitação média anual (isoietas). Os valores da precipitação média anual foram classificados nos seguintes intervalos: 1000 a $1500 ; 1500$ a 2 000;2 000 a 2 500; 2500 a 3000 e maior que $3000 \mathrm{~mm}$.

O número de perfis analisados para cada faixa de precipitação está indicado na Tabela 2.

Tabela 2 - Número de perfis analisados para cada faixa de precipitação média anual.

\begin{tabular}{|c|c|c|c|c|}
\hline \multirow{3}{*}{$\begin{array}{c}\text { Faixa de Precipitação } \\
\text { (mm) }\end{array}$} & \multicolumn{4}{|c|}{$N^{o}$ de perfis } \\
\hline & \multicolumn{2}{|c|}{ Amazônia } & \multicolumn{2}{|c|}{ Cerrado } \\
\hline & $L A$ & $L V$ & $L V$ & $L E$ \\
\hline $1000-1500$ & - & 9 & 15 & 42 \\
\hline $1500-2000$ & 21 & 33 & 85 & 71 \\
\hline $2000-2500$ & 23 & 68 & 25 & 8 \\
\hline $2500-3000$ & 33 & 61 & - & - \\
\hline$>3000$ & - & 15 & - & - \\
\hline
\end{tabular}

\subsubsection{Vegetação}

$\mathrm{Na}$ Amazônia a vegetação dominante é a Floresta Tropical Densa, representada por árvores de grande porte, característica de regiões de clima quente, úmido e superúmido com elevada precipitação pluviométrica (Coelho et al., 1976; Silva et al., 1977). Nas regiões da Amazônia onde predominam climas úmidos quentes, com chuvas torrenciais bem marcadas por um pequeno período seco, ocorre a Floresta Tropical Aberta, caracterizando-se sobretudo, por possuir árvores bastante espaçadas com freqüentes agrupamentos de palmeiras e outros tipos de vegetação que envolvem as de maior porte e cobrem inteiramente o solo. $\mathrm{Na}$ área de contato dos climas tropical superúmidos amazônicos, e o monçônico do planalto central, ocorre a Floresta Estacional (semi-decidual e decidual). Para este tipo de vegetação adotou-se, na 
presente pesquisa, a designação de Contato Floresta Ombrófila/Floresta Estacional e que se encontra bem caracterizada nos mapeamentos do Projeto RADAMBRASIL.

$\mathrm{Na}$ área dos Cerrados, encontram-se com maior expressão a Savana Arbórea e a Floresta Aberta (EMBRAPA, 1975), embora a área contínua dos Cerrados apresenta heterogeneidade em sua vegetação, dando lugar a uma caracterização que distingue Savana Densa, Savana Arbórea, Savana Parque e Floresta Aberta. Estes tipos de vegetação de cerrado, além dos principais fatores determinantes da presença dos Cerrados, quais sejam: solos ácidos, de baixa fertilidade e clima estacional, são resultantes de outros fatores associados e que implicam em diferentes tipos de limitações adicionais. Dessa forma, solos arenosos, litólicos ou hidromórficos, por exemplo, tendem a comportar formas mais abertas, ao passo que em condições ambientais que implicam em compensações hídricas ou edáficas, surgem as formas mais densas de cerrado.

De maneira generalizada e ocupando menor área, tanto na região amazônica como na dos Cerrados, estão as Florestas Secundárias originadas da retirada da vegetação primária e comumente designadas de "capoeiras" (Falesi et al., 1969; Veloso et al., 1974). Na presente pesquisa não foram considerados os horizontes A dos perfis de solo localizados neste tipo de vegetação.

O número de perfis analisados para cada tipo de vegetação está indicado na Tabela 3.

Tabela 3 - Número de perfis analisados para cada tipo de vegetação.

\begin{tabular}{|c|c|c|c|c|}
\hline \multirow{3}{*}{$\begin{array}{c}\text { Tipo } \\
\text { de } \\
\text { vegetação }\end{array}$} & \multicolumn{4}{|c|}{$N^{o}$ de perfis } \\
\hline & \multicolumn{2}{|c|}{ Amazônia } & \multicolumn{2}{|c|}{ Cerrado } \\
\hline & $L A$ & $L V$ & $L V$ & $L E$ \\
\hline FD & 55 & 82 & - & - \\
\hline FA & - & 66 & - & - \\
\hline $\mathrm{FO} / \mathrm{FE}$ & - & 19 & - & - \\
\hline SA & - & - & 80 & 83 \\
\hline Outros & 24 & 44 & 44 & 38 \\
\hline
\end{tabular}

FD: Floresta Tropical Densa

FA: Floresta Tropical Aberta
FO/FE: Contato Floresta Ombrófila/Floresta Estacional SA: Savana Arbórea Outros: Outros tipos de vegetação 


\subsubsection{Relevo}

Na região Amazônica, Vieira \& Santos (1987) definiram seis grandes unidades de relevo: a) altos planaltos; b) planaltos rebaixados; c) superfícies aplainadas; d) depressões; e) planícies fluviais, e f) planícies flúvio-marinhas.

Os altos planaltos constituem relevos elevados em formas tabulares, em cristas e em colinas formando um conjunto de blocos que margeiam a norte e a sul a bacia sedimentar do Amazonas. As altitudes geralmente variam de 400 a $800 \mathrm{~m}$. Ao norte do Estado do Amazonas observam-se planaltos com cotas mais elevadas, de 600 a $2000 \mathrm{~m}$, por vezes até $3000 \mathrm{~m}$.

Os planaltos rebaixados ocorrem do nordeste paraense, como uma faixa ao sul e ao norte do rio Amazonas, alargando-se considerávelmente no sentido oeste a partir de Manaus, onde se constitui parte dominante da Amazônia Ocidental. Possui comumente, relevo dissecado com interflúvios tabulares (tabuleiros), e, secundariamente, com colinas que margeiam as planícies fluviais. Apresentam rede de drenagem com pequeno grau de aprofundamento e baixa densidade de canais. Os vales assumem geralmente a forma em "V", embora possam ser encontrados os do tipo de fundo chato. As altitudes variam de $50 \mathrm{~m}$ próximo à planície do Rio Amazonas, até mais de $200 \mathrm{~m}$ nas bordas norte e sul destes planaltos.

As superficies aplainadas constituem relevo de aspecto aplainado, situando-se entre as altitudes 100 a $400 \mathrm{~m}$ e apresentando rede de drenagem pouco desenvolvida. Ocorrem predominantemente no Estado de Roraima.

As depressões localizam-se na porção mais ocidental, onde fazem limites com o Perú, e caracterizam-se pela altitude média em torno de $150 \mathrm{~m}$, com relevo dissecado em colina, além de alta densidade de canais de drenagem.

As planícies fluviais ocorrem nas faixas marginais dos inúmeros rios que drenam a área, principalmente o rio Amazonas e seus afluentes. 
As planícies flúvio-marinhas são de ocorrência mais restrita, estendendose numa faixa alongada no litoral do Amapá desde Macapá até Oiapoque. São formadas por sedimentos de origem mista, fluvial e marinha.

$\mathrm{Na}$ área dos Cerrados, o relevo é dominado pelos maciços planaltos, com superfícies aplainadas de cimeira e um conjunto significativo de planaltos sedimentares compartimentados, ambos designados de chapadões e que ocupam altitudes que variam entre 300 a mais de $1500 \mathrm{~m}$. Os cerrados recobrem predominantemente os interflúvios e vertentes suaves dos chapadões. A área, como um todo, apresenta uma certa heterogeneidade, marcada por uma distribuição dessimétrica da altimetria. $\mathrm{Na}$ área central e sudeste, predominam altimetrias maiores, enquanto que no setor norte da região situam-se as menores, inferiores a $300 \mathrm{~m}$. Conforme Adámoli et al. (1986), $50,2 \%$ da área situam-se em altimetria de 300 a $600 \mathrm{~m}$ e $22,5 \%$, entre 600 a $900 \mathrm{~m}$.

As superficies do Brasil Central são tidas como as das mais antigas e estáveis do país, o que propiciou o desenvolvimento de latossolos, os mais intemperizados. Grande parte dessas superfícies apresentam um padrão, em termos de superficies geomórficas, conforme esquematizado na Figura 2, adaptada de Rodrigues, 1977. No topo superior da chapada, superficie aplainada e mais estável, encontram-se os latossolos, os mais profundos e desenvolvidos; nas superfícies erosionais (encosta superior) ou deposicionais (calha aluvial), os latossolos menos desenvolvidos; e na encosta inferior, superfíce geomórfica estável, porém mais jovem que a primeira, ocorrem latossolos com estágio intermediário de desenvolvimento.

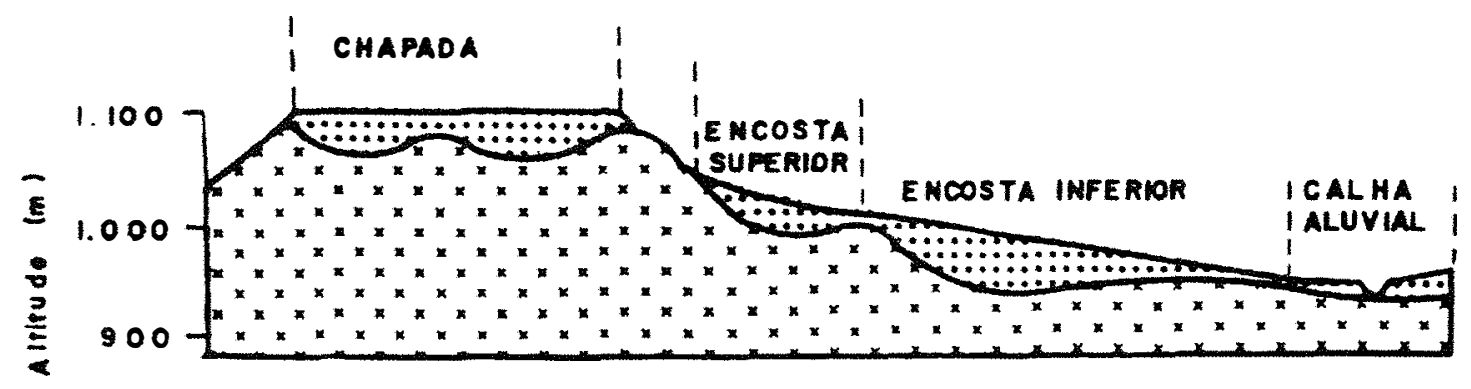

Figura 2 - Seqüencia de solos nas distintas superficies geomórficas (adaptado de Rodrigues, 1977). 


\subsubsection{Geologia e Material de Origem}

O embasamento das áreas da Amazônia e dos Cerrados em estudo, é constituído de rochas de idade pré-siluriana, em sua maior parte formando extensos complexos metamórficos e eruptivos. Estão expostos em dois grandes escudos: o das Guianas ao norte e do Brasil Central. Sobre eles, espalharam-se áreas menores de coberturas de plataforma, sendo as mais antigas, datadas do início do Proterozóico Médio. Sobre esse embasamento, iniciou-se a partir do Siluriano Inferior a sedimentação das bacias paleozóicas do Amazonas e a do Paraná.

Rochas desse embasamento cristalino, de suas coberturas pré-silurianas e das coberturas sedimentares pós-ordovicianas das duas bacias constituem o material de partida da maior parte dos latossolos formados nestas duas regiões.

Em grande parte da superficie amazônica destacam a ocorrência de rochas sedimentares da Formação Solimões (TQs), da Formação Barreiras (KTb), outros sedimentos terciários e quaternários (TQ), rochas pré-cambrianas do Complexo Xingu $(\mathrm{pCx})$ e de várias outras formações pré-cambrianas $(\mathrm{pC})$. Essas formações, agrupadas dessa forma, constituem as unidades geológicas consideradas neste trabalho. Nelas foi locada a maior parte dos perfis de latossolos apresentados pelo projeto RADAM, dos quais a quase totalidade foi considerada por este trabalho.

O número de perfis analisados em cada unidade geológica considerada está indicado na Tabela 4.

Tabela 4 - Número de perfis analisados em cada unidade geológica considerada.

\begin{tabular}{|c|c|c|c|c|}
\hline \multirow{3}{*}{ Unidade geológica } & \multicolumn{4}{|c|}{$N^{o}$ de perfis } \\
\hline & \multicolumn{2}{|c|}{ Amazônia } & \multicolumn{2}{|c|}{ Cerrado } \\
\hline & $L A$ & $L V$ & $L V$ & $L E$ \\
\hline TQ & & 15 & 66 & 45 \\
\hline TQs & 26 & 12 & - & - \\
\hline $\mathrm{KTb}$ & 37 & - & - & - \\
\hline $\mathrm{K}$ & - & - & 18 & 35 \\
\hline $\mathrm{pC}$ & 7 & 114 & 32 & 17 \\
\hline $\mathrm{pCx}$ & - & 31 & - & - \\
\hline
\end{tabular}

TQ: Formações terciárias e quaternárias TQs: Formação Solimões
$\mathrm{KTb}$ : Formação Barreiras $\mathrm{pC}$ : Formações precambrianas $\mathrm{K}$ : Formações cretáceas $\mathrm{pCx}$ : Complexo Xingu 
Dessa forma, serão abordados a seguir, os aspectos geológicos apenas dessas unidades geológicas consideradas.

Formações terciárias e quaternárias (TQ)

Foram agrupadas sob a designação de formações terciárias e quaternárias, todas as formações geológicas mapeadas dessas idades e que face a abrangência do Projeto RADAM, cada uma foi contemplada por apenas alguns perfis de solo, não permitindo, individualmente, uma análise estatística significativa dos atributos dos solos delas originados. Incluem-se neste agrupamento, sedimentos inconsolidados ou poucos consolidados do Terciário e Quaternário que se distribuem, ou sobre planícies dos principais rios e seus afluentes (aluviões) ou sobre relevo mais elevado, recobrindo rochas mais antigas sobre a forma de coberturas sedimentares (Cobertura Detrítica, Cobertura Detrito-Lateritica, etc.)

\section{A Formação Solimões (TQs)}

Constitui uma unidade litoestratigráfica de caráter transgressivo recobrindo ou a) substratos rochosos mais antigos, pertencentes ao Embasamento Cristalino (Complexo Guianense e Complexo Xingu), ou b) depósitos de cobertura de plataforma pré-cambriana, ou c) sedimentos mesozóicos e cenozóicos das Bacias do Acre e Alto Amazonas. Seus sedimentos caracterizam-se como típicos de ambientes continentais fluviais e lacustres de planície de inundação. São predominantemente pelíticos, constituídos sobretudo por argilitos e siltitos finamente laminados ou maciços, de coloração geralmente castanho avermelhada e amarelada. Associados a essa seqüência pelíticas, ocorrem, em menor quantidade, sedimentos siltosos e arenosos finos a médios (Fernandes et al., 1977; Lourenço et al., 1978). 
A Formação Barreiras (KTb)

De acordo com Oliveira \& Leonardos (1943), é constituída por intercalações de arenitos e argilitos, com conglomerados subordinados. Os arenitos são finos a médios, geralmente com estratificação cruzada, tendo cores vermelhas a variegadas, argilosos, cauliníticos, friáveis, podendo apresentar bancos silificados e endurecidos, mal classificados, contendo grânulos e seixos de quartzo esparsos, bem como bolas de argila. Quanto aos argilitos, são avermelhados e variegados, pobremente consolidados, maciços, laminados, e contêm bolsões de areias.

Formações Cretáceas (K)

$\mathrm{Na}$ área dos Cerrados cerca de 53 perfis de Latossolo foram locados sobre produtos de intemperização de rochas sedimentares de várias formações cretáceas. Seus sedimentos são arenosos, subordinadamente pelíticos, e originados em ambientes fluviais e lacustres. Para a presente pesquisa foram tratadas como um único conjunto.

Formações Pré-Cambrianas ( $p C$ )

As formações pré-cambrianas, tanto na área amazônica como na dos Cerrados estão representadas pelos mais diversos tipos de rochas ígneas e metamórficas, metassedimentos e migmatitos. Sobre seus produtos de intemperização foram distribuídos grande número de perfis dos latossolos estudados.

Complexo Xingu $(p C x)$

$\mathrm{Na}$ área amazônica, face ao grande número de perfis de Latossolo Vermelho Amarelo distribuídos sobre produtos de intemperização de rochas pertencentes a esta unidade geológica optou-se por proceder a sua análise separadamente das demais rochas pré-cambrianas. O Complexo Xingu na área amazônica constitui-se predominantemente por granitos, granodioritos, gnaisses, migmatitos e anfibolitos. 


\subsection{Obtenção e seleção dos dados}

Para a presente pesquisa formou-se um banco de dados em microcomputadores IBM-PC/AT com os dados analíticos dos 506 perfis de solo referentes aos latossolos que constam nos volumes $4,5,6,7,8,9,10,11,12,13,14,15$, $16,17,18,19,20,22,25,26,27$ e 31 do Projeto RADAMBRASIL.

O número de perfis arquivados e analisados para cada classe de solo das duas regiões estudadas está indicado na Tabela 5.

Tabela 5 - Número de perfís analisados para cada classe de latossolo estudado.

\begin{tabular}{lcc}
\hline \multirow{2}{*}{ Classe de solo } & \multicolumn{2}{c}{ Número de perfis analisados } \\
\cline { 2 - 3 } & \multicolumn{1}{c}{ Região Amazônica } & Região dos Cerrados \\
\hline \multicolumn{1}{c}{ Latossolos } & 262 & 244 \\
Latossolo Amarelo & 78 & - \\
Latossolo Vermelho Amarelo & 184 & 123 \\
Latossolo Vermelho Escuro & - & 121 \\
\hline
\end{tabular}

\subsubsection{Seleção dos horizontes}

Embora a maior parte dos perfis dos latossolos descritos pelo Projeto RADAM apresenta as notações de horizonte: A1, A3, B1, B21, B22 e B23, adotou-se nesta pesquisa a notação mais atualizada, proposta pela EMBRAPA-SNLCS, 1988. Dessa forma, fêz-se necessário enquadrar aquelas notações, respectivamente em: $A$, $\mathrm{A} / \mathrm{B}, \mathrm{B} / \mathrm{A}, \mathrm{Bw} 1, \mathrm{Bw} 2$ e Bw3. Outras notações, também apresentadas pelo RADAM, quais sejam, $A 11, A 12$ e $A 13$ foram incluídas como horizonte $A$; os horizontes $A 3 / B 1$, $\mathrm{A} 31$, $\mathrm{A} 32$, como $\mathrm{A} B \mathrm{~B}$; os horizontes $\mathrm{B} 11$, como $\mathrm{B} / \mathrm{A}$; os horizontes $\mathrm{B} 12$, como $\mathrm{Bw1}$; os horizontes $\mathrm{B} 2$, como $\mathrm{Bw} 2$; e os horizontes $\mathrm{B} 3$, como Bw3.

Não foram considerados, nesta pesquisa, os horizontes correspondentes à camada de serrapilheira e os horizontes denominados $\mathrm{O} 2, \mathrm{~A} 2, \mathrm{~A} 3 \mathrm{cn}, \mathrm{A}, \mathrm{AB}, \mathrm{B} 2 \mathrm{cn}$, $\mathrm{B} 21 \mathrm{pl}, \mathrm{B} 22 \mathrm{cn}, \mathrm{B} 23 \mathrm{cn}, \mathrm{B} 23 \mathrm{pl}, \mathrm{B} 3 \mathrm{cn}$, IIB22, IIIB23 e C, bem como, os horizontes A1 dos 
perfis de solo localizados em vegetação secundária e os Ap de áreas de culturas e pastagens.

\subsubsection{Determinação da profundidade dos horizontes}

Tendo em vista a comparação entre os latossolos das regiões dos Cerrados e da Amazônia, fez-se necessário padronizar as profundidades dos horizontes. Após análises de suas espessuras médias, estabeleceram-se as seguintes espessuras e profundidades aproximadas para cada horizonte e/ou camada estudada:

profundidade 1 (horiz. A) de $0-15 \mathrm{~cm}$ (espessura aprox. $15 \mathrm{~cm}$ ); profundidade 2 (horiz. A/B) de $15-35 \mathrm{~cm}$ (espessura aprox. $20 \mathrm{~cm}$ ); profundidade 3 (horiz. B/A) de $35-60 \mathrm{~cm}$ (espessura aprox. $30 \mathrm{~cm}$ ); profundidade 4 (horiz. Bw1) de $60-100 \mathrm{~cm}$ (espessura aprox. $40 \mathrm{~cm}$ ); profundidade 5 (horiz. Bw2) de $100-150 \mathrm{~cm}$ (espessura aprox. $50 \mathrm{~cm}$ ); profundidade 6 (horiz. Bw3) de $150-180+\mathrm{cm}$ (espessura aprox. $>30 \mathrm{~cm}$ ).

\subsubsection{Seleção das características granulométricas e químicas}

Para os horizontes de todos os perfis dos solos estudados foram selecionadas as seguintes características granulométricas: conteúdo de areia, de silte, de argila, de argila natural, grau de floculação, relação silte/argila.

As características químicas selecionadas foram: $\mathrm{pH}$ em água e em $\mathrm{KCl}$;

$\Delta \mathrm{pH}$; teor de matéria orgânica; relação $\mathrm{C} / \mathrm{N}$; teor de fósforo; bases trocáveis: $\mathrm{Ca}^{++}$, $\mathrm{Mg}^{++}, \mathrm{K}^{+}$; o cátion $\mathrm{Al}^{++}$; capacidade de troca catiônica em pH $7\left(\mathrm{CTC}_{7}\right)$; capacidade de troca catiônica efetiva $\left(\mathrm{CTC}_{\mathrm{e}}\right)$; saturação por aluminio; saturação por bases; teores de sílica, alumina, óxido de ferro total extraídos pelo ataque sulfúrico e índice ki.

Convém observar que parte dos 506 perfis dos latossolos examinados nas duas regiões deixa de apresentar valores de determinações de um ou mais dos seguintes 
atributos: relação $\mathrm{C} / \mathrm{N}$, teor de fósforo; de sílica, de alumina, de óxido de ferro total e indices ki.

\subsubsection{Métodos analíticos de laboratório}

Conforme relato do Projeto RADAMBRASIL, para a obtenção dos resultados analíticos das características referidas no ítem anterior, foram utilizados os seguintes métodos analíticos de laboratório:

- Análise granulométrica: foi empregado o método internacional da pipeta, utilizandose $\mathrm{NaOH} \mathrm{N}$ como agente dispersor. Para a argila natural (dispersa em água) utilizouse apenas água destilada.

- pH: determinado em água e solução normal de $\mathrm{KCl}$ na proporção de 1:1.

- Carbono orgânico: determinado por oxidação com dicromato de potássio em meio ácido.

- Nitrogênio: determinado pelo método de Kjeldahl, semi-micro, utilizando-se o ácido bórico a $4 \%$ e titulando-se o hidróxido de amônio por alcalimetria.

- Fósforo assimilável: obtido por espectrofotometria de absorção, medindo-se a coloração azul desenvolvida pela reação dos fosfatos do solo com molibidato de amônio, em presença de um sal de bismuto como catalizador.

- Cálcio e Magnésio permutáveis: determinados pela extração com cloreto de potássio $\mathrm{N}$ a pH 7,0 e dosados por espectrofotometria de absorção atômica.

- Potássio trocável: extraído com solução de $\mathrm{HCl}$ 0,05 $\mathrm{N}$ determinado por fotometria de chama.

- Alumínio e Hidrogênio permutáveis: determinados pela utilização de solução extratora de acetato de cálcio $\mathrm{N}, \mathrm{pH} 7,0$. Em seguida, com cloreto de potássio $\mathrm{N}$ e $\mathrm{pH}$ 7,0 , foi estraído o alumínio. O hidrogênio foi obtido por diferença.

- Após submeter a amostra de solo ao ataque de $\mathrm{H}_{2} \mathrm{SO}_{4}(\mathrm{~d}=1,47)$, foram determinados $\mathrm{SiO}_{2}, \mathrm{Al}_{2} \mathrm{O}_{3}$ e $\mathrm{Fe}_{2} \mathrm{O}_{3}$, como segue: 
- $\mathrm{SiO}_{2}$ : determinado por colorimetria, com a finalidade de eliminar silicatos secundários.

- $\mathrm{Al}_{2} \mathrm{O}_{3}$ : determinado por complexometria, através de titulação pelo método indireto do excesso de $\mathrm{Na}_{2}$-EDTA por solução de sulfato de zinco, em presença de ditizona, como indicador.

- $\mathrm{Fe}_{2} \mathrm{O}_{3}$ : dosado por dicromatometria numa alíquota do filtrado do ataque sulfúrico, usando-se solução de cloreto estanhoso como redutor e difenilamina como indicador.

- ki: a relação ki foi calculada sob forma molecular:

$$
\mathrm{ki}=1,7 \times \mathrm{SiO}_{2} \% / \mathrm{Al}_{2} \mathrm{O}_{3} \% \text {. }
$$

\subsection{Métodos estatísticos empregados e tratamentos dos dados}

A base dos procedimentos estatísticos utilizados neste trabalho, refere-se ao programa denominado "Statistical Analysis System" (SAS).

No tratamento estatístico dos dados, os parâmetros utilizados foram: média $(\mathrm{m})$ com o intervalo de confiança referente ao nível de $95 \%$ de probabilidade, desvio padrão $(\mathrm{s})$, erro padrão da média $(\mathrm{sm}=\mathrm{s} / \sqrt{n})$ e o coeficiente de variação $\mathrm{CV}=100 . \mathrm{s} / \mathrm{m})$.

As variações das propriedades físicas e químicas foram estudadas para cada classe de solo e comparadas entre si e por região, de acordo com os seguintes procedimentos:

- tratamento estatístico de cada classe de latossolo referente a cada região, visando a obtenção de valores médios das características físicas e químicas do solo;

- tratamento estatístico dos horizontes de cada classe de latossolo considerando-se os seguintes atributos: classes de textura, material de origem, tipos de vegetação, classes de pluviometria anual e classes climáticas de Köppen, a fim de se verificar a variabilidade nas características físicas e químicas em cada região estudada. 
- cálculo da reserva de matéria orgânica por hectare e por intervalo de profundidade para as classes texturais argilosa e muito argilosa de cada latossolo estudado, obtido através do produto da densidade do solo pelo teor médio de matéria orgânica em cada horizonte da classe de latossolo considerada. Estimou-se para a densidade dos solos com textura argilosa o valor $1,2 \mathrm{~kg} \mathrm{~cm}^{-3} \mathrm{e}$ para a classe muito argilosa, $1,0 \mathrm{~kg} \mathrm{~cm}^{-3}$. 


\section{RESULTADOS E DISCUSSÃO}

\subsection{Clima}

A região amazônica apresenta maior diversidade de climas do que a região dos Cerrados. Enquanto que o tipo de clima tropical chuvoso com uma estação seca bem definida (Awi) abrange 52\% da área da Amazônia (Tabela 6), nos Cerrados é predominante, e cobre cerca de $95 \%$ de sua área. No restante da Amazônia, em 20\% da área ocorre o clima tropical chuvoso sem estação seca definida (Afi) e nos outros $28 \%$, o clima tropical chuvoso com um período seco previsto de até 90 dias (Ami). As precipitações médias anuais distribuem-se na faixa de 1300 a mais de $3000 \mathrm{~mm}$, com média em torno de $2100 \mathrm{~mm}$, enquanto que na região dos Cerrados, $65 \%$ da precipitação

Tabela 6 - Resumo das características climáticas das regiões: amazônica e dos Cerrados

\begin{tabular}{ccc}
\hline Características climáticas & Região amazônica ${ }^{(l)}$ & ${\text { Região dos } \text { Cerrados }^{(2)}}$ \\
\hline Precipitação pluciométrica (mm/ano) & 1300 a 3 000 & 1200 a 1 $600(65 \%)$ \\
Temperatura & 2100 (média) & 1000 a $2000(86 \%)$ \\
Radiação solar (cal/cm $/ \mathrm{dia})$ & 25 a $27^{\circ} \mathrm{C}$ & 22 a $27^{\circ} \mathrm{C}$ \\
Período chuvoso & 373 (Manaus) & 475 a 500 \\
Período seco & set/out a abr/mai & set/out a abr/mai \\
Défice hídrico & mai/jun a set/out & mai/jun a set/out \\
Regime de umidade ústico (\% da área): & 0 a 5 meses & 4 a 6 meses $(90 \%)$ \\
údico: & $52 \%$ & $95 \%$ \\
perúdico: & $28 \%$ & $5 \%$ \\
\hline
\end{tabular}

Fonte: ${ }^{(1)}$ Demattè (1988); ${ }^{(2)}$ Adamoli et al. (1986). 
média anual situa-se na faixa de 1200 a $1600 \mathrm{~mm}$. Em termos de radiação solar, considerando Manaus como referência, na Amazônia ela é menor do que na dos Cerrados. Os períodos chuvosos e secos nos ambientes ústico e údico de umidade do solo são semelhantes nas duas regiões.

\section{2. Índices mineralógicos}

\subsection{1. Índice $\mathrm{ki}$}

Um dos índices que pode ser correlacionado com a mineralogia da fração argila de solos é o ki (Bennema, 1964; Moniz \& Jackson, 1966; Verdade, 1972). Valores de ki abaixo de 1,0, segundo Verdade (1972), há dominância de óxidos (gibsita); entre 1,0 e 1,5 dominam os óxidos, porém com contribuição de caulinita; entre 1,5 e 2,0 já existe uma participação maior de caulinita, porém com menor presença de óxidos; entre 2,0 e 2,5, dominância de caulinita com contribuição de minerais 2:1 (vermiculita, micas e montmorilonita); entre 2,5 e 3,0, uma boa contribuição de minerais 2:1 e menor contribuição de caulinita; acima de 3,0, dominância de minerais 2:1. Ao mesmo tempo, tal índice indica o estágio de intemperismo de um solo (Jackson et al., 1948).

Os resultados do ki (Figura 3 e Tabela 7) para os latossolos da Amazônia indicam valores na faixa de 2,0 para os LA e 1,6 para os LV. Com tais grupos de valores pode-se estimar que os LA são essencialmente cauliníticos, porém com contribuição de minerais 2:1, enquanto que os LV são mais cauliníticos. Dessa forma, em termos de intemperismo, os LA são menos intemperizados do que os LV (Jackson et al., 1948). Sendo assim, o potencial para liberação de alumínio na solução do solo através do intemperismo é maior no LA do que no LV (Lindsay, 1979). A mineralogia caulinítica com contribuição de minerais 2:1 nos LA, tem sido diagnosticada por diversos autores, entre eles Iwasa (1976), Kitagawa \& Moller (1979), Lima (1980), Moller \& Klamt (1982), Moller \& Araki (1984), Rodrigues (1996). 


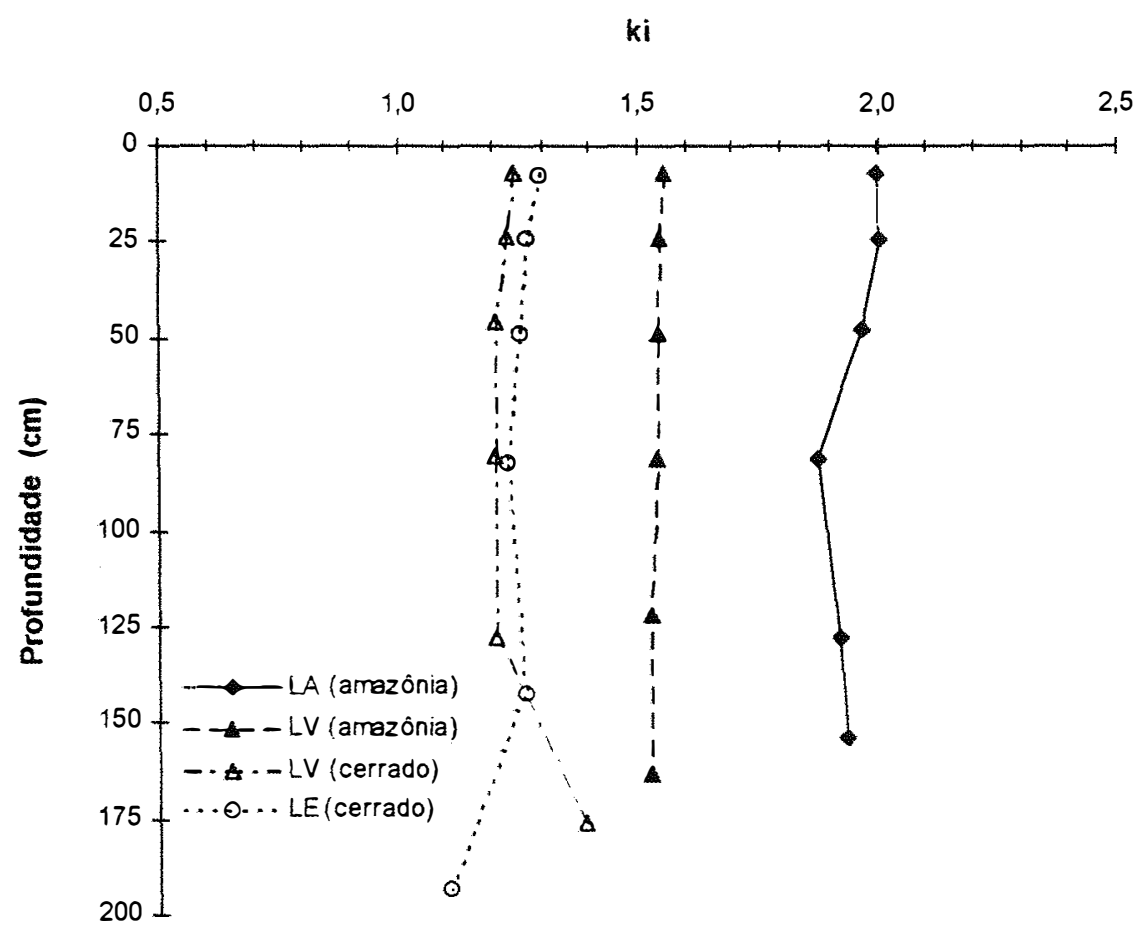

Figura 3 - Distribuição em profundidade dos valores médios do indice ki dos latossolos.

Por sua vez, os valores de ki para os latossolos dos Cerrados estão na faixa de 1,3 para ambos conjuntos, LV e LE. Com tais resultados, nota-se que tanto o LV como o LE são solos mais intemperizados do que os correspondentes na Amazônia, havendo dominância de óxidos, porém com contribuição de caulinita. Neste caso, os óxidos, principalmente a gibsita, são mais estáveis do que a caulinita, conseqüentemente, liberam menos aluminio na solução do solo (Lindsay, 1979). Outro aspecto fundamental que reflete a própria mineralogia, refere-se às características eletroquímicas destes solos. Devido à dominância dos óxidos, o PCZ destes solos está na faixa de $\mathrm{pH}$ 5,0 a 6,0 (Parks, 1967) o que contribui para o próprio $\mathrm{pH}$ do solo manter-se em faixas mais elevadas, independentemente dos teores de bases no solo. 
Tabela 7 - Valores da média do índice ki com o intervalo de confiança a $95 \%$ de probabilidade ( $\hat{\mathrm{m}} \pm$ t.s $\hat{\mathrm{m}})$, valor mínimo, máximo e coeficientes de variação nos horizontes dos latossolos.

\begin{tabular}{|c|c|c|c|c|c|}
\hline \multirow[t]{2}{*}{ Horizonte } & \multirow{2}{*}{$\begin{array}{c}N^{o} \text { de } \\
\text { pontos }\end{array}$} & \multicolumn{4}{|c|}{ Indice ki } \\
\hline & & $\hat{\mathrm{m}} \pm t . s \hat{\mathrm{m}}$ & Mínimo & Máximo & $C V(\%)$ \\
\hline \multicolumn{6}{|c|}{ LATOSSOLO AMARELO (AMAZÔNIA) } \\
\hline A & 29 & $2,00 \pm 0,09$ & 1,45 & 2,39 & 12 \\
\hline $\mathrm{A} / \mathrm{B}$ & 26 & $2,00 \pm 0,10$ & 1,49 & 2,55 & 13 \\
\hline $\mathrm{B} / \mathrm{A}$ & 25 & $1,97 \pm 0,10$ & 1,44 & 2,57 & 12 \\
\hline Bwl & 24 & $1,87 \pm 0,10$ & 1,13 & 2,22 & 14 \\
\hline $\mathrm{Bw} 2$ & 28 & $1,92 \pm 0,09$ & 1,37 & 2,53 & 13 \\
\hline $\mathrm{Bw} 3$ & 8 & $1,94 \pm 0,11$ & 1,66 & 2,13 & 13 \\
\hline \multicolumn{6}{|c|}{ LATOSSOLO VERMELHO AMARELO (AMAZÔNIA) } \\
\hline$A$ & 93 & $1,55 \pm 0,09$ & 0,28 & 2,53 & 30 \\
\hline $\mathrm{A} / \mathrm{B}$ & 90 & $1,55 \pm 0,10$ & 0,40 & 2,37 & 30 \\
\hline $\mathrm{B} / \mathrm{A}$ & 88 & $1,54 \pm 0,10$ & 0,30 & 2,53 & 32 \\
\hline Bw1 & 87 & $1,54 \pm 0,10$ & 0,33 & 2,57 & 32 \\
\hline Bw2 & 103 & $1,53 \pm 0,09$ & 0,40 & 2,46 & 32 \\
\hline Bw3 & 40 & $\underline{1,53 \pm 0,13 \ldots}$ & $.0,58$ & 2,49 & 28 \\
\hline \multicolumn{6}{|c|}{ LATOSSOLO VERMELHO AMARELO (CERRADO) } \\
\hline A & 81 & $1,25 \pm 0,10$ & 0,45 & 2,45 & 38 \\
\hline$A / B$ & 80 & $1,23 \pm 0,10$ & 0,48 & 2,44 & 36 \\
\hline $\mathrm{B} / \mathrm{A}$ & 83 & $1,21 \pm 0,09$ & 0,48 & 2,10 & 34 \\
\hline Bwl & 81 & $1,21 \pm 0,10$ & 0,43 & 2,48 & 38 \\
\hline Bw2 & 76 & $1,20 \pm 0,10$ & 0,43 & 2,41 & 37 \\
\hline$B w 3$ & 17 & $\underline{1,39 \pm 0,21}$ & $\underline{0,81} \ldots$ & 2,31 & 32 \\
\hline \multicolumn{6}{|c|}{ LATOSSOLO VERMELHO ESCURO (CERRADO) } \\
\hline A & 81 & $1,30 \pm 0,13$ & 0,31 & 2,51 & 44 \\
\hline $\mathrm{A} / \mathrm{B}$ & 93 & $1,27 \pm 0,11$ & 0,29 & 2,33 & 44 \\
\hline $\mathrm{B} / \mathrm{A}$ & 105 & $1,25 \pm 0,11$ & 0,27 & 2,51 & 46 \\
\hline Bw 1 & 103 & $1,23 \pm 0,11$ & 0,26 & 2,52 & 45 \\
\hline Bw2 & 100 & $1,27 \pm 0,11$ & 0,23 & 2,53 & 46 \\
\hline Bw3 & 12 & $1,30 \pm 0,46$ & 0,42 & 3,38 & 62 \\
\hline
\end{tabular}


Um ponto que tem chamado muito a atenção de pesquisadores é o fato do LA, muitas vezes localizado em ambiente perúdico de umidade, ou seja, em condições excepcionais de intenso intemperismo, ser menos intemperizado do que os LV ou LE do Brasil Central situados em ambiente de umidade exclusivamente ústico. Diversos pontos podem ser levantados para esclarecer tal fato, porém o efeito"anti-gibsítico", já demonstrado por Jackson (1963), pode explicar. Em síntese, devido à intensa reciclagem da sílica feita pela mata, há uma grande reposição de sílica na solução do solo, principalmente na superfície, o que vem dificultar a formação de gibsita. Dessa forma, o efeito "anti-gibsítico" retarda o processo, não permitindo que os solos atinjam os estágios mais avançados de intemperização. Porém, de acordo com Melfi \& Pedro (1977), este fato possa ser atribuído à maior intemperização do quartzo na superfície do solo que, apesar de sua estabilidade, libera silica aumentando sua concentração no solo e, conseqüentemente aumentando a relação $\mathrm{SiO}_{2} / \mathrm{Al}_{2} \mathrm{O}_{3}$ e assim, estabilizando a caulinita. Fauk (1970) e Millot et al. (1971) relataram que o quartzo chega a impedir que a alitização se desenvolva. Neste sentido, como o quartzo da fração areia e silte apresenta-se em quantidade elevada nos latossolos da Amazônia, pois são originados principalmente das formações Barreiras e Solimões, supõe-se haver maior desenvolvimento da caulinização nestes solos em detrimento da alitização.

De acordo com os trabalhos pioneiros de Kittrick (1969), e posteriormente, de Lindsay (1979), a respeito dos processos termodinâmicos na previsão do intemperismo, à medida em que há remoção da sílica do sistema, os minerais 2:1 tendem para 1:1 e estes para gibsita. Se a concentração de ácido silícico for tal que mantenha a caulinita estável, esta não se intemperizará para gibsita. A propósito, observa-se na Tabela A1 (página 133) que os valores mais elevados do ki para o LA e LV estão nos horizontes superfíciais.

Valores superiores a 2,0 ou 2,2, bem como os valores máximos encontrados para o LA e LV (Tabela Al, página 133), não representam latossolos, possivelmente sejam enquadrados como cambissolos latossólicos. Aliás, relatos neste 
sentido, já foram emitidos por outros autores entre eles Lima (1980), Moller \& Klamt (1982).

A influência do material de origem sobre a mineralogia do solo pode ser observada pelos dados da Tabela A2 (página 133). Note que, no caso do LA da Amazônia, o valor do ki para a Formação Barreiras é mais elevado do que o ki da Formação Solimões, 2,13 contra 1,96, respectivamente. Como grande parte do LA é originário da Formação Barreiras, o seu ki é dominantemente mais elevado do que o LV originado quase exclusivamente da Formação Solimões, de menor ki. Fica aqui, portanto, registrado a grande importância do material de origem na diferenciação destes dois grupos de solos.

No caso dos latossolos dos Cerrados, as formações geológicas também influenciam os valores do ki. Assim é que para o LV, valores mais elevados são encontrados nos solos derivados das formações terciárias e quaternárias, quando comparados com os solos derivados das formações pré-cambrianas. O mesmo se aplica para os LE.

O clima por sua vez, como já foi observado, influência a mineralogia e, conseqüentemente, o índice ki (Tabela A3, página 134). À medida que aumenta a precipitação há uma tendência de aumento do intemperismo, e conseqüentemente, decréscimo nos valores de ki. Os valores para o LV da Amazônia indicam ki de 2,0 para precipitações na faixa de 1000 a $1500 \mathrm{~mm}$ e de 1,10 para a faixa de precipitação acima de $3000 \mathrm{~mm}$.

Um fato que tem chamado a atenção, refere-se às relações ki x CTC $\times$ Al trocável para solos desenvolvidos das formações Solimões e Barreiras na Amazônia. Os dados indicados na Tabela 8 , extraídos das tabelas correspondentes, resumem tais relações. 
Tabela 8 - Relações entre ki X CTC X Al trocável nas formações Solimões e Barreiras.

\begin{tabular}{|c|c|c|c|c|c|c|}
\hline \multirow{4}{*}{ Material de origem } & \multirow{2}{*}{\multicolumn{2}{|c|}{$k i$}} & \multicolumn{2}{|c|}{$C T C$} & \multicolumn{2}{|c|}{ Al trocável } \\
\hline & & & \multicolumn{4}{|c|}{$\left(\mathrm{cmol}_{c} \mathrm{~kg}^{-1}\right)$} \\
\hline & \multicolumn{2}{|c|}{ Horizonte } & \multicolumn{2}{|c|}{ Horizonte } & \multicolumn{2}{|c|}{ Horizonte } \\
\hline & A & $\mathrm{B} / \mathrm{A}$ & A & $\mathrm{B} / \mathrm{A}$ & A & $\mathrm{B} / \mathrm{A}$ \\
\hline Formação Solimões & 1,9 & 1,8 & 10,0 & 5,7 & 3,4 & 2,5 \\
\hline Formação Barreiras & 2,1 & 2,15 & 7,8 & 3,9 & 1,7 & 1,0 \\
\hline
\end{tabular}

Nota-se que o ki da Formação Solimões é inferior ao ki da Formação Barreiras, porém a CTC é mais elevada, inclusive o teor de $\mathrm{Al}$ trocável. Tais resultados deveriam ser invertidos, uma vez, que para maiores valores de ki, teria que haver correspondência de maior valor da CTC e, conseqüentemente de alumínio. Tais resultados já tinham sido relatados por Demattê \& Demattê (1994). Pereira (1987) levantou a hipótese que os cristais de caulinita da Formação Barreiras são maiores do que os da Formação Solimões, daí esta possível inversão de resultados. A propósito, Besoin (1985) afirmou que o baixo valor da CTC da caulinita pode aumentar à medida que o tamanho das partículas diminuem e a desordem na rede critalina aumenta, isto é, a caulinita muito desordenada tem valor de CTC pouco maior do que a bem ordenada.

De acordo com os resultados do índice ki, notou-se que os solos da região amazônica são menos intemperizados do que os da região dos Cerrados, apesar das condições climáticas atuais serem mais favoráveis na região amazônica para um intemperismo mais acentuado. É necessário, entretanto, levar em consideração que a ação climática do passado teve uma influência muito grande no intemperismo, e neste particular as paisagens do Brasil Central são tidas como mais velhas do que da Amazônia (Cline \& Buol, 1973; Rodrigues, 1977). Por outro lado, o efeito "antigibsítico" aqui relatado, na região amazônica, deve ser observado com certo cuidado. Foi constatado por Chauvel (1981), a ocorrência de gibbsans ao longo de canais e fissuras de alguns perfis do LA indicando que a alitização é possivel, porém apenas em condições específicas como o caso aqui relatado.

Em síntese, quanto ao aspecto mineralógico, os resultados obtidos por esta pesquisa mostram que os latossolos da região amazônica são menos intemperizados 
do que os solos da região dos Cerrados, com índice ki na faixa de 1,8 a 2,1, contra ki inferiores a 1,5 para a região dos Cerrados. Dentre os latossolos amazônicos, o LA apresenta maior valor de ki quando comparado com o LV e, conseqüentemente, menos intemperizado. De acordo com tais valores, há dominância de caulinita com pequena contribuição de minerais $2: 1$ para a região amazônica contra a dominância de caulinita e óxidos para a região dos Cerrados.

\subsubsection{Silica}

Os dados sobre o teor de sílica nos horizontes dos latossolos estão apresentados na Tabela 9. O teor de $\mathrm{SiO}_{2}$ para todos os solos tende a aumentar com a profundidade (Figura 4), ficando na faixa de $11 \%$ no horizonte superficial para o LA e LV da região amazônica e 17 a 18\% nos horizontes mais inferiores (Bw3). Quanto aos solos dos Cerrados, os teores são mais baixos, na faixa de $10 \%$ no A e $14 \%$ no Bw3. Sendo assim, os resultados indicam decréscimo do intemperismo da superficie para as camadas mais inferiores dos solos, fato este, que está de acordo com as seqüências de intemperismo para solos (Jackson et al., 1948). A maior quantidade de $\mathrm{SiO}_{2}$ nos solos amazônicos pode estar relacionada a sua mineralogia da fração argila constituída por caulinita e pequena contribuição de minerais $2: 1$, que possuem maior quantidade de sílica, quando comparado com argilas de menor atividade como é o caso dos solos dos Cerrados.

A influência da textura do solo no teor de sílica pode ser observada pelos dados da Tabela A6, página 135, onde há uma tendência do aumento da sílica à medida que o teor de argila aumenta, principalmente para os solos da Amazônia. Tal fato pode ser explicado pela maior contribuição de $\mathrm{SiO}_{2}$ nos minerais de argila, destruídos pelo ataque sulfúrico. 
Tabela 9 - Média do teor de sílica com o intervalo de confiança a 95\% de probabilidade $(\hat{\mathrm{m}} \pm$ t.s $\hat{\mathrm{m}})$, valor mínimo, máximo e coeficientes de variação nos horizontes dos latossolos.

\begin{tabular}{|c|c|c|c|c|c|}
\hline \multirow[t]{2}{*}{ Horizonte } & \multirow{2}{*}{$\begin{array}{l}N^{o} \text { de } \\
\text { pontos }\end{array}$} & \multicolumn{4}{|c|}{ Sílica $\left(\mathrm{SiO}_{2} \%\right)$} \\
\hline & & $m \pm t . s m$ & Mínimo & Máximo & $C V(\%)$ \\
\hline \multicolumn{6}{|c|}{ LATOSSOLO AMARELO (AMAZÔNIA) } \\
\hline A & 29 & $11,37 \pm 2,10$ & 4,28 & 27,70 & 139 \\
\hline $\mathrm{A} / \mathrm{B}$ & 27 & $13,09 \pm 2,05$ & 3,80 & 27,81 & 95 \\
\hline $\mathrm{B} / \mathrm{A}$ & 25 & $13,82 \pm 2,47$ & 3,08 & 32,20 & 85 \\
\hline Bwl & 24 & $15,28 \pm 1,90$ & 6,70 & 26,73 & 74 \\
\hline Bw2 & 28 & $15,87 \pm 2,38$ & 5,49 & 38,00 & 72 \\
\hline Bw3 & 8 & $18,56 \pm 4,67$ & 7,90 & $.28,66$ & 65 \\
\hline \multicolumn{6}{|c|}{ LATOSSOLO VERMELHO AMARELO (AMAZÔNIA) } \\
\hline A & 100 & $11,78 \pm 1,55$ & 0,42 & 29,32 & 67 \\
\hline $\mathrm{A} / \mathrm{B}$ & 94 & $13,71 \pm 1,28$ & 0,90 & 32,22 & 46 \\
\hline $\mathrm{B} / \mathrm{A}$ & 94 & $14,91 \pm 1,30$ & 0,90 & 32,70 & 43 \\
\hline Bwl & 88 & $15,80 \pm 1,40$ & 0,90 & 33,58 & 42 \\
\hline Bw2 & 104 & $16,85 \pm 2,05$ & 1,39 & 34,87 & 63 \\
\hline $\mathrm{Bw3}$ & 41 & $17,29 \pm 2,16$ &. & 33,66 & 41 \\
\hline \multicolumn{6}{|c|}{ LATOSSOLO VERMELHO AMARELO (CERRADO) } \\
\hline$A$ & 82 & $9,30 \pm 1,02$ & 2,80 & 20,61 & 51 \\
\hline$A / B$ & 80 & $10,05 \pm 1,10$ & 2,50 & 22,90 & 50 \\
\hline $\mathrm{B} / \mathrm{A}$ & 83 & $10,80 \pm 1,11$ & 2,70 & 25,19 & 48 \\
\hline Bwl & 81 & $11,23 \pm 1,16$ & 0,43 & 24,51 & 47 \\
\hline Bw2 & 76 & $11,58 \pm 1,17$ & 3,00 & 25,65 & 45 \\
\hline Bw3 & 17 & $13,88 \pm 2,16$ & 7,17 & $22,30$. & 33 \\
\hline \multicolumn{6}{|c|}{ LATOSSOLO VERMELHO ESCURO (CERRADO) } \\
\hline$A$ & 82 & $10,03 \pm 1,10$ & 3,02 & 26,60 & 51 \\
\hline $\mathrm{A} / \mathrm{B}$ & 97 & $10,39 \pm 1,08$ & 3,00 & 23,80 & 52 \\
\hline $\mathrm{B} / \mathrm{A}$ & 105 & $10,92 \pm 1,04$ & 3,30 & 24,60 & 50 \\
\hline Bwl & 105 & $11,39 \pm 1,05$ & 3,87 & 27,70 & 48 \\
\hline $\mathrm{Bw} 2$ & 100 & $11,42 \pm 1,06$ & 2,23 & 25,20 & 48 \\
\hline Bw3 & 12 & $14,28 \pm 3,53$ & 4,80 & 25,30 & 44 \\
\hline
\end{tabular}




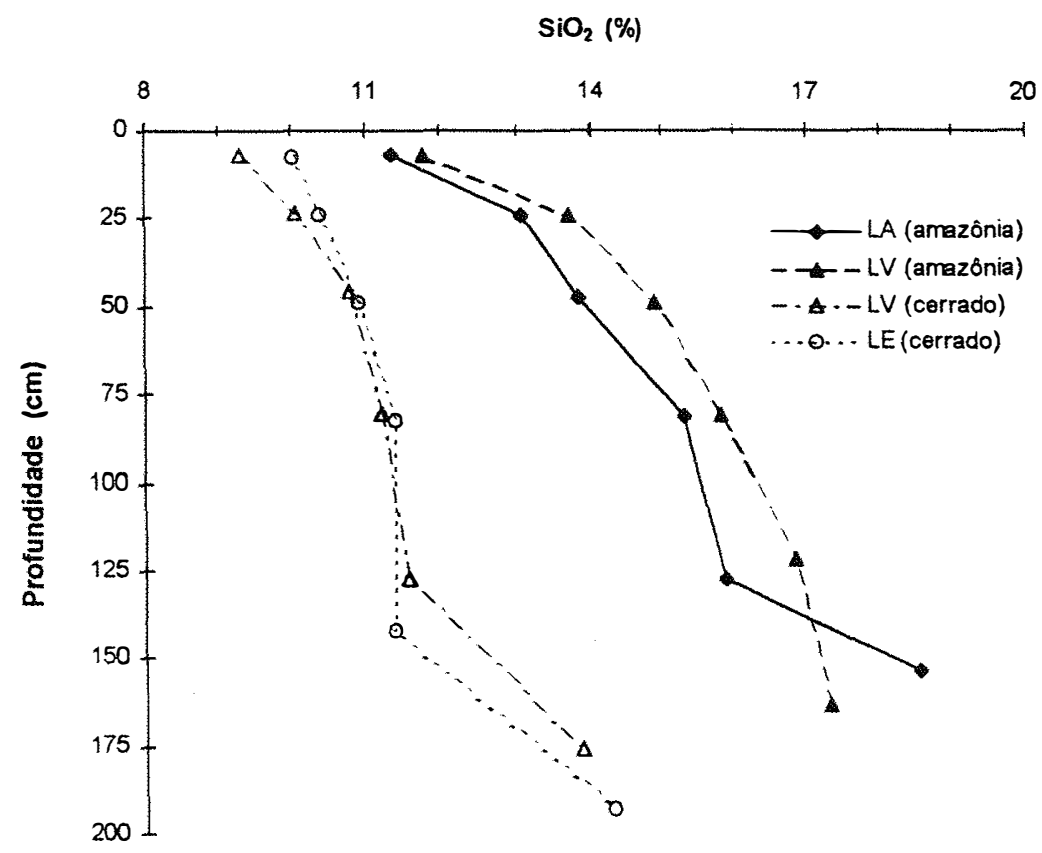

Figura 4- Distribuição em profundidade dos valores médios da sílica dos latossolos.

\subsubsection{Alumina}

Os dados sobre o teor de alumina nos horizontes dos latossolos estão apresentados na Tabela 10. Como já foi esclarecido, o ataque sulfúrico tende a destruir a grade dos minerais, principalmente dos minerais da fração argila. Assim, a gibsita, mais rica em alumínio, porém mais estável do que a caulinita, também é destruída pelo ataque sulfúrico. Dessa forma, o teor de $\mathrm{Al}_{2} \mathrm{O}_{3}$ apresentado na Tabela 10 e Figura 5 indica:

- aumento no teor de $\mathrm{Al}_{2} \mathrm{O}_{3}$ à medida que aumenta a profundidade;

- teores mais elevados de $\mathrm{Al}_{2} \mathrm{O}_{3}$ nos latossolos dos Cerrados, demonstrando possivelmente uma maior riqueza de gibsita;

- aumento no teor de $\mathrm{Al}_{2} \mathrm{O}_{3}$ à medida que o solo se torna mais argiloso, principalmente para os solos dos Cerrados (Tabela A10, página 137). 
Tabela 10 - Média do teor de alumina com o intervalo de confiança a $95 \%$ de probabilidade $(\hat{\mathrm{m}} \pm$ t.s $\hat{\mathrm{m}})$, valor mínimo, máximo e coeficientes de variação nos horizontes dos latossolos

\begin{tabular}{|c|c|c|c|c|c|}
\hline \multirow[t]{2}{*}{ Horizonte } & \multirow{2}{*}{$\begin{array}{l}N^{o} \text { de } \\
\text { pontos }\end{array}$} & \multicolumn{4}{|c|}{ Alumina $\left(\mathrm{Al}_{2} \mathrm{O}_{3} \%\right)$} \\
\hline & & $m \pm t . s m$ & Mínimo & Máximo & $C V(\%)$ \\
\hline \multicolumn{6}{|c|}{ LATOSSOLO AMARELO (AMAZÔNIA) } \\
\hline A & 29 & $9,72 \pm 1,71$ & 3,57 & 22,70 & 48 \\
\hline $\mathrm{A} / \mathrm{B}$ & 27 & $11,24 \pm 1,83$ & 2,55 & 25,50 & 43 \\
\hline $\mathrm{B} / \mathrm{A}$ & 25 & $12,07 \pm 1,98$ & 2,04 & 25,50 & 42 \\
\hline Bwl & 24 & $14,01 \pm 1,75$ & 5,36 & 27,90 & 31 \\
\hline Bw2 & 28 & $13,95 \pm 1,76$ & 5,61 & 25,50 & 34 \\
\hline $\mathrm{Bw} 3$ & 8 & $13,43 \pm 4,58$ & 7,65 & 29,33 & 40 \\
\hline \multicolumn{6}{|c|}{ LATOSSOLO VERMELHO AMARELO (AMAZÔNIA) } \\
\hline A & 100 & $11,85 \pm 1,53$ & 1,53 & 28,82 & 47 \\
\hline $\mathrm{A} / \mathrm{B}$ & 94 & $14,75 \pm 1,14$ & 3,83 & 28,05 & 38 \\
\hline $\mathrm{B} / \mathrm{A}$ & 94 & $16,08 \pm 1,15$ & 5,10 & 29,50 & 36 \\
\hline Bw 1 & 88 & $17,48 \pm 1,23$ & 4,59 & 32,39 & 34 \\
\hline Bw2 & 104 & $17,91 \pm 1,17$ & 1,03 & 32,13 & 34 \\
\hline Bw3 & 41 & $19,24 \pm 1,88$ & 7,10 & 31,10 & 32 \\
\hline \multicolumn{6}{|c|}{ LATOSSOLO VERMELHO AMARELO (CERRADO) } \\
\hline A & 82 & $13,94 \pm 1,71$ & 2,40 & 40,70 & 57 \\
\hline $\mathrm{A} / \mathrm{B}$ & 80 & $15,11 \pm 1,78$ & 4,00 & 42,40 & 57 \\
\hline $\mathrm{B} / \mathrm{A}$ & 83 & $16,51 \pm 1,69$ & 4,70 & 43,60 & 54 \\
\hline Bw1 & 81 & $17,67 \pm 1,74$ & 5,20 & 44,80 & 48 \\
\hline Bw2 & 76 & $18,04 \pm 1,80$ & 5,30 & 45,10 & 45 \\
\hline $\mathrm{Bw} 3$ & 17 & $22,83 \pm 2,27$ & 6,38 & 47,44 & 46 \\
\hline \multicolumn{6}{|c|}{ LATOSSOLO VERMELHO ESCURO (CERRADO) } \\
\hline A & 82 & $15,85 \pm 2,08$ & 3,00 & 36,97 & 61 \\
\hline $\mathrm{A} / \mathrm{B}$ & 97 & $16,39 \pm 1,96$ & 2,70 & 36,51 & 60 \\
\hline $\mathrm{B} / \mathrm{A}$ & 105 & $17,91 \pm 1,90$ & 3,00 & 38,25 & 55 \\
\hline Bwl & 105 & $18,53 \pm 1,89$ & 3,70 & 38,86 & 53 \\
\hline Bw2 & 100 & $18,75 \pm 1,95$ & 4,14 & 40,03 & 53 \\
\hline Bw3 & 12 & $25,82 \pm 2,61$ & 6,40 & 39,01 & 38 \\
\hline
\end{tabular}




\subsubsection{Teor de ferro total, extraído pelo ataque sulfúrico}

O teor de ferro extraído pelo ataque sulfúrico inclue o ferro amorfo, ferro cristalino (hematita e goethita) e o ferro presente nas estruturas dos silicatos secundários. Sendo assim, não deixa de ser um parâmetro muito útil na comparação de solos, uma vez que este elemento tem ação nas mais diversas áreas, principalmente no auxílio à estruturação dos solos. Através da Figura 6 e os dados da Tabela 11, nota-se que o teor de ferro total (ferro extraído pelo ataque sulfúrico) está na faixa de 2,5 a 3,5\% no LA e entre 5 e $6 \%$ nos LV, tanto da Amazônia como dos Cerrados. De acordo com o Sistema Brasileiro de Classificação de Solo (Camargo et al., 1987), os LA apresentam teores de ferro total na faixa aqui especificada, enquanto que os LV, na faixa dos 5 aos $6 \%$. Os latossolos Vermelho Escuro apresentam teores de ferro total entre 8 e $10 \%$.

Talvez resida no teor de ferro desses solos, uma das grandes diferenças relacionadas à estabilidade de suas estruturas. Enquanto que a microestrutura dos LE e também dos LV da região dos Cerrados é bem desenvolvida e de grande estabilidade (Adamoli et al., 1986), isto não ocorre com a estrutura do LA (Demattê, 1988; Sánchez, 1985). É bastante comum as análises morfológicas do LA apresentarem poros bloqueados, principalmente na posição do horizonte $A / B$, fato este atribuído a uma maior instabilidade da estrutura (Demattê et al, 1994). Aparentemente os problemas com a compactação nos LA argilosos são mais pronunciados do que nos solos onde o teor de ferro é mais elevado ( $\mathrm{Lal}, 1986)$. O teor de ferro, independentemente do solo, se correlaciona com a textura. À medida que o solo torna-se mais argiloso, aumenta o teor de ferro (Tabela A16, página 140).

Em relação ao LV das duas regiões, aparentemente não há diferenciações

entre eles, pelo menos quanto ao aspecto ferro total. Entretanto, pesquisas devem ser direcionadas nestes dois solos, no sentido de se compreender melhor a maior estabilidade da estrutura do LV dos Cerrados, quando comparado com o da Amazônia. Por outro lado, a grande diferença entre esses grupos de latossolos reside no fato de que no LA predomina a goethita, enquanto que no LE a hematita (Melfi \& Pedro, 1978). 


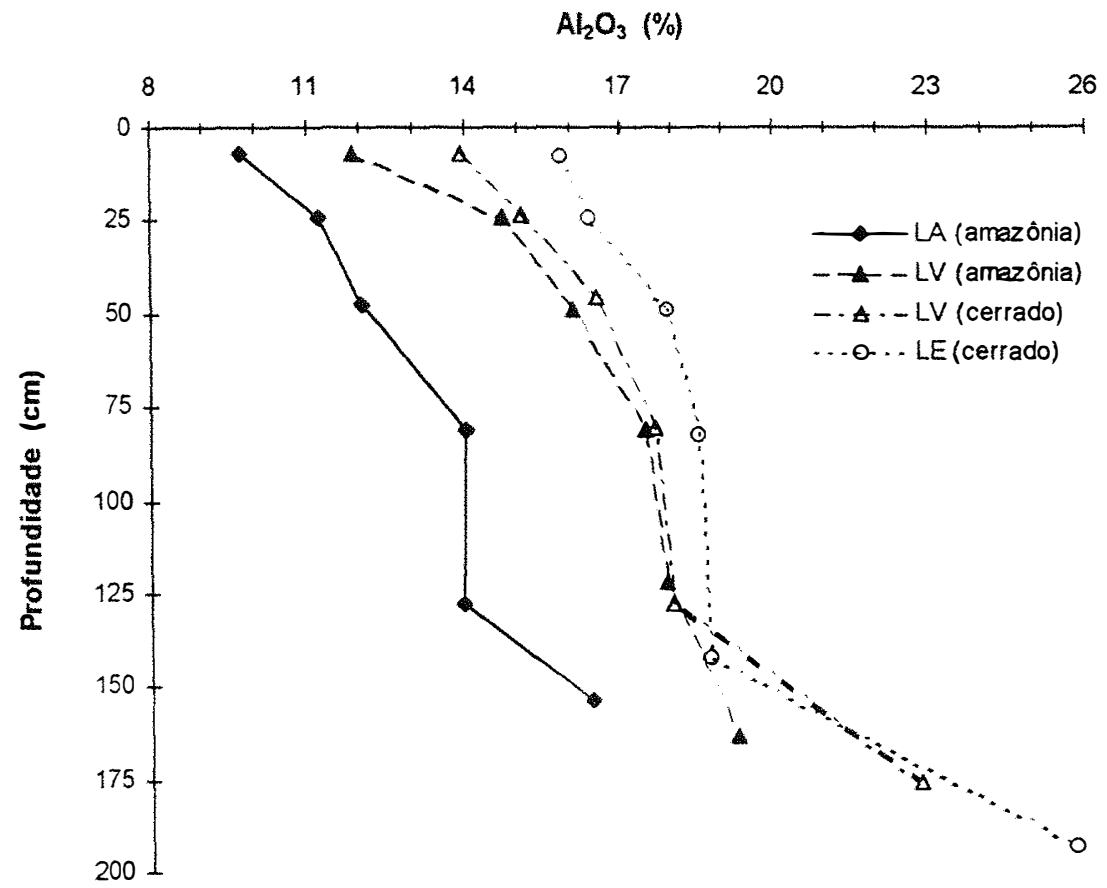

Figura 5 - Distribuição em profundidade dos valores médios da alumina dos latossolos.

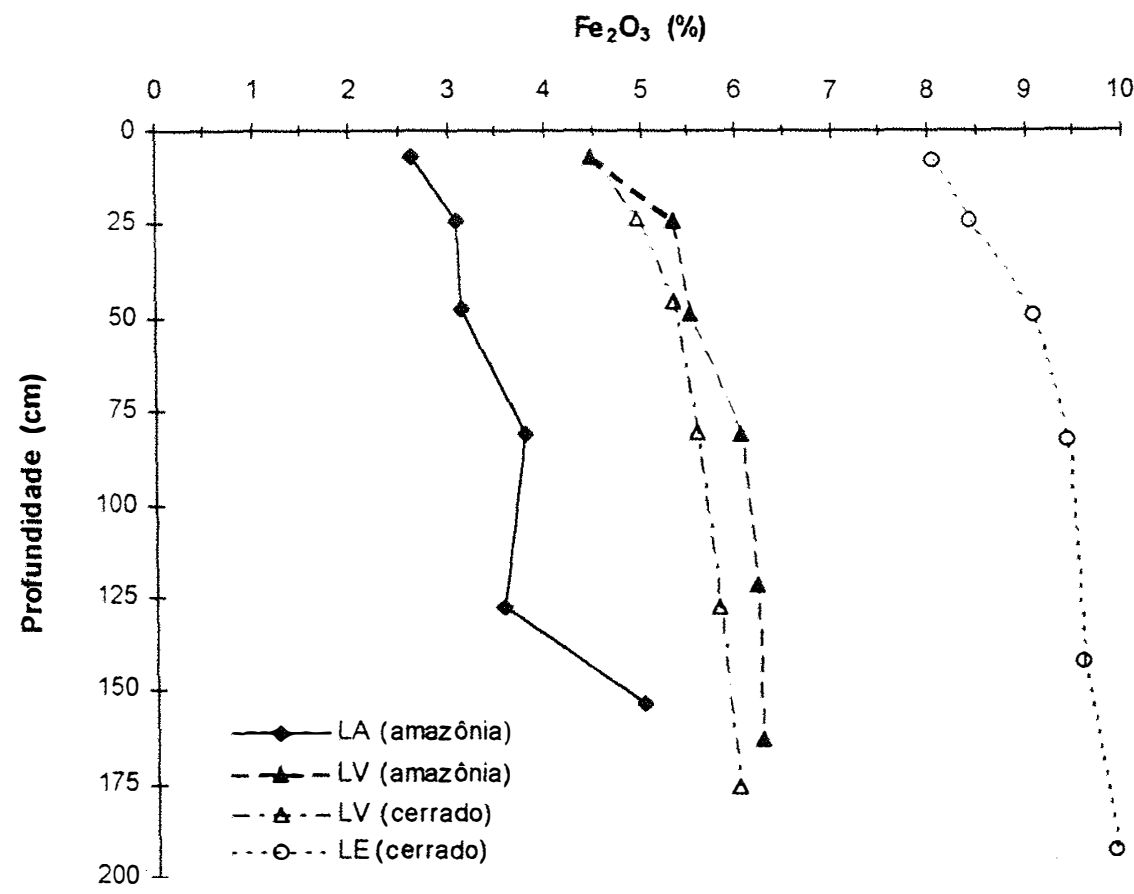

Figura 6 - Distribuição em profundidade dos valores médios do óxido de ferro total dos latossolo 
Tabela 11 - Média do teor de ferro total, extraído pelo ataque sulfúrico com o intervalo de confiança a $95 \%$ de probabilidade ( $\hat{\mathrm{m}} \pm \mathrm{t} . \mathrm{s} \hat{\mathrm{m}}$ ), valor mínimo, máximo e coeficientes de variação nos horizontes dos latossolos.

\begin{tabular}{|c|c|c|c|c|c|}
\hline \multirow[t]{2}{*}{ Horizonte } & \multirow{2}{*}{$\begin{array}{l}N^{0} d e \\
\text { pontos }\end{array}$} & \multicolumn{4}{|c|}{ Ferro total $\left(\mathrm{Fe}_{2} \mathrm{O}_{3} \%\right)$} \\
\hline & & $m \pm t . s m$ & Mínimo & Máximo & $C V(\%)$ \\
\hline \multicolumn{6}{|c|}{ LATOSSOLO AMARELO (AMAZÔNIA) } \\
\hline A & 29 & $2,63 \pm 0,44$ & 1,12 & 5,36 & 46 \\
\hline $\mathrm{A} / \mathrm{B}$ & 27 & $3,09 \pm 0,51$ & 0,99 & 6,40 & 44 \\
\hline $\mathrm{B} / \mathrm{A}$ & 25 & $3,15 \pm 0,62$ & 3,00 & 6,80 & 50 \\
\hline Bwl & 24 & $3,80 \pm 0,63$ & 1,39 & 7,50 & 41 \\
\hline $\mathrm{Bw} 2$ & 28 & $3,56 \pm 0,62$ & 0,99 & 7,90 & 47 \\
\hline $\mathrm{Bw} 3$ & 8 & $5,01 \pm 1,77$ & 0,99 & 8,90 & 51 \\
\hline \multicolumn{6}{|c|}{ LATOSSOLO VERMELHO AMARELO (AMAZÔNIA) } \\
\hline $\mathrm{A}$ & 97 & $4,48 \pm 0,57$ & 0,60 & 18,17 & 64 \\
\hline$A / B$ & 91 & $5,34 \pm 0,55$ & 0,79 & 16,17 & 50 \\
\hline $\mathrm{B} / \mathrm{A}$ & 92 & $5,51 \pm 0.58$ & 0,99 & 18,37 & 52 \\
\hline Bw1 & 86 & $6,05 \pm 0,57$ & 0,99 & 17,97 & 45 \\
\hline $\mathrm{Bw} 2$ & 101 & $6,22 \pm 0,55$ & 0,99 & 19,56 & 45 \\
\hline $\mathrm{Bw} 3$ & 41 & $6,29 \pm 0,82 \ldots$ & 1,59 & 13,11 & 43 \\
\hline \multicolumn{6}{|c|}{ LATOSSOLO VERMELHO AMARELO (CERRADO) } \\
\hline A & 82 & $4,49 \pm 0,47$ & 0,40 & 11,90 & 49 \\
\hline $\mathrm{A} / \mathrm{B}$ & 80 & $4,95 \pm 0,50$ & 0,50 & 10,85 & 46 \\
\hline $\mathrm{B} / \mathrm{A}$ & 83 & $5,33 \pm 0,50$ & 0,50 & 11,90 & 44 \\
\hline Bwl & 81 & $5,59 \pm 0,56$ & 0,70 & 12,00 & 46 \\
\hline $\mathrm{Bw} 2$ & 76 & $5,82 \pm 0,55$ & 0,80 & 11,90 & 42 \\
\hline Bw3 & 17 & $6,03 \pm 1,26$ & 1,70 & 11,42 & 44 \\
\hline \multicolumn{6}{|c|}{ LATOSSOLO VERMELHO ESCURO (CERRADO) } \\
\hline A & 82 & $8,05 \pm 0,, 83$ & 3,02 & 17,00 & 48 \\
\hline$A / B$ & 97 & $8,43 \pm 0,74$ & 3,00 & 15,10 & 44 \\
\hline $\mathrm{B} / \mathrm{A}$ & 105 & $9,09 \pm 0,73$ & 3,30 & 17,73 & 42 \\
\hline Bw1 & 105 & $9,43 \pm 0,72$ & 3,87 & 17,12 & 40 \\
\hline Bw2 & 100 & $9,60 \pm 0,73$ & 2,23 & 17,57 & 39 \\
\hline Bw3 & 12 & $9,92 \pm 1,89$ & 4,80 & 15,20 & 34 \\
\hline
\end{tabular}




\subsection{Propriedades morfológicas e granulométricas}

Embora não se enquadre neste trabalho uma descrição pormenorizada das propriedades morfológicas e fisicas dos latossolos estudados na região amazônica e na dos Cerrados, são apresentadas e discutidas a seguir, as que se mostram relevantes para os objetivos desta pesquisa.

\subsubsection{Espessura dos horizontes}

As espessuras médias dos horizontes dos latossolos estão apresentadas na Tabela 12 , onde se encontram a média com o intervalo de confiança a $95 \%$ de probabilidade ( $\hat{\mathrm{m}} \pm$ t.s $\hat{\mathrm{m}}$ ), espessura mínima, máxima e coeficientes de variação $(\mathrm{CV})$.

Pelos dados da Tabelas 12 verifica-se que tanto os latossolos da Amazônia como dos Cerrados, possuem perfis profundos e bem desenvolvidos. Nesses latossolos os horizontes A possuem espessuras médias praticamente semelhantes, distribuindo-se predominantemente entre 10 a $20 \mathrm{~cm}$ de espessura. Da mesma forma, assemelham-se as médias de espessura do horizonte $A / B$, cujos dados de espessura se inserem predominantemente entre 10 a $30 \mathrm{~cm}$. No entanto, os horizontes $B$ mostram espessuras médias pouco mais diferenciadas, notadamente as do LE dos Cerrados, onde há um acréscimo maior na espessura dos horizontes com a profundidade.

\subsubsection{Textura}

Os dados referentes à textura, teores de argila, silte e areia assumem importância para o entendimento do comportamento desses solos, dada sua estreita relação com a capacidade de retenção de água, "fixação" de fósforo, capacidade de troca catiônica, além de outros parâmetros importantes para o manejo destes solos.

Os valores do conteúdo de argila, silte e areia dos horizontes dos latossolos estudados estão apresentados nas Tabelas 13,14 e 15, onde se encontram a média com o intervalo de confiança a $95 \%$ de probabilidade ( $\hat{\mathrm{m}} \pm \mathrm{t} . \mathrm{s} \hat{\mathrm{m}}$ ), valor mínimo, máximo e coeficientes de variação $(\mathrm{CV})$.

Conforme ilustra a Figura 7 e de acordo com os dados da Tabela 13, 
Tabela 12 - Média das espessuras dos horizontes com o intervalo de confiança a $95 \%$ de probabilidade ( $\hat{\mathrm{m}} \pm$ t.s $\hat{\mathrm{m}}$ ), valor mínimo, máximo e coeficientes de variação dos latossolos.

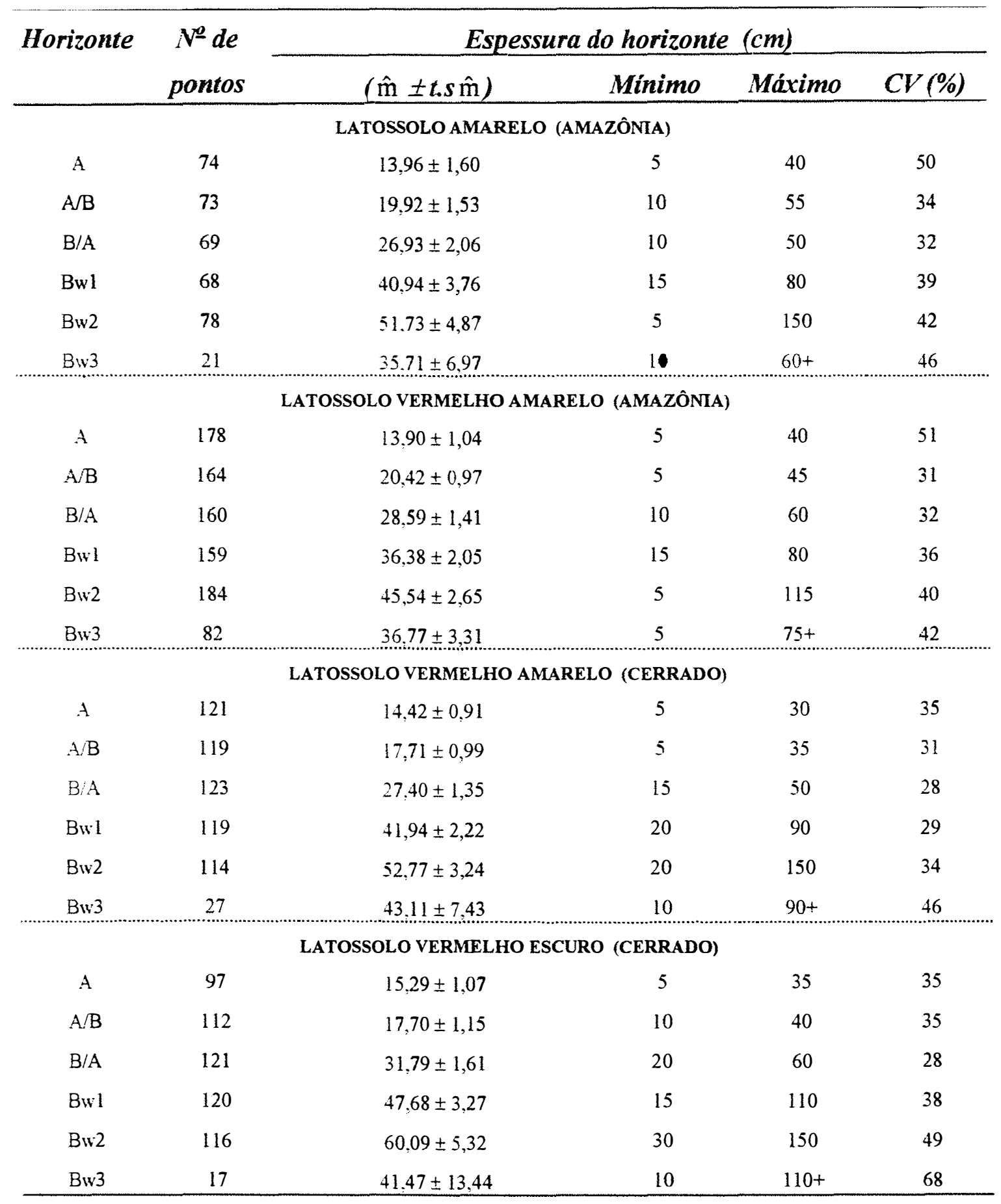


verifica-se que em todos os latossolos estudados há um acréscimo contínuo nos valores do conteúdo médio de argila do horizonte superficial para os horizontes inferiores, resultados estes também observados por Vieira et al. (1967), Falesi (1969), Rosatelli et al. (1974), Correa et al. (1975), Amaral Filho et al. (1978), Macedo et al. (1979). Os maiores acréscimos na variação textural entre os horizontes A e $A / B$ dos latossolos da região amazônica podem estar relacionados a uma maior instabilidade das argilas na camada superficial. Tal instabilidade permite que a água remova parte desta argila, provocando assim o gradiente textural. Alguns autores, entre eles Sombroek (1966) e Vieira et al. (1967) têm atribuído esta instabilidade à ação dispersante da matéria orgânica. A generalizada concentração de serrapilheira, muito rica em matéria orgânica em decomposição, estando em contato íntimo com o solo, dispersa a argila dos seus primeiros centímetros, favorecendo dessa forma, sua remoção por erosão. Aliás, o horizonte A/B dos LA e LV da região amazônica é mais estruturado, porém, apresentam pontuações que indicam encharcamento temporário, como foi observado por Demattê et al. (1994). Tais características já são indicativas de poros bloqueados devido justamente, a tal instabilidade da argila. Por outro lado, os solos dos Cerrados apresentam menor gradiente textural indicando com isso, maior estabilidade das argilas e, conseqüentemente, maior estruturação superficial.

Esses aspectos granulométricos e morfológicos, por si, já indicam diferenças entre os dois grupos de solos. Entretanto, o aumento da argila em profundidade, mais acentuado nos solos da Amazônia, pode até configurar horizontes $B$ textural. Neles, os valores da média de argila podem variar de 33,8 (A) a 55,1 (Bw3). Em média, entre $A$ e $A / B$ a variação no teor percentual de argila é de $7 \%$ nos latossolos LA e LV da Amazônia e de 5 e 4\%, respectivamente para o LV e LE dos Cerrados.

De maneira geral, para os latossolos estudados, tanto os da Amazônia como os dos Cerrados, a maior frequência do conteúdo de argila em seus horizontes $B$ (Tabela A21, página 143) possibilitam enquadrá-los, em grande parte como de textura argilosa a muito argilosa para os latossolos da Amazônia e de textura argilosa e média 


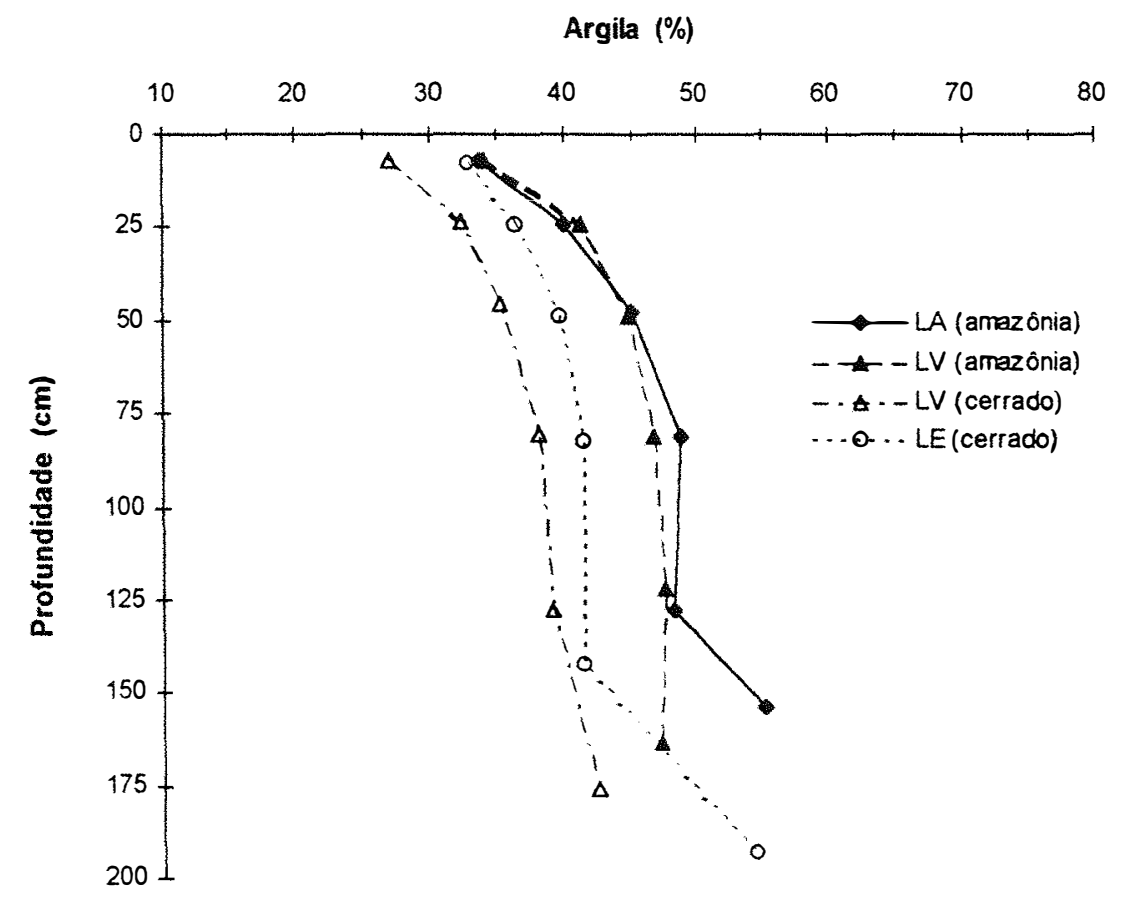

Figura 7 - Distribuição em profundidade dos valores médios do conteúdo de argila dos latossolos.

para os latossolos dos Cerrados. Em profundidade, a maioria dos solos de ambas as regiões são argilosos, sendo o conteúdo médio de argila 55 e $47 \%$ para o LA e LV da Amazônia e em torno de 42 e $54 \%$ para os LV e LE dos Cerrados, respectivamente.

Por outro lado, nos exames preliminares para a seleção dos perfís da Amazônia, notou-se acentuada variação textural para os primeiros $10 \mathrm{~cm}$ da camada superficial. Se considerar valores individuais do teor de argila dos perfis e não os valores médios, observa-se que grande parte dos LA e LV da Amazônia apresenta acentuado gradiente textural suficiente para definir o horizonte B textural do Sistema Brasileiro de Classificação de Solo (Camargo et al., 1988). Entretanto, não há evidências nas descrições morfológicas de translocação de argila na posição do B para caracterizar um horizonte argílico do Soil Taxonomy (1975). As observações das descrições morfológicas são bastante claras na descrição de horizontes B latossólico, como o grau fraco da estrutura e as transições graduais e difusas. Se fosse considerar tais variações texturais, como atributo isolado para a definição do B textural, grande parte dos LA e 
LV da Amazônia não seriam classificados como tal. A herança do material originário tem muita influência na textura desses solos. Assim é que (Tabela A23, página 144) os LA originados da Formação Solimões são ligeiramente mais argilosos do que os da Formação Barreiras. Porém, ambas formações a partir do $\mathrm{A} / \mathrm{B}$, tendem a formar solos argilosos. As formações cretáceas têm originado solos mais arenosos, principalmente na região dos Cerrados.

Outro ponto que deve ser salientado nesta área granulométrica, refere-se ao teor de silte. Conforme se verifica na Figura 8 e Tabela 14, os solos da Amazônia, principalmente os LV, apresentam maior teor de silte. Neste aspecto granulométrico, tais valores indicam ser esses solos menos intemperizados do que os solos dos Cerrados.

Os valores máximos de silte (Tabela 14) tanto para uma região como para a outra, entre 30 e $45 \%$ não são indicativos de latossolos. Grande parte destes valores é devido a falhas na dispersão, principalmente para o caso dos latossolos dos Cerrados, de microestrutura mais estável. Entretanto, pelo que se pode pesquisar, há muito LA e LV da Amazônia com elevado teor de silte, valor este que não está atribuído a falhas na dispersão (Chauvel, 1981; Demattê et al., 1994), mas ao próprio material de origem (Tabela A29, página 147). Se se levar em consideração que o teor de silte pode ser um atributo de diferenciação entre horizonte $B$ latossólico $\mathrm{e} \quad \mathrm{B}$ incipiente (Camargo et al., 1987), muitos LA e LV da região amazônica não poderiam ser classificados como tal. O maior teor de silte no LV amazônico é devido à herança do material originário. Apesar do clima bastante agressivo da região amazônica, a região dos Cerrados vem indicar, novamente, pelo teor de silte, ser ela constituída de solos mais intemperizados.

Quanto ao conteúdo médio de areia nos horizontes (Tabela 15) verifica-se uma distribuição no perfil do solo contrária à da argila, isto é, diminui do horizonte superior para os inferiores. 
Tabela 13 - Conteúdo médio de argila com intervalo de confiança a $95 \%$ de probabilidade ( $\hat{\mathrm{m}} \pm$ t.s $\hat{\mathrm{m}})$, mínimo, máximo e coeficientes de variação nos horizontes dos latossolos.

\begin{tabular}{|c|c|c|c|c|c|}
\hline \multirow[t]{2}{*}{ Horizonte } & \multirow{2}{*}{$\begin{array}{l}N^{o} d e \\
\text { pontos }\end{array}$} & \multicolumn{4}{|c|}{ Conteúdo de argila (\%) } \\
\hline & & $(\hat{\mathrm{m}} \pm t . s \hat{\mathrm{m}})$ & Mínimo & Máximo & $C V(\%)$ \\
\hline \multicolumn{6}{|c|}{ LATOSSOLO AMARELO (AMAZÔNIA) } \\
\hline A & 66 & $33.80 \pm 5,14$ & 7,2 & 88,6 & 63 \\
\hline $\mathrm{A} / \mathrm{B}$ & 64 & $40,00 \pm 5,22$ & 11,3 & 90,5 & 53 \\
\hline $\mathrm{B} / \mathrm{A}$ & 62 & $45,11 \pm 5,85$ & 11,0 & 91,9 & 52 \\
\hline Bwl & 61 & $48,82 \pm 5,84$ & 15,8 & 93,4 & 48 \\
\hline Bw2 & 68 & $48,31 \pm 5,39$ & 15,7 & 93,6 & 47 \\
\hline $\mathrm{Bw} 3$ & 19 & $55,12 \pm 10,70$ & 19,0 & 92.5 & 43 \\
\hline \multicolumn{6}{|c|}{ LATOSSOLO VERMELHO AMARELO (AMAZÔNIA) } \\
\hline A & 174 & $34,06 \pm 2,55$ & 3,0 & 74,7 & 50 \\
\hline $\mathrm{A} / \mathrm{B}$ & 161 & $41,12 \pm 2,66$ & 10,2 & 80,6 & 42 \\
\hline $\mathrm{B} / \mathrm{A}$ & 156 & $44,79 \pm 2,74$ & 12,9 & 83,0 & 39 \\
\hline Bwl & 157 & $46,74 \pm 2,73$ & 11,0 & 84,0 & 37 \\
\hline Bw2 & 179 & $47,52 \pm 2,55$ & 16,5 & 83,0 & 37 \\
\hline $\mathrm{Bw} 3$ & 79 & $47,20 \pm 3,51$ & 17,5 & 84,1 & 34 \\
\hline \multicolumn{6}{|c|}{ LATOSSOLO VERMELHO AMARELO (CERRADO) } \\
\hline A. & 121 & $27,10 \pm 2.66$ & 6,4 & 77 & 55 \\
\hline $\mathrm{A} / \mathrm{B}$ & 119 & $32,38 \pm 2.96$ & 10,1 & 88 & 51 \\
\hline $\mathrm{B} / \mathrm{A}$ & 123 & $35,29 \pm 2,86$ & 11,0 & 88 & 46 \\
\hline Bwl & 119 & $38,08 \pm 3,01$ & 13,0 & 90 & 44 \\
\hline $\mathrm{Bw} 2$ & 114 & $39,08 \pm 3,03$ & 13,3 & 89 & 42 \\
\hline Bw3 & 27 & $42.43 \pm 7.01$ & 18,4 & 87 & 44 \\
\hline \multicolumn{6}{|c|}{ LATOSSOLO VERMELHO ESCURO (CERRADO) } \\
\hline A & 97 & $32,85 \pm 3,64$ & 6,9 & 77 & 56 \\
\hline $\mathrm{A} / \mathrm{B}$ & 112 & $36,36 \pm 3,84$ & 7,6 & 84 & 57 \\
\hline $\mathrm{B} / \mathrm{A}$ & 121 & $39,54 \pm 3,74$ & 9,2 & 87 & 53 \\
\hline Bwl & 120 & $41,29 \pm 3,69$ & 11,8 & 90 & 50 \\
\hline $\mathrm{Bw} 2$ & 116 & $41,30 \pm 3,79$ & 10,9 & 89 & 50 \\
\hline Bw3 & 17 & $54,48 \pm 10,05$ & 16,0 & 85 & 39 \\
\hline
\end{tabular}


Tabela 14 - Conteúdo médio de silte com intervalo de confiança a 95\% de probabilidade ( $\hat{\mathrm{m}} \pm$ t.s $\hat{\mathrm{m}}$ ), mínimo, máximo e coeficientes de variação dos horizontes dos latossolos.

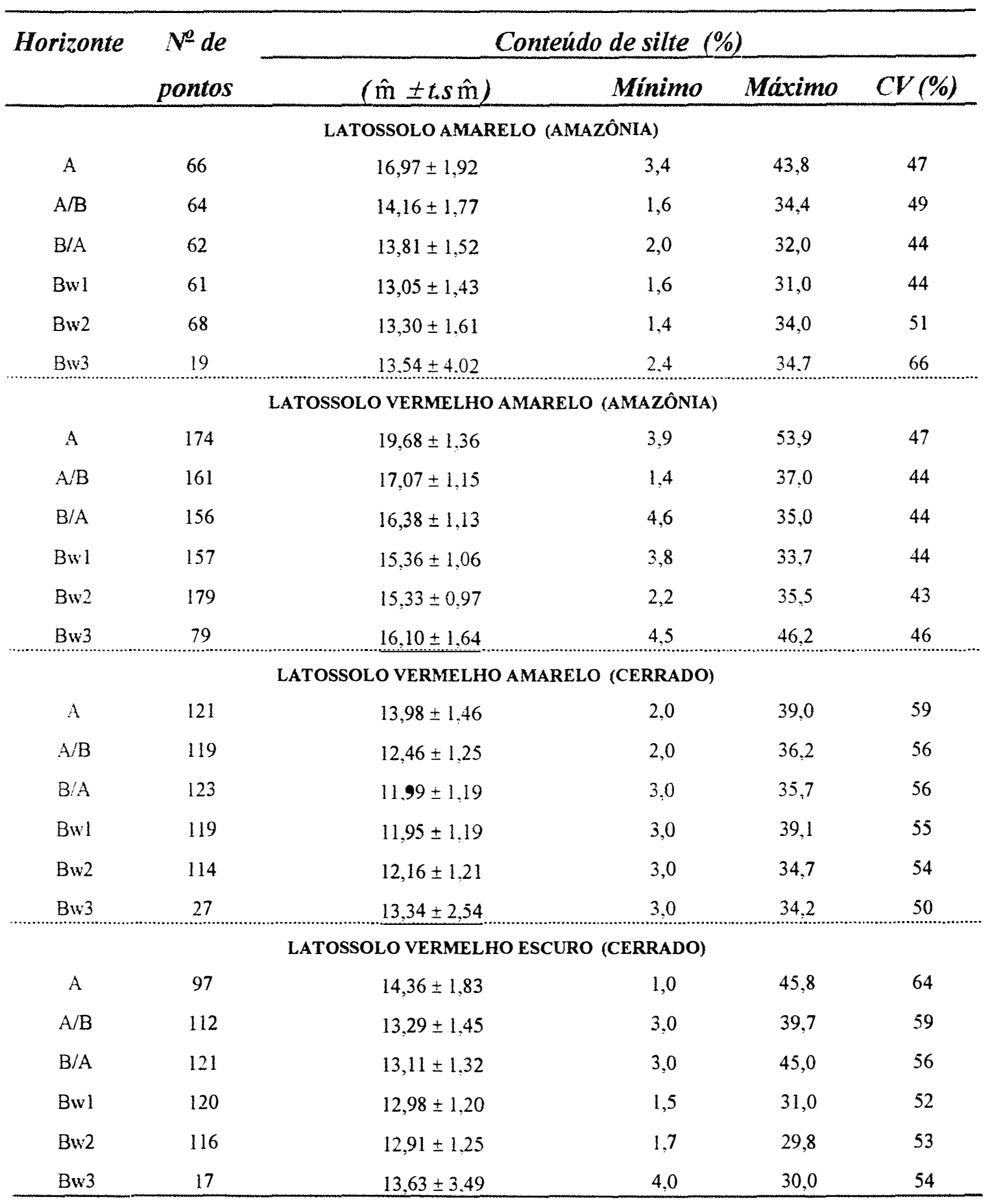


Tabela 15- Conteúdo médio de areia com intervalo de confiança a 95\% de probabilidade ( $\hat{\mathrm{m}} \pm$ t.s $\hat{\mathrm{m}})$, mínimo, máximo e coeficientes de variação dos horizontes dos latossolos.

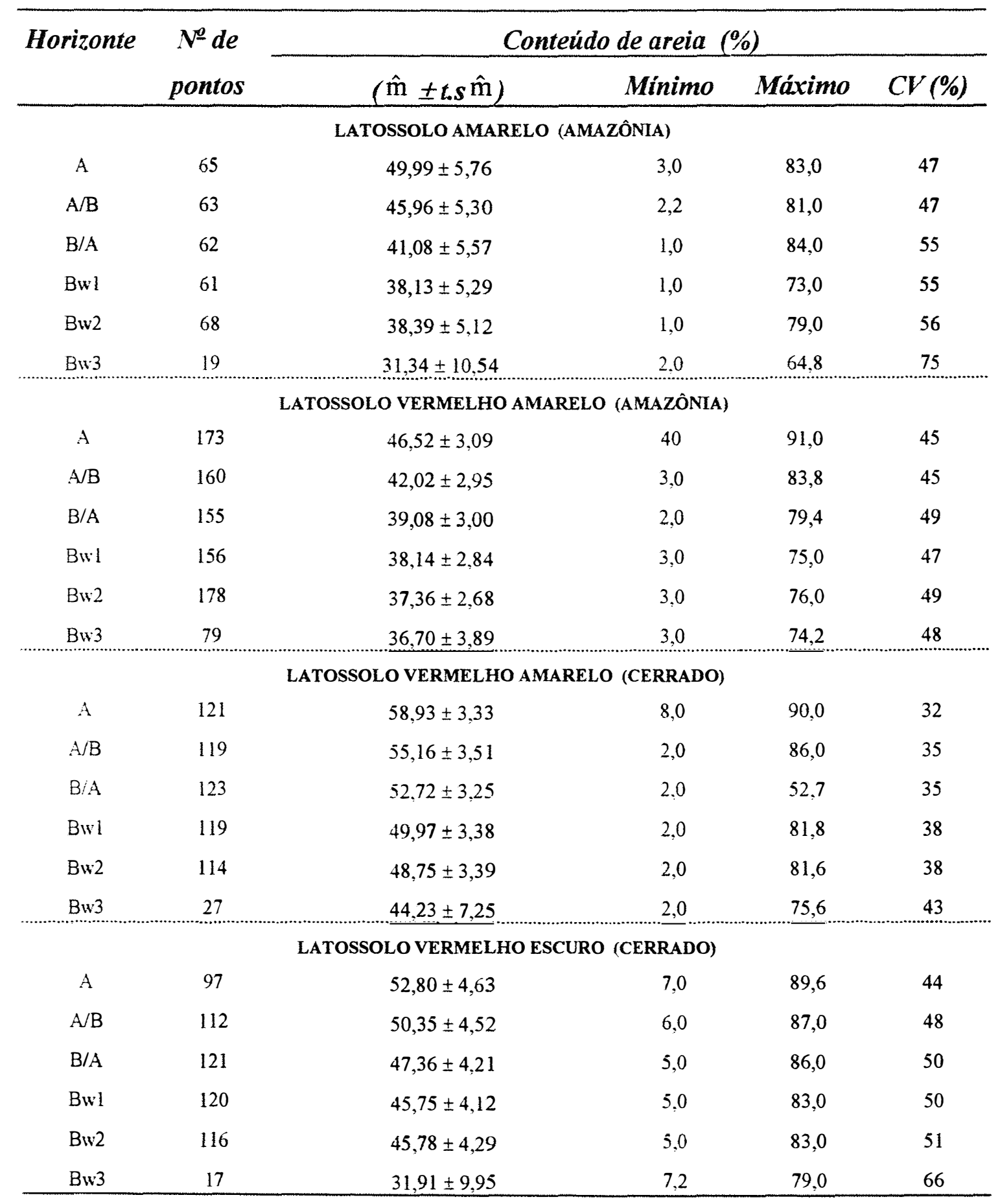


Silte (\%)

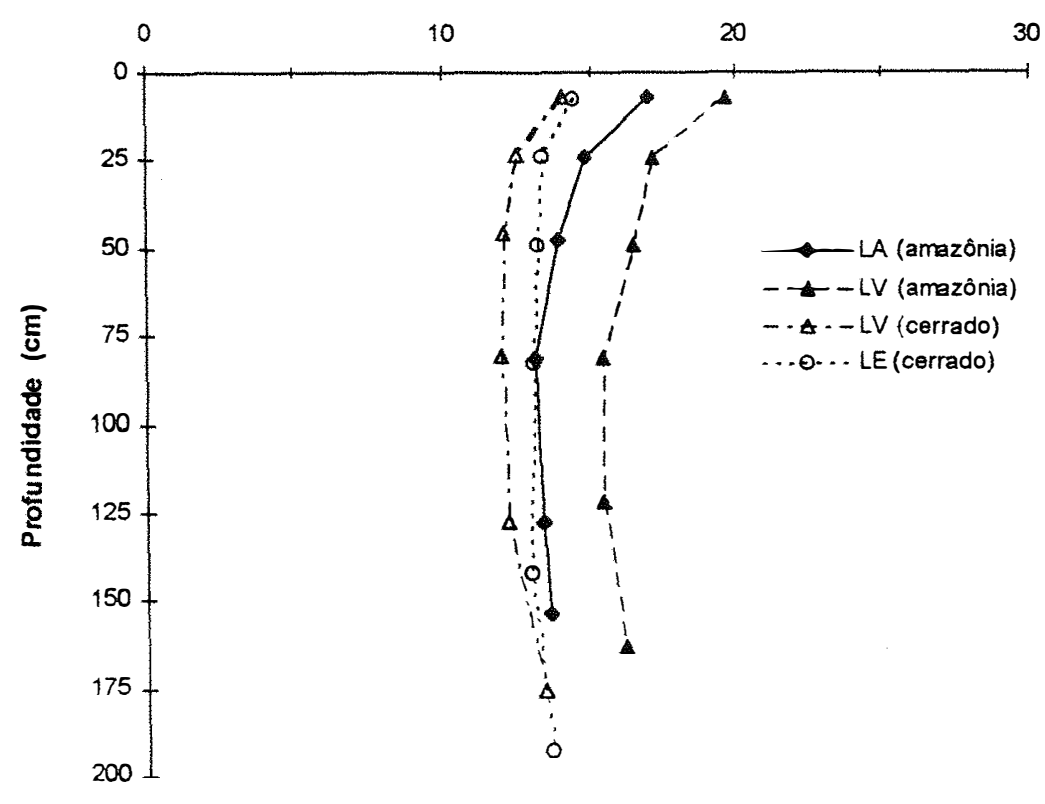

Figura 8 - Distribuição em profundidade dos conteúdos médios de silte dos latossolos.

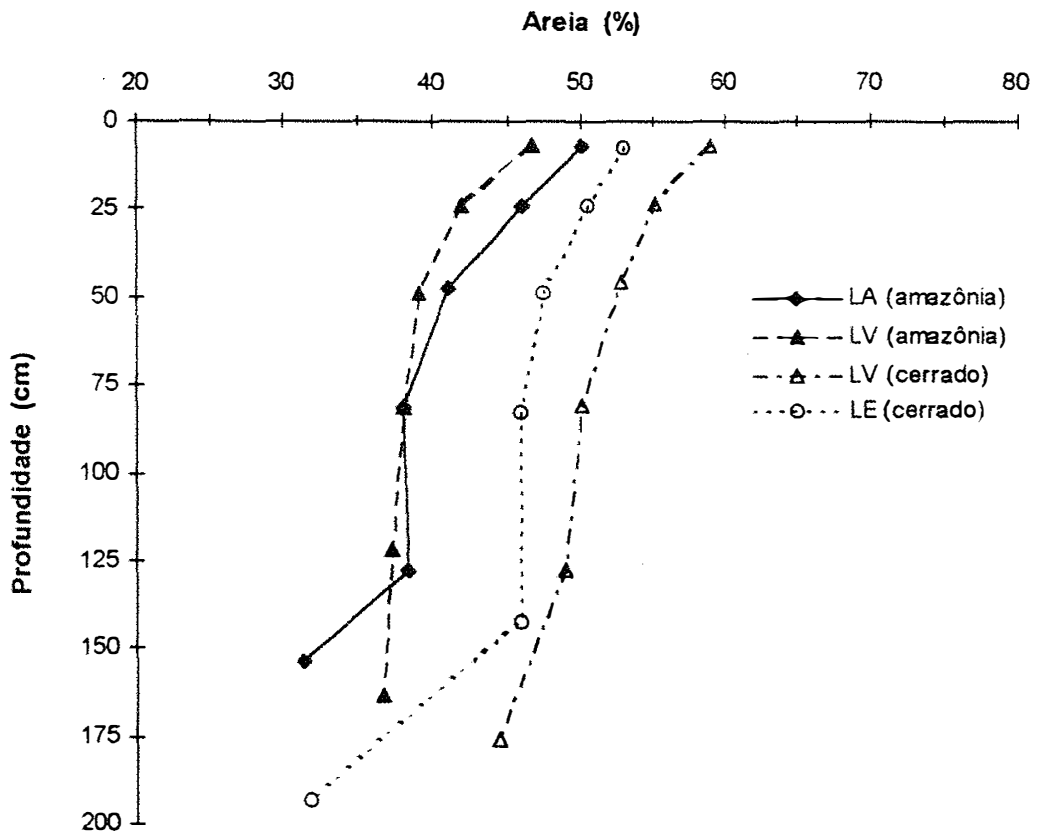

Figura 9 - Distribuição em profundidade dos conteúdos médios de areia dos latossolos. 


\subsubsection{Relação silte/argila}

Os dados sobre a relação silte/argila dos horizontes dos latossolos estudados estão apresentados na Tabela 16. De maneira geral, a relação silte/argila tende a decrescer em profundidade (Figura 10), uma evidência do aumento da argila neste sentido, como já foi salientado. Os maiores valores desta relação para o horizonte $A$, principalmente para os solos da Amazônia, 0,69 e 0,78 contra 0,61 e 0,52 para o Cerrado, indicam que os solos da Amazônia têm menor teor de argila nesta camada, como foi evidenciado.

Por outro lado, tomando-se os valores da relação silte/argila como índice de intemperismo físico como sugere Van Vambeck (1962), os solos amazônicos, principalmente na camada superficial, são menos intemperizados que os dos Cerrados. Especificamente para o LE, o valor da relação no Bw3 é de 0,30, o mais baixo de todos, indicando ser este solo, através deste índice, o mais intemperizado. Por outro lado, considerando os valores da relação de 0,7 para textura argilosa ou muito argilosa e 0,6 para textura média, como sendo os limites para a definição do $B$ latossólico (EMBRAPA, 1988), os valores indicados na Tabela 13 são concordantes de que na média os perfis, tanto da Amazônia como dos Cerrados, são devidamente caracterizados como latossólicos. Entretanto, é preciso alertar novamente, que parte dos solos classificados como latossolos, pelo critério da relação silte/argila, realmente não é, pois em certos casos parte da fração silte pode estar sob forma de caulinita microagregada, o que não significa estágio pouco avançado de intemperismo.

\subsubsection{Argila dispersa em água}

Em relação à argila dispersa em água (Tabela 17 e Figura 11) nota-se que de maneira geral, há uma tendência de decrescer em profundidade. Tal tendência é comum nos latossolos e normalmente é atribuída à maior ação da matéria orgânica na dispersão das argilas da camada superficial. Entretanto, a dispersão também pode estar relacionada à atividade da argila. Argilas de menor atividade, como os óxidos de $\mathrm{Fe} \mathrm{e} \mathrm{Al}$ que podem ter delta $\mathrm{pH}$ positivo em profundidade, tendem a dispersar mais do que 
aquelas com atividade alta. Ao se observar particularmente os dados do LE dos Cerrados, na camada mais inferior, $\mathrm{Bw} 3$, o teor de argila natural é de 2,55\% contra $0,82 \%$ no LA e $1,63 \%$ no LV da Amazônia, ou seja, o valor é mais elevado. Tal resultado vem salientar novamente, serem os latossolos dos Cerrados, no caso representado pelo LE, mais intemperizados que os da Amazônia. Os maiores valores da argila dispersa do LV da Amazônia, quando comparado com o LA, indicam ser o LV, em profundidade, mais evoluído do que o LA.

\subsubsection{Grau de floculação da argila}

Pelos valores da média do grau de floculação (Tabela 18) verifica-se que a argila está em alto grau de floculação no horizonte B desses latossolos, inclusive sendo maior no LA e LV da Amazônia, talvez influenciado pela pequena quantidade de óxido de ferro na fração argilosa, conforme observado por Livens et al. (1953), Sombroek (1966) e Kondo et al. (1981).

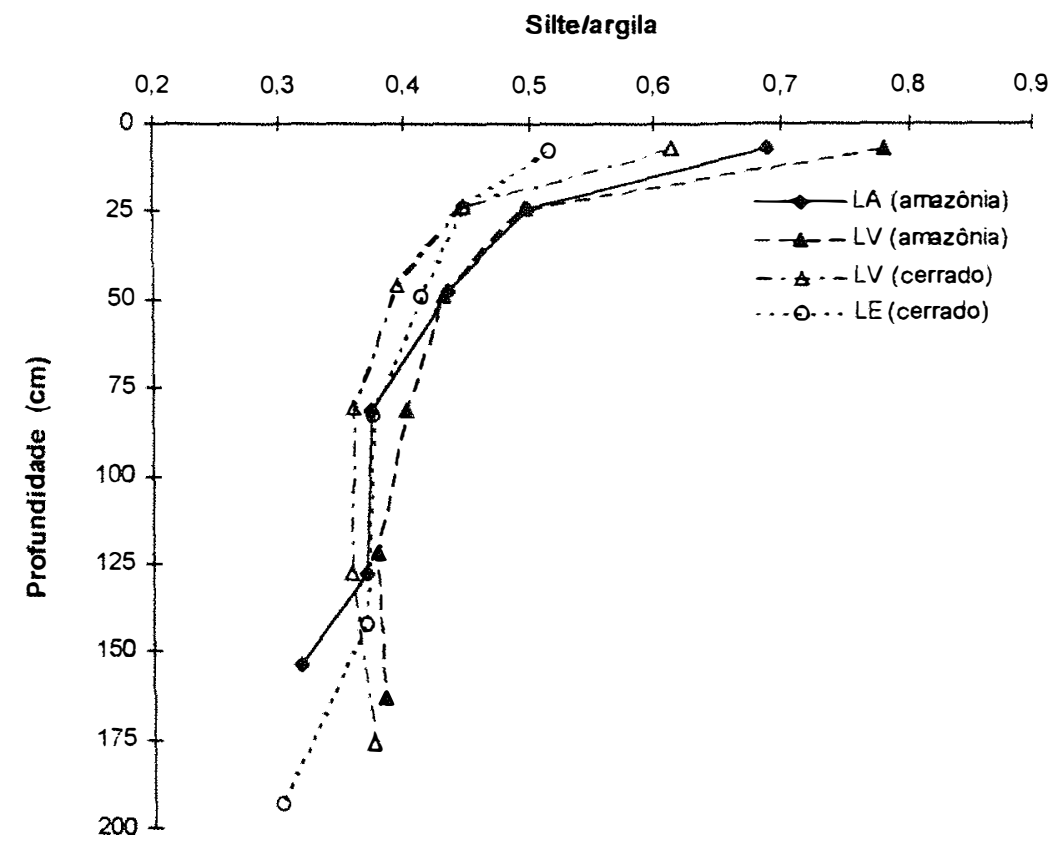

Figura 10 - Distribuição em profundidade dos valores médios da relação siltelargila dos latossolos. 


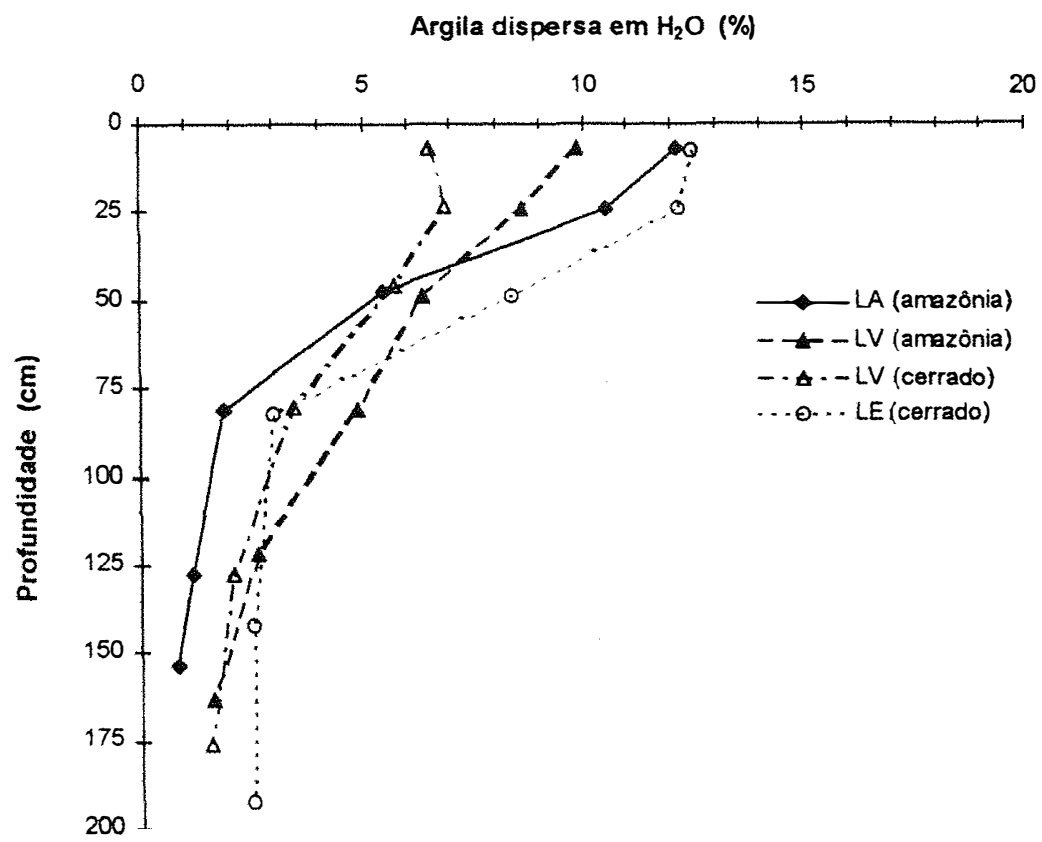

Figura 11 - Distribuição em profundidade dos conteúdos médios da argila dispersa em água dos latossolos.

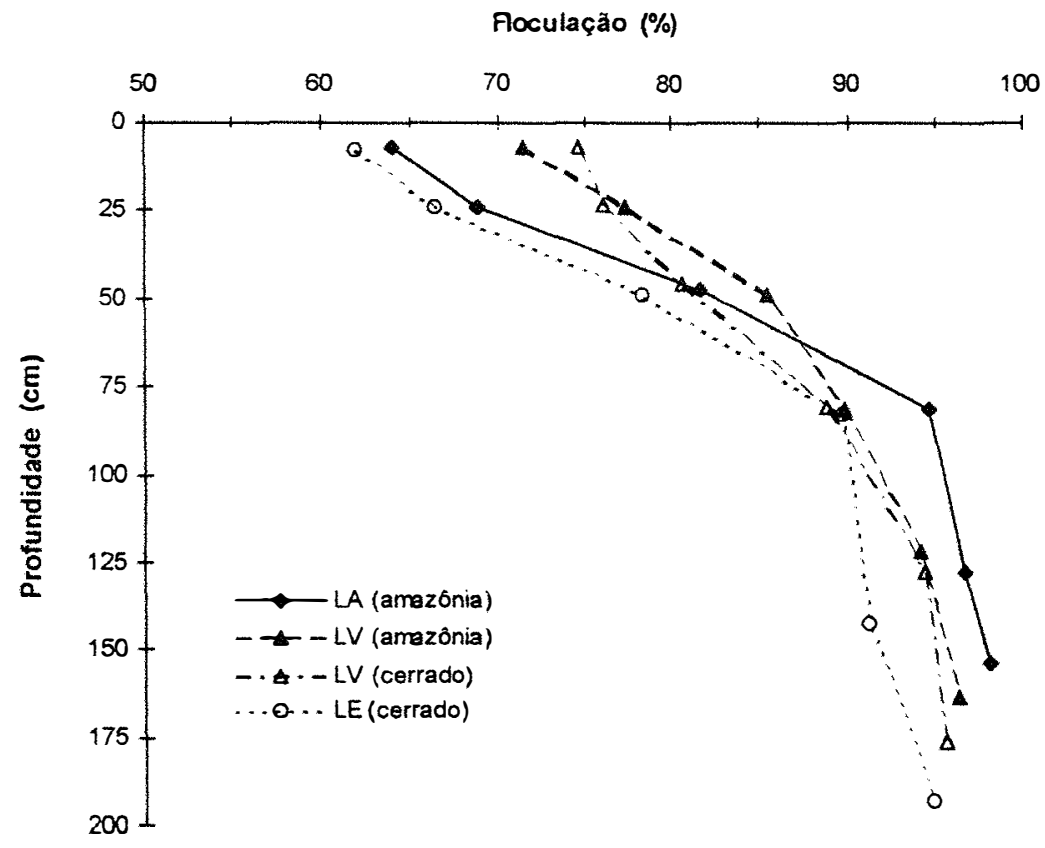

Figura 12 - Distribuição em profundidade dos valores médios do grau de floculação dos latossolos. 
Tabela 16 - Valores da média da relação silte/argila com o intervalo de confiança a $95 \%$ de probabilidade ( $\hat{\mathrm{m}} \pm$ t.s $\hat{\mathrm{m}}$ ), mínimo, máximo e coeficientes de variação dos horizontes dos latossolos.

\begin{tabular}{|c|c|c|c|c|c|}
\hline \multirow[t]{2}{*}{ Horizonte } & \multirow{2}{*}{$\begin{array}{c}N^{o} \text { de } \\
\text { pontos }\end{array}$} & \multicolumn{4}{|c|}{ Relaçâo silte/argila } \\
\hline & & $(\hat{\mathrm{m}} \pm t . s \hat{\mathrm{m}})$ & Mínimo & Máximo & $C V(\%)$ \\
\hline \multicolumn{6}{|c|}{ LATOSSOLO AMARELO (AMAZÔNIA) } \\
\hline A & 66 & $0,69 \pm 0,11$ & 0,08 & 2,17 & 67 \\
\hline $\mathrm{A} / \mathrm{B}$ & 64 & $0,50 \pm 0,09$ & 0,04 & 1,69 & 74 \\
\hline $\mathrm{B} / \mathrm{A}$ & 62 & $0,44 \pm 0,09$ & 0,03 & 1,53 & 80 \\
\hline Bw 1 & 61 & $0,37 \pm 0,07$ & 0,02 & 1,30 & 75 \\
\hline Bw2 & 68 & $0,37 \pm 0,07$ & 0,01 & 1,40 & 79 \\
\hline Bw3 & 19 & $0,37 \pm 0,12$ & $0,03 \ldots$ & $\underline{0,85}$ & 82 \\
\hline \multicolumn{6}{|c|}{ LATOSSOLO VERMELHO AMARELO (AMAZÔNIA) } \\
\hline A & 174 & $0,78 \pm 0,10$ & 0,11 & 4,67 & 84 \\
\hline $\mathrm{A} / \mathrm{B}$ & 161 & $0,50 \pm 0,05$ & 0,02 & 2,20 & 63 \\
\hline $\mathrm{B} / \mathrm{A}$ & 156 & $0,43 \pm 0,04$ & 0,07 & 1,53 & 63 \\
\hline Bw1 & 157 & $0,40 \pm 0,05$ & 0,05 & 2,73 & 81 \\
\hline Bw2 & 179 & $0,38 \pm 0,03$ & 0,04 & 2,73 & 62 \\
\hline Bw3 & 79 & $0,38 \pm 0,05$ & 0,06 & $\underline{1,44}$ & 57 \\
\hline \multicolumn{6}{|c|}{ LATOSSOLO VERMELHO AMARELO (CERRADO) } \\
\hline A & 121 & $0,61 \pm 0,08$ & 0,11 & 2,46 & 70 \\
\hline $\mathrm{A} / \mathrm{B}$ & 119 & $0,45 \pm 0,05$ & 0,10 & 2,06 & 66 \\
\hline $\mathrm{B} / \mathrm{A}$ & 123 & $0,40 \pm 0,05$ & 0,07 & 1,92 & 71 \\
\hline Bwl & 119 & $0,36 \pm 0,04$ & 0,06 & 1,34 & 63 \\
\hline Bw2 & 114 & $0,36 \pm 0,04$ & 0,06 & 1,30 & 65 \\
\hline Bw3 & 27 & $0,38 \pm 0,10$ & 0,06 & 1,20 & 70 \\
\hline \multicolumn{6}{|c|}{ LATOSSOLO VERMELHO ESCURO (CERRADO) } \\
\hline $\mathrm{A}$ & 97 & $0,52 \pm 0,07$ & 0,02 & 1,96 & 65 \\
\hline $\mathrm{A} / \mathrm{B}$ & 112 & $0,45 \pm 0,05$ & 0,06 & 1,63 & 63 \\
\hline $\mathrm{B} / \mathrm{A}$ & 121 & $0,41 \pm 0,06$ & 0,05 & 1,42 & 80 \\
\hline Bwl & 120 & $0,38 \pm 0,04$ & 0,04 & 1,17 & 58 \\
\hline Bw2 & 116 & $0,37 \pm 0,04$ & 0,05 & 1,16 & 60 \\
\hline Bw3 & 17 & $0,30 \pm 0,10$ & 0,05 & 0,84 & 71 \\
\hline
\end{tabular}


Tabela 17 - Valores da média da argila dispersa em água com o intervalo de confiança a $95 \%$ de probabilidade ( $\hat{\mathrm{m}} \pm \mathrm{t} . \mathrm{s} \hat{\mathrm{m}}$ ), valor mínimo, máximo e coeficientes de variação nos horizontes dos latossolos.

\begin{tabular}{|c|c|c|c|c|c|}
\hline \multirow[t]{2}{*}{ Horizonte } & \multirow{2}{*}{$\begin{array}{c}N^{o} \text { de } \\
\text { pontos }\end{array}$} & \multicolumn{4}{|c|}{ Argila dispersa em água (\%) } \\
\hline & & $(\hat{\mathrm{m}} \pm \operatorname{ts} \hat{\mathrm{m}})$ & Minimo & Máximo & $C V(\%)$ \\
\hline \multicolumn{6}{|c|}{ LATOSSOLO AMARELO (AMAZÔNIA) } \\
\hline A & 62 & $12,13 \pm 2,42$ & 0 & 42 & 80 \\
\hline $\mathrm{A} / \mathrm{B}$ & 61 & $10,52 \pm 2,58$ & 0 & 48 & 98 \\
\hline $\mathrm{B} / \mathrm{A}$ & 56 & $5,47 \pm 2,17$ & 0 & 32 & 151 \\
\hline Bwl & 50 & $1,88 \pm 1,23$ & 0 & 26 & 236 \\
\hline Bw2 & 50 & $1,17 \pm 0,69$ & 0 & 15 & 212 \\
\hline $\mathrm{Bw} 3$ & 16 & $0,82 \pm 0,64$ & 0 & 5 & 160 \\
\hline \multicolumn{6}{|c|}{ LATOSSOLO VERMELHO AMARELO (AMAZÔNIA) } \\
\hline A & 169 & $9,89 \pm 1,41$ & 0 & 43 & 95 \\
\hline $\mathrm{A} / \mathrm{B}$ & 150 & $8,59 \pm 1,48$ & 0 & 41 & 108 \\
\hline $\mathrm{B} / \mathrm{A}$ & 132 & $6,36 \pm 1,52$ & 0 & 41 & 140 \\
\hline Bwl & 126 & $4,86 \pm 1,42$ & 0 & 45 & 167 \\
\hline Bw2 & 127 & $2,64 \pm 0,98$ & 0 & 43 & 213 \\
\hline Bw3 & 61 & $1,63 \pm 0,74$ & 0 & 20 & 181 \\
\hline \multicolumn{6}{|c|}{ LATOSSOLO VERMELHO AMARELO (CERRADO) } \\
\hline A & 118 & $6,55 \pm 1,06$ & 0 & 38 & 90 \\
\hline $\mathrm{A} / \mathrm{B}$ & 116 & $6,89 \pm 1,02$ & 0 & 39 & 81 \\
\hline $\mathrm{B} / \mathrm{A}$ & 120 & $5,72 \pm 1,01$ & 0 & 43 & 99 \\
\hline Bwl & 116 & $3,42 \pm 0,73$ & 0 & 22 & 118 \\
\hline Bw2 & 111 & $2,05 \pm 0,56$ & 0 & 19,2 & 147 \\
\hline $\mathrm{Bw} 3$ & 26 & $1,56 \pm 0,76$ & 0 & 6,4 & 127 \\
\hline \multicolumn{6}{|c|}{ LATOSSOLO VERMELHO ESCURO (CERRADO) } \\
\hline $\mathrm{A}$ & 97 & $12,52 \pm 1,94$ & 0,78 & 45 & 78 \\
\hline $\mathrm{A} / \mathrm{B}$ & 111 & $12,18 \pm 2,14$ & 0 & 48 & 95 \\
\hline $\mathrm{B} / \mathrm{A}$ & 120 & $8,33 \pm 1,91$ & 0 & 51 & 128 \\
\hline Bw1 & 120 & $3,01 \pm 0,78$ & 0 & 23 & 144 \\
\hline Bw2 & 115 & $2,52 \pm 0,94$ & 0 & 30 & 203 \\
\hline Bw3 & 17 & $2,55 \pm 2,49$ & 0 & 21 & 206 \\
\hline
\end{tabular}


Tabela 18 - Valores da média do grau de floculação da argila com o intervalo de confiança a $95 \%$ de probabilidade ( $\hat{\mathrm{m}} \pm$ t.s $\hat{\mathrm{m}}$ ), mínimo, máximo e coeficientes de variação nos horizontes dos latossolos.

\begin{tabular}{|c|c|c|c|c|c|}
\hline \multirow[t]{2}{*}{ Horizonte } & \multirow{2}{*}{$\begin{array}{c}N^{o} \text { de } \\
\text { pontos }\end{array}$} & \multicolumn{4}{|c|}{ Grau de floculação da argila (\%) } \\
\hline & & $(\hat{\mathrm{m}} \pm t . s \hat{\mathrm{m}})$ & Minimo & Máximo & $C V(\%)$ \\
\hline \multicolumn{6}{|c|}{ LATOSSOLO AMARELO (AMAZÔNIA) } \\
\hline A & 66 & $64,00 \pm 5,91$ & 7,6 & 100 & 38 \\
\hline $\mathrm{A} / \mathrm{B}$ & 64 & $68,92 \pm 6,99$ & 8,0 & 100 & 41 \\
\hline $\mathrm{B} / \mathrm{A}$ & 62 & $81,61 \pm 7,17$ & 0,0 & 100 & 35 \\
\hline Bwl & 61 & $94,69 \pm 3,73$ & 21,0 & 100 & 16 \\
\hline Bw2 & 68 & $96,72 \pm 2,64$ & 25,0 & 100 & 12 \\
\hline $\mathrm{Bw} 3$ & 19 & $98,11 \pm 1,61$ & 87,0 & 100 & 3,7 \\
\hline \multicolumn{6}{|c|}{ LATOSSOLO VERMELHO AMARELO (AMAZÔNIA) } \\
\hline$A$ & 172 & $71,44 \pm 3,15$ & 7,6 & 100 & 30 \\
\hline $\mathrm{A} / \mathrm{B}$ & 158 & $77,29 \pm 3,50$ & 16,0 & 100 & 29 \\
\hline $\mathrm{B} / \mathrm{A}$ & 154 & $85,48 \pm 3,10$ & 13,0 & 100 & 23 \\
\hline Bwl & 155 & $89,86 \pm 2,80$ & 14,0 & 100 & 20 \\
\hline Bw2 & 176 & $94,18 \pm 2,12$ & 9,0 & 100 & 15 \\
\hline Bw3 & 79 & $96,30 \pm 2,04$ & 26,0 & 100 & 9,6 \\
\hline \multicolumn{6}{|c|}{ LATOSSOLO VERMELHO AMARELO (CERRADO) } \\
\hline$A$ & 121 & $74,60 \pm 2,97$ & 22,0 & 99 & 22 \\
\hline$A B$ & 119 & $76.03 \pm 2,94$ & 29,0 & 100 & 22 \\
\hline $\mathrm{B} / \mathrm{A}$ & 123 & $80,66 \pm 3,13$ & 13,0 & 100 & 22 \\
\hline Bwl & 119 & $88,82 \pm 2,77$ & 14,0 & 100 & 17 \\
\hline Bw2 & 114 & $94,45 \pm 1,34$ & 57 & 100 & 7,7 \\
\hline $\mathrm{Bw} 3$ & 27 & $95,56 \pm 2,36$ & 72 & 100 & 6,5 \\
\hline \multicolumn{6}{|c|}{ LATOSSOLO VERMELHO ESCURO (CERRADO) } \\
\hline$A$ & 97 & $62,01 \pm 3,59$ & 15 & 94 & 29 \\
\hline $\mathrm{A} / \mathrm{B}$ & 112 & $66,43 \pm 4,17$ & 00 & 100 & 34 \\
\hline $\mathrm{B} / \mathrm{A}$ & 121 & $78,30 \pm 3,50$ & 22 & 100 & 25 \\
\hline Bwl & 120 & $89,72 \pm 2,66$ & 00 & 100 & 17 \\
\hline Bw2 & 116 & $91,15 \pm 2,80$ & 00 & 100 & 17 \\
\hline Bw3 & 17 & $94,94 \pm 5,38$ & 53 & 100 & 12 \\
\hline
\end{tabular}




\subsection{Propriedades químicas}

\subsubsection{Matéria orgânica}

Os dados sobre o teor de matéria orgânica nos horizontes dos latossolos estudados na região amazônica e na região dos Cerrados, estão apresentados na Tabela 19, onde se encontram os valores médios com o intervalo de confiança a $95 \%$ de probabilidade ( $\hat{\mathrm{m}} \pm \mathrm{t} . \mathrm{s} \hat{\mathrm{m}})$, mínimo, máximo e coeficiente de variação $(\mathrm{CV})$.

Conforme a Figura 13 e pelos dados da Tabela 19, verifica-se que as médias dos valores da matéria orgânica em todos os latossolos estudados, diminuem acentuadamente com a profundidade do solo. A diferença nos teores de matéria orgânica entre os horizontes A (A) e B (Bw3) é marcante. Condição semelhante foi relatada por Volkoff et al. (1982).

Levando-se em consideração apenas os tipos de solo das duas regiões, no horizonte superficial (A), praticamente não há diferenças nos teores entre os latossolos da Amazônia (3,21\% para o LA e 3,22\% para o LV) e entre os dos Cerrados (2,65 e $2,66 \%$ para o LV e LE, respectivamente), porém com teores mais elevados para os solos amazônicos. Entretanto, em profundidade, a matéria orgânica torna-se ligeiramente superior nos latossolos dos Cerrados a partir do horizonte B/A com maiores diferenças no horizonte $\mathrm{Bw} 2$, onde se encontram valores médios em torno de $0,58 \%$ nos latossolos da Amazônia e 0,71\% para os latossolos dos Cerrados.

Outro ponto que deve ser considerado em relação à matéria orgânica, refere-se aos valores mínimos e máximos observados. Novamente, neste caso, os valores máximos observados para os horizontes A dos solos da Amazônia são mais elevados do que nos Cerrados. Entretanto, à medida que se dirige aos horizontes mais inferiores os teores ficam mais elevados nos solos dos Cerrados. Os dados da Tabela A41 (página 154), que mostra os teores de matéria orgânica por freqüência, indicam diferenças acentuadas entre tais solos. Enquanto que nos solos dos Cerrados, principal- 


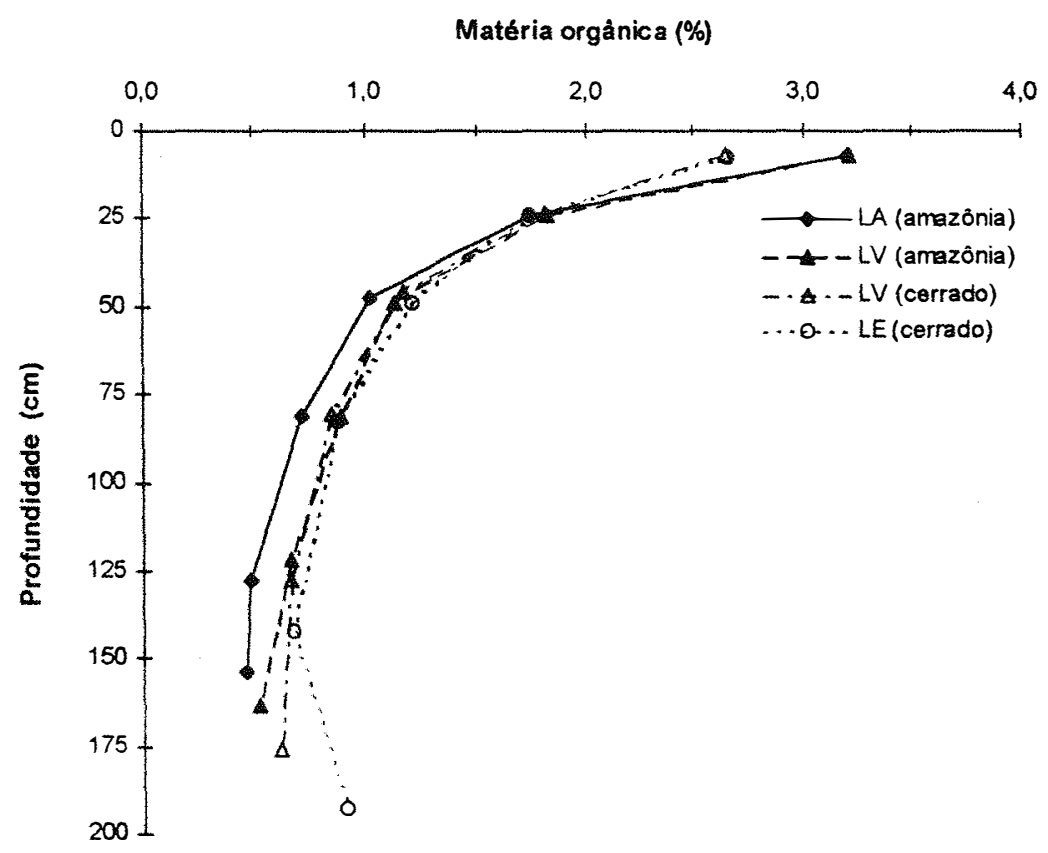

Figura 13 - Distribuição em profundidade dos conteúdos médios de matéria orgânica dos latossolos.

mente no LV há uma concentração maior de matéria orgânica na faixa de 1 a $3 \%$ (em torno de $65 \%$ no A), nos solos da Amazônia a frequêencia da distribuição é mais diluída. Teores de matéria orgânica sempre superiores a 5\% na camada superficial são encontrados em 20\% dos perfis do LA e 13,5\% nos LV da região amazônica contra 7,3 e $4,6 \%$, respectivamente, para os LV e LE dos Cerrados. Conforme se observa na Tabela A43 da página 155, enquanto que os valores da matéria orgânica do horizonte superficial (A) são superiores, em torno de 3,2\%, nos latossolos da Amazônia, onde predomina a floresta tropical densa, na savana arbórea da região dos Cerrados, esses valores ficam em torno de 2,6\%. Nos horizontes inferiores (Bw2 e Bw3) a floresta densa da Amazônia apresenta médias em torno de $0,54 \%$ contra $0,73 \%$ da savana arbórea da região dos Cerrados. 
Tabela 19 - Valores da média da matéria orgânica com o intervalo de confiança a 95\% de probabilidade $(\hat{\mathrm{m}} \pm \mathrm{t} . \mathrm{s} \hat{\mathrm{m}})$, valor mínimo, máximo e coeficientes de variação nos horizontes dos latossolos.

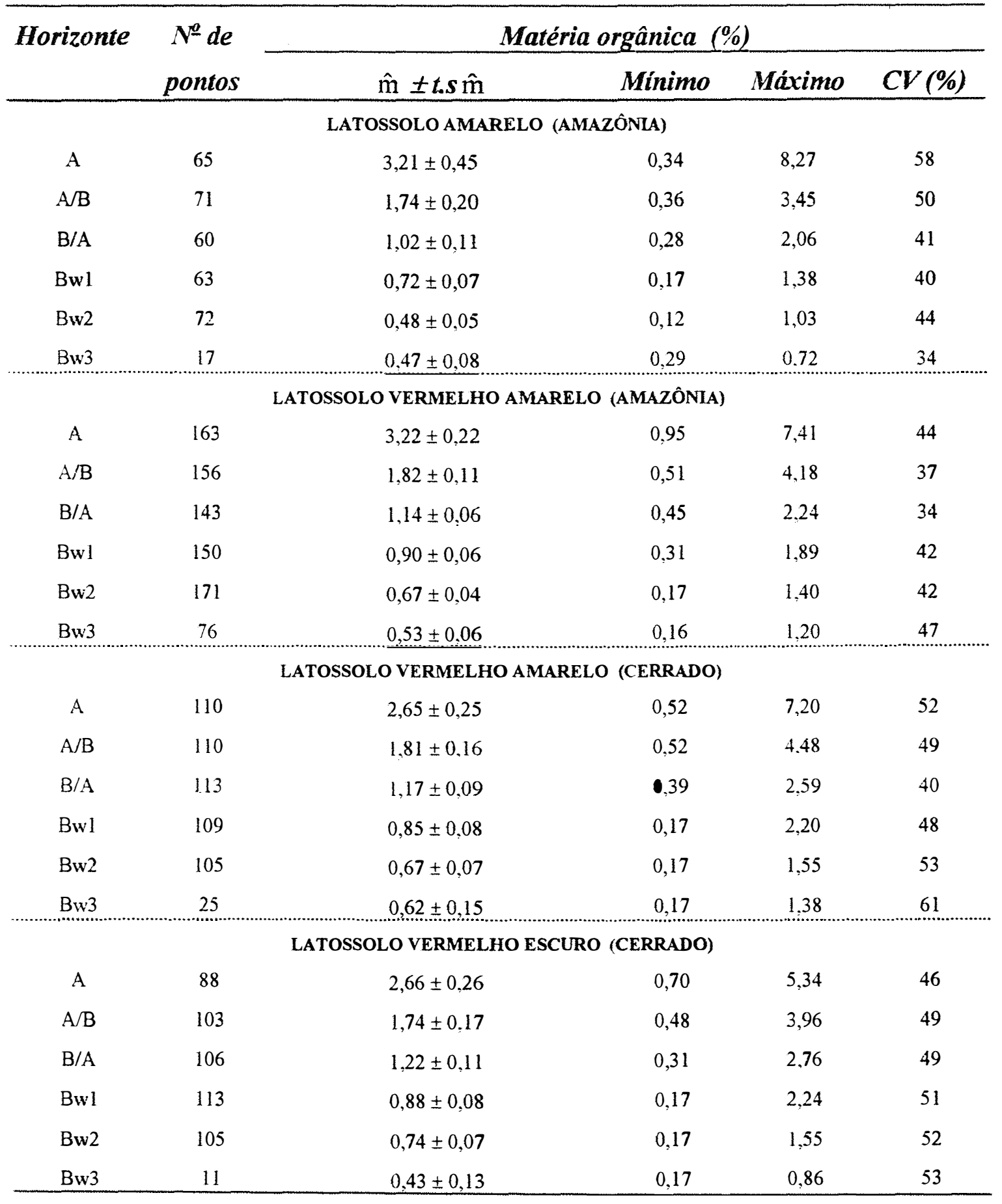


Outro aspecto que deve ser levado em consideração, refere-se à dispersão dos dados, quando se comparam os teores de matéria orgânica em função do conteúdo de argila. $O$ teor de matéria orgânica, independentemente da região, aumenta com o teor de argila (Tabela A42, página 154), com exceção apenas no Bw3 do LA da Amazônia cujos valores se mantêm constantes nesse horizonte para as classes texturais argilosa e muito argilosa. Na região amazônica, o teor de matéria orgânica para solos na faixa de 15 a $25 \%$ de argila é de 2,7\% para ambos os solos e de 2,0\% para os solos da região dos Cerrados. Na faixa acima de $60 \%$ de argila, há maior variação entre os teores de matéria orgânica para os latossolos das duas regiões. Entretanto, para o caso dos solos da Amazônia, mantendo-se constante a faixa de argila, nota-se uma maior variabilidade nos teores de matéria orgânica, principalmente para o LV (Tabela A42, página 154). Tal variabilidade também é comum nos horizontes mais inferiores. A possivel causa para tal distribuição está relacionada à fonte de matéria orgânica. Enquanto que, nos solos dos Cerrados, o sistema radicular graminóide, é mais homogêneo em sua própria composição e distribuição, na região amazônica têm-se composição e distribuição e reação bem diferenciadas.

Outros fatos que devem ser analisados são os seguintes:

- Considerando o mesmo intervalo de argila para o horizonte superficial, há de maneira geral, mais matéria orgânica nos solos da Amazônia.

- À medida que aumenta a profundidade do solo, os teores de matéria orgânica dos solos dos Cerrados tendem a ficar mais elevados, principalmente para os solos de textura argilosa e muito argilosa.

- Para os solos de textura média, o teor de matéria orgânica nos horizontes superficiais são mais altos para os LV, independentemente da região de ocorrência.

Diferenças no conteúdo de matéria orgânica dos solos estão associadas, dentre outras características do solo e fatores bióticos, às diferenças texturais. O controle da textura no conteúdo da matéria orgânica tem sido ressaltada por diversos pesquisadores (Parton et al., 1987, Moraes et al., 1995). Dessa forma, transformando-se os dados percentuais em $\mathrm{t} \mathrm{ha}^{-1}$ de matéria orgânica apenas para as classes texturais argilosa e muito argilosa, observa-se através das Figuras 14 e 15, que as diferenças na 


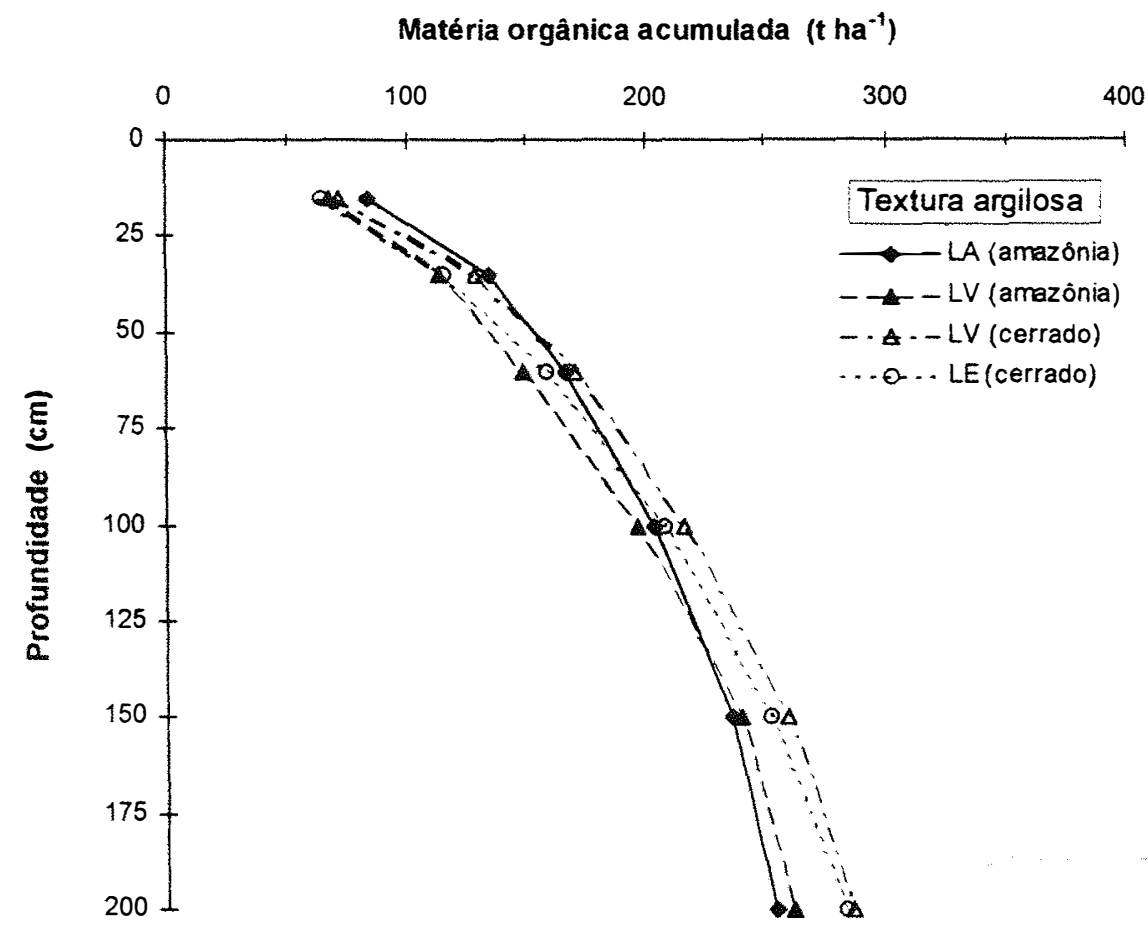

Figura 14 - Reserva acumulada em profundidade de matéria orgânica dos latossolos argilosos.

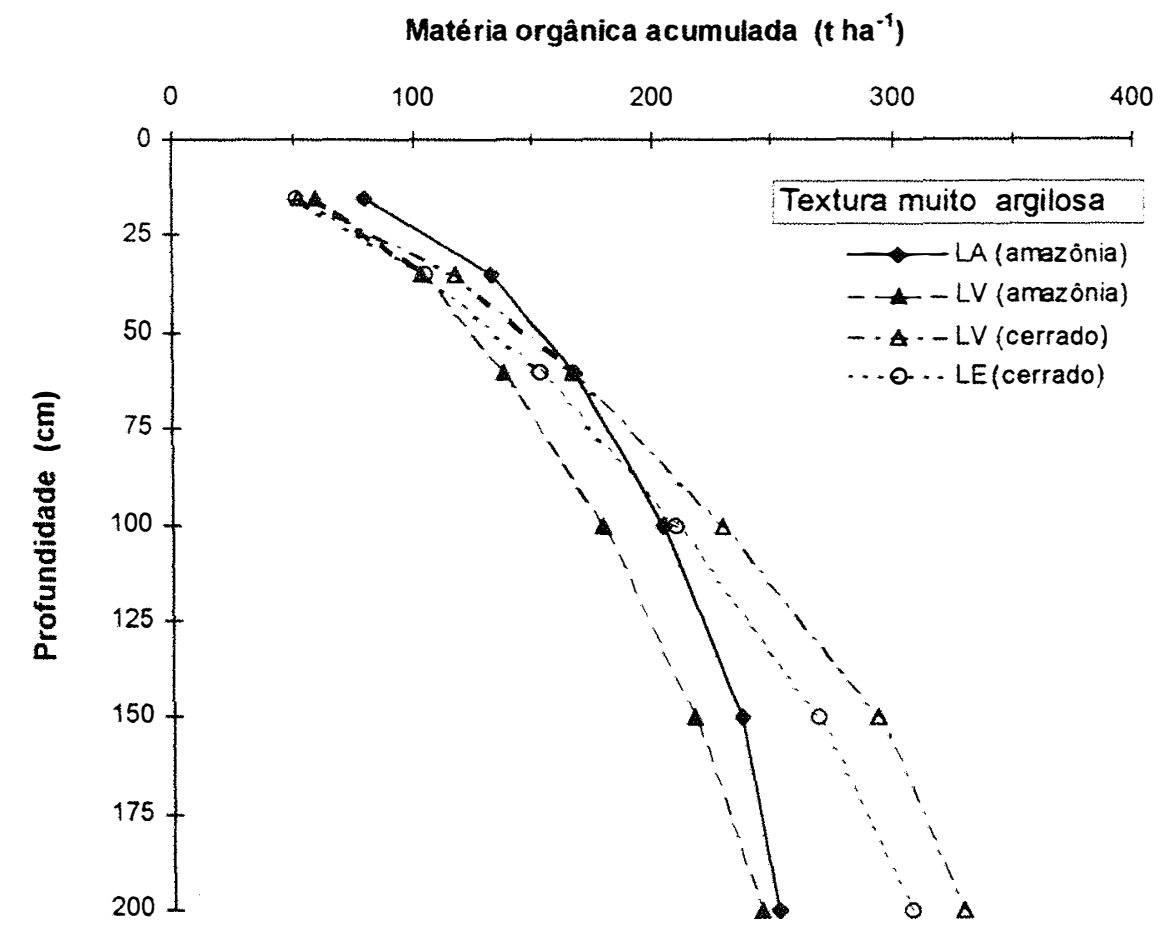

Figura 15 - Reserva acumulada em profundidade de matéria orgânica dos latossolos muito argilosos. 
reserva acumulada de matéria orgânica, tendem a se acentuar nos latossolos dos Cerrados a partir de aproximadamente $80 \mathrm{~cm}$ de profundidade. Até o intervalo de $60 \mathrm{a}$ $100 \mathrm{~cm}$ de profundidade, para a classe de textura argilosa, a diferença da quantidade de matéria orgânica entre o solo das duas regiões é de $11,5 \mathrm{t} \mathrm{ha}^{-1}$ de matéria orgânica (Tabela 20) e para a classe muito argilosa passa para $26,9 \mathrm{t} \mathrm{ha}^{-1}$. Quando a profundidade do solo passa os $200 \mathrm{~cm}$, as diferenças médias passam para $26,6 \mathrm{t} \mathrm{ha}^{-1}$ para a textura argilosa e $68,2 \mathrm{t} \mathrm{ha}^{-1}$ para a muito argilosa. Por outro lado, nestas faixas de teores de argila, praticamente não há diferença na quantidade de matéria orgânica entre o LA e LV da Amazônia. Em síntese, esses dados mostram que o teor de matéria orgânica é maior na região amazônica nos horizontes superficiais. À medida que aumenta a profundidade do solo e o teor de argila, aumenta o teor de matéria orgânica na região dos Cerrados, ultrapassando os da Amazônia.

Tabela 20 - Quantidade de matéria orgânica, em $\mathrm{t} \mathrm{ha}^{-1}$ para os latossolos de textura argilosa e muito argilosa da Amazônia e dos Cerrados

\begin{tabular}{|c|c|c|c|c|c|c|c|}
\hline \multirow[t]{2}{*}{ Solo } & \multicolumn{6}{|c|}{ Profundidade $(\mathrm{cm})$} & \multirow[t]{2}{*}{ Total } \\
\hline & $0-15$ & $15-35$ & $35-60$ & $60-100$ & $100-150$ & $150-200$ & \\
\hline \multicolumn{8}{|c|}{$\cdots \cdots \cdot \boldsymbol{t h a ^ { - 1 } \cdots \cdots \cdots}$} \\
\hline \multicolumn{8}{|c|}{ Amazônia (teor de argila $35-60 \%$ ) } \\
\hline LA & 83,2 & 51,6 & 31,8 & 36,5 & 32,4 & 18,4 & 253,9 \\
\hline LV & 67.0 & 46,6 & 35,7 & 47.0 & 43,2 & 21.6 & 261.1 \\
\hline média & 75,1 & 49,1 & 33.8 & 41,8 & 37,8 & 20.0 & 257.5 \\
\hline \multicolumn{8}{|c|}{ Cerrados (teor de argila $35-60 \%$ ) } \\
\hline LV & 71,5 & 56,9 & 42,2 & 45,1 & 43,8 & 26,3 & 285,6 \\
\hline LE & 64,6 & 50,6 & 42,6 & 49,0 & 45,0 & 31,0 & 282,8 \\
\hline média & 68,1 & 53,8 & 42,3 & 47,1 & 44,4 & 28,7 & 284,2 \\
\hline \multicolumn{8}{|c|}{ Amazônia (teor de argila maior que $60 \%$ ) } \\
\hline LA & 80,1 & 53,0 & 34,5 & 36,8 & 32,5 & 14,7 & 251,6 \\
\hline LV & 58,8 & 43,8 & 35,3 & 40,8 & 38,0 & 28,5 & 245,2 \\
\hline média & 69,5 & 48,4 & 34,9 & 38,8 & 35,3 & 21,6 & 248,4 \\
\hline \multicolumn{8}{|c|}{ Cerrados (teor de argila maior que $60 \%$ ) } \\
\hline LV & 51,7 & 66,0 & 48,8 & 61,6 & 65,0 & 34,2 & 327,3 \\
\hline $\mathrm{LE}$ & 50,6 & 54,8 & 47,8 & 55,6 & 59,5 & 37,5 & 305,8 \\
\hline média & 51,2 & 60,4 & 48,3 & 58,6 & 62,3 & 35,9 & 316,7 \\
\hline
\end{tabular}

Considerou-se a densidade do solo de $1,2 \mathrm{~g} \mathrm{~cm}^{-3}$ para a textura argilosa e $1,0 \mathrm{~g} \mathrm{~cm}^{-3}$ para muito argilosa. 
Explicações para as diferenças nos teores de matéria orgânica entre as duas regiões, podem estar relacionadas à própria vegetação, à sua natureza e ao tipo de sistema radicular. No caso da floresta amazônica, há acentuada acumulação de matéria orgânica na superfície do solo devido à reciclagem da mata constituída por galhos, folhas e sistema radicular superficial. Entretanto, a heterogeneidade da vegetação é grande, contribuindo para a variação quanto à natureza da matéria orgânica. Além disso, as espécies florestais de maneira geral têm sistema radicular com hábitos pivotantes, e apesar das raizes serem grossas e se aprofundar no solo, incorporam pouca matéria orgânica. No caso da região dos Cerrados, o substrato graminóide entre as árvores dos Cerrados, com gramíneas adequadamente adaptadas, cujo sistema radicular fasciculado, penetra em profundidade e com isso, tende a distribuir maior quantidade de matéria, quando comparada com os solos da Amazônia. Aliás, as gramíneas têm a capacidade de introduzir matéria orgânica via sistema radicular em maior profundidade do que a vegetação de floresta como acentuou Buol et al. (1973), ao tratar das diferenças entre entre os solos de floresta com os desenvolvidos nas pradarias (prairie) americanas.

O teor de matéria orgânica nos solos é influenciada por uma série de fatores, porém o clima atua como um forte componente (Buol et al., 1973; Birkeland, 1984). Em trabalhos pioneiros, Jenny $(1941,1961)$ constatou que o teor de matéria orgânica e conseqüentemente de nitrogênio, aumentam logaritmicamente de acordo com o aumento de umidade e decresce exponencialmente com o aumento da temperatura.

A Tabela A45 (página 156) resume as variações nos teores de matéria orgânica dos solos estudados, de acordo com as classes pluviométricas, a partir de 1000 até $3000 \mathrm{~mm}$, sem levar em consideração as variações de temperatura. Levando-se em consideração o horizonte superficial, os dados são pouco consistentes para alguns solos para indicar algumas tendências, tanto nos solos da Amazônia como nos dos Cerrados. Entretanto para o caso do LA da Amazônia os teores de matéria orgânica passam de $3,19 \%$, na faixa de precipitação 1500 a $2000 \mathrm{~mm}$, para 3,63\% na faixa de 2500 a $3000 \mathrm{~mm}$. No caso do horizonte $\mathrm{A} / \mathrm{B}$, as tendências foram as mesmas, com ligeiro 
acréscimo de matéria orgânica, à medida que a precipitação aumenta. Nos horizontes mais inferiores praticamente não há distinção. Possível explicação para tal caso poderia estar relacionada ao próprio hábito do sistema radicular pivotante que incorpora pouca matéria orgânica em profundidade.

Para o caso do LV, com exceção do teor de matéria orgânica da faixa de 1000 a $1500 \mathrm{~mm}$, há tendência de aumento no teor de matéria orgânica ao passar da faixa dos $1500 \mathrm{~mm}$ para os $3000 \mathrm{~mm}$. No caso dos solos dos Cerrados e particularmente para o LV, as tendências são as mesma, ou seja, acréscimo do teor de matéria orgânica à medida que aumenta a precipitação. Em relação ao horizonte superficial, os teores de matéria orgânica passam de 2,06\% a 3,18\% (aumento significativo), enquanto que a precipitação passa de 1000 a $2500 \mathrm{~mm}$. Quanto ao horizonte $\mathrm{A} / \mathrm{B}$, a tendência tem sido a mesma com acréscimo de 1,70 a 2,12\%. Tais tendências de acréscimo se mantêm principalmente, nos horizontes mais inferiores, contrariamente aos solos da Amazônia. Assim é que para o horizonte Bw2 o aumento foi de 0,52 a 0,79\% para um acréscimo de 1000 a $2500 \mathrm{~mm}$ de chuva, e para o horizonte mais profundo foi de 0,58 para $0,77 \%$. Em relação ao LE, também houve acréscimo no teor de matéria orgânica de acordo com o aumento da precipitação, porém com dados menos consistentes. As grandes variações para os LE estão na faixa dos 1000 a $2000 \mathrm{~mm}$ de precipitação pluviométrica.

A manutenção do aumento do teor de matéria orgânica de acordo com o aumento da precipitação para os horizontes mais inferiores, principalmente para os LV dos Cerrados, deve-se ao hábito do sistema radicular fasciculado.

Outro parâmetro climático que pode ser levado em consideração no estudo da matéria orgânica, refere-se à combinação da precipitação com a temperatura, originando as classes climáticas, como indicado na Tabela A46, página 156. Partindo da classe Afi para a classe $\mathrm{Cw}$, há aumento da estação seca. $\mathrm{Na}$ classe climática Afi praticamente não há estação seca definida.

Para o caso da região amazônica, as classes climáticas estudadas foram o Afi, Ami e Awi, enquanto que para a região dos Cerrados apenas as classes Awi e Cw. 
A classe Awi é comum às duas regiões e corresponde grosseiramente ao ambiente ústico de umidade do solo, a classe Afi ao ambiente perúdico e a classe Ami ao údico.

Levando-se em consideração os horizontes superficiais do LA, à medida que o clima tende a ficar com estação seca mais prolongada, o teor de matéria orgânica decresce, passando de 3,91\% no Afi para 1,81 no Awi. Tal tendência porém, não é acompanhada pelo LV nesta mesma região, onde praticamente não houve diferença no teor da matéria orgânica ao passar do clima Afi para o Awi. No horizonte $A / B$ as tendências de decréscimo da matéria orgânica foram as mesmas para o caso do LA, passando de $1,92 \%$ para $0,94 \%$. À medida que aumenta a profundidade do solo, há o decréscimo do teor de matéria orgânica, porém, este decréscimo é compatível com as condições climáticas.

Em relação ao ambiente dos Cerrados, as tendências são as mesmas, ou seja, à medida que a classe de clima tende a ficar com a estação seca mais prolongada o teor de matéria orgânica tende a decrescer. No horizonte superficial decresce de 2,67 para $1,86 \%$ no A para o LV e de 2,67 a $2,63 \%$ no A do LE.

Outro fator que deve ser considerado na questão da matéria orgânica, refere-se à influência da própria vegetação. A relação vegetação-solo, designada como fator biótico na pedogênese (Birkeland, 1984), é dificil de ser analisada devido às interações envolvidas (Jenny, 1949), pricipalmente levando-se em consideração o ambiente climático da Amazônia.

Entretanto, foi feita uma tentativa de separação de perfis de solos de acordo com o tipo de vegetação, principalmente para a região amazônica, cujos dados estão resumidos na Tabela A43, página 155. Neste particular, foram separados os tipos de vegetação indicados pelo RADAM, ou seja, Floresta Tropical Densa (FD); Floresta Tropical Aberta (FA), contato Floresta Ombrófila e Floresta Estacional (FO/FE).

Inicialmente, o que chama a atenção na Tabela A43, página 155 é a ocorrência do LA praticamente só em ambiente de FD, enquanto que o LV já ocorre em outros tipos de vegetação. Sem dúvida, tal diferença entre tais solos não deixa de ser um 
parâmetro que deve ser utilizado em futuros mapeamentos como ferramenta de apoio. Por outro lado, não há distinção entre o LA e o LV quanto ao teor de matéria orgânica quando se leva em consideração apenas o tipo de vegetação, principalmente para os horizontes mais inferiores.

Por outro lado, observando apenas o LV da Amazônia, verifica-se que há diferenças quanto ao teor de matéria orgânica, quando se muda o tipo de vegetação. Ao passar da vegetação $\mathrm{FD}$ para $\mathrm{FA}$ e posteriormente a $\mathrm{FO} / \mathrm{FE}$, o teor de matéria orgânica tende a aumentar, para todos os horizontes. Tal fato se deve seguramente às características desta matéria orgânica e ao próprio ambiente mais propício à acumulação. No caso específico dos Cerrados, praticamente não há diferenças quanto ao teor de matéria orgânica entre os solos, principalmente nos horizontes mais inferiores.

As formações geológicas, representadas pelas rochas de origem do solo, têm influência em diversas propriedades do solo (Buol et al., 1973) e seguramente no teor de matéria orgânica. Assim, na Tabela A44, página 155 resumem-se as variações dos teores de matéria orgânica dos solos estudados, de acordo com as principais formações geológicas.

Para o caso dos LA, eles ocorrem principalmente em duas formações geológicas, a Solimões (TQs) e a Barreiras ( $\mathrm{KTb}$ ), enquanto que o LV não possui perfis descritos pelo RADAM na Formação Barreiras. Além da ocorrência na Formação Solimões, o LV ocorre nas formações terciárias e quaternárias (TQ), mais típicas de solos podzolizados, não estudados nesta pesquisa.

Analisando apenas as principais formações geológicas TQs e KTb para o caso dos LA, observa-se que há sensiveis diferenças no teor de matéria orgânica. De maneira geral, o teor de matéria orgânica é mais elevado nos solos derivados da Formação Solimões. Se considerarmos que a dominância dos LA está na região de Floresta Densa (Tabela A43, página 155), conclui-se que as diferenças no teor de matéria orgânica estejam relacionadas mais à influência do material de origem. Para o caso do horizonte superficial, os solos da Formação Solimões, na camada superficial, apresentam teores de matéria orgânica de $4,43 \%$ para o LA e $4,12 \%$ para o LV, 
enquanto que na Formação Barreiras o teor no LA cai para 3,10\%. Tais diferenças continuam à medida que o solo tende a ficar mais profundo, ou seja, as taxas de matéria orgânica para os solos da Formação Barreiras são sempre menores do que na Formação Solimões.

Mantendo-se a mesma formação geológica, no caso a Solimões, os teores de matéria orgânica não diferem para os solos LA e LV da Amazônia.

Para os solos dos Cerrados, o teor de matéria orgânica também difere de acordo com as formações geológicas, no caso, das formações terciárias e quaternárias (TQ) e das formações cretáceas $(K)$. Neste caso particular, as formações cretáceas têm dado origem a solos mais arenosos e conseqüentemente, com menores teores de matéria orgânica.

Levando-se em consideração os dados sobre matéria orgânica dos solos de clima temperado (Sánchez, 1976), nota-se que seu teor na camada superficial não difere dos solos das regiões aqui estudadas, assim como os teores em profundidade. Os valores encontrados para os molissóis são semelhantes aos dos latossolos aqui estudados. As causas para tais semelhanças devem-se a:

- No caso do ambiente perúdico de umidade, apesar do teor de matéria orgânica que entra no sistema por ha/ano na mata ser 5 vezes superior aos solos da região temperada, a taxa de decomposição também é 5 vezes maior na região tropical úmida.

- No caso do ambiente ústico de umidade (região dos Cerrados), o período seco prolongado tem o mesmo efeito do inverno rigoroso do hemisfério norte, fazendo com que se reduza a taxa de queima da matéria orgânica, de tal forma que seus níveis se mantêm semelhantes para as duas regiões. 


\subsubsection{Relação $\mathrm{C} / \mathrm{N}$}

Os resultados obtidos a respeito da relação C/N (Figura 16 e Tabela 21) indicam o seguinte:

- Decréscimo em profundidade para todos os solos, com valores de $\mathrm{C} / \mathrm{N}$ na faixa de 12,7 e 12,5 nos horizontes superficiais dos LA e LV da Amazônia e 8,5 e 10,8 para os horizontes Bw3 dos mesmos solos, respectivamente. Quanto aos valores dos Cerrados, estes são ligeiramente superiores na superfície, na faixa de 14,7 no A do LV e 13,8 no LE, decrescendo para 11,7 no Bw3 destes solos.

- Os maiores valores da relação $\mathrm{C} / \mathrm{N}$ dos solos dos Cerrados indicam diferenças na própria composição química da matéria orgânica. Neste caso, o teor de nitrogênio dos solos da região dos Cerrados é menor do que na Amazônia, principalmente quando se refere aos horizontes superficiais.

- Se considerarmos os solos amazônicos em profundidade, os valores da relação $\mathrm{C} / \mathrm{N}$ dos LV são mais elevados do que os do LA e, conseqüentemente, mais pobres em nitrogênio.

- Outro ponto que distingue tais solos no que diz respeito à relação $\mathrm{C} / \mathrm{N}$, se refere à freqüência de ocorrência dos resultados (Tabela A47, página 157). Enquanto que nos solos da Amazônia, 60 a 70\% da relação C/N do horizonte A estão na faixa de 10 a 20, nesta mesma faixa ocorrem 86 a $90 \%$ dos horizontes A dos latossolos dos Cerrados.

- Em profundidade, os resultados também são distintos. Enquanto que nos horizontes Bw2 dos solos da Amazônia, a grande percentagem dos solos (68 a 70\%) apresenta relação C/N na faixa de 5 a 15 , nos Cerrados, a totalidade (70 a 80\%) fica na faixa de 10 a 20.

Tais diferenças nas relações $\mathrm{C} / \mathrm{N}$ entre os solos das duas regiões vem confïrmar novamente, que os solos da região amazônica apresentam maior teor de nitrogênio. Entretanto, levando-se em consideração que relações $\mathrm{C} / \mathrm{N}$ na faixa de 12 a 14 


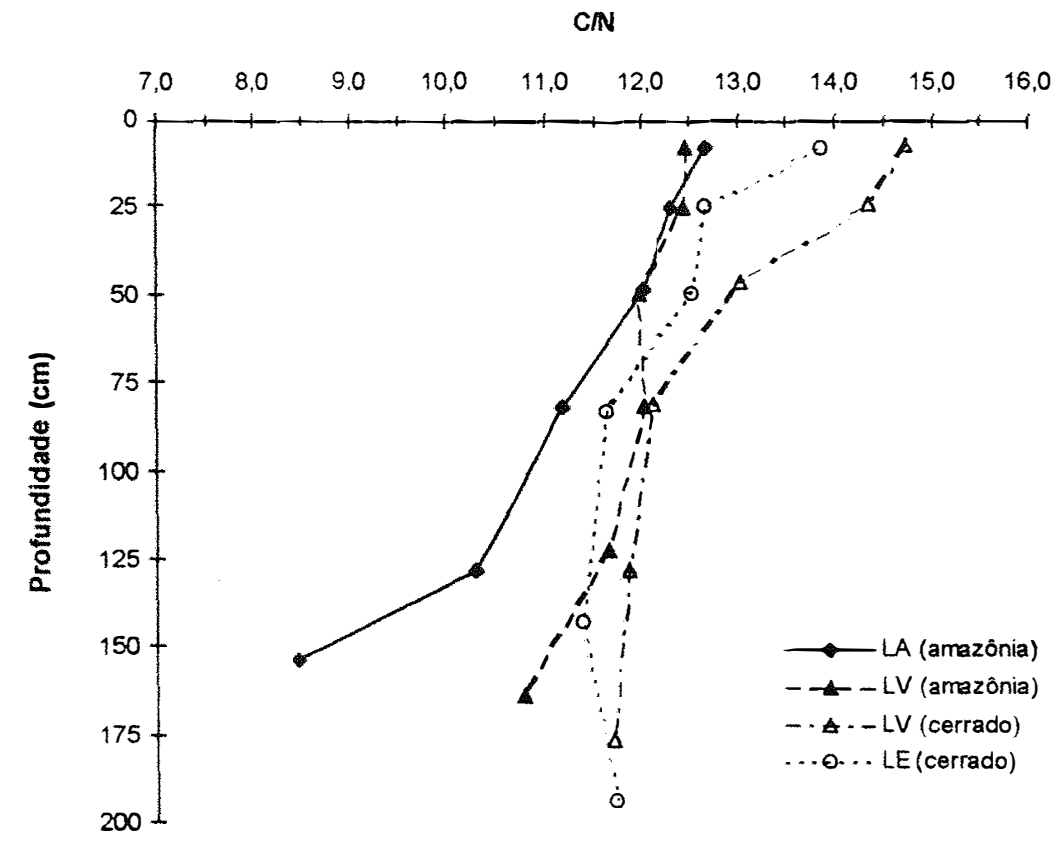

Figura 16 - Distribuição em profundidade dos valores médios da relação $C N$ dos latossolos.

indicam maior estabilidade da matéria orgânica, isto significa que os latossolos dos Cerrados, em profundidade, apresentam matéria orgânica mais estabilizada.

Da mesma maneira que o teor de matéria orgânica varia de acordo com a textura, a relação $\mathrm{C} / \mathrm{N}$ segue as mesmas tendências (Tabela $\mathrm{A} 48$, página 157), porém com resultados mais consistentes na região dos Cerrados. Para os solos desta região, a relação $\mathrm{C} / \mathrm{N}$ aumenta à medida que a textura torna-se mais argilosa, tanto nos horizontes superficiais como nos de subsuperfície. No caso do LV e LE para o horizonte A, os valores da relação $\mathrm{C} / \mathrm{N}$ passam de 13,5 e 12,4 respectivamente, para os de textura arenosa e para 16,6 e 14,3 respectivamente, para os de textura argilosa. Para os solos amazônicos a variação é bem menor. Novamente, neste caso, a diferença na qualidade e distribuição da matéria orgânica para o caso dos Cerrados, é mais homogênea e conseqüentemente apresenta maior consistência nos resultados. 
Tabela 21 - Média da relação $\mathrm{C} / \mathrm{N}$ com o intervalo de confiança a 95\% de probabilidade $(\hat{\mathrm{m}} \pm$ t.s $\hat{\mathrm{m}})$, valor mínimo, máximo e coeficientes de variação nos horizontes dos latossolos.

\begin{tabular}{|c|c|c|c|c|c|}
\hline \multirow[t]{2}{*}{ Horizonte } & \multirow{2}{*}{$\begin{array}{c}N^{o} d e \\
\text { pontos }\end{array}$} & \multicolumn{4}{|c|}{ Relação CN } \\
\hline & & $\hat{\mathrm{m}} \pm t . s \hat{\mathrm{m}}$ & Mínimo & Máximo & $C V(\%)$ \\
\hline \multicolumn{6}{|c|}{ LATOSSOLO AMARELO (AMAZÔNIA) } \\
\hline A & 50 & $12,67 \pm 1,04$ & 3,4 & 20,9 & 30 \\
\hline $\mathrm{A} / \mathrm{B}$ & 52 & $12,31 \pm 1,22$ & 1,0 & 26,7 & 37 \\
\hline $\mathrm{B} / \mathrm{A}$ & 43 & $12,00 \pm 1,42$ & 4,6 & 25,0 & 40 \\
\hline Bwl & 47 & $11,18 \pm 1,96$ & 0,7 & 35,0 & 61 \\
\hline $\mathrm{Bw} 2$ & 55 & $10,32 \pm 1,48$ & 0,7 & 27,0 & 54 \\
\hline Bw3 & 14 & $8 \underline{8,47 \pm 1,98} \ldots$ & 3,3 & 17.0 & 45 \\
\hline \multicolumn{6}{|c|}{ LATOSSOLO VERMELHO AMARELO (AMAZÔNIA) } \\
\hline A & 133 & $12,46 \pm 0,62$ & 4,0 & 29,0 & 29 \\
\hline $\mathrm{A} / \mathrm{B}$ & 127 & $12,44 \pm 0,73$ & 6,2 & 43,0 & 34 \\
\hline $\mathrm{B} / \mathrm{A}$ & 119 & $11,96 \pm 0,81$ & 5,0 & 45,0 & 38 \\
\hline Bwl & 125 & $12,01 \pm 0,80$ & 4,4 & 35,0 & 38 \\
\hline Bw2 & 139 & $11,66 \pm 0,79$ & 4,0 & 33,0 & 41 \\
\hline Bw3 & 58 & $10,78 \pm 1,16$ & 2,0 & 25,0 & 42 \\
\hline \multicolumn{6}{|c|}{ LATOSSOLO VERMELHO AMARELO (CERRADO) } \\
\hline$A$ & 100 & $14,74 \pm 0,72$ & 7,0 & 36,0 & 25 \\
\hline$\therefore / B$ & 100 & $14,35 \pm 0,83$ & 4,0 & 40,0 & 29 \\
\hline $\mathrm{B} / \mathrm{A}$ & 103 & $13,03 \pm 0,82$ & 2.0 & 45.0 & 33 \\
\hline$B w 1$ & 100 & $12,12 \pm 0,79$ & 5,0 & 33,0 & 33 \\
\hline Bw2 & 97 & $11,85 \pm 0.86$ & 2,0 & 30,0 & 37 \\
\hline Bw3 & 24 & $\ldots 11,69 \pm 1,96$ & 1,0 & 20,0 & 42 \\
\hline \multicolumn{6}{|c|}{ LATOSSOLO VERMELHO ESCURO (CERRADO) } \\
\hline$A$ & 83 & $13,86 \pm 0,62$ & 3,0 & 20,3 & 21 \\
\hline$A / B$ & 98 & $12,65 \pm 0,62$ & 3,0 & 22,0 & 25 \\
\hline $\mathrm{B} / \mathrm{A}$ & 101 & $12,52 \pm 0,67$ & 1,0 & 23,0 & 28 \\
\hline Bwl & 109 & $11,63 \pm 0,76$ & 1,0 & 33,0 & 35 \\
\hline Bw2 & 98 & $11,37 \pm 0,76$ & 3,0 & 22,0 & 34 \\
\hline Bw3 & 11 & $11,73 \pm 0,53$ & 3,0 & 25,0 & 25 \\
\hline
\end{tabular}


Quanto a influência do tipo de vegetação na relação $\mathrm{C} / \mathrm{N}$, observa-se que apenas no LV da Amazônia constata-se essa influência (Tabela A49, página 158). De maneira geral, há diferenças na relação $\mathrm{C} / \mathrm{N}$ ao se considerar a Floresta Densa, Floresta Aberta e Contato Floresta Ombrófila/Floresta Estacional, pois a relação aumenta neste sentido para todos os horizontes. Tais diferenças são atribuídas ao próprio tipo e concentração de matéria orgânica nestes ambientes.

Em relação à variação da relação $\mathrm{C} / \mathrm{N}$ de acordo com as características climáticas (Tabelas A51 e A52, página 159), seguem-se as mesmas tendências da matéria orgânica, já analisadas.

\subsection{3. $\mathrm{pH}$ em $\mathrm{H}_{2} \mathrm{O}, \mathrm{pH}$ em $\mathrm{KCl}$ e delta $\mathrm{pH}(\Delta \mathrm{pH})$}

Os valores de $\mathrm{pH}$ em $\mathrm{H}_{2} \mathrm{O}$ para todo o horizonte $\mathrm{A}$ ( $\mathrm{A}$ e $\mathrm{A} / \mathrm{B}$ ) do LA e do LV da Amazônia mostram média em torno de 4,23 e 4,28, respectivamente (Tabela 22). Considerando que solos com valores de $\mathrm{pH}$ em água abaixo de 5,0 apresentam acidez elevada, um total de $83,5 \%$ dos perfis do LA e $88,9 \%$ do LV contém horizonte A situando-se abaixo desse valor. Acidez média ( $\mathrm{pH}$ em $\mathrm{H}_{2} \mathrm{O}$ de 5,0 a 5,9) são encontrados em $10,9 \%$ dos perfis do LA e em $11,1 \%$ do LV da Amazônia. Para o horizonte A do LV e LE dos Cerrados obtem-se média em torno de 5,08, sendo que $88,3 \%$ dos perfis do LV e $36,9 \%$ do LE contêm nível de acidez considerado elevado. Acidez média é encontrada em $11,7 \%$ do LV e $62,1 \%$ do LE. Convém ressaltar que somente $1,1 \%$ dos perfis do LE apresentou $\mathrm{pH}$ em água igual ou superior a 6,0\%. Esses dados indicam a generalizada condição ácida dos latossolos estudados, sendo 78,4\% dos perfis da Amazônia e 62,1\% dos Cerrados com pH entre 4,5 e 5,0, com relação ao horizonte A. Além disso, os dados 
Tabela 22 - Valores da média do $\mathrm{pH}$ em $\mathrm{H}_{2} \mathrm{O}$ com o intervalo de confiança a $95 \%$ de probabilidade ( $\hat{\mathrm{m}} \pm$ t.s $\hat{\mathrm{m}}$ ), valor mínimo, máximo e coeficientes de variação nos horizontes dos latossolos.

\begin{tabular}{|c|c|c|c|c|c|}
\hline \multirow[t]{2}{*}{ Horizonte } & \multirow{2}{*}{$\begin{array}{c}N^{o} d e \\
\text { pontos }\end{array}$} & \multicolumn{4}{|c|}{$\mathrm{pH} \mathrm{em} \mathrm{H}_{2} \mathrm{O}$} \\
\hline & & $\hat{\mathrm{m}} \pm \operatorname{ts} s \hat{\mathrm{m}}$ & Mínimo & Máximo & $C V(\%)$ \\
\hline \multicolumn{6}{|c|}{ LATOSSOLO AMARELO (AMAZÔNIA) } \\
\hline A & 74 & $4,09 \pm 0,15$ & 3,0 & 5,8 & 16 \\
\hline $\mathrm{A} / \mathrm{B}$ & 73 & $4,33 \pm 0,12$ & 3,5 & 5,9 & 12 \\
\hline $\mathrm{B} / \mathrm{A}$ & 69 & $4,47 \pm 0,10$ & 3,4 & 5,5 & 10 \\
\hline Bwl & 68 & $4,61 \pm 0,09$ & 3,8 & 5,7 & 8,3 \\
\hline $\mathrm{Bw} 2$ & 78 & $4,77 \pm 0,08$ & 3,8 & 5,5 & 7,9 \\
\hline $\mathrm{Bw} 3$ & 21 & $4.82 \pm 0.21$ & 3.9 & 5.6 & 10 \\
\hline \multicolumn{6}{|c|}{ LATOSSOLO VERMELHO AMARELO (AMAZÔNIA) } \\
\hline$A$ & 179 & $4,18 \pm 0,08$ & 3,2 & 5,9 & 13,1 \\
\hline $\mathrm{A} / \mathrm{B}$ & 165 & $4,35 \pm 0,08$ & 3,3 & 6,1 & 12,7 \\
\hline $\mathrm{B} / \mathrm{A}$ & 160 & $4,58 \pm 0,07$ & 3,1 & 5,8 & 10,5 \\
\hline $\mathrm{Bw} 1$ & 159 & $5,10 \pm 0,61$ & 3,8 & 6.3 & 10,3 \\
\hline$B w 2$ & 184 & $4,95 \pm 0,07$ & 3,8 & 6,5 & 9,9 \\
\hline $\mathrm{Bw} 3$ & 82 & $5,07 \pm 0,11$ & 3,9 & 6,0 & 9.9 \\
\hline \multicolumn{6}{|c|}{ LATOSSOLO VERMELHO AMARELO (CERRADO) } \\
\hline$A$ & 121 & $5,02 \pm 0,11$ & 3,4 & 6,3 & 12,2 \\
\hline $\mathrm{A} / \mathrm{B}$ & 119 & $5,13 \pm 0,09$ & 3.7 & 6.1 & 9,4 \\
\hline $\mathrm{B} / \mathrm{A}$ & 123 & $5,27 \pm 0,08$ & 3,9 & 60 & 9,1 \\
\hline$B w 1$ & 119 & $5,41 \pm 0,09$ & 3,9 & 6,1 & 8,8 \\
\hline$B w 2$ & 114 & $5,52 \pm 0,09$ & 4,0 & 6,3 & 8,8 \\
\hline $\mathrm{Bw} 3$ & 27 & $.5,60 \pm 0,15$ & 4,4 & 6,1 & 7,3 \\
\hline \multicolumn{6}{|c|}{ LATOSSOLO VERMELHO ESCURO (CERRADO) } \\
\hline$A$ & 95 & $5,07 \pm 0,10$ & 3,9 & 6,0 & 9,4 \\
\hline $\mathrm{A} / \mathrm{B}$ & 110 & $5,15 \pm 0,08$ & 3,8 & 7,0 & 8,6 \\
\hline $\mathrm{B} / \mathrm{A}$ & 119 & $5,28 \pm 0,08$ & 4,0 & 7,1 & 8,6 \\
\hline $\mathrm{Bw} 1$ & 118 & $5,46 \pm 0,09$ & 4,0 & 6,9 & 8,7 \\
\hline$B w 2$ & 114 & $5,55 \pm 0,09$ & 4,0 & 6,4 & 8,8 \\
\hline Bw3 & 17 & $5,48 \pm 0,28$ & 4,3 & 6,3 & 10,9 \\
\hline
\end{tabular}




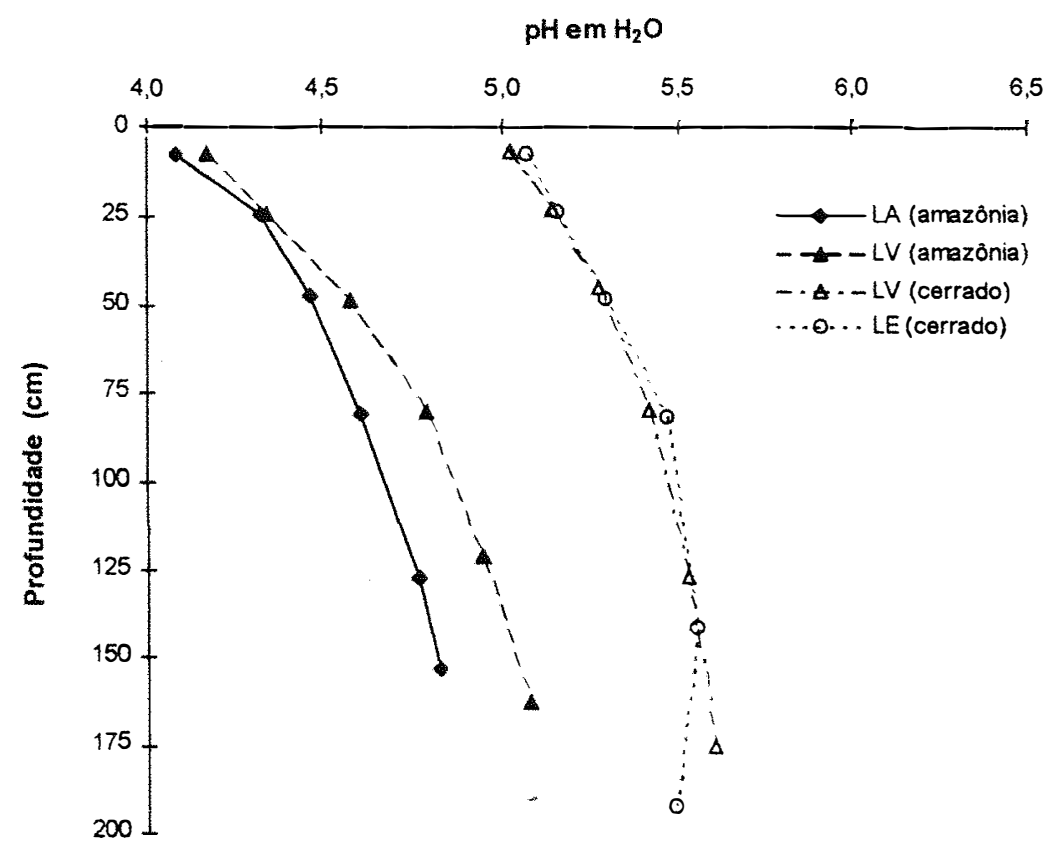

Figura 17 - Distribuição em profundidade dos valores médios do pH em água dos latossolos.

referentes ao $\mathrm{pH}$ dos solos das duas regiões estudadas indicam (Tabela 22 e Figura 17):

- Elevada acidez nos horizontes superficiais dos solos da Amazônia, na faixa de 4,0 a 4,2 , aumentando o valor gradativamente em profundidade, atingindo valores na faixa de 4,8 a 5,0 no Bw3.

- Moderada acidez na camada superficial dos solos dos Cerrados na faixa de 5,0, aumentando o valor em profundidade, até valores da ordem de 5,5 no Bw3.

Observando-se a freqüência dos valores do $\mathrm{pH}$ (Tabela $\mathrm{A} 53$, página 160) nota-se que $12 \%$ dos LA apresentam pH entre 3,0 e 3,5 no horizonte $\mathrm{A}$ contra $1 \%$ na região dos Cerrados. Se for ampliado o nível, por exemplo de 3 a 4, a freqüência passa praticamente para 40 e $50 \%$ para o LV e LA respectivamente, enquanto que nos Cerrados tal freqüência se mantem na faixa de $1 \%$ no LE e $12 \%$ no LV.

Praticamente $90 \%$ dos casos no LA e LV apresentam o pH abaixo de 5,0, não havendo praticamente distinção entre os dois solos. Entretanto, na região dos 
Cerrados, há uma grande diferença entre os dois grupos de solos. O LV, regra geral, é mais ácido do que o LE. Este, no caso, tem $60 \%$ dos solos com pH acima de 5,0. Em profundidade a tendência permanece a mesma, porém, com valores menos ácidos. Tomando-se o Bw3 como referência nota-se que mais de $50 \%$ dos casos nos dois solos da Amazônia apresenta os valores de pH até 5,0 contra 10\% apenas nos dois solos dos Cerrados. Enquanto que na Amazônia praticamente não há solo com pH superior a 6,0 nesta profundidade, nos Cerrados $15 \%$ do LV e $22 \%$ do LE apresentam.

Em relação à região dos Cerrados, aparentemente não há distinção, quanto ao $\mathrm{pH}$, em relação aos dois solos estudados, LV e LE (Figura 16), o mesmo podendo-se afirmar dos solos da Amazônia. Entretanto, há notável diferença no pH, quando se considera os dois ambientes. $\mathrm{O}$ aumento do $\mathrm{pH}$ em profundidade, menor nos solos da Amazônia e maior nos solos dos Cerrados, está relacionado à natureza mineralógica destes solos. Nos solos dos Cerrados há dominância de óxidos, enquanto que na Amazônia, de caulinita com pequena contribuição de minerais 2:1. Como se sabe o PCZ destes minerais são distintos, com valores de $\mathrm{pH}$ mais próximos a 5,5 - 6,0 nos óxidos.

Entretanto, os valores extremamente ácidos de $\mathrm{pH}$ para os horizontes superficiais dos solos da Amazônia, estão relacionados à combinação de fatores como a própria natureza e quantidade da matéria orgânica associadas às condições climáticas, principalmente as de ambientes perúdico e údico.

Outros fatos que diferenciam os solos das duas regiões são os seguintes:

- Nos solos da Amazônia, a acidez torna-se mais elevada à medida em que o solo fica mais argiloso, o que não ocorre na região dos Cerrados. Para as texturas mais arenosas dos LA e LV amazônicos, o pH está na faixa de 4,46 e 4,43 respectivamente, e para a textura muito argilosa, passa para 3,71 e 3,91, respectivamente.

- Tal tendência verifica-se em todo o solo, até o horizonte Bw3.

Considerando-se que a constituição mineralógica destes solos em profundidade é pouco variável (ver valores de ki em profundidade, Figura 3 e Tabela 7) 
as variações do $\mathrm{pH}$ não podem ser atribuídas à variação da mineralogia. $\mathrm{O}$ único fator para o caso dos solos da Amazônia, que tendem a aumentar com o aumento da textura, é a matéria orgânica. Sendo assim, atribui-se a maior acidez nos solos mais argilosos, à ação da matéria orgânica. Ao que parece o pH é influenciado também pelo tipo de matéria orgânica (Tabela A55, página 161), como se verifica para o LV da Amazônia. A vegetação Floresta Densa tende a ter solos com $\mathrm{pH}$ mais ácido do que as demais vegetações, principalmente para os horizontes mais inferiores.

Outro fator que tem influenciado o $\mathrm{pH}$, é a própria formação geológica (Tabela A56, página 161). Para o caso dos LA da Amazônia, o material da Formação Solimões tem gerado solos mais ácidos do que a Formação Barreiras. O mesmo ocorre para o LV quando se comparam a Formação Solimões com as demais formações terciárias e quaternárias.

Quanto à ação climática no $\mathrm{pH}$, os dados apresentados (Tabela A57, página 162) são mais consistentes para o LV da Amazônia e para os solos dos Cerrados. Neste caso particular, à medida que aumentam as precipitações os solos tendem a ficar mais ácidos. Na faixa de precipitação de 1000 e $1500 \mathrm{~mm}$ o pH do LV no A é de 4,4 e à medida que aumenta a precipitação, o pH tende a ficar mais ácido, na faixa de 3,63 para precipitação superior aos $3000 \mathrm{~mm}$ de precipitação. A acidificação, à medida que aumenta a precipitação, verifica-se também em profundidade. Tal tendência de acidificação ocorre também nos latossolos dos Cerrados, porém com valores de $\mathrm{pH}$ mais elevados.

pH em KCl

Os valores do $\mathrm{pH}$ em $\mathrm{KCl}$ (Tabela 23) têm indicado as mesmas tendências de variações do $\mathrm{pH}$ em água, porém para faixas mais ácidas, tanto para os solos da Amazônia como dos Cerrados. $\mathrm{O}$ aumento em profundidade, também se verifica para ambos os casos, principalmente para o LE (Figura 18). 
Tabela 23 - Valores da média do $\mathrm{pH}$ em $\mathrm{KCl}$ com o intervalo de confiança a 95\% de probabilidade ( $\hat{\mathrm{m}} \pm$ t.s $\hat{\mathrm{m}}$ ), valor mínimo, máximo e coeficientes de variação nos horizontes dos latossolos.

\begin{tabular}{|c|c|c|c|c|c|}
\hline \multirow[t]{2}{*}{ Horizonte } & \multirow{2}{*}{$\begin{array}{l}N^{o} \text { de } \\
\text { pontos }\end{array}$} & \multicolumn{4}{|c|}{ pH em KCl } \\
\hline & & $\hat{\mathrm{m}} \pm \boldsymbol{t . s} \hat{\mathrm{m}}$ & Minimo & Máximo & $C V(\%)$ \\
\hline \multicolumn{6}{|c|}{ LATOSSOLO AMARELO (AMAZÔNIA) } \\
\hline A & 74 & $3,72 \pm 0,10$ & 3,1 & 5,4 & 11,6 \\
\hline $\mathrm{A} / \mathrm{B}$ & 73 & $3,00 \pm 0,06$ & 3,0 & 4,8 & 6,4 \\
\hline $\mathrm{B} / \mathrm{A}$ & 69 & $4,01 \pm 0,05$ & 3,6 & 4,8 & 5,1 \\
\hline Bwl & 68 & $4,05 \pm 0,06$ & 3,7 & 5,0 & 6,0 \\
\hline Bw2 & 78 & $4,06 \pm 0,06$ & 3,0 & 5,0 & 6,6 \\
\hline Bw3 & 21 & $4,13 \pm 0,12$ & 3,7 & 4.7 & 6,6 \\
\hline \multicolumn{6}{|c|}{ LATOSSOLO VERMELHO AMARELO (AMAZÔNIA) } \\
\hline A & 179 & $3,81 \pm 0,06$ & 2,6 & 5,2 & 10,4 \\
\hline $\mathrm{A} / \mathrm{B}$ & 165 & $4,19 \pm 0,38$ & 3,0 & 5,4 & 10,1 \\
\hline $\mathrm{B} / \mathrm{A}$ & 160 & $4,15 \pm 0,06$ & 2,8 & 5,5 & 9,8 \\
\hline $\mathrm{Bw} 1$ & 159 & $4,28 \pm 0,07$ & 3,1 & 6,0 & 11,1 \\
\hline$B w 2$ & 184 & $4,41 \pm 0,08$ & 3,0 & 6,2 & 12,4 \\
\hline $\mathrm{Bw} 3$ & 82 & $4,57 \pm 0,14$ & 3,6 & 6,0 & 13,8 \\
\hline \multicolumn{6}{|c|}{ LATOSSOLO VERMELHO AMARELO (CERRADO) } \\
\hline A & 121 & $4,31 \pm 0,07$ & 3,4 & 5,5 & 9,6 \\
\hline $\mathrm{A} / \mathrm{B}$ & 119 & $4,33 \pm 0,06$ & 3,7 & 5,4 & 7,1 \\
\hline $\mathrm{B} / \mathrm{A}$ & 123 & $4,54 \pm 0.07$ & 3,7 & 5,7 & 9,1 \\
\hline Bwl & 119 & $4,84 \pm 0,10$ & 3,8 & 6,4 & 11,7 \\
\hline $\mathrm{Bw} 2$ & 114 & $5,06 \pm 0,11$ & 3,9 & 6,4 & 12,3 \\
\hline $\mathrm{Bw} 3$ & 27 & $5,16 \pm 0.23$ & 3,8 & 6,0 & 12,0 \\
\hline \multicolumn{6}{|c|}{ LATOSSOLO VERMELHO ESCURO (CERRADO) } \\
\hline A & 95 & $4,35 \pm 0,07$ & 3,7 & 5,7 & 8,0 \\
\hline $\mathrm{A} / \mathrm{B}$ & 110 & $4,38 \pm 0,08$ & 1,9 & 5,8 & 9,6 \\
\hline $\mathrm{B} / \mathrm{A}$ & 119 & $4,59 \pm 0,10$ & 1,8 & 6,0 & 11,8 \\
\hline Bwl & 118 & $4,90 \pm 0,12$ & 1,7 & 6,5 & 14,1 \\
\hline$B w 2$ & 114 & $5,12 \pm 0,14$ & 1,5 & 6,7 & 15,2 \\
\hline Bw3 & 17 & $5,28 \pm 0,39$ & 3,8 & 6,7 & 15,5 \\
\hline
\end{tabular}




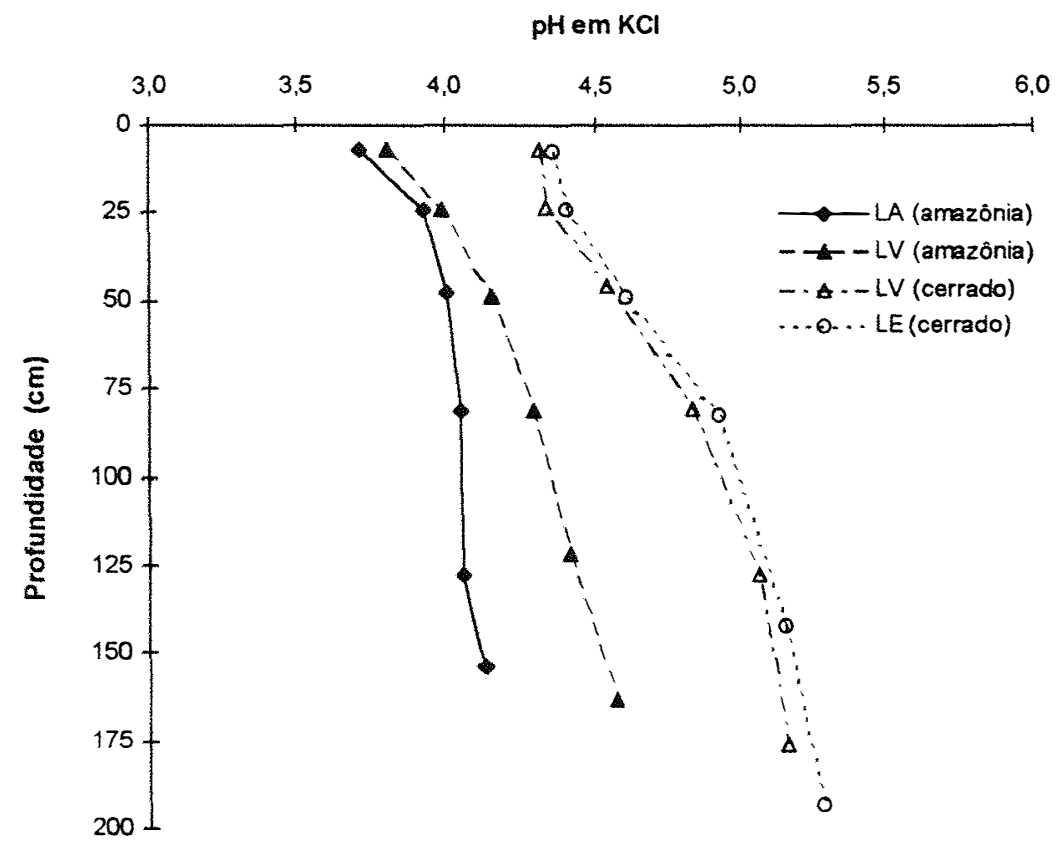

Figura 18 - Distribuição em profundidade dos valores médios de $\mathrm{pH}$ em $\mathrm{KCl}$ dos latossolos

Delta $\mathrm{pH}$

Os valores de delta $\mathrm{pH}$ dos horizontes dos latossolos estudados estão apresentados na Tabela 24. Os horizontes com valores de $\Delta \mathrm{pH}$ negativos (-) apresentam balanço final de cargas negativas ou CTC líquida; e os com $\Delta \mathrm{pH}$ positivos $(+)$ refletem um balanço final de cargas positivas ou CTA líquida; valores de $\Delta \mathrm{pH}$ iguais a zero demonstram equilíbrio no balanço entre as cargas negativas e positivas.

A diferença de valores delta $\mathrm{pH}$ (Tabela 24), tem indicado que em ambas regiões há um balanço negativo das cargas, porém com maior tendência para o balanço positivo para os solos dos Cerrados nos horizontes inferiores. Enquanto que na Amazônia, o delta $\mathrm{pH}$ tende a aumentar em profundidade, $-0,70$ para o LA e $-0,51$ para o LV, nos Cerrados ele tende a descrescer, $-0,44$ para o LV e -0,20 para o LE (Figura 19). 
Tabela 24 - Valores da média do $\Delta \mathrm{pH}$ com o intervalo de confiança a $95 \%$ de probabilidade ( $\hat{\mathrm{m}} \pm$ t.s $\hat{\mathrm{m}})$, valor mínimo, máximo e coeficientes de variação nos horizontes dos latossolos.

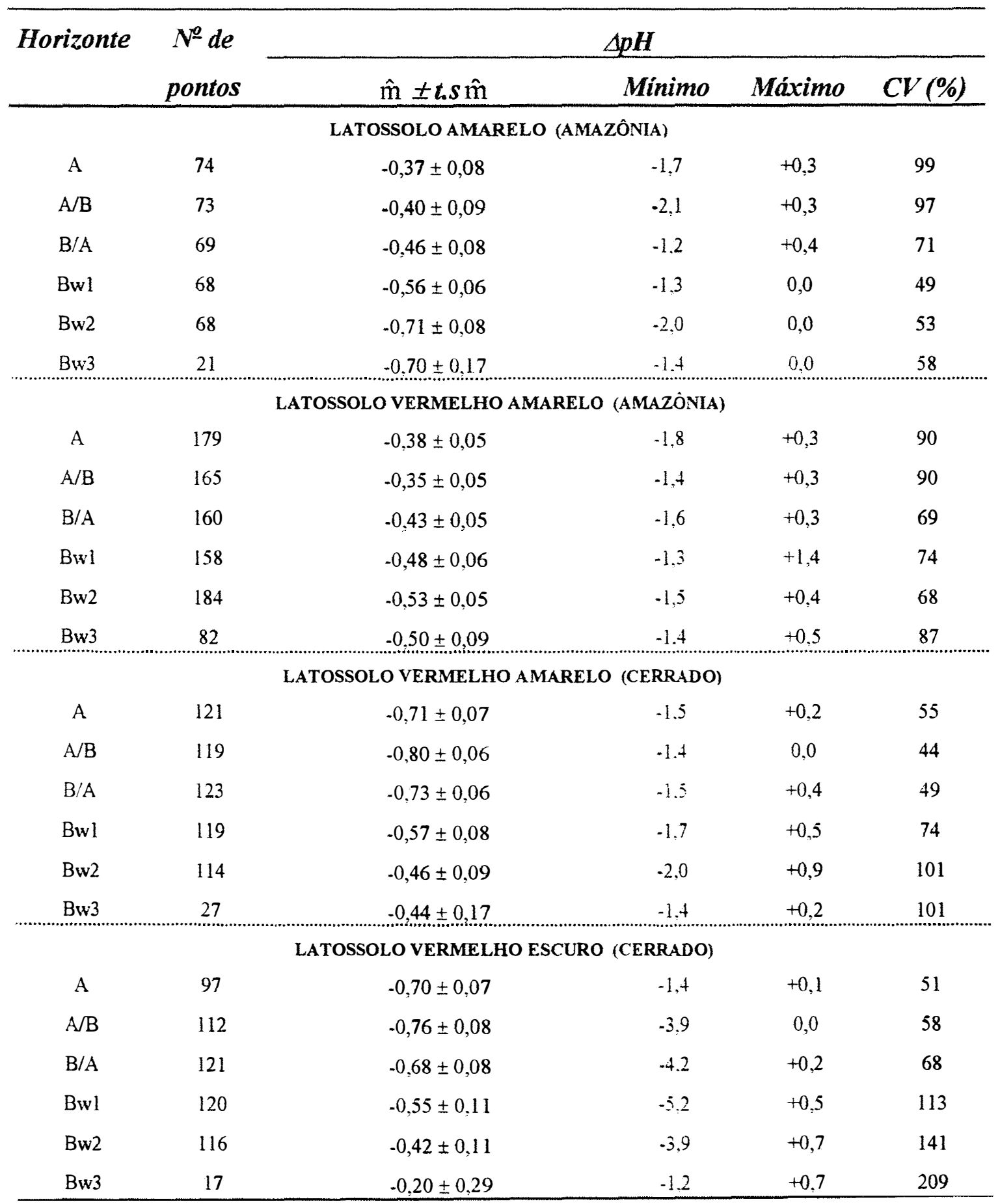




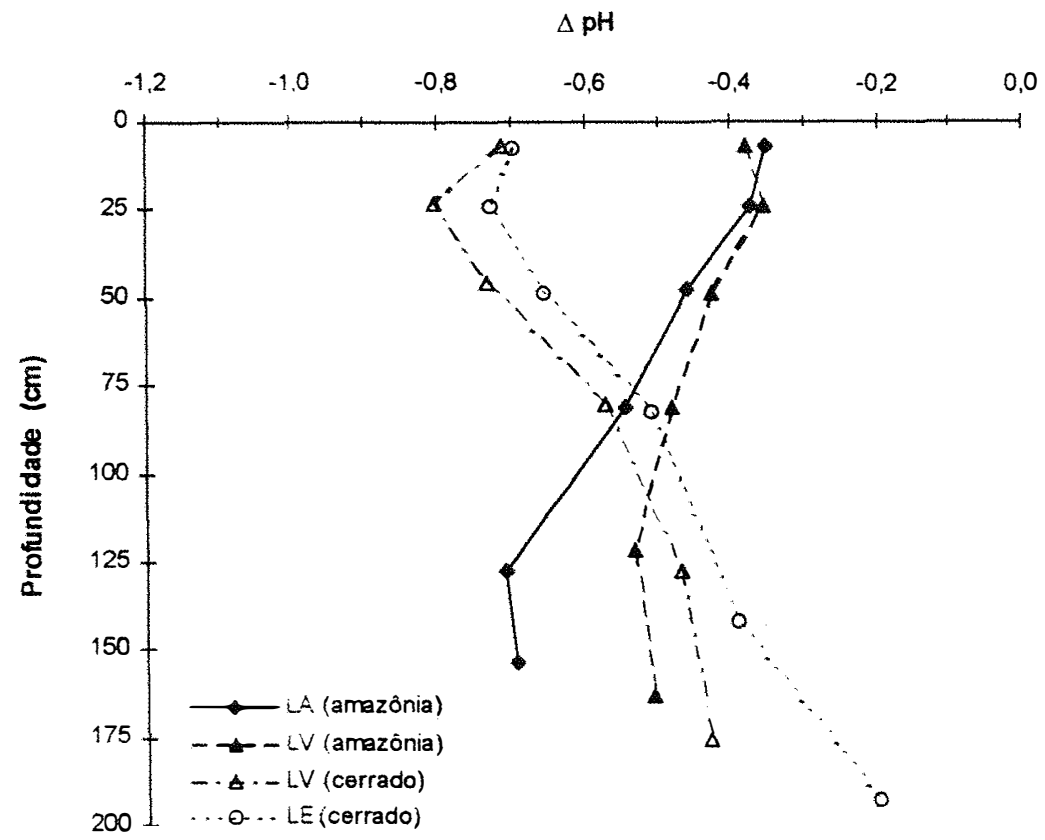

Figura 19 - Distribuição em profundidade dos valores médios do delta pH dos latossolos.

Ao se examinar os diversos perfis individualmente, nota-se que na região dos Cerrados é mais comum a ocorrência do delta $\mathrm{pH}$ positivo nos horizontes mais profundos e menos freqüente na Amazônia. Aliás, os próprios dados da Tabela 24 indicam tais resultados. Esses valores de delta $\mathrm{pH}$ tendendo para zero ou ficando positivo em profundidade, deve-se à própria composição mineralógica destes solos. $\mathrm{O}$ ponto de carga zero dos óxidos (hematita, goetita e gibsita) está na faixa de 5,5 e 6,0 (Raij \& Peech, 1972; Sánchez, 1974), o que proporciona pHs próximo a tais valores para os solos dos Cerrados.

Valores positivos do delta $\mathrm{pH}$ em superfície, são extremamente raros devido à própria ação da matéria orgânica que tende a deslocar o PCZ para faixas mais ácidas (Sánchez, 1976). No caso dos dados apresentados na Tabela 24, onde aparecem valores de delta pH positivo na superfície do solo, tanto para a região Amazônica como dos Cerrados devem ser observados com muito cuidado. 
As influências da vegetação, material de origem e do clima que influenciaram o pH em $\mathrm{H}_{2} \mathrm{O}$, também são assinaladas no delta $\mathrm{pH}$ conforme se verifica nas Tabelas A66, A67 (página 167), A68 e A69 (página 168).

\subsubsection{Fósforo solúvel}

Os valores do conteúdo de $\mathrm{P}$ solúvel nos horizontes dos latossolos estudados estão apresentados na Tabela 25. Os teores de fósforo solúvel para os solos de ambas regiões estudadas, indicam valores descrescentes em profundidade (Figura 20), assim como valores extremamente baixos. Teores médios deste nutriente na camada superficial dos solos da Amazônia, ficam na faixa de 3,5 a 4,0 mg kg-1, contra 1,0 a $2,0 \mathrm{mg} \mathrm{kg}^{-1}$ nos solos dos Cerrados. Tais valores estão abaixo do nível crítico para a maioria das culturas (Lopes, 1983) e independem da textura (Tabela A71, página 169). A maior fonte deste nutriente está na matéria orgânica uma vez que não há influência tanto da vegetação como do material de origem (Tabelas A72 e A73, página 170). A maior concentração do P na superficie dos solos amazônicos deve-se ao maior teor de matéria orgânica destes solos nesta camada, se comparado com os latossolos dos Cerrados.

Com teores de $1 \mathrm{mg} \mathrm{kg}^{-1}$ nos horizontes inferiores vem indicar que tais solos não apresentam minerais com fósforo, como apatita. Esta total escassez deste nutriente não deixa de ser um dos principais fatores limitantes ao uso agrícola em agricultura de baixo nível. Por outro lado, deve-se entender que escassez de fósforo na região tropical não é novidade, haja visto os próprios trabalhos do RADAM, os trabalhos de levantamento de solo feito pelo Serviço Nacional de Levantamento e Conservação de Solo da Embrapa, bem como de vários pesquisadores (Demattê, 1988; Diez et al., 1989).

Quanto à freqüência de distribuição, 50\% do teor de fósforo abaixo de $4 \mathrm{mg} \mathrm{kg}^{-1}$ encontra-se na camada superficial dos solos da Amazônia, contra 83\% no LE e $95 \%$ no LV dos Cerrados. 
Tabela 25 - Valores da média de P solúvel com o intervalo de confiança a $95 \%$ de probabilidade $(\hat{\mathrm{m}} \pm$ t.s $\hat{\mathrm{m}})$, valor mínimo, máximo e coeficientes de variação nos horizontes dos latossolos.

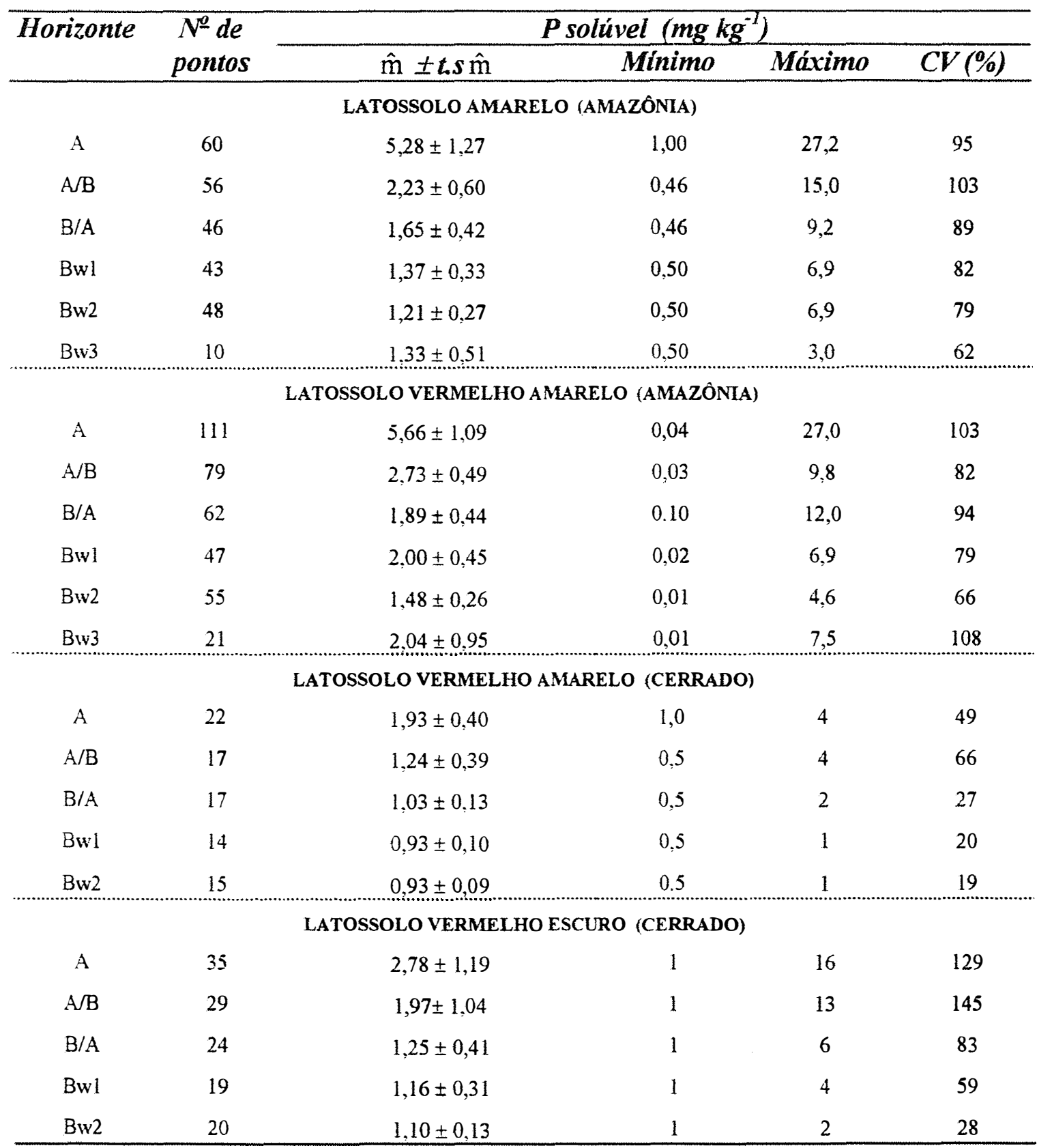




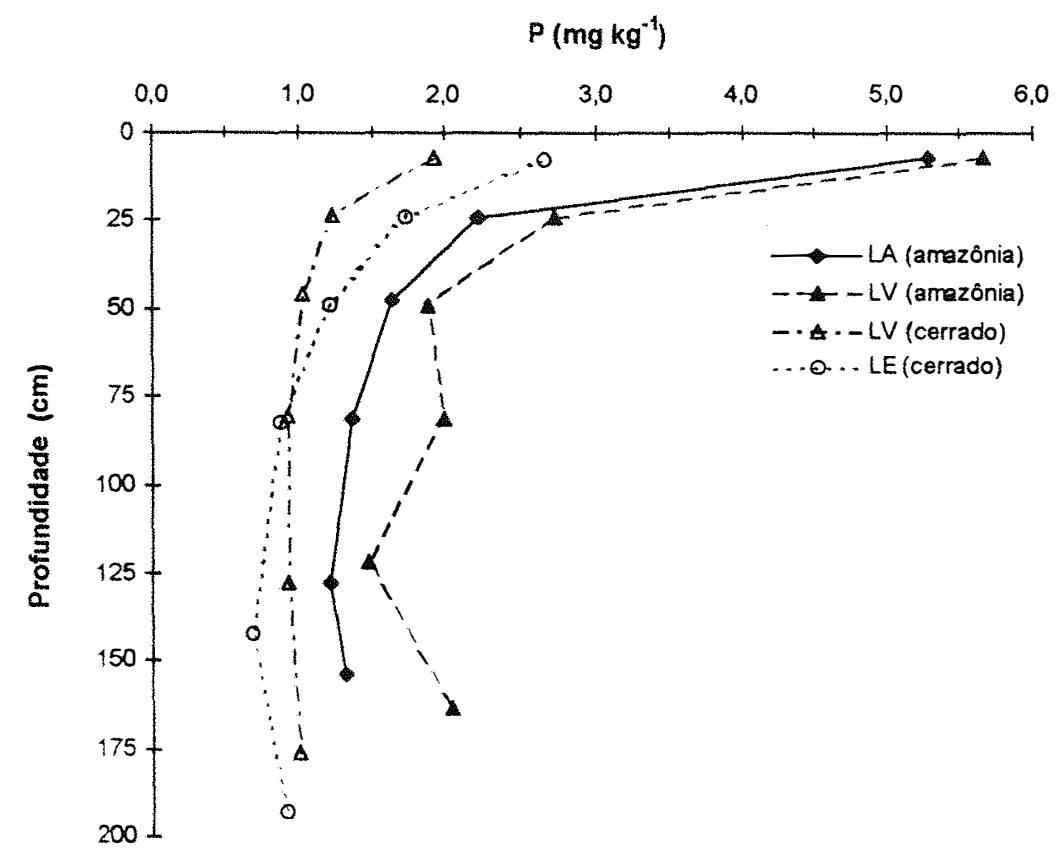

Figura 20 - Distribuição em profundidade dos valores médios dos teores de fósforo dos latossolos

Nos horizontes mais inferiores, Bw2 no caso, praticamente $100 \%$ dos solos dos Cerrados apresentam teores abaixo de $2 \mathrm{mg} \mathrm{kg}^{-1}$, contra $87,5 \%$ no LA e $68 \%$ no LV da Amazônia.

\subsubsection{Potássio trocável}

Os teores de $\mathrm{K}$ trocável para os solos das duas regiões estudadas (Tabela 26) têm indicado:

- descrécimo acentuado em seus valores em profundidade (Figura 21);

- valores muito baixos, inferiores a $0,05 \mathrm{cmol}_{\mathrm{c}} \mathrm{kg}^{-1}$, a partir do B/A.

Levando-se em consideração a freqüência de ocorrência do $\mathrm{K}$ trocável (Tabela A76, página 172) nota-se:

- Teores abaixo de $0,10 \mathrm{cmol}_{\mathrm{c}} \mathrm{kg}^{-1}$ no horizonte superficial, ou seja, valores considerados baixos por muitos autores (Lopes, 1983; Raij, 1992), são representados 
por $64 \%$ no LA; $43 \%$ no LV da Amazônia e $61 \%$ no LV e $57 \%$ no LE dos Cerrados. Como se observa, não há distinção quanto a este nutriente entre os solos das duas regiões.

- Se considerarmos uma faixa de 0,10 a $0,20 \mathrm{cmol}_{\mathrm{c}} \mathrm{kg}^{-1}$, teor médio segundo os autores já citados, a freqüência passa para $28 \%$ no LA; $34 \%$ no LV; $24 \%$ no LV e $32 \%$ no LE, novamente sem distinção entre os solos dos dois ambientes.

- O percentual de solos com teor acima de $0,20 \mathrm{cmol}_{\mathrm{c}} \mathrm{kg}^{-1}$, considerado médio-elevado, é ainda razoável no horizonte superficial de tais solos, principalmente no LV da Amazônia com 20\%, 10 e 12\% no LV e LE dos Cerrados, respectivamente.

- Em profundidade, a maior concentração de solos apresenta valores inferiores a $0,10 \mathrm{cmol}_{\mathrm{c}} \mathrm{kg}^{-1}$ até o horizonte B/A. No Bw2 a maior concentração fica abaixo dos $0,05 \mathrm{cmol}_{\mathrm{c}} \mathrm{kg}^{-1}$.

Levando-se em consideração os valores mínimos para a maioria das culturas em relação ao potássio (Raij, 1992; Lopes, 1983), nota-se que este nutriente não seria limitante como é o caso do fósforo.

Outro ponto a ser levado em consideração, é o fato de que também o potássio é dependente da matéria orgânica, e não é dependente da textura, conforme se observa na Tabela A77 (página 172). Apesar desta dependência, o maior teor de matéria orgânica dos solos da Amazônia no horizonte superficial, não reflete um maior teor de potássio, haja visto a similaridade entre os teores de potássio nos solos das duas regiões.

Com uma mineralogia dominantemente oxídica nos latossolos dos Cerrados e caulinítica na região da Amazônia, não haveria reserva mineral para fornecer o potássio, aliás como indicado na Tabela A79 (página 173). Como os teores deste nutriente são baixos, não se notam correlações com as características climáticas (Tabelas A80 e A81, página 174). 
Tabela 26 - Valores da média de $\mathrm{K}^{+}$trocável com o intervalo de confiança a $95 \%$ de probabilidade ( $\hat{\mathrm{m}} \pm \mathrm{t} . \mathrm{s} \hat{\mathrm{m}})$, valor, mínimo, máximo e coeficientes de variação nos horizonte dos latossolos.

\begin{tabular}{|c|c|c|c|c|c|}
\hline \multirow[t]{2}{*}{ Horizonte } & \multirow{2}{*}{$\begin{array}{l}N^{o} \text { de } \\
\text { pontos }\end{array}$} & \multicolumn{4}{|c|}{$K^{+}$trocável $\left(\mathrm{cmol}_{c} \mathrm{~kg}^{-1}\right)$} \\
\hline & & $\hat{\mathrm{m}} \pm \operatorname{t.s} \hat{\mathrm{m}}$ & Minimo & Máximo & $C V(\%)$ \\
\hline \multicolumn{6}{|c|}{ LATOSSOLO AMARELO (AMAZÔNIA) } \\
\hline A & 74 & $0,10 \pm 0,02$ & 0,01 & 0,44 & 84 \\
\hline $\mathrm{A} / \mathrm{B}$ & 73 & $0,05 \pm 0,01$ & 0,01 & 0,40 & 118 \\
\hline $\mathrm{B} / \mathrm{A}$ & 68 & $0,03 \pm 0,0$ & 0,01 & 0,05 & 44 \\
\hline Bwl & 68 & $0,03 \pm 0,0$ & 0,01 & 0,09 & 62 \\
\hline $\mathrm{Bw} 2$ & 77 & $0,03 \pm 0,0$ & 0,01 & 0,06 & 52 \\
\hline $\mathrm{Bw} 3$ & 21 & $0,05 \pm 0,05$ & 0,01 & 0,56 & 251 \\
\hline \multicolumn{6}{|c|}{ LATOSSOLO VERMELHO AMARELO (AMAZÔNIA) } \\
\hline A & 179 & $0,15 \pm 0,02$ & 0,02 & 0,68 & 83 \\
\hline $\mathrm{A} / \mathrm{B}$ & 165 & $0,08 \pm 0,02$ & 0,01 & 1,20 & 139 \\
\hline $\mathrm{B} / \mathrm{A}$ & 160 & $0,05 \pm 0,01$ & 0,01 & 0,46 & 96 \\
\hline Bwl & 159 & $0,05 \pm 0,01$ & 0,01 & 0,66 & 166 \\
\hline Bw2 & 184 & $0,04 \pm 0,01$ & 0,01 & 0,70 & 174 \\
\hline $\mathrm{Bw} 3$ & 82 & $0,05 \pm 0,02$ & 0,01 & 0,80 & 191 \\
\hline \multicolumn{6}{|c|}{ LATOSSOLO VERMELHO AMARELO (CERRADO) } \\
\hline A & 121 & $0,11 \pm 0,01$ & 0,01 & 0,47 & 76 \\
\hline $\mathrm{A} / \mathrm{B}$ & 119 & $0,06 \pm 0,01$ & 0,01 & 0,42 & 99 \\
\hline $\mathrm{B} / \mathrm{A}$ & 123 & $0,04 \pm 0,01$ & 0,01 & 0,44 & 122 \\
\hline Bw1 & 119 & $0,03 \pm 0,02$ & 0,01 & 0,98 & 275 \\
\hline Bw2 & 114 & $0,03 \pm 0,01$ & 0,01 & 0,26 & 140 \\
\hline $\mathrm{Bw} 3$ & 27 & $0,04 \pm 0,04$ & 0,01 & 0,57 & 260 \\
\hline \multicolumn{6}{|c|}{ LATOSSOLO VERMELHO ESCURO (CERRADO) } \\
\hline A & 97 & $0,11 \pm 0,02$ & 0,01 & 0,68 & 92 \\
\hline $\mathrm{A} / \mathrm{B}$ & 112 & $0,06 \pm 0,01$ & 0,01 & 0,44 & 94 \\
\hline $\mathrm{B} / \mathrm{A}$ & 121 & $0,04 \pm 0,01$ & 0,01 & 0,23 & 97 \\
\hline Bwl & 120 & $0,04 \pm 0,01$ & 0,01 & 0,41 & 162 \\
\hline $\mathrm{Bw} 2$ & 116 & $0,03 \pm 0,01$ & 0,01 & 0,19 & 108 \\
\hline Bw3 & 17 & $0,03 \pm 0,02$ & 0,01 & 0,15 & 130 \\
\hline
\end{tabular}




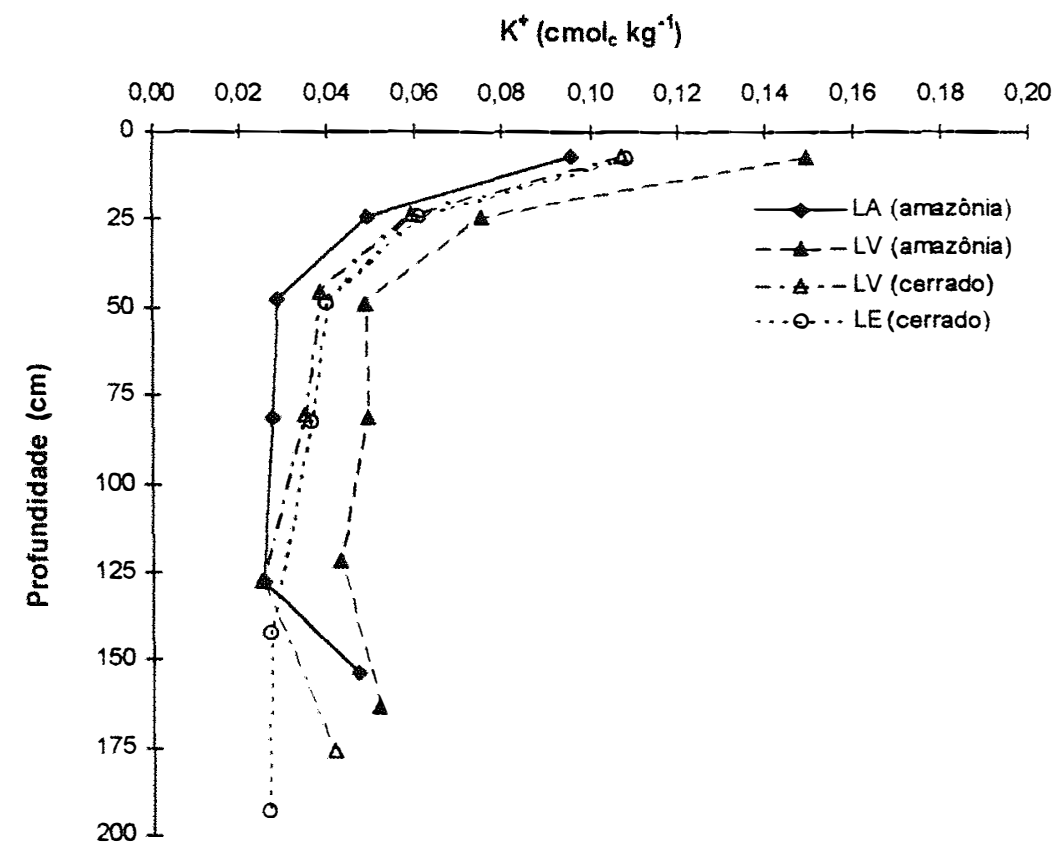

Figura 21 - Distribuição em profundidade dos valores médios dos teores de potássio dos latossolos.

\subsubsection{Cálcio trocável}

Os valores do conteúdo de $\mathrm{Ca}^{++}$trocável nos horizontes dos latossolos estudados estão apresentados na Tabela 27. Considerando-se baixos em $\mathrm{Ca}^{++}$trocável, solos com menos de 1,5 $\mathrm{cmol}_{\mathrm{c}} \mathrm{kg}^{-1}$ (Lopes, 1983; Raij, 1992), os resultados para este parâmetro indicam que todas as médias de todos os horizontes dos latossolos estudados estão abaixo deste valor. Os dados da Tabela A82 (página ) mostram que na Amazônia, $97 \%$ dos horizontes $\mathrm{A}$ e $\mathrm{A} / \mathrm{B}$ do $\mathrm{LA}$ e $96 \%$ dos $\mathrm{A}$ e $\mathrm{A} / \mathrm{B}$ do $\mathrm{LV}$ possuem teor de $\mathrm{Ca}^{++}$ trocável inferior a $1,5 \mathrm{cmol}_{\mathrm{c}} \mathrm{kg}^{-1}$, ressaltando-se ainda, que dentre eles, $88 \%$ dos perfis do LA e $76 \%$ do LV encontram-se abaixo de $0,4 \mathrm{cmol}_{\mathrm{c}} \mathrm{kg}^{-1}$, indicando extrema deficiència de cálcio trocável. Nos Cerrados $92 \%$ dos horizontes A e A/B do LV e $88 \%$ dos $\mathrm{A}$ e $\mathrm{A} / \mathrm{B}$ do $\mathrm{LE}$, possuem teor de $\mathrm{Ca}^{++}$trocável inferior a $1,5 \mathrm{cmol}_{\mathrm{c}} \mathrm{kg}^{-1}$ e nestes horizontes, $46 \%$ dos perfis de LV e $51 \%$ do LE encontram-se abaixo de $0,4 \mathrm{cmol}_{\mathrm{c}} \mathrm{kg}^{-1}$. 
Nos latossolos da Amazônia, a média do teor de cálcio para o horizonte B encontra-se em torno de 0,14 e $0,16 \mathrm{cmol}_{\mathrm{c}} \mathrm{kg}^{-1}$, respectivamente, para o LA e LV, e nos latossolos dos Cerrados, em torno de $0,33 \mathrm{cmol}_{\mathrm{c}} \mathrm{kg}^{-1}$.

Nos horizontes B dos latossolos encontram-se extrema deficiência de cálcio ( $\left.<0,4 \mathrm{cmol}_{\mathrm{c}} \mathrm{kg}^{-1}\right)$ em $94 \%$ dos perfís do LA e LV da Amazônia, e em 68\% e 78\%, respectivamente, para o LV e LE dos Cerrados (Tabela A82, página 175).

Levando-se em consideração que os latossolos dos Cerrados são mais intemperizados e conseqüentemente com ausência de minerais intemperizáveis, o que se verifica nos trabalhos de Lopes (1975), Adamoli et al. (1986), a possivel explicação para o maior teor de cálcio nos horizontes mais inferiores dos latossolos dos Cerrados (Figura 22), quando comparado com os da Amazônia, pode estar relacionada à ação do sistema radicular graminóide dos Cerrados, mais abundante nesta faixa do que na Amazônia. Por outro lado, apesar dos solos da Amazônia serem menos intemperizados, isto não significa presença de minerais intemperizáveis. A caulinita, mineral predominante nestes solos, não apresenta cálcio em sua estrutura, que possa enriquecer o solo. Em ambas as regiões, esta extrema pobreza em bases, abaixo do nível crítico para as culturas, não deixa de ser, junto com o fósforo, um dos fatores limitantes mais marcantes. A maior concentração destes nutrientes na superfície do solo está relacionada ao teor de matéria orgânica, e não devido às classes de textura (Tabela A83, página 175).

A influência do tipo de vegetação sobre o teor de cálcio pode ser observada na Tabela A84 (página 176) e mais particularmente, para o LV da Amazônia. Neste particular, os LV em Floresta Densa apresentam teores mais baixos de cálcio do que a Floresta Aberta e a vegetação de Contato Floresta Ombrófila e Floresta Estacional, onde o teor de cálcio passa de 0,31 para $0,53 \mathrm{cmol}_{\mathrm{c}} \mathrm{kg}^{-1}$ no $\mathrm{A}$, e de 0,10 para $0,27 \mathrm{cmol}_{\mathrm{c}} \mathrm{kg}^{-1}$ respectivamente, para o $\mathrm{Bw} 3$.

Aparentemente a influência do material de origem para os latossolos amazônicos, quanto ao teor de cálcio, é pequena, inclusive quando se leva em consideração os dados das formações pré-cambrianas, mais ricas em minerais contendo 
Tabela 27 - Valores da média do $\mathrm{Ca}^{++}$trocável com o intervalo de confiança a $95 \%$ de probabilidade ( $\hat{\mathrm{m}} \pm$ t.s $\hat{\mathrm{m}})$, valor mínimo, máximo e coeficientes de variação nos horizontes dos latossolos.

\begin{tabular}{|c|c|c|c|c|c|}
\hline \multirow[t]{2}{*}{ Horizonte } & \multirow{2}{*}{$\begin{array}{c}N o d e \\
\text { pontos }\end{array}$} & \multicolumn{4}{|c|}{$\mathrm{Ca}^{++}$trocável $\left(\mathrm{cmol}_{c} \mathrm{~kg}^{-1}\right)$} \\
\hline & & $\hat{\mathrm{m}} \pm \boldsymbol{t} . s \hat{\mathrm{m}}$ & Minimo & Máximo & $C V(\%)$ \\
\hline \multicolumn{6}{|c|}{ LATOSSOLO AMARELO (AMAZÔNIA) } \\
\hline A & 65 & $0,41 \pm 0,22$ & 0,02 & 5,20 & 222 \\
\hline $\mathrm{A} / \mathrm{B}$ & 62 & $0,17 \pm 0,05$ & 0,01 & 1,50 & 130 \\
\hline $\mathrm{B} / \mathrm{A}$ & 59 & $0,15 \pm 0,04$ & 0,01 & 0,73 & 101 \\
\hline Bw1 & 57 & $0,14 \pm 0,03$ & 0,01 & 0,52 & 91 \\
\hline Bw2 & 67 & $0,13 \pm 0,04$ & 0,01 & 1,20 & 129 \\
\hline $\mathrm{Bw} 3$ & 17 & $0,13 \pm 0,05$ & 0,01 & 0,40 & 84 \\
\hline \multicolumn{6}{|c|}{ LATOSSOLO VERMELHO AMARELO (AMAZÔNIA) } \\
\hline A & 173 & $0,55 \pm 0,17$ & 0,02 & 3,72 & 203 \\
\hline $\mathrm{A} / \mathrm{B}$ & 160 & $0,23 \pm 0,05$ & 0,01 & 1,92 & 133 \\
\hline $\mathrm{B} / \mathrm{A}$ & 155 & $0,17 \pm 0,03$ & 0,01 & 1,00 & 110 \\
\hline Bwl & 154 & $0,16 \pm 0,02$ & 0,01 & 0,80 & 91 \\
\hline Bw2 & 178 & $0,14 \pm 0,02$ & 0,01 & 1,00 & 101 \\
\hline $\mathrm{Bw} 3$ & 81 & $0,17 \pm 0,04$ & 0,01 & 1,01 & 104 \\
\hline \multicolumn{6}{|c|}{ LATOSSOLO VERMELHO AMARELO (CERRADO) } \\
\hline A & 109 & $0,81 \pm 0,16$ & 0,12 & 4,36 & 107 \\
\hline$A / B$ & 104 & $0,43 \pm 0,06$ & 0,06 & 1,90 & 68 \\
\hline $\mathrm{B} / \mathrm{A}$ & 106 & $0,36 \pm 0,03$ & 0,06 & 0,90 & 49 \\
\hline Bw1 & 102 & $0,33 \pm 0,03$ & 0,10 & 0,90 & 46 \\
\hline $\mathrm{Bw} 2$ & 96 & $0,32 \pm 0,03$ & 0,10 & 0,80 & 43 \\
\hline Bw3 & 24 & $0,31 \pm 0,05$ & 0,10 & 0,50 & 39 \\
\hline \multicolumn{6}{|c|}{ LATOSSOLO VERMELHO ESCURO (CERRADO) } \\
\hline A & 73 & $0,80 \pm 0,21$ & 0,13 & 4,23 & 112 \\
\hline $\mathrm{A} / \mathrm{B}$ & 76 & $0,48 \pm 0,13$ & 0,12 & 3,30 & 116 \\
\hline $\mathrm{B} / \mathrm{A}$ & 81 & $0,34 \pm 0,06$ & 0,10 & 1,95 & 80 \\
\hline Bw1 & 82 & $0,32 \pm 0,04$ & 0,06 & 1,30 & 58 \\
\hline Bw2 & 81 & $0,31 \pm 0,03$ & 0,12 & 0,70 & 40 \\
\hline Bw3 & 12 & $0,32 \pm 0,08$ & 0,12 & 0,60 & 42 \\
\hline
\end{tabular}




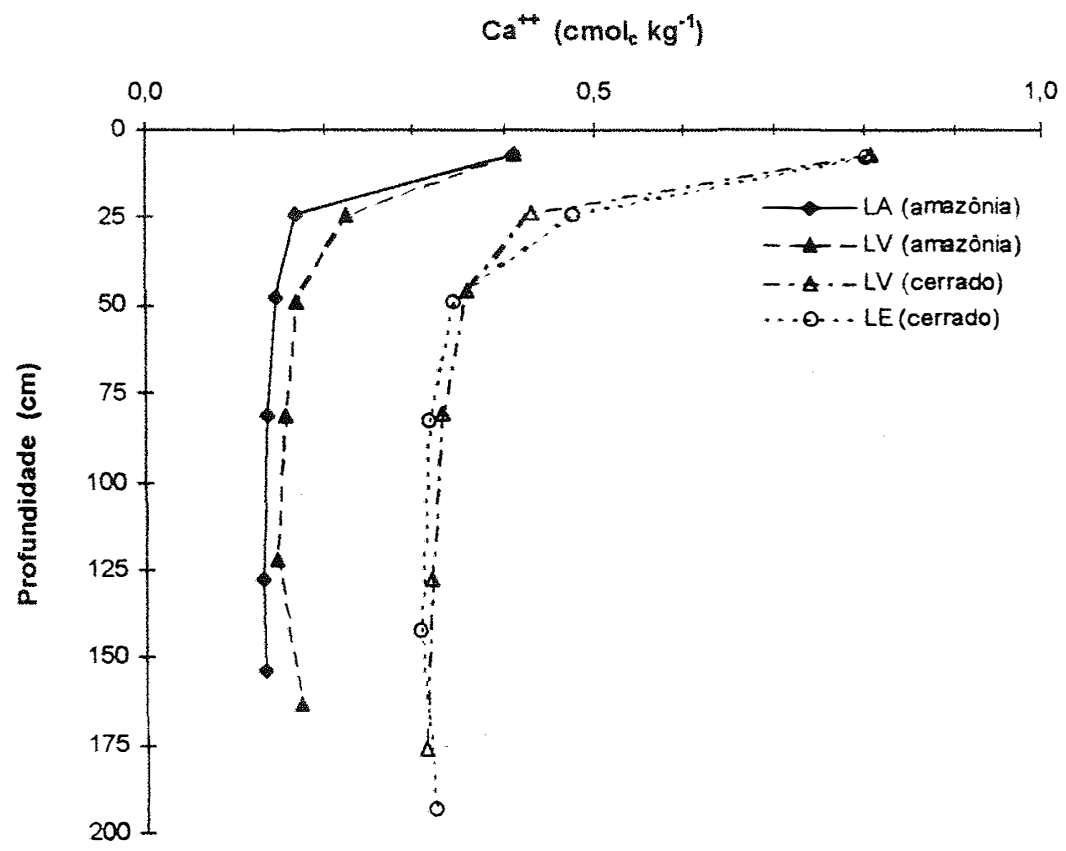

Figura 22 - Distribuição em profundidade dos valores médios dos teores de cálcio dos latossolos

cálcio (Tabela A85, página 176). O que se observa é a maior concentração do cálcio na superfície, independentemente da formação geológica.

Por outro lado, as formações pré-cambrianas têm fornecido mais cálcio na região dos Cerrados do que na Amazônia.

Climaticamente pode-se notar de maneira geral (Tabela A86, página 177) para os solos LV da Amazônia e LV e LE dos Cerrados, que há um decréscimo no teor de cálcio em todos os horizontes, à medida que aumenta a precipitação. Tal fato se justifica, pois, o aumento de precipitação tende a aumentar a lixiviação não só para o cálcio, como para as demais bases potássio e magnésio.

\subsubsection{Magnésio trocável}

Os teores de $\mathrm{Mg}^{++}$trocável nos solos estudados (Tabela 28 e Figura 23), assim como a freqüência de distribuição (Tabela A88, página 178) indicam a mesma 
tendência do que o cálcio. Se considerarmos $0,5 \mathrm{cmol}_{\mathrm{c}} \mathrm{kg}^{-1}$ como nível crítico para a maioria das culturas (CFSEMG, 1978), têm-se $90 \%$ do solo de ambas as regiões com valores abaixo deste limite para o horizonte superficial. Se levarmos em consideração horizontes mais profundos, 95\% para o LA e 92\% para o LV da Amazônia apresentaram teores abaixo dos $0,2 \mathrm{cmol}_{\mathrm{c}} \mathrm{kg}^{-1}$, contra 87 e $80 \%$ para os latossolos dos Cerrados.

\subsubsection{Alumínio trocável}

Os valores para o $\mathrm{Al}^{++1}$ trocável (Tabela 29) para as regiões estudadas indicam o seguinte:

- decréscimo em profundidade para todos os solos (Figura 24);

- valores mais elevados, em todos os horizontes para os solos da Amazônia quando comparados com os solos dos Cerrados;

- em relação aos solos da Amazônia, notam-se diferenças acentuadas entre os LA e LV. No horizonte superficial, os valores estão na faixa de $2,36 \mathrm{cmol}_{\mathrm{c}} \mathrm{kg}^{-1}$ no LA, contra 1,74 no LV e 1,42 no Bw3 do LA e $0,85 \mathrm{cmol}_{\mathrm{c}} \mathrm{kg}^{-1}$ no LV. Tais valores são considerados elevados (Lopes, 1983) principalmente para o caso dos horizontes superficiais.

Levando-se em consideração os valores máximos encontrados notam-se teores na faixa de 6,0 e 8,0 e até $14 \mathrm{cmol}_{\mathrm{c}} \mathrm{kg}^{-1}$ considerados extremamente elevados, inclusive em se tratando de oxissolos. Muitos destes solos, com valores acima dos $5,0 \mathrm{cmol}_{\mathrm{c}} \mathrm{kg}^{-1}$, podem não ser considerados como oxissolos.

Em relação à frequência de ocorrência (Tabela A94, página 181), nota-se que no horizonte A, $56 \%$ dos LA e $74 \%$ dos LV apresentam alumínio acima de $2 \mathrm{cmol}_{\mathrm{c}}$ $\mathrm{kg}^{-1}$. Se considerarmos valores de alumínio acima de $1,0 \mathrm{cmol}_{\mathrm{c}} \mathrm{kg}^{-1}$, estes valores sobem para $81 \%$ no LA e $68 \%$ no LV. Teores de alumínio abaixo dos $0,5 \mathrm{cmol}_{\mathrm{c}} \mathrm{kg}^{-1}$ são representados por $9 \%$ dos LA e $12 \%$ dos LV. 
Tabela 30 - Valores da média de $\mathrm{Mg}^{++}$trocável com o intervalo de confiança a $95 \%$ de probabilidade ( $\hat{\mathrm{m}} \pm \mathrm{t} . \mathrm{s} \hat{\mathrm{m}}$ ), valor mínimo, máximo e coeficientes de variação nos horizontes dos latossolos.

\begin{tabular}{|c|c|c|c|c|c|}
\hline \multirow[t]{2}{*}{ Horizonte } & \multirow{2}{*}{$\begin{array}{l}N^{o} \text { de } \\
\text { pontos }\end{array}$} & \multicolumn{4}{|c|}{$\mathrm{Mg}^{++}$trocável $\left(\mathrm{cmol}_{c} \mathrm{~kg}^{-1}\right)$} \\
\hline & & $\hat{\mathrm{m}} \pm t . s \hat{\mathrm{m}}$ & Mínimo & Máximo & $C V(\%)$ \\
\hline \multicolumn{6}{|c|}{ LATOSSOLO AMARELO (AMAZÔNIA) } \\
\hline A & 65 & $0,21 \pm 0,05$ & 0,02 & 1,05 & 102 \\
\hline $\mathrm{A} / \mathrm{B}$ & 62 & $0,11 \pm 0,03$ & 0,01 & 0,73 & 116 \\
\hline $\mathrm{B} / \mathrm{A}$ & 59 & $0,09 \pm 0,02$ & 0,01 & 0,56 & 99 \\
\hline Bw1 & 57 & $0,07 \pm 0,02$ & 0,01 & 0,35 & 96 \\
\hline Bw2 & 67 & $0,07 \pm 0,01$ & 0,01 & 0,32 & 96 \\
\hline $\mathrm{Bw} 3$ & 17 & $0,06 \pm 0,03$ & 0,01 & 0.23 & 106 \\
\hline \multicolumn{6}{|c|}{ LATOSSOLO VERMELHO AMARELO (AMAZÔNIA) } \\
\hline A & 173 & $0,27 \pm 0,07$ & 0,01 & 3,74 & 167 \\
\hline $\mathrm{A} / \mathrm{B}$ & 160 & $0,13 \pm 0,03$ & 0,01 & 1,02 & 134 \\
\hline $\mathrm{B} / \mathrm{A}$ & 155 & $0,08 \pm 0,02$ & 0,01 & 1,04 & 144 \\
\hline Bwl & 154 & $0,08 \pm 0,02$ & 0,01 & 1,10 & 165 \\
\hline Bw2 & 178 & $0,07 \pm 0,02$ & 0,01 & 0,78 & 150 \\
\hline Bw3 & 81 & $0,07 \pm 0,02$ & 0,01 & 0,68 & 150 \\
\hline \multicolumn{6}{|c|}{ LATOSSOLO VERMELHO AMARELO (CERRADO) } \\
\hline A & 109 & $0,34 \pm 0,09$ & 0,02 & 2,90 & 139 \\
\hline $\mathrm{A} / \mathrm{B}$ & 104 & $0,15 \pm 0,03$ & 0,02 & 0,71 & 96 \\
\hline $\mathrm{B} / \mathrm{A}$ & 106 & $0,13 \pm 0,02$ & 0,02 & 0,76 & 93 \\
\hline Bwl & 102 & $0,12 \pm 0,02$ & 0,02 & 0,74 & 91 \\
\hline Bw2 & 96 & $0,11 \pm 0,01$ & 0,02 & 0,38 & 70 \\
\hline Bw3 & 24 & $0,13 \pm 0,03$ & 0,02 & 0,35 & 62 \\
\hline \multicolumn{6}{|c|}{ LATOSSOLO VERMELHO ESCURO (CERRADO) } \\
\hline A & 73 & $0,32 \pm 0,09$ & 0,02 & 2,02 & 122 \\
\hline $\mathrm{A} / \mathrm{B}$ & 76 & $0,18 \pm 0,04$ & 0,02 & 1,10 & 105 \\
\hline $\mathrm{B} / \mathrm{A}$ & 81 & $0,14 \pm 0,03$ & 0,02 & 1,08 & 101 \\
\hline Bw1 & 82 & $0,14 \pm 0,03$ & 0,02 & 1,20 & 112 \\
\hline Bw2 & 81 & $0,12 \pm 0,02$ & 0,02 & 0,42 & 75 \\
\hline Bw3 & 12 & $0,12 \pm 0,07$ & 0,02 & 0,43 & 98 \\
\hline
\end{tabular}




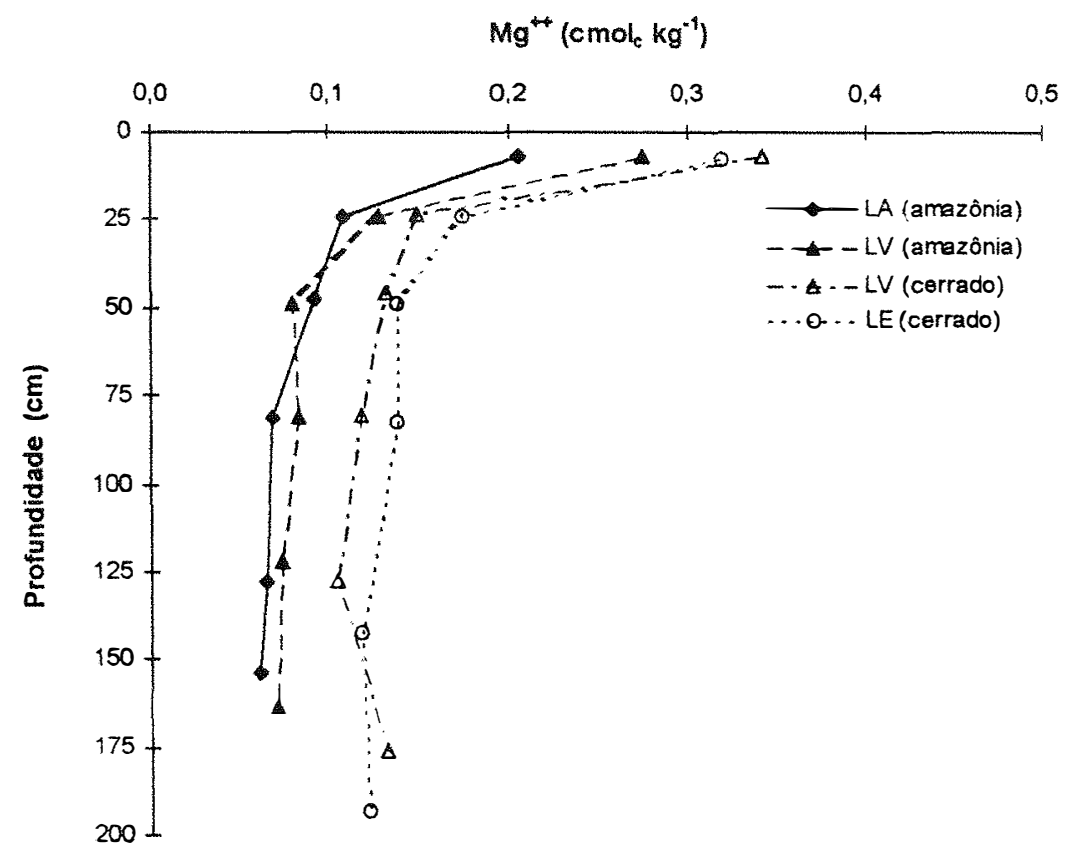

Figura 23 - Distribuição em profundidade dos valores médios dos teores de magnésio dos latossolos.

Ao se analisar os valores de horizontes mais inferiores, no caso o Bw2, nota-se que $50 \%$ do LA e $30 \%$ do LV apresentam teores acima de $1,0 \mathrm{cmol}_{\mathrm{c}} \mathrm{kg}^{-1}$. Se a faixa for aumentada para valores acima de $0,5 \mathrm{cmol}_{\mathrm{c}} \mathrm{kg}^{-1}$, o porcentual sobe para $80 \%$ no LA e $52 \%$ no LV.

Quanto aos latossolos dos Cerrados os teores de $\mathrm{Al}$ trocável são bem menores, não havendo disparidades entre o LV e o LE. Os valores médios dos horizontes superficiais estão na faixa dos $0,5 \mathrm{cmol}_{\mathrm{c}} \mathrm{kg}^{-1}$ para ambos os solos, decrescendo para 0,24 e $0,16 \mathrm{cmol}_{\mathrm{c}} \mathrm{kg}^{-1}$ para os horizontes Bw3. Em termos de frequência de ocorrência (Tabela A94, página 181), nota-se que $30 \%$ do LV e $28 \%$ do LE apresentam teores abaixo de $0,5 \mathrm{cmol}_{\mathrm{c}} \mathrm{kg}^{-1}$ no A. Se a faixa for ampliada para $1,0 \mathrm{cmol}_{\mathrm{c}} \mathrm{kg}^{-1}$, tal valor passa passa para $84 \%$ e $81 \%$, respectivamente, para o LV e o LE. Para o caso dos horizontes Bw2, tais valores passam a 98\% para ambos os solos. 
Como se observa, em termos de alumínio trocável, as diferenças entre os solos destas duas regiões são significativas. Os solos da região amazônica são bem mais limitantes ao uso agrícola, devido aos teores mais elevados de alumínio quando comparados aos solos dos Cerrados. Além dissso, na própria região amazônica, os LA são mais problemáticos do que os LV, em se considerando os teores de alumínio. Os maiores valores de alumínio para os solos da região amazônica estão relacionados a sua mineralogia. Como há dominância de minerais 1:1 e traços de minerais 2:1 estes, de acordo com a estabilidade de minerais, são considerados mais instáveis do que os óxidos (Lindsay, 1979; Kittrick, 1969) que dominam nos Cerrados. Sendo mais instáveis, estes minerais de grade 2:1 ou a decomposição da própria caulinita condicionam a liberação do alumínio na solução do soio. Por sua vez, os óxidos de alumínio, representados pela gibsita, na região do Brasil Central, são minerais de grande estabilidade (Lindsay, 1979), e portanto, resistentes ao intemperismo. Sendo assim, haverá maior concentração de alumínio na região amazônica do que nos Cerrados.

Outro ponto relacionado ao alumínio trocável refere-se ao próprio $\mathrm{pH}$, bem mais ácido nos solos da região amazônica, o que permite maiores teores deste elemento na solução do solo.

Entretanto, é necessário uma análise mais profunda nos dois conjuntos de solos da Amazônia. As diferenças nos teores de alumínio entre eles sugerem ser o LV mais intemperizado do que o LA e, conseqüentemente, com menor quantidade de minerais que possam liberar alumínio por intemperismo. O maior intemperismo no LV é constatado pelos valores do ki (Tabela 7).

- Por outro lado, apesar dos LV da Amazônia serem morfologicamente semelhantes ao LV dos Cerrados, há sensíveis diferenças principalmente em relação ao alumínio, bem maior para os LA da Amazônia.

O teor de aluminio pode estar relacionado também em função da textura do solo, principalmente para os latossolos da Amazônia. Assim, nota-se através dos dados da Tabela A95, página 181, que o teor de alumínio trocável tende a aumentar dos solos mais arenosos para os mais argilosos, tanto para o LA como para o LV. O aumento 
Tabela 29 - Valores da média do $\mathrm{Al}^{+1}$ trocável com o intervalo de confiança a $95 \%$ de probabilidade $(\hat{\mathrm{m}} \pm$ t.s $\hat{\mathrm{m}})$, valor mínimo, máximo e coeficientes de variação nos horizontes dos latossolos.

\begin{tabular}{|c|c|c|c|c|c|}
\hline \multirow[t]{2}{*}{ Horizonte } & \multirow{2}{*}{$\begin{array}{l}N^{o} d e \\
\text { pontos }\end{array}$} & \multicolumn{4}{|c|}{$A I^{++}$trocável $\left(\mathrm{cmol}_{c} \mathrm{~kg}^{-1}\right)$} \\
\hline & & $\hat{\mathrm{m}} \pm t . s \hat{\mathrm{m}}$ & Mínimo & Máximo & $C V(\%)$ \\
\hline \multicolumn{6}{|c|}{ LATOSSOLO AMARELO (AMAZÔNIA) } \\
\hline A & 74 & $2,36 \pm 0,35$ & 0 & 6,1 & 65 \\
\hline $\mathrm{A} / \mathrm{B}$ & 73 & $1,82 \pm 0,29$ & 0,2 & 5,3 & 68 \\
\hline $\mathrm{B} / \mathrm{A}$ & 69 & $1,59 \pm 0,26$ & 0,1 & 4,7 & 69 \\
\hline Bw1 & 68 & $1,49 \pm 0,28$ & 0,1 & 4,6 & 78 \\
\hline Bw2 & 78 & $1,36 \pm 0,28$ & 0,1 & 5,8 & 91 \\
\hline Bw3 & 21 & $1,42 \pm 0,59$ & 0 & 4,8 & 97 \\
\hline \multicolumn{6}{|c|}{ LATOSSOLO VERMELHO AMARELO (AMAZÔNIA) } \\
\hline A & 179 & $1,74 \pm 0,20$ & 0 & 7,4 & 77 \\
\hline $\mathrm{A} / \mathrm{B}$ & 165 & $1,38 \pm 0,18$ & 0 & 8,2 & 87 \\
\hline $\mathrm{B} / \mathrm{A}$ & 158 & $1,09 \pm 0,21$ & 0 & 12,0 & 123 \\
\hline Bwl & 155 & $0,87 \pm 0,16$ & 0 & 7,0 & 119 \\
\hline Bw2 & 180 & $0,86 \pm 0,19$ & 0 & 11,9 & 150 \\
\hline Bw3 & 81 & $0,85 \pm 0,40$ & 0 & 14,9 & 219 \\
\hline \multicolumn{6}{|c|}{ LATOSSOLO VERMELHO AMARELO (CERRADO) } \\
\hline $\mathrm{A}$ & 121 & $0,53 \pm 0,09$ & 0 & 3,0 & 93 \\
\hline$A / B$ & 119 & $0,44 \pm 0,07$ & 0 & 2,8 & 92 \\
\hline $\mathrm{B} / \mathrm{A}$ & 123 & $0,30 \pm 0,06$ & 0 & 2,1 & 119 \\
\hline Bw1 & 119 & $0,20 \pm 0,06$ & 0 & 2,2 & 177 \\
\hline Bw2 & 114 & $0,12 \pm 0,06$ & 0 & 2,3 & 269 \\
\hline$B w 3$ & 27 & $0,24 \pm 0,23$ & 0 & 2,3 & 258 \\
\hline \multicolumn{6}{|c|}{ LATOSSOLO VERMELHO ESCURO (CERRADO) } \\
\hline A & 96 & $0,58 \pm 0,10$ & 0 & 2,1 & 88 \\
\hline $\mathrm{A} / \mathrm{B}$ & 112 & $0,50 \pm 0,08$ & 0 & 3,0 & 91 \\
\hline $\mathrm{B} / \mathrm{A}$ & 121 & $0,35 \pm 0,08$ & 0 & 3,3 & 133 \\
\hline Bw1 & 120 & $0,25 \pm 0,08$ & 0 & 2,7 & 182 \\
\hline $\mathrm{Bw} 2$ & 116 & $0,19 \pm 0,07$ & 0 & 2,4 & 201 \\
\hline Bw3 & 17 & $0,16 \pm 0,17$ & 0 & 1,1 & 224 \\
\hline
\end{tabular}




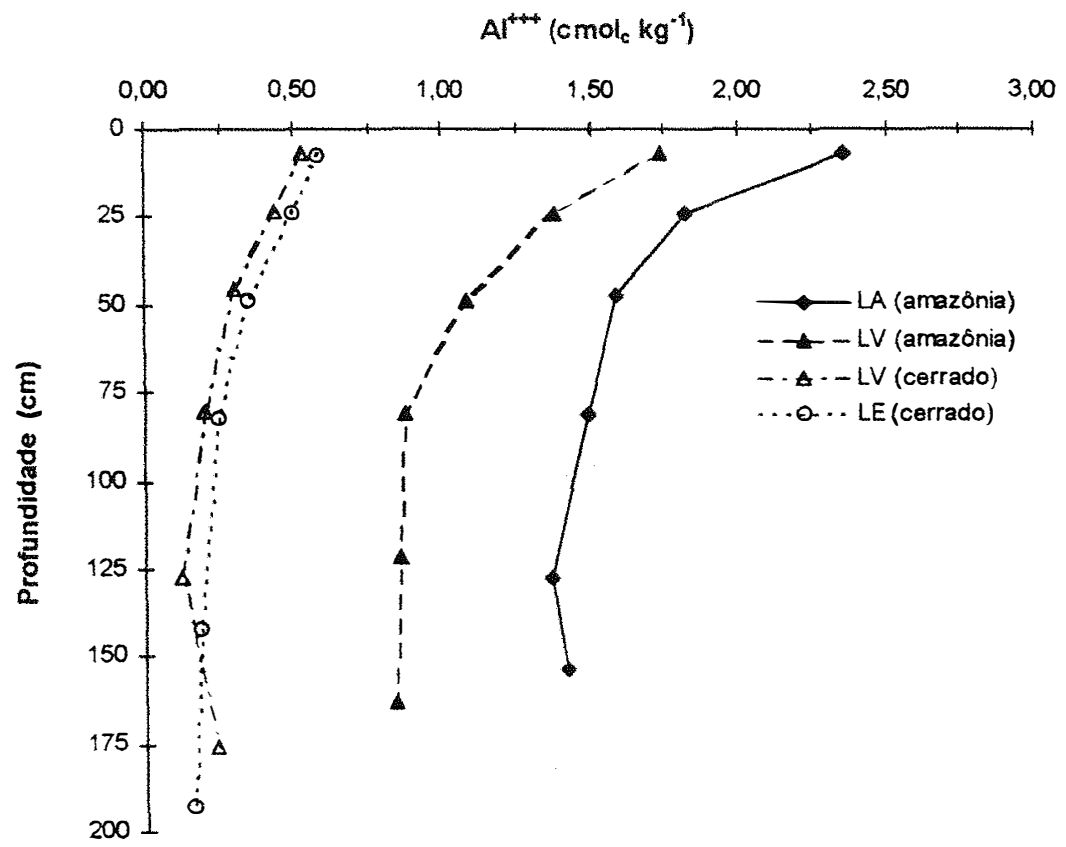

Figura 24 - Distribuição em profundidade dos valores médios dos teores de alumínio dos latossolos.

do teor de argila tende a elevar os teores de caulinita e minerais $2: 1$, conseqüentemente maior fonte de alumínio para a solução do solo. Para o caso dos solos dos Cerrados, tal fato não ocorre justamente devido estes solos serem constituídos por minerais mais resistentes ao intemperismo e terem $\mathrm{pH}$ mais elevados.

A ação do tipo de vegetação no teor de alumínio pode ser constatada principalmente para o LV da Amazônia (Tabela A96, página 182), onde os teores mais elevados são encontrados no tipo de vegetação de Floresta Densa, decrescendo para a Floresta Aberta e com os menores valores na vegetação de transição Floresta Ombrófila/Floresta Estacional.

Quanto às formações geológicas, os solos originados do material da Formação Solimões possuem sempre teores mais elevados de alumínio do que os da Formação Barreiras. Na região dos Cerrados, os menores teores de alumínio localizamse em latossolos recobrindo as formações pré-cambrianas. 
Em relação à precipitação pluviométrica, à medida que ela aumenta, a tendência é a maior liberação de alumínio para os solos de mineralogia instável, como os da Amazônia (Tabelas A98 e A99, página 183), e teores mais constantes, como na região dos Cerrados. Com uma precipitação na faixa de 1500 a $2000 \mathrm{~mm}$, o teor de alumínio no LA e LV para o horizonte A é de 1,40 e $1,30 \mathrm{cmol}_{\mathrm{c}} \mathrm{kg}^{-1}$, respectivamente, passando para 2,73 e $1,86 \mathrm{cmol}_{\mathrm{c}} \mathrm{kg}^{-1}$ para a faixa de 2500 a $3000 \mathrm{~mm}$. Da mesma maneira, à medida que o clima tende a ficar mais seco, há redução no teor de alumínio. Para o caso do horizonte A no clima Afi, os teores de alumínio foram de 3,0 e $2,5 \mathrm{cmol}_{\mathrm{c}} \mathrm{kg}^{-1}$, respectivamente, para o LA e LV, passando para 0,96 e $1,21 \mathrm{cmol}_{\mathrm{c}} \mathrm{kg}^{-1}$ para o clima mais seco Awi, respectivamente, para o LA e LV.

\subsection{9. $\mathrm{CTC}_{7}$ e $\mathrm{CTC}_{\mathrm{e}}$}

Os resultados analíticos dos solos das duas regiões estudadas sobre a $\mathrm{CTC}_{7}$ obtida pela soma das bases, alumínio trocável e acidez indicam (Tabela 30) o seguinte:

- Descréscimo dos valores de acordo com a profundidade para todos os solos (Figura 25).

- Praticamente não há diferenças nos valores para o LA e LV da Amazônia, em torno de $9,5 \mathrm{cmol}_{\mathrm{c}} \mathrm{kg}^{-1}$ para os horizontes A e 3,7 para os horizontes Bw3. O mesmo ocorre para o LV e LE dos Cerrados com valores mais baixos, em torno de 7,0 para horizontes superficiais e 3,2 para os horizontes mais inferiores;

- Os decréscimos dos valores em profundidade estão relacionados ao teor de matéria orgânica, uma vez que o teor de argila aumenta neste sentido;

- Aumento da CTC em relação ao teor de argila (Tabela A101, página 184), porém, sempre maior para os solos da Amazônia. Tal fato, reflete novamente, o menor intemperismo dos solos da Amazônia. 
Tabela 30 - Valores da média da $\mathrm{CTC}_{7}$ com o intervalo de confiança a $95 \%$ de probabilidade ( $\hat{\mathrm{m}} \pm \mathrm{t} . \mathrm{s} \hat{\mathrm{m}})$, valor mínimo, máximo e coeficientes de variação nos horizontes dos latossolos.

\begin{tabular}{|c|c|c|c|c|c|}
\hline \multirow[t]{2}{*}{ Horizonte } & \multirow{2}{*}{$\begin{array}{l}N^{o} \text { de } \\
\text { pontos }\end{array}$} & \multicolumn{4}{|c|}{$C T C_{7}\left(\mathrm{cmol}_{c} \mathrm{~kg}^{-1}\right)$} \\
\hline & & $\hat{\mathrm{m}} \pm t . s \hat{\mathrm{m}}$ & Mínimo & Máximo & $C V(\%)$ \\
\hline \multicolumn{6}{|c|}{ LATOSSOLO AMARELO (AMAZÔNIA) } \\
\hline $\mathrm{A}$ & 74 & $9,48 \pm 1,04$ & 1,20 & 23,50 & 48 \\
\hline $\mathrm{A} / \mathrm{B}$ & 73 & $6,32 \pm 0,62$ & 0,89 & 14,12 & 43 \\
\hline $\mathrm{B} / \mathrm{A}$ & 69 & $5,02 \pm 0,57$ & 0,16 & 17,18 & 48 \\
\hline Bwl & 68 & $4,09 \pm 0,38$ & 1,27 & 8,10 & 39 \\
\hline Bw2 & 78 & $3,59 \pm 0,38$ & 1,13 & 10,31 & 47 \\
\hline Bw3 & 21 & $3,73 \pm 0,85$ & 1,30 & 10,00 & 53 \\
\hline \multicolumn{6}{|c|}{ LATOSSOLO VERMELHO AMARELO (AMAZÔNIA) } \\
\hline A & 179 & $9,57 \pm 0,71$ & 0,75 & 28,15 & 51 \\
\hline $\mathrm{A} / \mathrm{B}$ & 165 & $6,17 \pm 0,43$ & 1,11 & 16,30 & 45 \\
\hline $\mathrm{B} / \mathrm{A}$ & 160 & $4,82 \pm 0,34$ & 1,37 & 13,50 & 46 \\
\hline Bw 1 & 159 & $4,13 \pm 0,28$ & 1,07 & 12,10 & 44 \\
\hline Bw2 & 184 & $3,77 \pm 0,31$ & 0,07 & 14,28 & 56 \\
\hline Bw3 & 82 & $.3,69 \pm 0,48$ & $.0,65$ & 16,56 & 60 \\
\hline \multicolumn{6}{|c|}{ LATOSSOLO VERMELHO AMARELO (CERRADO) } \\
\hline A & 121 & $7,09 \pm 0,92$ & 1,63 & 43,00 & 73 \\
\hline $\mathrm{A} / \mathrm{B}$ & 119 & $5,21 \pm 0,60$ & 1,00 & 26,00 & 65 \\
\hline $\mathrm{B} / \mathrm{A}$ & 123 & $4,06 \pm 0,41$ & 0,80 & 18,00 & 57 \\
\hline Bwl & 119 & $3,40 \pm 0,31$ & 0,74 & 11,00 & 51 \\
\hline Bw2 & 114 & $3,03 \pm 0,31$ & 0,20 & 14,00 & 56 \\
\hline$B w 3$ & 27 & $\ldots \underline{3,14 \pm 0,51}$ & $0, \underline{0,85}$ & 6,04 & 43 \\
\hline \multicolumn{6}{|c|}{ LATOSSOLO VERMELHO ESCURO (CERRADO) } \\
\hline A & 96 & $6,62 \pm 0,61$ & 1,00 & 18,20 & 46 \\
\hline $\mathrm{A} / \mathrm{B}$ & 111 & $5,00 \pm 0,41$ & 1,50 & 10,50 & 44 \\
\hline $\mathrm{B} / \mathrm{A}$ & 120 & $3,82 \pm 0,28$ & 1,40 & 8,00 & 41 \\
\hline Bw 1 & 119 & $3,17 \pm 0,24$ & 0,90 & 7,03 & 43 \\
\hline Bw2 & 114 & $2,71 \pm 0,23$ & 0,90 & 7,10 & 46 \\
\hline Bw3 & 16 & $3,38 \pm 0,75$ & 1,10 & 6,79 & 45 \\
\hline
\end{tabular}




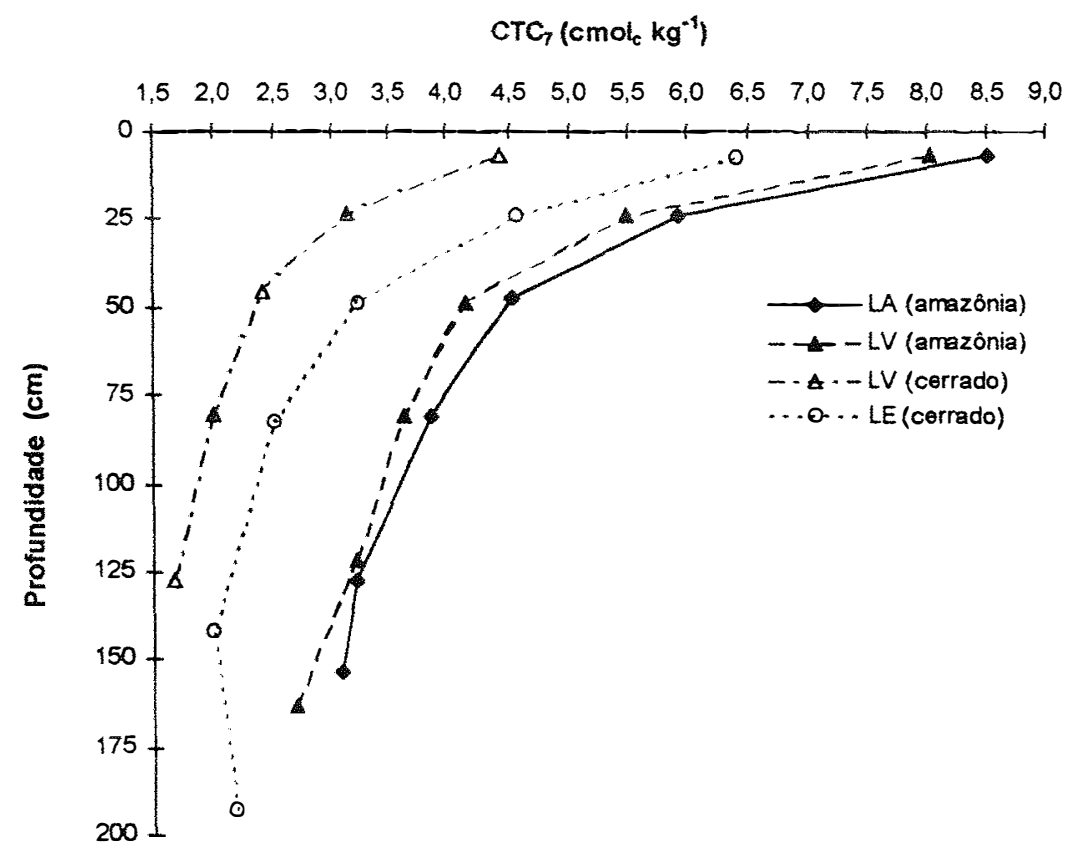

Figura 25 - Distribuição em profundidade dos valores médios da CTC, dos latossolos.

Os valores da CTC da argila podem ser determinados pela dedução da ação da matéria orgânica e tem indicado a mesma seqüência de valores em termos de descréscimo em profundidade e os maiores valores relacionados aos solos da Amazônia. Considerando os solos de textura argilosa e muito argilosa, os valores da CTC da argila para os horizonte Bw1 ficam na faixa de 11,1 e $7,7 \mathrm{cmol}_{\mathrm{c}} \mathrm{kg}^{-1}$ para o LA e LV da Amazônia e 3,9 e 4,8 $\mathrm{cmol}_{\mathrm{c}} \mathrm{kg}^{-1}$ para o LV e LE dos Cerrados respectivamente. Estes resultados podem ser correlacionados com a mineralogia de fração argila (Jackson, 1964; Sánchez 1976). Assim é que valores de 8 a $10 \mathrm{cmol}_{\mathrm{c}} \mathrm{kg}^{-1}$ estão relacionados à dominância de caulinita, 3 a $5 \mathrm{cmol}_{\mathrm{c}} \mathrm{kg}^{-1}$ aos óxidos (Sánchez, 1976). Sendo assim, verifica-se que os solos da Amazônia são constituídos por minerais de argila de maior atividade do que os solos dos Cerrados, comprovando assim, serem eles menos intemperizados.

Outro ponto que vem de encontro com tal afirmação, refere-se à freqüência de ocorrência dos valores da CTC. Tomando-se o último horizonte Bw2, no caso (Tabela A100, página 184), onde a ação da matéria orgânica é pequena, nota-se que 
a freqüência de ocorrência dos solos com CTC superior a $6 \mathrm{cmol}_{\mathrm{c}} \mathrm{kg}^{-1}$ é de $11 \%$ para os solos da Amazônia contra 1,8\% para os solos dos Cerrados.

Em relação aos valores máximos encontrados (Tabela 30), esta tendência também se observa com valores de 10 a $16 \mathrm{cmol}_{\mathrm{c}} \mathrm{kg}^{-1}$ nos solos da Amazônia para os horizontes inferiores contra 6 a $7 \mathrm{cmol}_{\mathrm{c}} \mathrm{kg}^{-1}$ nos solos dos Cerrados.

Como a CTC pode ser influenciada pelo teor e natureza da argila, assim como pelo teor de matéria orgânica, é inevitável a influência do tipo de vegetação na CTC (Tabela A102, página 185). Assim é que os LV da Amazônia apresentam maior valor de CTC em vegetação de Floresta Densa, e tende a decrescer quando em transição de Floresta Ombrófila/Floresta Estacional. Tais variações tendem a decrescer à medida que 0 solo fica mais profundo.

O mesmo raciocínio se aplica às formações geológicas (Tabela A103, página 185). Solos originados da Formação Solimões tendem a apresentar valores mais elevados de CTC do que os solos da Formação Barreiras. Tais diferenças se verificam em todo o perfil do solo.

Quanto à influência climática sobre a CTC, as melhores correlações foram encontradas com as classes de clima e não com a precipitação. Pode-se visualizar na Tabela A105, página , que à medida que o clima tende a ficar menos chuvoso e mais quente, há decréscimo nos valores da CTC. Como exemplo, citam-se os valores do horizonte A para o tipo climático Afi com 10,6 e $9,44 \mathrm{cmol}_{\mathrm{c}} \mathrm{kg}^{-1}$ para o LA e LV, decrescendo para 3,77 e 7,52 $\mathrm{cmol}_{\mathrm{c}} \mathrm{kg}^{-1}$ para o tipo climático Awi.

Outro ponto a ser levado em consideração refere-se à CTC efetiva, ou CTC a pH do solo. Os resultados deste parâmetro (Tabelas 31 e Figura 26) indicam as mesmas tendências do que a CTC a pH 7,0, porém, com valores mais baixos, principalmente para os solos dos Cerrados, inclusive para os solos mais argilosos. Tal fato vem demonstrar que os problemas de lixiviação são mais acentuados na região dos Cerrados do que na Amazônica. 
Tabela 30 - Valores da média da $\mathrm{CTC}_{\mathrm{e}}$ com o intervalo de confiança a $95 \%$ de probabilidade ( $\hat{\mathrm{m}} \pm \mathrm{t} . \mathrm{s} \hat{\mathrm{m}}$ ), valor mínimo, máximo e coeficientes de variação nos horizontes dos latossolos.

\begin{tabular}{|c|c|c|c|c|c|}
\hline \multirow[t]{2}{*}{ Horizonte } & \multirow{2}{*}{$\begin{array}{l}N^{o} d e \\
\text { pontos }\end{array}$} & \multicolumn{4}{|c|}{$\mathrm{CTC}_{e}\left(\mathrm{cmol}_{c} \mathrm{~kg}^{-1}\right)$} \\
\hline & & $\hat{\mathrm{m}} \pm t . s \hat{\mathrm{m}}$ & Minimo & Máximo & $C V(\%)$ \\
\hline \multicolumn{6}{|c|}{ LATOSSOLO AMARELO (AMAZÔNIA) } \\
\hline A & 73 & $3,13 \pm 0,37$ & 0,61 & 7,00 & 52 \\
\hline $\mathrm{A} / \mathrm{B}$ & 72 & $2,24 \pm 0,30$ & 0,43 & 6,10 & 57 \\
\hline $\mathrm{B} / \mathrm{A}$ & 69 & $1,91 \pm 0,26$ & 0,35 & 5,10 & 58 \\
\hline Bw1 & 67 & $1,81 \pm 0,29$ & 0,31 & 5,10 & 67 \\
\hline Bw2 & 77 & $1,65 \pm 0,28$ & 0,33 & 6,30 & 77 \\
\hline $\mathrm{Bw} 3$ & 20 & $1,78 \pm 0,63$ & 0,16 & 4,90 & 80 \\
\hline \multicolumn{6}{|c|}{ LATOSSOLO VERMELHO AMARELO (AMAZÔNIA) } \\
\hline A & 174 & $2,65 \pm 0,25$ & 0,09 & 13,67 & 64 \\
\hline $\mathrm{A} / \mathrm{B}$ & 163 & $1,89 \pm 0,19$ & 0,30 & 8,61 & 66 \\
\hline $\mathrm{B} / \mathrm{A}$ & 158 & $1,46 \pm 0,21$ & 0,12 & 12,56 & 91 \\
\hline Bw1 & 158 & $1,22 \pm 0,17$ & 0,09 & 7,15 & 87 \\
\hline Bw2 & 183 & $1,18 \pm 0,19$ & 0,09 & 12,41 & 110 \\
\hline $\mathrm{Bw} 3$ & 82 & $1,24 \pm 0,41$ & 0,13 & 15,53 & 152 \\
\hline \multicolumn{6}{|c|}{ LATOSSOLO VERMELHO AMARELO (CERRADO) } \\
\hline A & 118 & $1,63 \pm 0,18$ & 0,33 & 5,00 & 61 \\
\hline $\mathrm{A} / \mathrm{B}$ & 117 & $1,04 \pm 0,09$ & 0,23 & 3,47 & 45 \\
\hline $\mathrm{B} / \mathrm{A}$ & 123 & $0,81 \pm 0,08$ & 0,20 & 3,24 & 53 \\
\hline Bw1 & 119 & $0,66 \pm 0,08$ & 0,10 & 3,43 & 70 \\
\hline Bw2 & 114 & $0,56 \pm 0,07$ & 0,10 & 2,67 & 69 \\
\hline $\mathrm{Bw} 3$ & 27 & $0,73 \pm 0,29$ & 0,10 & 3,57 & 107 \\
\hline \multicolumn{6}{|c|}{ LATOSSOLO VERMELHO ESCURO (CERRADO) } \\
\hline A & 94 & $1,52 \pm 0,17$ & 0,20 & 4,20 & 56 \\
\hline $\mathrm{A} / \mathrm{B}$ & 111 & $1,09 \pm 0,12$ & 0,25 & 4,60 & 61 \\
\hline $\mathrm{B} / \mathrm{A}$ & 120 & $0,80 \pm 0,10$ & 0,10 & 3,90 & 68 \\
\hline Bwl & 120 & $0,69 \pm 0,10$ & 0,10 & 3,40 & 79 \\
\hline Bw2 & 116 & $0,59 \pm 0,08$ & 0,03 & 2,80 & 72 \\
\hline Bw3 & 17 & $0,58 \pm 0,24$ & 0,10 & 2,14 & 87 \\
\hline
\end{tabular}




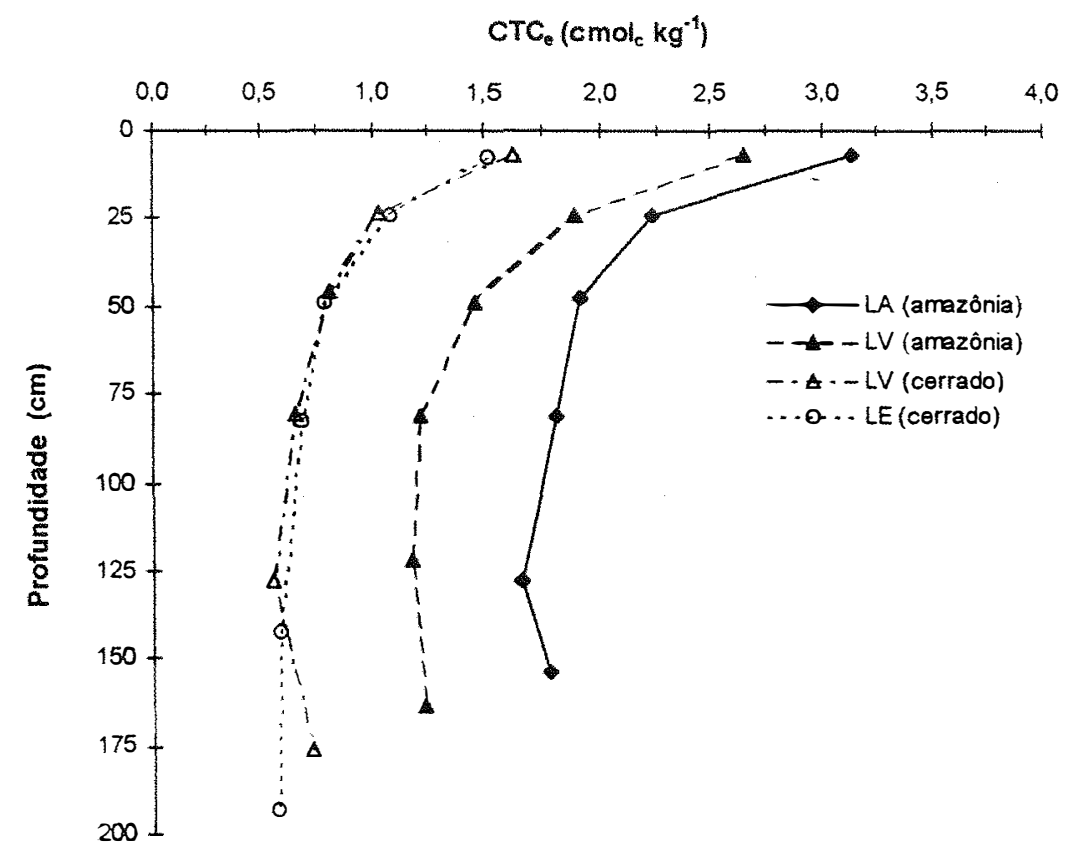

Figura 26 - Distribuição em profundidade dos valores médios da $C_{T} C_{e}$ dos latossolos.

\subsubsection{Saturação por bases ( $V \%)$}

Os resultados relacionados a este parâmetro (Tabela 32) refletem os valores da CTC a pH 7,0 e os teores de bases, já discutidos. Nota-se que para os solos da região amazônica tais valores são inferiores a 10\%, tanto na superfície como na subsuperficie (Figura 27), indicando assim extrema pobreza em bases. Por sua vez, os solos dos Cerrados, indistintamente, apresentam tais valores na faixa de 17 a $20 \%$ nos horizontes superficiais e 14 a $17 \%$ nos horizontes mais inferiores. Apesar de tais valores serem ligeiramente superiores aos solos da Amazônia, eles devem ser interpretados com cuidado. Como já foi salientado, a CTC dos solos dos Cerrados é mais baixa do que a dos solos da Amazônia, e conseqüentemente para o mesmo valor de bases $(\mathrm{Ca}+\mathrm{Mg}+\mathrm{K})$ para ambas as regiões, a saturação por bases será maior nos Cerrados.

Em termos de freqüência de ocorrência (Tabela A106, página 187), notase que $80 \%$ do LA e $68 \%$ do LV da Amazônia apresentam V\% menor do que $10 \%$ no horizonte superficial e $73 \%$ e $63 \%$ respectivamente no horizonte Bw2. Em relação aos 
Tabela 32 - Valores da média da saturação por bases com o intervalo de confiança a $95 \%$ de probabilidade ( $\hat{\mathrm{m}} \pm$ t.s $\hat{\mathrm{m}}$ ), valor mínimo, máximo e coeficientes de variação nos horizontes dos latossolos.

\begin{tabular}{|c|c|c|c|c|c|}
\hline \multirow[t]{2}{*}{ Horizonte } & \multirow{2}{*}{$\begin{array}{l}N^{o} \text { de } \\
\text { pontos }\end{array}$} & \multicolumn{4}{|c|}{ Saturação por bases (V\%) } \\
\hline & & $\hat{\mathrm{m}} \pm t . s \hat{\mathrm{m}}$ & Mínimo & Máximo & $C V(\%)$ \\
\hline \multicolumn{6}{|c|}{ LATOSSOLO AMARELO (AMAZÔNIA) } \\
\hline A & 74 & $9,38 \pm 2,97$ & 1 & 76 & 139 \\
\hline $\mathrm{A} / \mathrm{B}$ & 73 & $7,19 \pm 1,57$ & 1 & 33 & 95 \\
\hline $\mathrm{B} / \mathrm{A}$ & 69 & $7,37 \pm 1,47$ & 1 & 40 & 85 \\
\hline Bw1 & 68 & $8,17 \pm 1,44$ & 2 & 37 & 74 \\
\hline Bw2 & 78 & $8,34 \pm 1,33$ & 1 & 35 & 72 \\
\hline $\mathrm{Bw} 3$ & 21 & $8,97 \pm 2,50$ & 1. & 23 & 65 \\
\hline \multicolumn{6}{|c|}{ LATOSSOLO VERMELHO AMARELO (AMAZÔNIA) } \\
\hline A & 179 & $10,80 \pm 1,80$ & 1 & 83 & 114 \\
\hline $\mathrm{A} / \mathrm{B}$ & 165 & $7,97 \pm 1,18$ & 1 & 63 & 97 \\
\hline $\mathrm{B} / \mathrm{A}$ & 160 & $7,30 \pm 0,89$ & 1 & 42 & 79 \\
\hline Bwl & 159 & $8,41 \pm 0,95$ & 1 & 44 & 73 \\
\hline Bw2 & 184 & $8,56 \pm 0,85$ & 0,9 & 31 & 69 \\
\hline $\mathrm{Bw} 3$ & 82 & $9,31 \pm 1,34$ & 1. & 30 & 67 \\
\hline \multicolumn{6}{|c|}{ LATOSSOLO VERMELHO AMARELO (CERRADO) } \\
\hline A & 121 & $20,42 \pm 3,24$ & 2 & 81 & 89 \\
\hline $\mathrm{A} / \mathrm{B}$ & 119 & $15,52 \pm 2,08$ & 2 & 59 & 74 \\
\hline $\mathrm{B} / \mathrm{A}$ & 123 & $15,72 \pm 2,00$ & 3 & 86 & 72 \\
\hline Bwl & 119 & $16,56 \pm 2,05$ & 2 & 82 & 69 \\
\hline Bw2 & 114 & $17,80 \pm 2,21$ & 3 & 74 & 67 \\
\hline Bw3 & 27 & $17,04 \pm 2,99$ & 4 & 36 & 47 \\
\hline \multicolumn{6}{|c|}{ LATOSSOLO VERMELHO ESCURO (CERRADO) } \\
\hline A & 96 & $17,30 \pm 2,85$ & 2 & 73 & 82 \\
\hline $\mathrm{A} / \mathrm{B}$ & 111 & $13,41 \pm 1,94$ & 2 & 61 & 78 \\
\hline $\mathrm{B} / \mathrm{A}$ & 120 & $13,42 \pm 1,47$ & 2 & 40 & 61 \\
\hline Bwl & 119 & $15,31 \pm 1,63$ & 3 & 48 & 59 \\
\hline $\mathrm{Bw} 2$ & 115 & $16,92 \pm 1,84$ & 3 & 52 & 60 \\
\hline Bw3 & 16 & $14,31 \pm 6,22$ & 3 & 56 & 89 \\
\hline
\end{tabular}




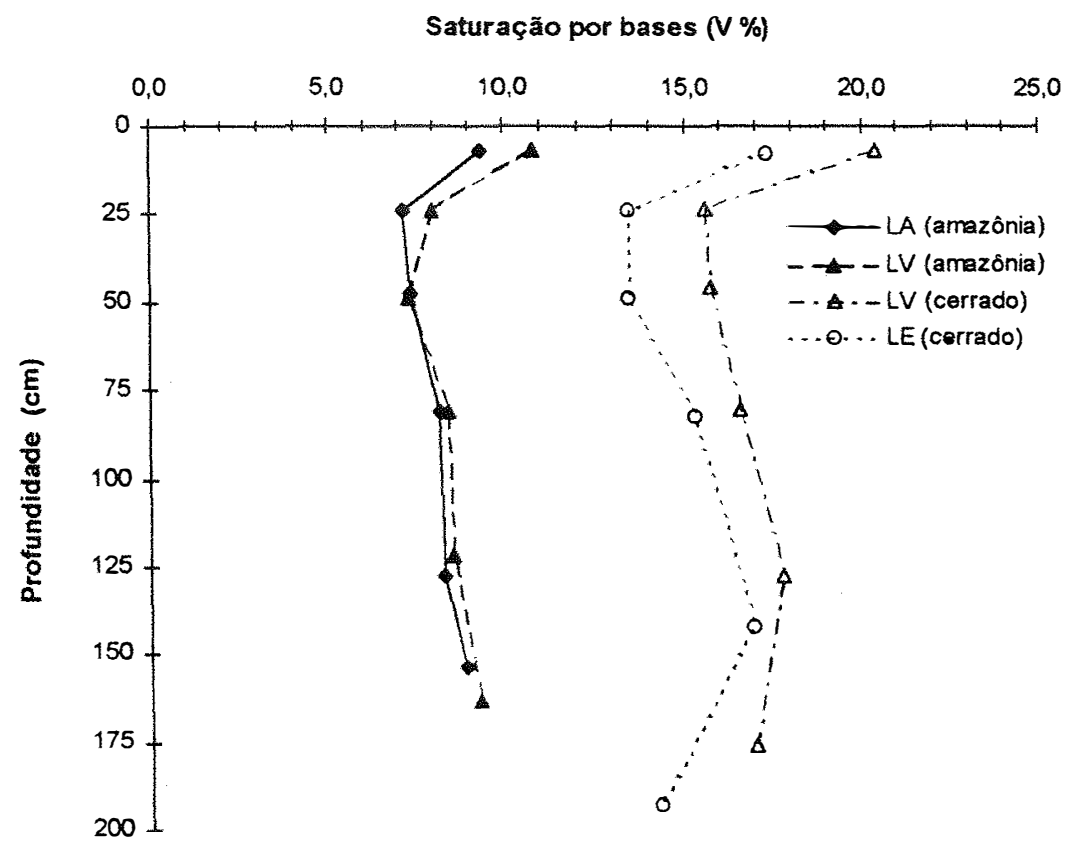

Figura 27 - Distribuição em profundidade dos valores médios da saturação pos bases dos latossolos.

solos dos Cerrados, os valores ficam na faixa de $37 \%$ na superfície, e 18 a $24 \%$ nos horizontes Bw2, respectivamente para LV e LE.

Se considerarmos uma saturação por bases menos limitante para o uso agricola, digamos de 20 a 40\%, nota-se que apenas 3 a $6 \%$ dos solos da Amazônia apresentam nos horizontes superficial e de subsuperfície (Bw2), valores dentro desta faixa, contra $22 \%$ para os horizontes superficiais e $26 \%$ para o Bw2 dos solos dos Cerrados.

É preciso novamente, ter cuidado nesta interpretação, uma vez que os teores de bases dos solos dos Cerrados são tão baixos como os da Amazônia. Como este indice reflete a relação das bases em função da CTC ou seja, de sua mineralogia, as influências da vegetação, geologia e clima se fazem presentes. Considerando os tipos de vegetação (Tabela A108, página 188) e apenas para o LV, nota-se que o índice V é maior para o tipo de vegetação FO/FE e decresce até o FD. Da mesma maneira para o 
LA, a influência do material de origem (Tabela A109, página 188) indica menores valores para a Formação Solimões, quando comparados com os da Formação Barreiras.

A ação do clima na lixiviação é notada nos valores da saturação por bases apresentados nas Tabelas A110 e All 1 (página 189). À medida que aumenta a quantidade de chuva, há uma tendência de decréscimo da saturação por bases, principalmente para os solos da Amazônia.

\subsubsection{Saturação por alumínio $(\mathrm{m} \%)$}

A saturação por alumínio reflete as variações da CTCe e o próprio teor de alumínio. Assim é que, tal saturação é maior nos solos da região amazônica (Tabela 33), na faixa de 64 e $70 \%$ para os horizontes superficiais do LV e LA respectivamente, e 37 e $39 \%$ para o LV e LE dos Cerrados. Nos horizontes mais inferiores, tais valores ficam na faixa de 44 e $63 \%$ para o LA e LV e 14\% para os solos dos Cerrados (Figura 28).

Em termos de freqüência de ocorrência, $50 \%$ do LA e $37 \%$ do LV apresentam saturação de alumínio superior a $80 \%$ nos horizontes superficiais na região amazônica, contra quantidade abaixo de $5 \%$ para os Cerrados. Se levar em consideração os horizontes inferiores, no caso Bw2, tais valores praticamente não mudam, indicando assim sérios problemas relacionados ao alumínio para os solos amazônicos.

Levando-se em consideração o caráter álico para a classificação de solos (Soil Taxonomy, 1975; Camargo et al., 1987), observa-se que grande parte dos LA e LV são álicos, enquanto que os latossolos dos Cerrados são predominantemente distróficos.

Da mesma maneira que houve influência do clima, do material de origem e da vegetação na saturação por bases, há também idêntica influência na saturação por alumínio conforme se verifica nas Tabelas Al14, Al15 (página 191) e Al16 (página 192). 
Tabela 33 - Valores da média da saturação por $\mathrm{Al}(\mathrm{m} \%)$ com o intervalo de confiança a $95 \%$ de probabilidade ( $\hat{\mathrm{m}} \pm$ t.s $\hat{\mathrm{m}}$ ), valor minimo, máximo e coeficientes de variação nos horizontes dos latossolos estudados.

\begin{tabular}{|c|c|c|c|c|c|}
\hline \multirow[t]{2}{*}{ Horizonte } & \multirow{2}{*}{$\begin{array}{l}N^{o} d e \\
\text { pontos }\end{array}$} & \multicolumn{4}{|c|}{ Saturação por Al (m\%) } \\
\hline & & $\hat{\mathrm{m}} \pm t . s \hat{\mathrm{m}}$ & Mínimo & Máximo & $C V(\%)$ \\
\hline \multicolumn{6}{|c|}{ LATOSSOLO AMARELO (AMAZÔNIA) } \\
\hline A & 73 & $70,97 \pm 5,79$ & 0 & 96 & 36 \\
\hline $\mathrm{A} / \mathrm{B}$ & 73 & $75,77 \pm 4,97$ & 0 & 98 & 29 \\
\hline $\mathrm{B} / \mathrm{A}$ & 69 & $77,12 \pm 4,58$ & 0 & 97 & 25 \\
\hline Bw1 & 68 & $75,70 \pm 4,94$ & 0 & 96 & 27 \\
\hline Bw2 & 78 & $74,46 \pm 4,80$ & 0 & 99 & 29 \\
\hline $\mathrm{Bw} 3$ & 21 & $63,01 \pm 15,02$ & 0 & 98 & 35 \\
\hline \multicolumn{6}{|c|}{ LATOSSOLO VERMELHO AMARELO (AMAZÔNIA) } \\
\hline A & 178 & $64,74 \pm 3,86$ & 0 & 96 & 41 \\
\hline $\mathrm{A} / \mathrm{B}$ & 164 & $69,78 \pm 3,76$ & 0 & 97 & 35 \\
\hline $\mathrm{B} / \mathrm{A}$ & 157 & $66,04 \pm 4,49$ & 0 & 97 & 43 \\
\hline Bw 1 & 154 & $58,68 \pm 5,17$ & 0 & 98 & 56 \\
\hline Bw2 & 179 & $55,86 \pm 5,33$ & 0 & 98 & 65 \\
\hline $\mathrm{Bw} 3$ & 80 & $45,32 \pm 8,51$ & 0 & 97 & 86 \\
\hline \multicolumn{6}{|c|}{ LATOSSOLO VERMELHO AMARELO (CERRADO) } \\
\hline A & 121 & $37,04 \pm 4,57$ & 0 & 91 & 69 \\
\hline $\mathrm{A} / \mathrm{B}$ & 119 & $39,99 \pm 4,43$ & 0 & 89 & 62 \\
\hline $\mathrm{B} / \mathrm{A}$ & 123 & $32,39 \pm 4,52$ & 0 & 91 & 79 \\
\hline Bw1 & 119 & $21,79 \pm 4,65$ & 0 & 92 & 119 \\
\hline Bw2 & 114 & $13,58 \pm 4,17$ & 0 & 92 & 167 \\
\hline $\mathrm{Bw} 3$ & 27 & $14,37 \pm 8,57$ & 0 & 77 & 158 \\
\hline \multicolumn{6}{|c|}{ LATOSSOLO VERMELHO ESCURO (CERRADO) } \\
\hline A & 95 & $39,62 \pm 5,09$ & 0 & 88 & 64 \\
\hline $\mathrm{A} / \mathrm{B}$ & 111 & $44,14 \pm 4,52$ & 0 & 92 & 55 \\
\hline $\mathrm{B} / \mathrm{A}$ & 120 & $35,50 \pm 4,69$ & 0 & 88 & 74 \\
\hline Bw1 & 119 & $23,66 \pm 5,12$ & 0 & 93 & 121 \\
\hline Bw2 & 115 & $18,68 \pm 5,01$ & 0 & 92 & 147 \\
\hline Bw3 & 17 & $14,59 \pm 13,31$ & 0 & 83 & 192 \\
\hline
\end{tabular}




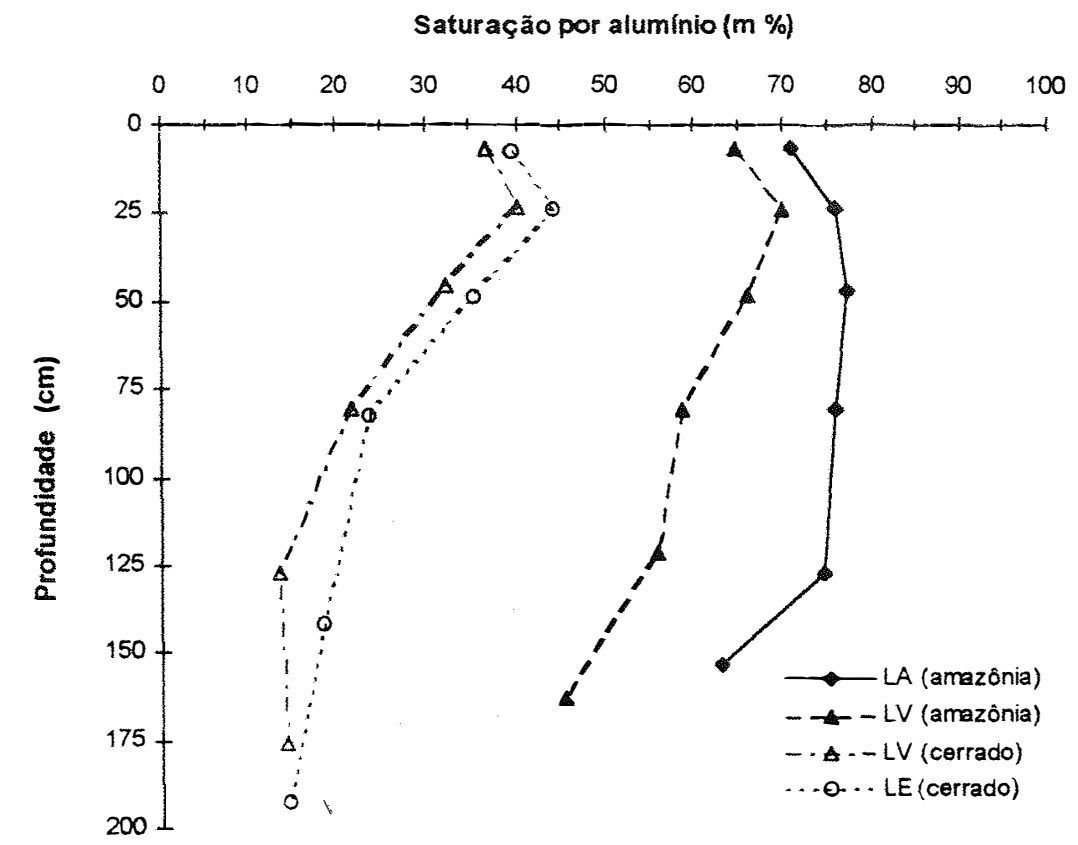

Figura 28 - Distribuição em profundidade dos valores médios da saturação por alumínio dos latossolos.

\subsection{Considerações finais}

Atualmente, a região dos Cerrados tem produzido cerca de $30 \%$ dos grãos do pais, entre eles soja, milho e arroz em áreas tidas no passado como extremamente pobres em fertilidade. A produtividade agrícola nesta região tem sido mais elevada do que a média nacional. $\mathrm{O}$ êxito obtido com a agricultura nesta região se deve a uma série de fatores tais como a proximidade de mercado, a criação de infra-estrutura, as boas condições de topografia que favorecem a mecanização. Entretanto, só foi possível o êxito nesta região com o uso da tecnologia, entre elas a mecanização, o conhecimento climático da região, o desenvolvimento de variedades adaptadas. Por outro lado, tal êxito não teria sido atingido se não tivesse sido efetuado a recuperação química dos solos através do uso de corretivos e fertilizantes. Ultimamente, tem-se investido na irrigação suplementar de diversas culturas possibilitando, dessa forma, o melhor uso do potencial climático da região. 
Em relação a região amazônica vem a questão: "Seria ela viável também para a produção de alimentos assim como a região dos Cerrados?". O trabalho aqui realizado vem responder parcialmente esta questão, uma vez que foi abordado apenas os aspectos climáticos e de solos da região amazônica. Não entrando em considerações de aspectos políticos, da falta de infra-estrutura, de estradas, mercado, fertilizantes, corretivos, etc., pode-se chegar aos seguintes pontos:

- Climaticamente, a região dos Cerrados é caracterizada por ter $95 \%$ de sua área com um clima $\mathrm{Aw}$ e $\mathrm{Cw}$, de período seco bastante prologado o que pode limitar algumas culturas semi-perenes e perenes. Por sua vez, a Amazônia apresenta 52\% deste tipo climático, 28\% coberta pelo clima Ami e o restante pelo Afi. Portanto se for considerado que o ambiente ústico é mais limitante do que o údico e o perúdico para a agricultura, principalmente para culturas semi-perenes e perenes, a região amazônica é menos limitante do que a região dos Cerrados. Quanto a culturas anuais, não há limitações climáticas para ambas regiões, uma vez que o período chuvoso no ambiente ústico é suficiente para o desenvolvimento de culturas.

- Os solos da Amazônia são mais ácidos tanto em superfície como na subsuperfĩcie, apresentam maior teor de Al trocável, porém de CTC mais elevada (Tabela 34). São também deficientes em bases, $\mathrm{Ca}$ e $\mathrm{Mg}$, principalmente. A deficiência em fósforo é mais acentuada nos latossolos dos Cerrado, apesar de que na Amazônia, tal deficiência ultrapassa os $70 \%$ na superficie e $95 \%$ na subsuperficie (Tabela 34 ). Teoricamente, pode-se afirmar que os solos são semelhantes neste aspecto, apesar que as recuperações químicas serão mais onerosas no que concerne ao uso de corretivos (devido ao maior valor da CTC e teores mais elevados de alumínio). Porém, uma vez recuperados quimicamente e devido justamente ao maior valor da CTC, tais solos têm melhores condições de sustentar a sua fertilidade do que os solos dos Cerrados. Portanto, uma vez retirada a mata, não haveria distinção química entre os solos destas duas regiões e as opções de manejo químico para a Amazônia serão os mesmos que para os Cerrados. Sendo assim, a região amazônica pode suportar a produção de alimentos da mesma maneira do que os Cerrados, sob tal ponto de vista. Aliás, 
resultados neste sentido têm sido publicado por diversos pesquisadores, entre eles: Smithy \& Bastos (1984), Smyth \& Cravo, (1989), e mais recentemente numa revisão a respeito, Demattê \& Demattê (1996).

Tabela 34 - Freqüência (\%) de ocorrência dos principais fatores químicos limitantes ao uso agrícola das regiões estudadas.

\begin{tabular}{|c|c|c|c|c|c|c|c|c|c|c|c|c|}
\hline \multirow{3}{*}{ Atributos do solo } & \multicolumn{6}{|c|}{ Amazônia } & \multicolumn{6}{|c|}{ Cerrado } \\
\hline & \multicolumn{3}{|c|}{$A(0-15 \mathrm{~cm})$} & \multicolumn{3}{|c|}{$\begin{array}{c}B / A(35- \\
60 \mathrm{~cm}) \\
\end{array}$} & \multicolumn{3}{|c|}{$A(0-15 \mathrm{~cm})$} & \multicolumn{3}{|c|}{$B / A(35-60 \mathrm{~cm})$} \\
\hline & $L A$ & $L V$ & média & $L A$ & $L V$ & média & $L V$ & $L E$ & medala & $L V$ & $L E$ & medien \\
\hline $\mathrm{pH}<4,5$ & 75 & 70 & 73 & 54 & 43 & 49 & 65 & 11 & 38 & 7 & 4 & 6 \\
\hline Deficiência em $\mathrm{P}\left(<6 \mathrm{mg} \mathrm{kg}^{-1}\right)$ & 71 & 66 & 69 & 97 & 92 & 95 & 99 & 83 & 91 & 100 & 100 & 100 \\
\hline Deficiência em K $\left(<\bullet, 6 \mathrm{cmol}_{\mathrm{c}} \mathrm{kg}^{-1}\right)$ & 65 & 43 & 54 & 100 & 90 & 95 & 62 & 56 & 59 & 100 & 100 & 100 \\
\hline Deficiência em $\mathrm{Ca}\left(<0.6 \mathrm{cmol}_{c} \mathrm{~kg}^{-1}\right)$ & 87 & 81 & 84 & 98 & 96 & 97 & 62 & 61 & 62 & 90 & 92 & 91 \\
\hline Deficiência em $\mathrm{Mg}\left(<0.6 \mathrm{cmol}_{\mathrm{c}} \mathrm{kg}^{-1}\right)$ & 88 & 81 & 85 & 98 & 98 & 98 & 72 & 75 & 74 & 95 & 94 & 95 \\
\hline Alumínio $>1,0 \mathrm{cmol}_{\mathrm{c}} \mathrm{kg}^{-1}$ & 81 & 68 & 75 & 93 & 44 & 69 & 15 & 19 & 17 & 5 & 8 & 7 \\
\hline Aluminio $>2,0 \mathrm{cmol}_{\mathrm{c}} \mathrm{kg}^{-1}$ & 57 & 34 & 46 & 28 & 14 & 21 & 3 & 2 & 3 & 1 & 2 & 2 \\
\hline $\mathrm{CTC}_{7}<4,0 \mathrm{cmol}_{\mathrm{c}} \mathrm{kg}^{-1}$ & 10 & 7 & 9 & 36 & 38 & 37 & 26 & 25 & 26 & 57 & 56 & 57 \\
\hline $\mathrm{CTC}_{7}<8,0 \mathrm{cmol}_{\mathrm{c}} \mathrm{kg}^{-1}$ & 41 & 46 & 44 & 91 & 92 & 92 & $70^{\circ}$ & 65 & 68 & 98 & 99 & 99 \\
\hline CTCe $<1,0 \mathrm{cmol}_{\mathrm{c}} \mathrm{kg}^{-1}$ & 4 & 7 & 6 & 16 & 39 & 28 & 19 & 29 & 24 & 70 & 79 & 75 \\
\hline CTCe $<2.0 \mathrm{cmol}_{\mathrm{c}} \mathrm{kg}^{-1}$ & 32 & 34 & 33 & 70 & 78 & 74 & 79 & 72 & 76 & 98 & 96 & 97 \\
\hline $\mathrm{V}<20 \%$ & 92 & 88 & 90 & 94 & 98 & 96 & 62 & 70 & 66 & 70 & 80 & 75 \\
\hline$V<10 \%$ & 80 & 68 & 74 & 83 & 77 & 80 & 37 & 37 & 37 & 35 & 39 & 37 \\
\hline$m>50 \%$ & 84 & 78 & 81 & 90 & 78 & 84 & 38 & 42 & 40 & 29 & 33 & 31 \\
\hline $\mathrm{m}>80 \%$ & 49 & 37 & 43 & 57 & 42 & 50 & 1 & 5 & 3 & 4 & 5 & 5 \\
\hline $\mathrm{Ca} / \mathrm{CTC}<20 \%$ & 97 & 94 & 95 & 98 & 97 & 98 & 54 & 75 & 64 & 80 & 86 & 83 \\
\hline $\mathrm{Ca} / \mathrm{CTC}<10 \%$ & 83 & 82 & 82 & 91 & 89 & 90 & 23 & 38 & 30 & 10 & 42 & 26 \\
\hline $\mathrm{Mg} / \mathrm{CTC}<10 \%$ & 98 & 92 & 95 & 98 & 99 & 98 & 70 & 71 & 71 & 77 & 75 & 76 \\
\hline $\mathrm{Mg} / \mathrm{CTC}<2 \%$ & 53 & 59 & 56 & 55 & 74 & 64 & 15 & 19 & 17 & 40 & 00 & 20 \\
\hline $\mathrm{K} / \mathrm{CTC}<3 \%$ & 94 & 81 & 87 & 100 & 90 & 95 & 67 & 87 & 77 & 83 & 93 & 88 \\
\hline $\mathrm{K} / \mathrm{CTC}<1 \%$ & 48 & 32 & 40 & 67 & 55 & 61 & 17 & 15 & 16 & 29 & 41 & 35 \\
\hline
\end{tabular}




\section{CONCLUSÕES}

Tendo-se por base os resultados obtidos por este trabalho, pode-se chegar às seguintes conclusões:

a. Quanto ao aspecto granulométrico, os latossolos da Amazônia são mais argilosos e siltosos do que os dos Cerrados. Dentre os latossolos da Amazônia os LV são pouco mais siltosos do que os LA. A presença de um horizonte $A / B$ mais denso, principalmente no LA e com características de encharcamento temporário, reflete uma estrutura menos estável, quando comparada com os solos de Cerrado. Neste particular, o menor teor de ferro no LA não deixa de ser um fator negativo na estabilidade da estrutura.

b. Quanto aos aspectos de fertilidade:

- Os solos da Amazônia comparados com os dos Cerrados são mais ácidos, com maior teor de Al trocável e com maior valor de CTC a pH 7,0. Levando-se em consideração apenas os latossolos da Amazônia, o LV apresenta menor teor de $\mathrm{Al}$ trocável e menor valor de $\mathrm{CTC}$ a pH 7,0.

- Os teores de bases ( $\mathrm{Ca}$ e $\mathrm{Mg}$ ) e de $\mathrm{P}$, estão abaixo do nível crítico para a maioria das culturas para ambas regiões, sendo talvez os principais fatores limitantes a uma agricultura desenvolvida.

- Grande parte dos latossolos amazônicos são álicos, enquanto que os dos Cerrados são predominantemente distróficos.

c. Quanto a influência do material de origem:

- Apesar da região amazônica ser caracterizada por apresentar condições bastante agressivas do clima atual para o intemperismo profundo, há fortes indícios da 
influência do material de origem nas propriedades do solo, tanto para o LA como para o LV. O material de origem da Formação Solimões comparado com o da Formação Barreiras tende a originar solos mais argilosos, mais siltosos e com maior teor de alumínio.

d. Quanto ao potencial da região para a produção de alimentos:

- Tendo-se por base os elementos aqui examinados, pode-se concluir que as diferenças básicas entre os solos da duas regiões se devem a uma melhor estrutura do solo para a região dos Cerrados e a um valor menor da CTC e do alumínio. Por outro lado, uma vez retirada a mata da região amazônica, os fatores limitantes dos solos para ambas regiões são semelhantes, porém mais acentuados na Amazônia. 


\section{REFERÊNCIAS BIBLIOGRÁFICAS}

ADAMOLI, J.; MACEDO, J.; AZEVEDO, L.G.; MADEIRA NETTO, J. Caracterização da região dos Cerrados. In: GOEDERT, W.J. Solos dos Cerrados: tecnologias e estratégias de manejo. Planaltina: EMBRAPA, CPAC; São Paulo: Nobel, 1986. cap. 2, p.33-74.

ALFAIA, S.S.; NOGUEIRA, F.D. Capacidade de troca de cátions da região mineral e orgânica de três solos da Amazônia Central. Ciência Prática, v.9, n.1, p.30-38, 1985.

ALVIM, P. Los trópicos bajos de la America Latina: recursos y ambiente para el desarollo agricola. In: SIMPOSIO SOBRE EL POTENCIAL DEL TRÓPICO BAJO, Cali, 1973. Cali CIAT, 1973. p.43-61.

BAGNOULS, T.; GAUSSEN, F. Les climats biologique et leur classification. Annale Geografique, v.66, n.355, p. 193-220, 1957.

BALDWIN, M.; KELLOGG, C.E.; THORP, J. Soil classification. In: ESTADOS UNIDOS. Department of Agriculture. Soils and men. Washington: USDA, 1938. p.979-1001. (Yearbook of Agriculture)

BEEK, J.; BRAMÃO, L. Nature and geography of South American soils. In: Biogeography and ecology in South America. The Hague: H. Junk, 1969. n.1, p.82-112. 
BENNEMA, J. Oxissolos brasileiros. In: CONGRESSO BRASILEIRO DE CIÊNCIA DO SOLO, 14., Santa Maria, 1974. Anais. Santa Maria: Sociedade Brasileira de Ciência do Solo, 1974. p.7-49.

BENNEMA, J. Report to the government of Brazil on classification of Brazilian soils. Rome: FAO, 1966. 83p.

BENNEMA, J. The red and yellow of the tropical and subtropical uplands. Soil Science, n.95, p.250-257, 1963.

BENNEMA, J. Soils. In: ALVIM, P.T.; KOSLOWSKI, (Coord.) Ecophysiology of tropical crop. New York: Academic Press, 1977. cap. 2, p.29-55.

BENNEMA, J.; CAMARGO, M. Segundo esboço parcial de classificação de solos brasileiros. Rio de Janeiro: Ministério da Agricultura, Divisão de Pedologia e Fertilidade do Solo, 1964. 17p.

BENNEMA, J.; LEMOS, R.C.; VETTORI, L. Latosols in Brazil. In: PROCEEDINGS INTER-AFRICAN SOILS CONFERENCE, 3., Dalaba Guinea,. v. 1, n.50, p.273-281, 1959.

BESOIN, E. Mineralogia de arcillas de suelos. San José: IICA, 1985. 1205p. (Série de Libros y Materiales Educativos, 60).

BIRKELAND, P.W. Soil and geomorphology. New York, Oxford University Press, 1984. 372p.

BRASIL. Ministério da Agricultura Os solos da área Manaus-Itacoatiara. Belém: IPEAN, 1969. 116p.

BRASIL. Serviço Nacional de Pesquisas Agronômicas. Comissão de Solos. Levantamento de reconhecimento dos solos do Estado de São Paulo. Rio de Janeiro, 1960. 634p. (Boletim, 12) 
BRINKMANN, W.L.F.; NASCIMENTO, J.C. de The effect of slash and burn agriculture on plant nutrients in the Tertiary Region of Central Amazonia. Acta Amazonica, v.3, p.55-61, 1973.

BROADBENT, F.E. The soil organic fraction. Advances in Agronomy , v.5, p.153$183,1953$.

BUOL, S.W.; HOLE, S.D.; McCRACKEN, R.J. Soil genesis and classification. Ames: Iowa State University Press, 1973. 306p.

CAMARGO, M.N.; KLANT, E.; KAUFFMAN, J.H. Classificação de solos usada em levantamentos pedológicos no Brasil. Boletim Informativo da Sociedade Brasileira de Ciência do Solo, v.12, n.1, p.11-33, 1987.

CASTRO, A.P. Correlação entre pH e saturação de bases de alguns solos brasileiros. Pesquisa Agropecuária Brasileira, n. 7, p.9-17, 1972.

CFSEMG - COMISSÃO DE FERTILIDADE DO SOLO DO ESTADO DE MINAS GERAIS. Recomendações para o uso de corretivos e fertilizantes em Minas Gerais - $3^{\mathfrak{a}}$ Aproximação. EPAMIG, Belo Horizonte, 1978. 80p.

CLINE, M.G. \& BUOL, S.W. Soils of the Central Plateau of Brazil. Agron. Mimeo. 73-17. Cornell University, Ithaca, N.Y., 1973.

CHAUVEL, A. Contribuição para o estudo da evolução dos latossolos amarelos, distróficos, argilosos na borda do Platô, na região de Manaus: mecanismos de gibbsitização. Acta Amazônica, v. 11, n.2, p.227-245, jun.1981.

CHIBA, M. Report on the Japan-Brazil: technical cooperation for the investigation of soils and fertilizers in the Amazon Region. Tokyo: OTCA, 1970. 87p. 
COELHO, F.J.F.; FERREIRA, H. C.; SILVA, S.B.; RIBEIRO, A.G.; TEREZO, E.F.M. Vegetação: as regiões fitoecológicas sua natureza e seus recursos econômicos. In: BRASIL. Departamento Nacional da Produção Mineral. Projeto RADAMBRASIL. Folha SA.21 Santarém. Rio de Janeiro, 1976. cap.4, p.311-405. (Levantamento de Recursos Naturais, 10).

DEMATTÊ, J.A.M.; ALOISI, R.R.; DEMATTÊ, J.L.I. Seqüência latossolo amarelo podzólico amarelo - areias quartzosas sob material da Formação Barreiras na região de Tucuruí, Estado do Pará. Scientia Agricola, v.51, n.2, p. 345-356, mai/ago. 1994.

DEMATTÊ, J.L.I. Manejo de solos ácidos dos trópicos úmidos: região amazônica. Campinas: Fundação Cargill, 1988. 215p.

DEMATTÊ, J.L.I. Manejo de solos e produtividade agrícola. In: CONGRESSO LATINO AMERICANO DE SOLO, 13., Águas de Lindóia, 1996. Solo-Suelo 96. Campinas: SBCS; SLACS, 1996. Compact disc.

DEMATTÊ, J.L.I; DEMATTÊ, J.A.M. Fertilidade e sustentabilidade de solos amazônicos. In: XXII REUNIÃO BRASILEIRA DE FERTILIDADE E NUTRIÇÃO DE PLANTAS 22., Manaus, Manaus: SBCS,1996. Compact disc.

DIEZ, J.A.; POLO, A.; CERRI, C.; ANDREUX, F. Estudio de la capacidad nutriente de dos oxisoles desarrolados sobre bosque tropical de Amazonia. An. Edafol. Agrobiol., v.48, p.391-402, 1989.

EMPRESA BRASILEIRA DE PESQUISA AGROPECUÁRIA. Centro de Pesquisas pedológicas. Mapa esquemático dos solos das regiões norte, meio norte e centrooeste do Brasil. Rio de Janeiro: Ministério da Agricultura, 1975. 553p. (Boletim Técnico, 17). 
EMPRESA BRASILEIRA DE PESQUISA AGROPECUÁRIA. Serviço Nacional de Levantamento e Conservação de Solos. Sistema brasileiro de classificação de solos. Rio de Janeiro, 1981. 107p.

EMPRESA BRASILEIRA DE PESQUISA AGROPECUÁRIA. Serviço Nacional de Levantamento e Conservação de Solos. Critérios para distinção de classes de solos e de fases de unidades de mapeamento; normas em uso pelo SNLCS. Rio de Janeiro, 1988. 67p. (Documento 11).

' ESTADOS UNIDOS. Departament of Statistics. Soil taxonomy: a basic system of soil classification for making and interpreting soil surveys. Washington: Government Printing Office, 1975. 754p. (Agriculture Handbook, 436).

FALESI, I.C O estado atual dos conhecimentos sobre os solos da Amazônia. Boletim Técnico IPEAN, n.54, p. 17-67, 1972.

FALESI, I.C. Levantamento de reconhecimento detalhado dos solos da Estrada de Ferro do Amapá. Belém: IPEAN,. 1964 (IPEAN. Boletim Técnico, 45).

FALESI, I.C. O estado atual dos conhecimentos sobre os solos da Amazônia Brasileira. Boletim Técnico IPEAN, n.54, p.68-122, 1972a.

FALESI, I.C. Solos da Rodovia Transamazônica. Boletim Técnico IPEAN, n.55, 1972.

FALESI, I.C.; CRUZ, E.S.; PEREIRA, F.B. Os solos da área Manaus-Itacoatiara. Manaus: Sepro, 1969. 117p. (Série Estudos e Ensaios, 1).

FALESI, I.C; SANTOS, W.H; VIEIRA, L.S. Os solos da colônia agrícola de ToméAçu. Belém. IPEAN 1964b. (Boletim Técnico, 44).

FAO. Soil map of the world: South America. Rome, 1971. 165p. 
FASSBENDER, H.W. Química de suelos: con énfasis en suelos de America latina. 4.ed. San José: IICA, 1984. 422p. (Serie de Libros y Materiales Educativos, 24).

FERNANDES, P.E.C.A; PINHEIRO, S. da S.; MONTALVÃO, R.M.G. de; ISSLER, R.S.; ABREU, A.S.; TASSINARI, C.C.G.. Geologia In: BRASIL. Departamento Nacional da Produção Mineral. Projeto RADAMBRASIL. Folha SA.19 Içá. Rio de Janeiro, 1977. cap.1, p.19-123. (Levantamento de Recursos Naturais, 14).

FEUER, R. An exploratory investigation of the soils and agricultural potential of the soils of the future Federal District in the Central Plateau of Brazil. Ph. D. Thesis, Cornell University, Ithaca, N.Y., University Microfilms Publ. 16254.1956, 432p.

FITTKAU, E.J.; KLINGE, H. On biomass and trophic structure of the Central Amazonian rain forest ecosystem. Biotropica v.5, p.2-14, 1973.

GALEZ, A.; JUD, A.S.R.; HERBILLON, A.J. Surface and charge characteristics of selected soils in the tropics. Soil Science Society of America Journal, n.40, p.601608, 1976.

IWASA, Y. Report on the Japan-Tecnical Cooperation to the investigation of soils and clay minerals in the Amazon Region. Tokyo, JICA, p.1-117, 1976.

JACKSON, M.L. Aluminum bondiing in soils: uniflying principle in Soil Science. Soil Science America Proceedings., v.27, n.1, p.1-10, jan/feb. 1963.

JACKSON, M.L. Chemical composition of soils. In: BEAR, F.E. Chemistry of the soil. 2.ed. New York: Reinhold, 1964. p.17-141.

JACKSON, M.L.; TYLER, S.A.; WILLIS, A.L.; BOURBEAU, G.A.; PENNINGTON, R.P. Weathering sequence of clay-size minerals in soils and sediments. J. Phys. Colloidal Chem. v.52, p1217-1260, 1948.

JENNY, H. Factors of soil formation: McGraw - Hill, New York, 281p., 1941. 
JENNY, H. Comparison of soil nitrogen and carbon in tropical and template regions: Missori Agri. Exp. St ${ }^{\mathrm{a}}$ Res. Bull. 765, p. 5-31, 1961.

KELLOGG, C.E. Preliminary suggestions for the classification and nomenclature of Great Soil Group in Tropical and Equatorial Region. In: Commonwealth CONFENCE ON TROPICAL AND SUBTROPICAL SOILS, 1st, 1949.

KELLOGG, C.E.; ORVEDAL, C. Potentialy arable soils of the World. Advances in Agronomy, v.21, p109-170, 1969.

KENG, J.C.V.; UEHARA, G. Chemistry, mineralogy and taxonomy of Oxisols and Ultisols. Soil Crop Science, n.33, p.119-126, 1974.

KITAGAWA, Y.; MOLLER, M.R.F. Clay mineralogy of same typical soils in the brazilian amazon region. Pesquisa Agropecuária. Brasileira, v.14, n.3, p.201-228, 1979

KITTRICK, J.A. Soil mineral in the $\mathrm{Al}_{2} \mathrm{O}_{3}-\mathrm{SiO}_{2}-\mathrm{H}_{2} \mathrm{O}$ systm and a theory of their formation. Clays and Clay Minerals, 17, p.157-167, 1969.

LEPSCH, I.F. Influência do cultivo de Eucalyptus e Pinus nas propriedades químicas de solos sob Cerrado. Revista Brasileira de Ciência do Solo, v.4, p. 103-107, 1980.

LIMA, A.A.C. Características de Latossolos Amarelos da Amazônia brasileira. Piracicaba, 1980. 142p. Dissertação (Mestrado) Escola Superior de Agricultura "Luiz de Queiroz", Universidade de São Paulo.

LINDSAY, W.L. Chemical equilibria in soils. New York: John Wiley, 1979. 449p.

LOPES, A.S. A survey of the fertility status of soils under "cerrado" vegetation in Brazil. Raleigh, North Carolina State University, 1975. 138p. Tese (Mestrado).

LOPES, A.S. Solos sob "Cerrado". Fosfato, Piracicaba: Instituto da Potassa, 1983 $162 p$. 
LOURENÇO, R.S.; MONTALVÃO, R.M.G. de; PINHEIRO, S. da S.; FERNANDES, P.E.C.A.; PEREIRA, E.R.; FERNANDES, C.A.C.; TEIXEIRA, W. Geologia. In Projeto RADAMBRASIL. Folha SA 20 Manaus. Rio de Janeiro, Ministério das Minas e Energia, 1978. v.18, I, 19-164p.

MACEDO, J. Os solos da região dos Cerrados. In: ALVAREZ, V.H.; FONTES, L.E.; FONTES, M.P. (Ed.). O solo nos grandes domínios morfoclimáticos do Brasil e o desenvolvimento sustentado. Viçosa: SBCS/UFV, 1996. p.135-155.

MASS, A. Colonización integral: modelo de un nuevo tipo de colonización incluyendo varios sistemas de uso de la tierra en el Peru. In: REUNIÕN INTERNACIONAL SOBRE SISTEMAS DE USO DE LA TIERRA, Lima, 1974. Lima IICA, 1974 (Informe de Conferencias Curso y Reuniones, 41).

McCALEB, S.B. Genesis of Red-Yellow Podzolic soils. Soil Science Society American Proceedings. v.23, n.2, p.164-168, 1959.

McGEORGE, W.T. The base-exchange properties of soil organic matter. Journal American Society Agronomy, n.23, p.331-336, 1931.

MEKARU, T.; UEHARA, G. Anion adsorption in Ferruginous Tropical. Soil Science Society American Proceedings, n.36, p.296-300, 1972.

MELFI, A.J.; PEDRO, G.; VOLKOFF, B. Natureza e distribuição dos compostos ferriferos nos solos do Brasil. Revista Brasileira de Ciência do Solo, v.3, p.47-54, 1979.

MELFI, A.J.; PEDRO,G. Considerações sobre os mecanismos geoquímicos envolvidos na alteração superficial e sua repartição no Brasil. Revista Brasileira de Geociências, v.8, p.11-22, 1978.

MOHR, E.C.J.; VANBAREN, F.A.; SCHUYLENBORGH, J. Tropical soils: a comprehensive study then genesis. 3.ed. Mouton, 1972. $481 \mathrm{p}$. 
MOLLER, M.R.F.; ARAKI, S. Intersalação de caulinitas separadas de latossolos. Belém: EMBRAPA,CPATU, 1984. 20p. (Boletim Técnico, 61).

MOLLER, M.R.F.; KLAMT, E. Quantificação de caulinita em latossolo por definição de raios-X. Belém: EMBRAPA,CPATU, 1982. 25p. (Boletim de Pesquisa, 39).

MONIZ, A.C.; JACKSON, M.L. Quantitation mineralogical analysis of Brazilian Soils derived from basic rocks and slate. Wisconsin soil Sci. Report, 1967, p.212-248.

MORAES, J.L.; CERRI, C.C.; MELILLO J.M. et al. Soil carbon stocks of the Brazilian Amazon Basin. Soil Sci. Soc. Am.J. 59:244-247, 1995.

MOTHCHI, E.P. Características, gênese e aptidão agrícola de uma sequência de solos no Planalto Central Brasileiro. Porto Alegre, 1977. 107p. Dissertação (Mestrado) Universidade Federal do Rio Grande do Sul.

OLIVEIRA, A.I.; LEONARDOS, O.H. Geologia do Brasil. Rio de Janeiro: Serviço de Informação Agrícola, 1943. 813p.

PARKS, G.A. Aqueous surface chemistry of oxides and complex oxide minerals. Isoeletric point and zero point of charge. Advances in Chemistry Series, n.67, p. 121-60, 1967.

PARTON, W.J.; SCHIMEL, D.S; COLE,C.V.; OJIMA D.S. Analysis of factors controlling soil organic matter levels in Great Plains grasslands. Soil Sci. Soc. Am. J. 51:1173-1179, 1987.

PEREIRA, H.C. A rainfall test for structure of the tropical soils. J. Soil Sci. 7:68-74. 1956.

PEREIRA, L.C. Características químicas de latossolos amarelos da região amazônica brasileira. Piracicaba, 1987. 96p. Dissertação (Mestrado) Escola Superior de Agricultura "Luiz de Queiróz", Universidade de São Paulo. 
PIRES, J.M. Tipos de vegetação da Amazônia. Museu Paraense Emilio Goeldi, n.20, p.170-202, 1973.

QUEIRÓZ NETO, J.P. de 'Solos da região dos cerrados e suas interpretações. Revista Brasileira de Ciência do Solo, v.6, n. 1, p.1-12, 1982.

RAIJ, B. van. A capacidade de troca de cátions das frações orgânica e mineral em solos. Bragantia, v.8, n.28, p.85-115, 1969.

RAIJ, B. van. Determinação do ponto de carga zero em solos. Bragantia, v.18, n.32, p.337-347, 1973.

RAIJ, B. van. Propriedades eletroquímicas de solos. In: SIMPÓSIO AVANÇADO DE QUÍMICA E FERTILIDADE DO SOLO, 1., Piracicaba, 1986. Anais. Campinas: Fundação Cargill, 1986. p.9-41.

RAIJ, B. van; PEECH, M. Eletrochemical properties of some oxisols and alfisols of the tropics. Soil Science Society of America Proceedings, n.36, p.587-593, 1972.

RAIJ, B. van; SACCHETTO, M.T.D.; IGUE, T. Correlações entre pH e o grau de saturação em bases nos solos com horizonte B textural e horizonte latossólico. Bragantia, v.17, n.27, p.193-200, 1968.

RAIJ, B. van; Silva, N.M. da; Bataglia, O.C.; e outros Recomendações de adubação e calagem para o Estado de São Paulo. Boletim Técnico, Instituto Agronômico, n.100, Campinas, 1992. 107p.

RODRIGUES, T.E. Mineralogia e gênese de uma seqüência de solos dos Cerrados no Distrito Federal. Porto Alegre. 1977. Dissertação (Mestrado) Faculdade de Agronomia, Universidade Federal do Rio Grande do Sul..

RODRIGUES, T.E.; MORIKAWA, I.K.; REIS, R.S. DOS; FALESI, I.C. Solos do distrito agropecuário da SUFRAMA. Manaus: IPEAAOC, 1971. 99p. (Série Solos, 1). 
SÁNCHEZ P.A.; BUOL, S.W. Properties of some soils of upper Amazon basin of Peru. Proceedings of the Soil Science Society of America, n.38, p. 11 7-121, 1974.

SÁNCHEZ, P.A.; BUOL, S.W. Características morfologicas químicas y mineralogicas de algunos suelos de la Selva Amazonica Peruana. Lima: Programa Nacional Arroz., 1971. 22p. (Informe Técnico n.56).

SÁNCHEZ, P.A. Properties and management of soil in tropics. New York: John Wiley, 1976. 619p.

SANTOS, W.H.P., FALESI, I.C. Contribuição ao estudo de solos da Ilha de Marajó. Boletim Técnico do IPEAN, n.45, p.55-161, 1964.

SERRÃO, E.A.S.; FALESI, I.C.; VEIGA, J.B.; TEIXEIRA,J.F. Produtivity of cultivated pastures in low fertility soils of the Amazon of Brazil. In: SÁNCHEZ, P.A.; TERGAS, L.E. Pasture prodution in acid soils of the tropics. Cali: CIAT, 1979. p. $195-226$.

SILVA, B.N.R.; ARAUJO,J.V.; RODRIQUES, T.E. Os solos da área Cacau PireraManacapuru. Belém: IPEAN, 1970. 198p. (Solos da Amazônia, v.2, n.3)

SILVA, F.C.F da et al. Vegetação: as regiões fitoecológicas, sua natureza e seus recursos econômicos. Estudo fitogeográfico. In: BRASIL. Departamento Nacional de Produção Mineral. Projeto RADAMBRASIL. Folha SA 19 Içá, Rio de Janeiro, 1977, . cap.4, p.299-393, (Levantamento de Recursos Naturais, 14).

SMYTH, T.; BASTOS, J.B. Alterações na fertilidade em um latossolo amarelo álico pela queima da vegetação. Rev. Brasileira de Ciência do Solo, v.8, p. 127-132, 1984.

SMYTH, T.; CRAVO, M.S. Soil fertily management in oxisols of Manaus. In Trop Soils Thechnical Report. 1989. Nesu-Raleigh, p. 147-154.

SOMBROEK, W.E. Amazon soil: a reconnaissance of the Brazilian Amazon region. Wageningen: Center for Agricultural Publications and Documentations, 1966. 303p. 
SOMBROEK, W.E. Reconnaissance soil survey of the Area Guama-Imperatriz. Belém, FAO/SPVEA, 1962. 54p.

SOUZA, G.A. Estudo comparativo de propriedades de Latossolos do Brasil. Porto Alegre, 1977. 105p. Dissertação (Mestrado) - Universidade Federal do Rio Grande do Sul.

STARK, N. Nutrient cycling: 1. Nutrient distribution in some amazonian soils. Tropical Ecology, v.12, p.24-50, 1971.

THORP, J.; SMITH, G.D. Higher categories of soil classification: Order, suborder, and great soil groups. Journal Soil Science, n.67, p.117-126, 1949.

UEHARA, G.; GILLMAN, G. The mineralogy, chemistry, and physics of tropical soils with variable charge clays. United States of America. Boulder: Westview Press, 1981. 170p. (Westview Tropical Agriculture Series, 4).

VELlOSO, A.C.; LEAL, J.R.; SANTOS, G.A. Ponto de carga zero de latossolos cauliníticos e latossolos gibsíticos sob Cerrado. In: CONGRESSO BRASILEIRO DE CIÊNCIA DO SOLO, 16., São Luiz, 1977. Anais . São Luiz: Sociedade Brasileira de Ciência do Solo, 1977.

VELOSO, H.P; JAPIASSU, A.M.S.; FILHO, L.G.; LEITE, P.F. Vegetação: as regiões fitoecológicas sua natureza e seus recursos econômicos. In: BRASIL. Departamento Nacional da Produção Mineral. Projeto RADAMBRASIL. Folha SB.22 Araguaia e parte da Folha SC.22 Tocantins. Rio de Janeiro, 1974 . cap.4, p.1-119. (Levantamento de Recursos Naturais, 4).

VERDADE, F.C. Análise química total. In: MONIZ, A.C., (Coord.), Elementos de pedologia. São Paulo: EDUSP, 1972. p. 200-209. 
VIANA, C.D.B.; ARAÚJO, J.V.; SOUZA, L.F.P. DE; CARVALHO, A.L. de. Pedologia. In: BRASIL. Departamento Nacional da Produção Mineral. Projeto RADAMBRASIL. Folha SA.21 Santarém. Rio de Janeiro, 1976. cap.3, p.201-303. (Levantamento de Recursos Naturais, 10).

VIEIRA, L.S.; SANTOS, P.C.C. dos. Amazônia: seus solos e outros recursos naturais. Belém: Faculdade de Ciências Agrárias do Pará, 1988.

VIEIRA, L.S.; SANTOS, W.H. dos; FALESI, I.C. Levantamento de reconhecimento dos solos da Região Bragantina. Boletim Técnico IPEAN, n.47. 1967.

VIEIRA, L.S.; VIEIRA, M.N.F.; CHAVES, R. de S.; MARTINS, P.F. da S.; SANTOS, P.T.C. dos Os solos das áreas de campos da regiāo Bragantina, Estado do Pará. Belém: Faculdade de Ciências Agrárias do Pará, 1982. 65p. (Informe Técnico, 8).

VOLKOFF, B.; CERRI, C.C. Húmus em solos da floresta amazônica na região do Rio Madeiras. Revista Brasileira de Ciência do Solo, v.5, p.15-21, 1981.

VOLKOFF, B.; MATSUI, E.; CERRI, C.C. Discriminação isotópica do carbono nos humus de latossol e podzol da região amazônica do Brasil. In: COLÓQUIO REGIONAL SOBRE MATÉRIA ORGÂNICA DO SOLO, Piracicaba, 1982. Anais. Piracicaba: CENA/PROMOCET, 1982. p.147-153.

WANBEKE, A.R. van Criteria for classifying soils by age. Journal Soil Science. V.13, p.124-32, 1962.

WEAVER, R.M. Soils of the central plateau of Brazil: Chemical and mineralogical properties. New York, Ithaca, Cornell University. Agronomy. 45p. 1974

WUTKE, A.C.P.; CAMARGO, O.A. de. Adsorção e troca iônica. In: MONIZ, A.C. Elementos de pedologia. Rio de Janeiro: Livros Técnicos e Científicos, 1975. p.122-147. 
APÊNDICE 


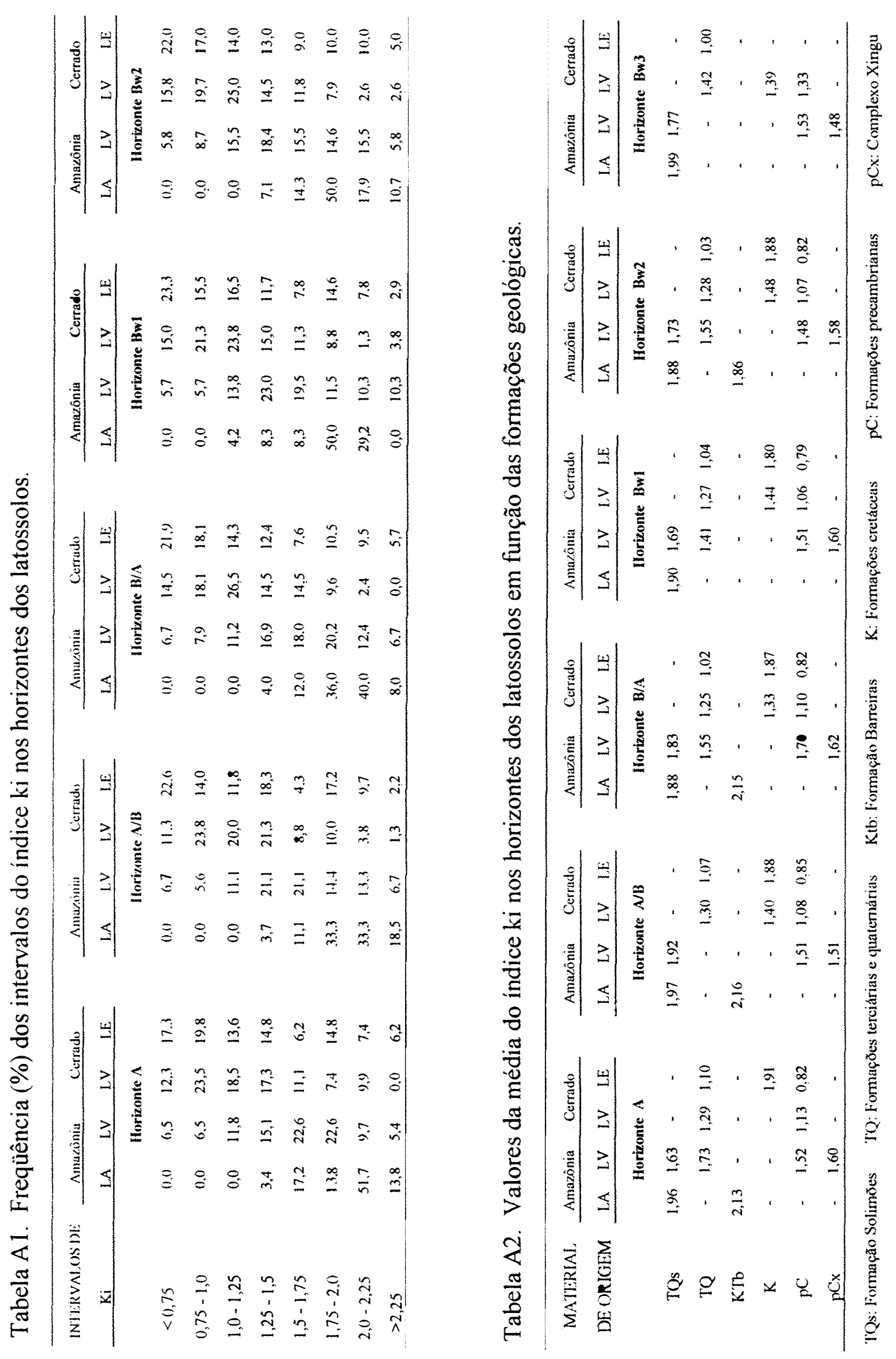

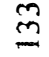



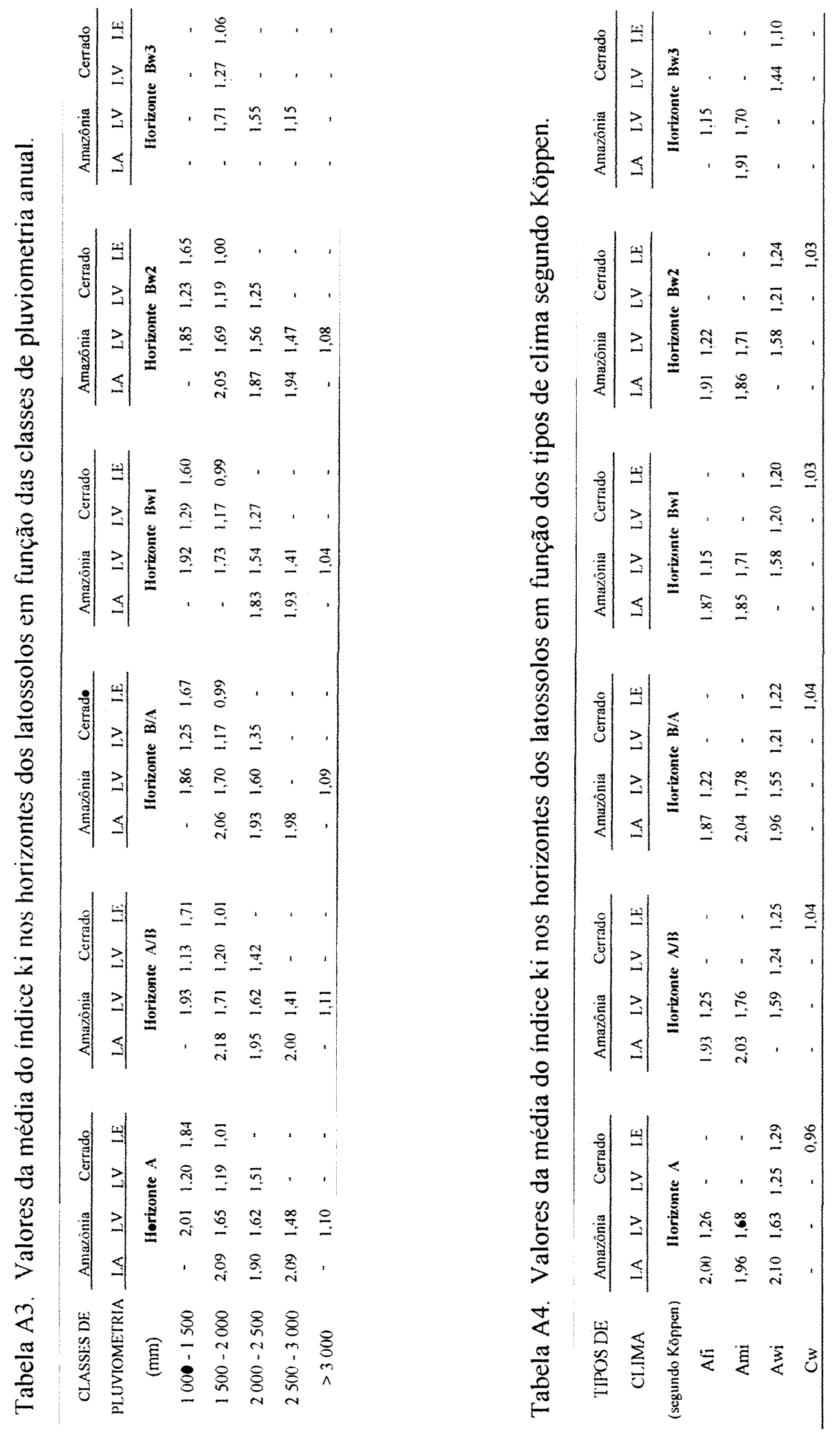

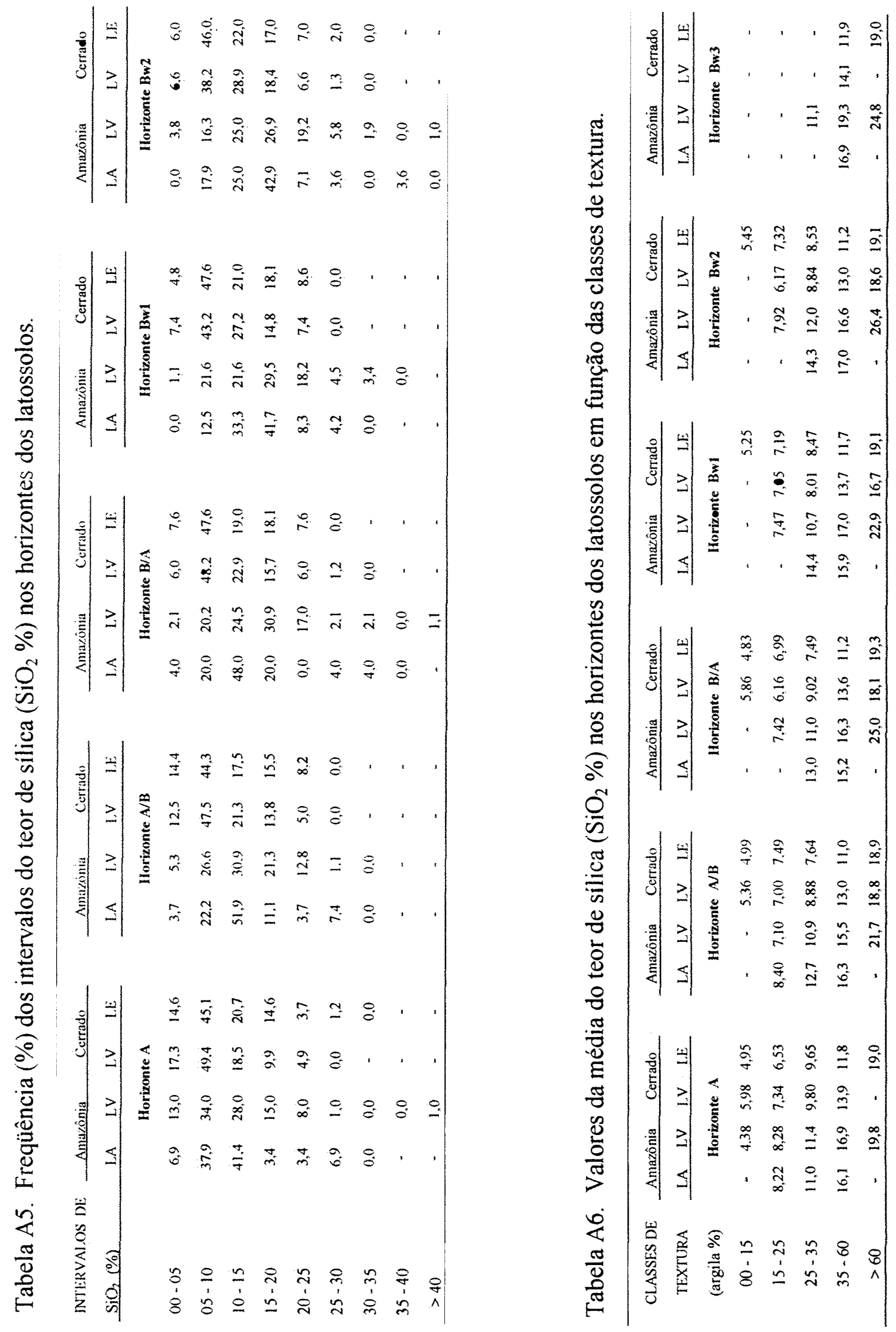

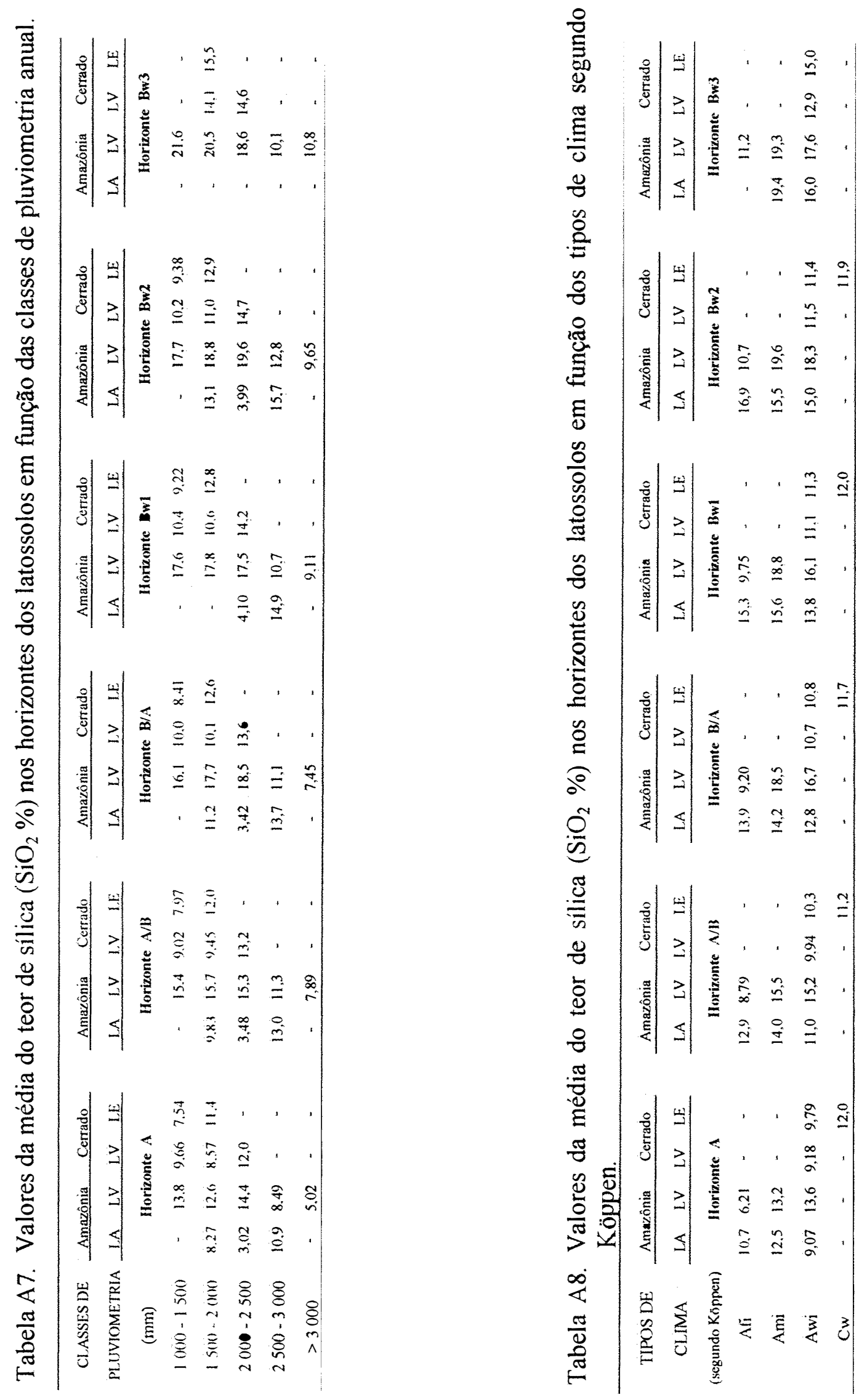

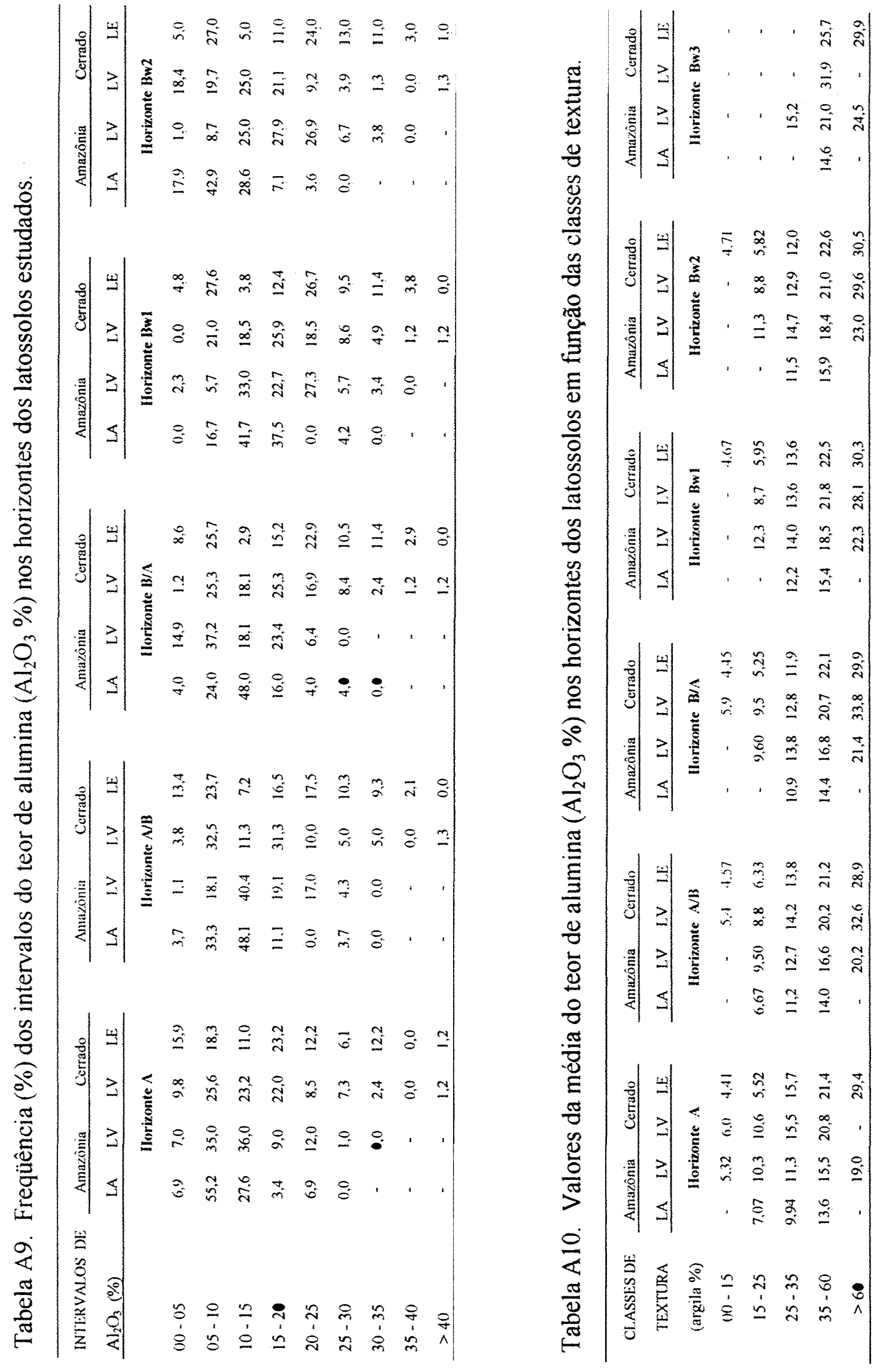


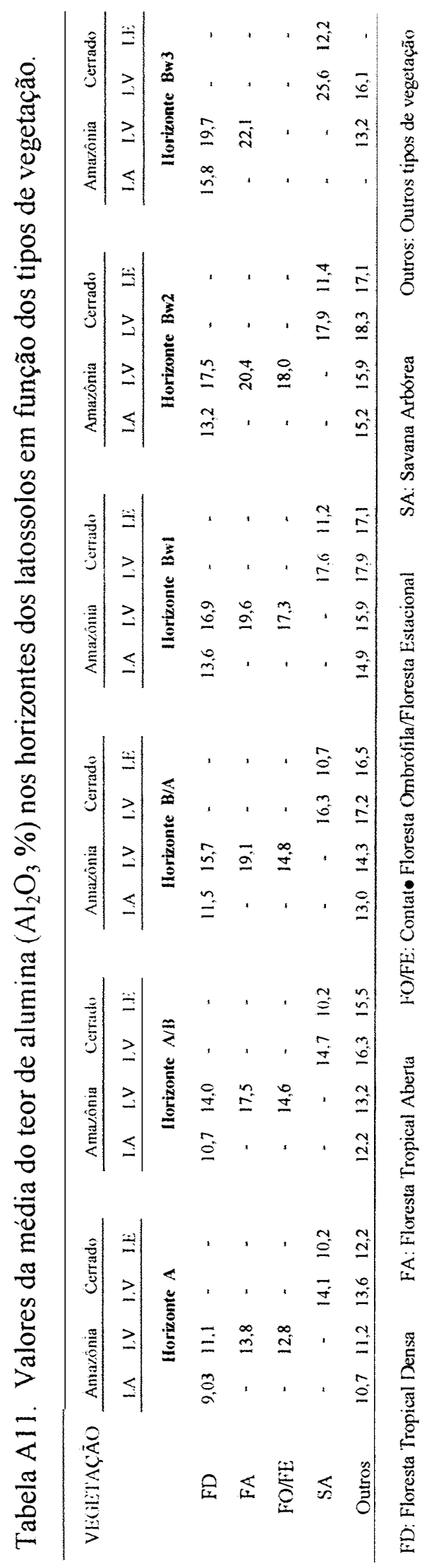

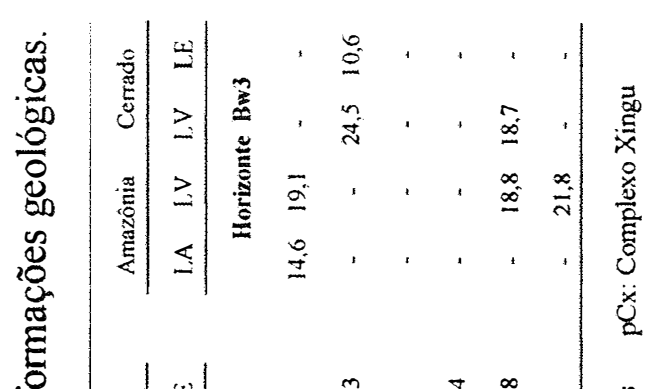

$\stackrel{\infty}{2}$

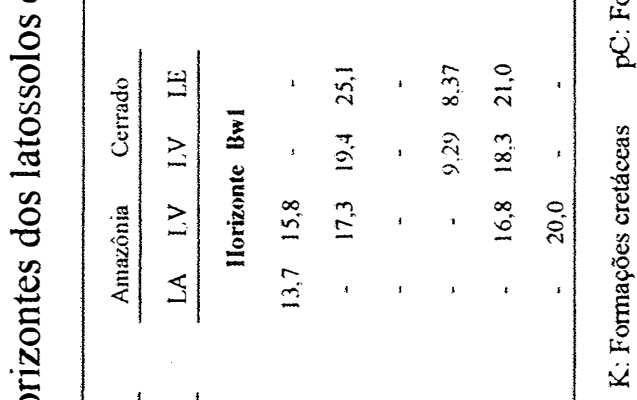

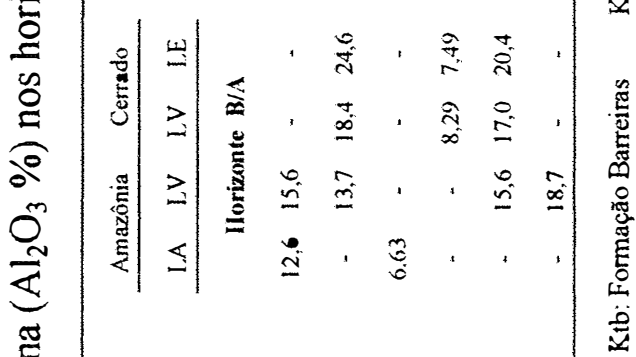

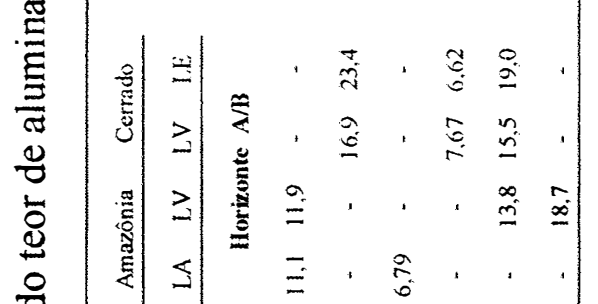

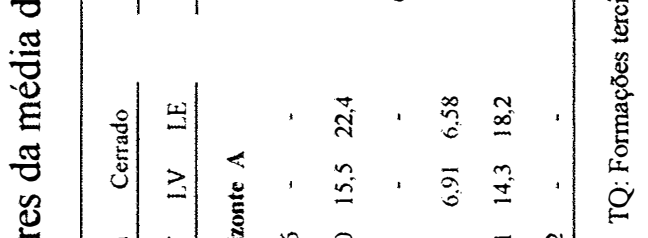

党

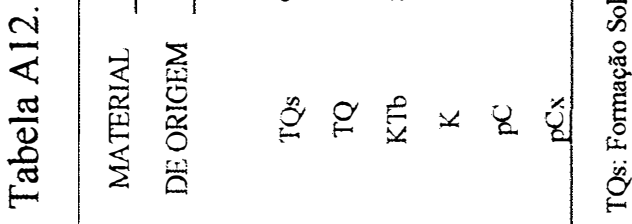



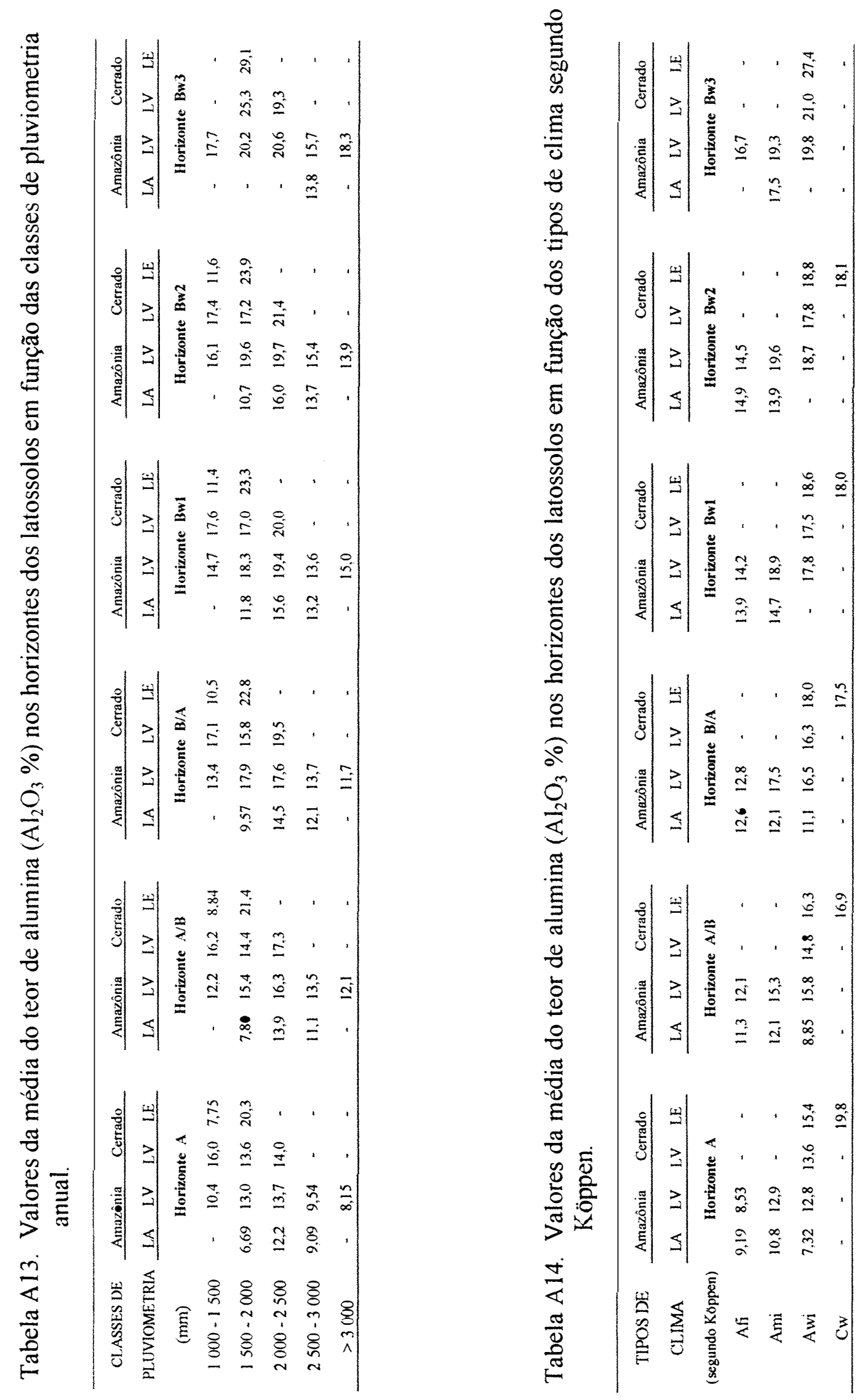


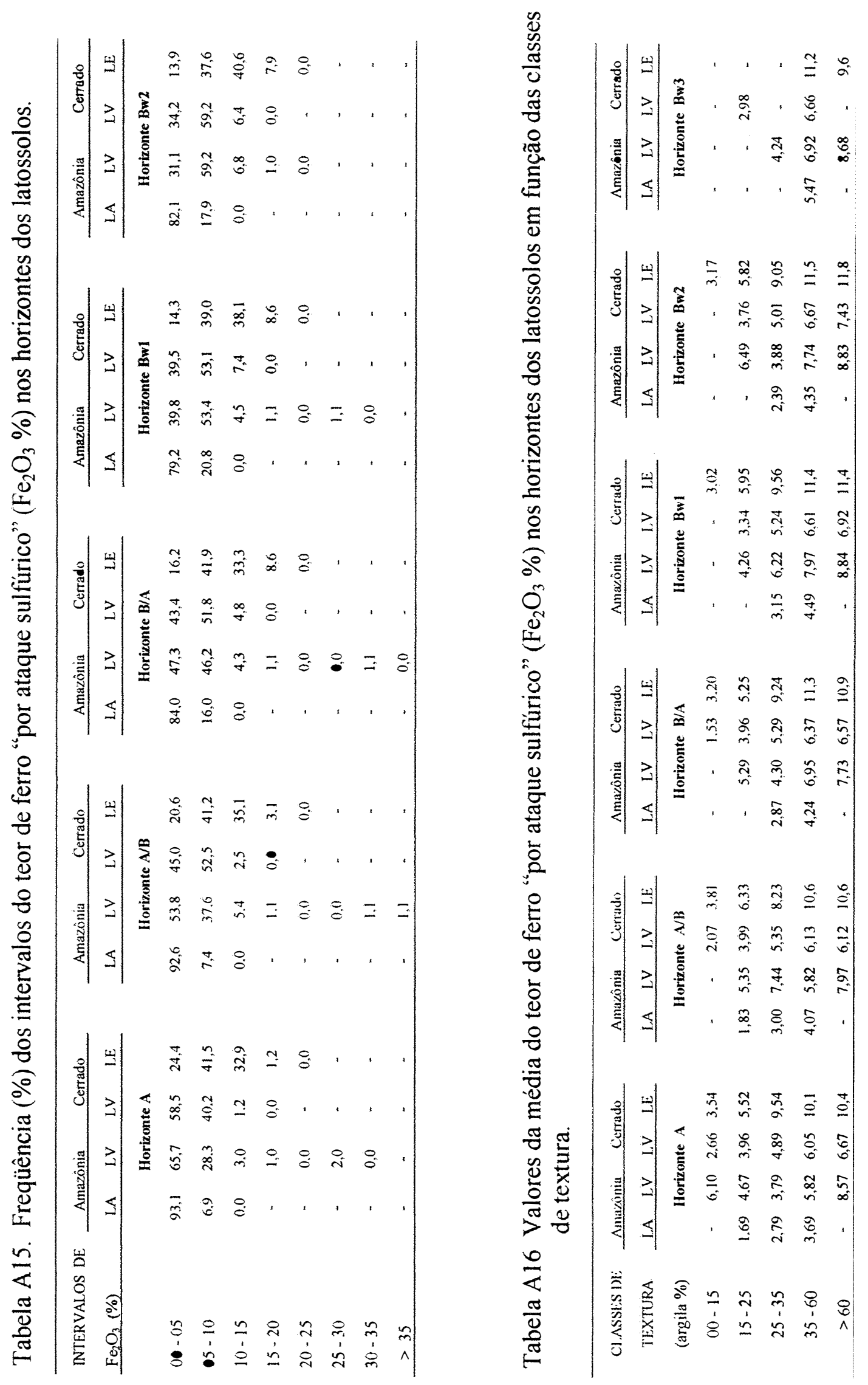




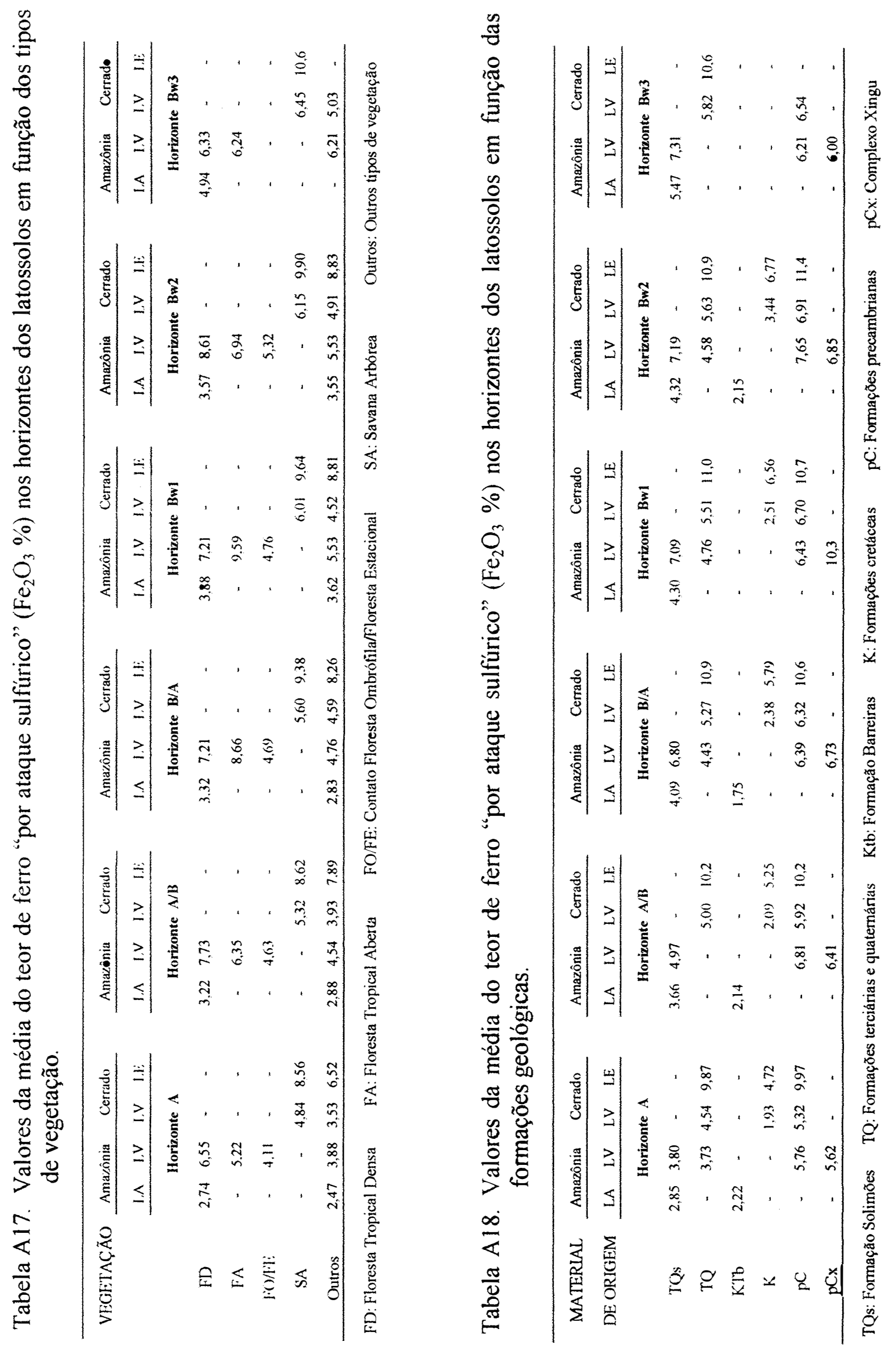



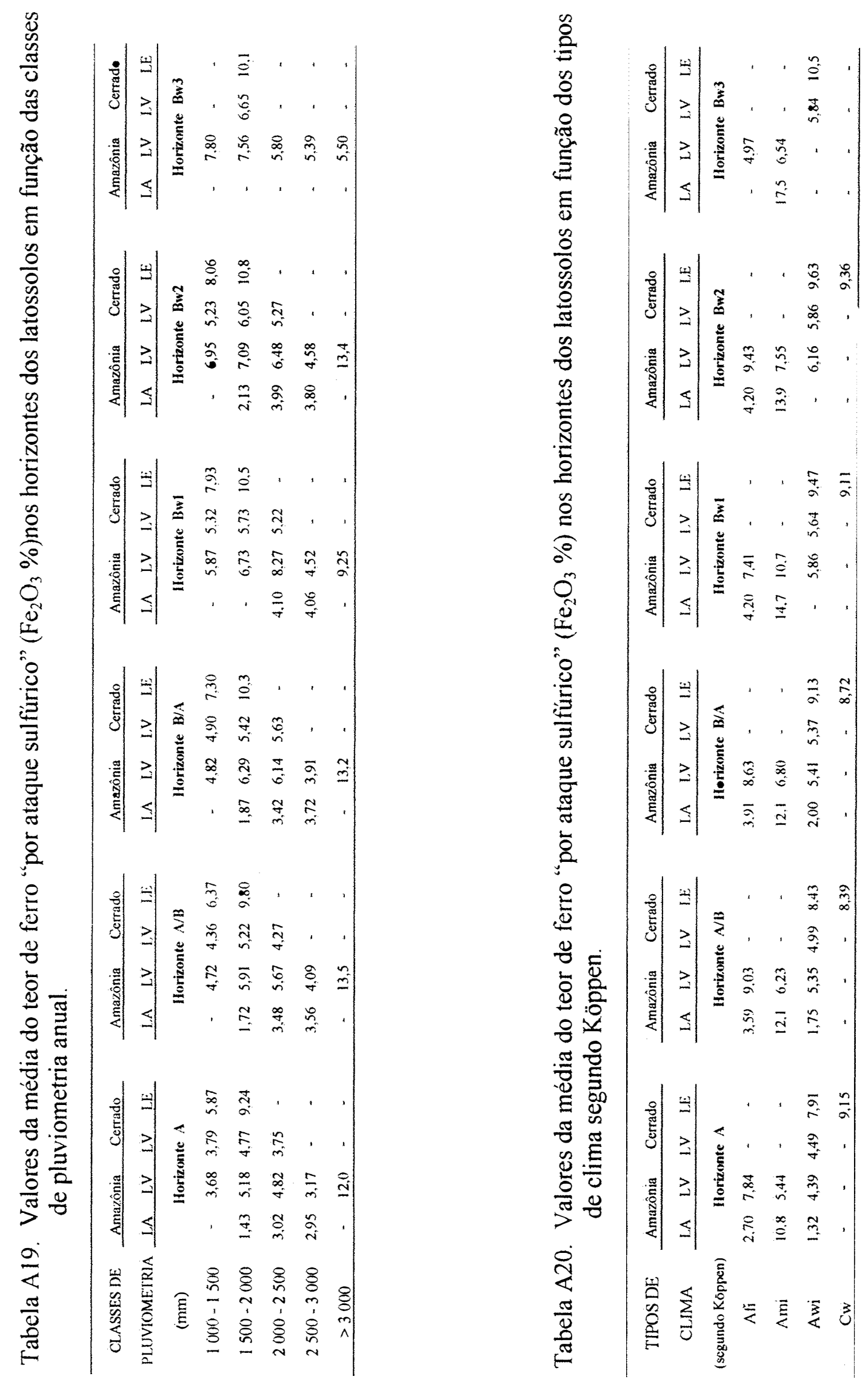


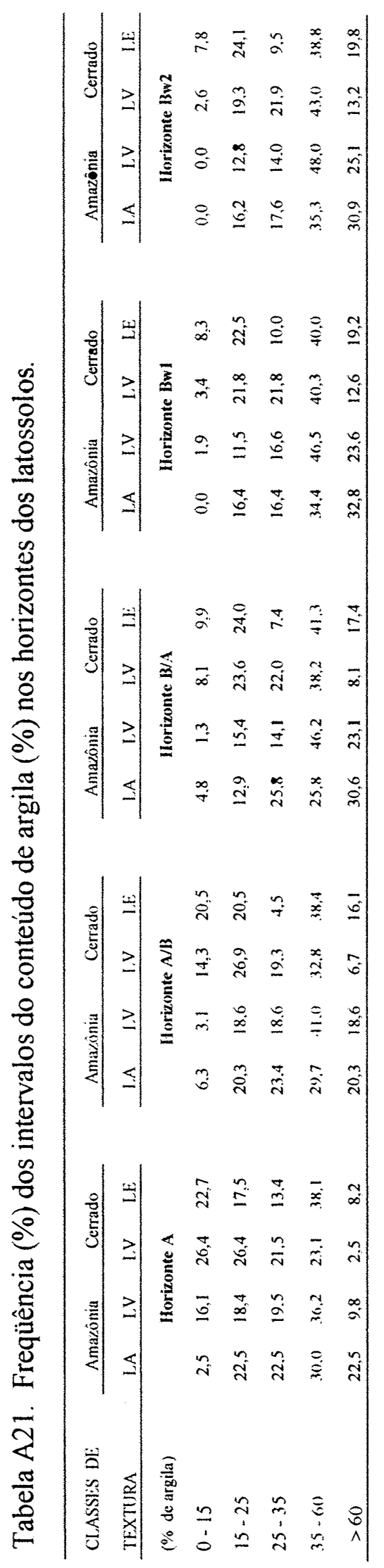




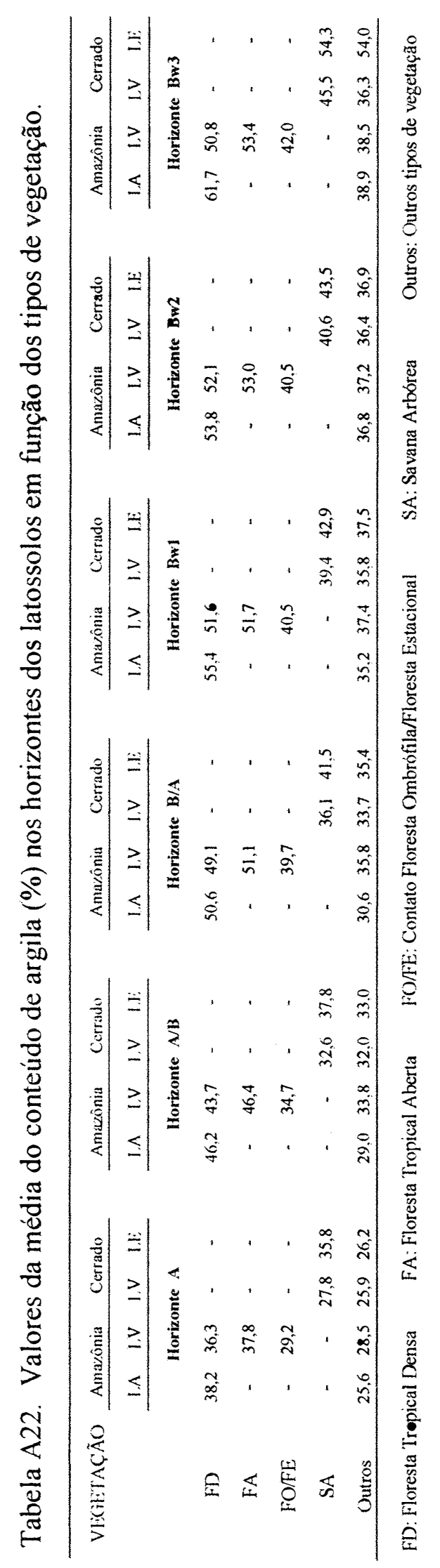

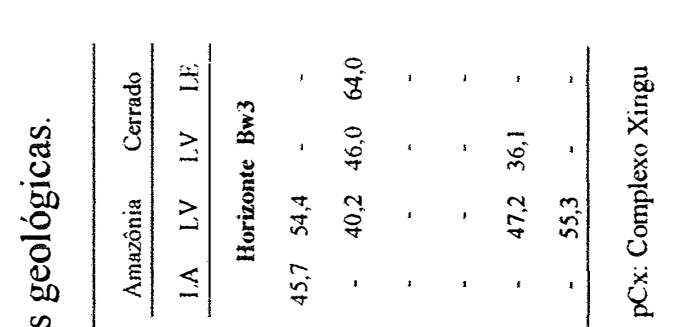

造

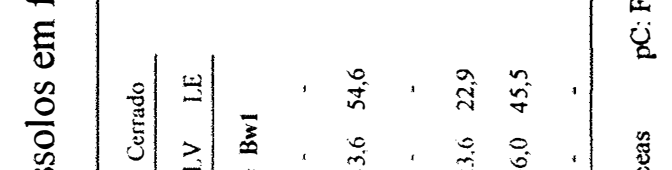

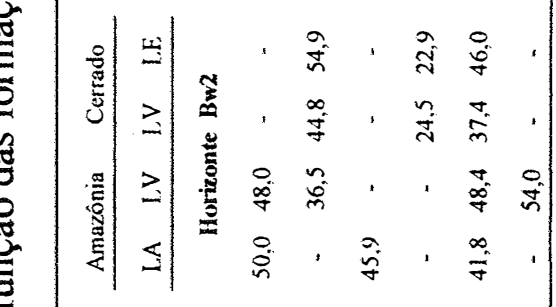

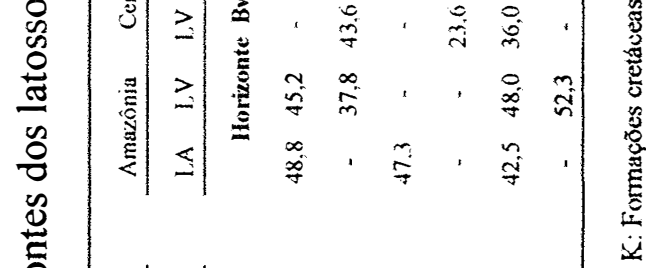

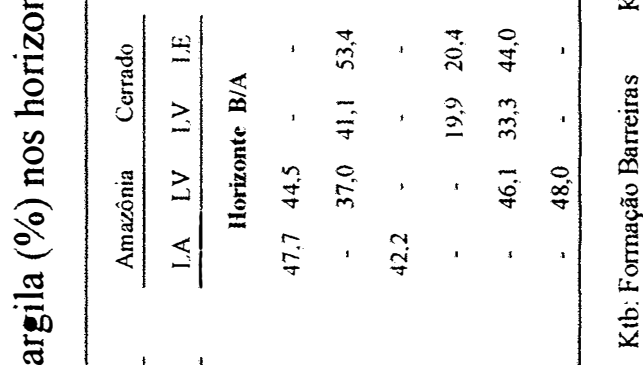

8

$\frac{8}{7}$

氖

용

:

용

$\frac{\sqrt{2}}{\frac{\pi}{5}}$

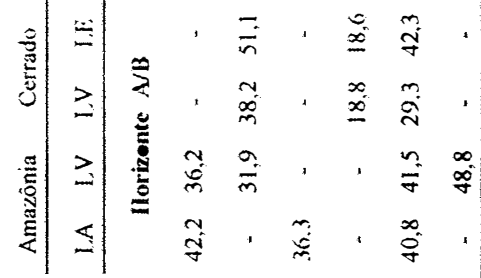

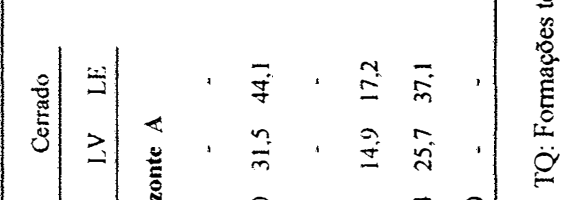

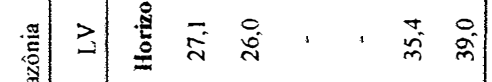

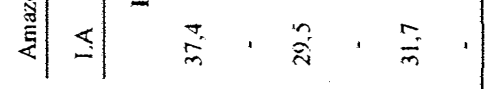

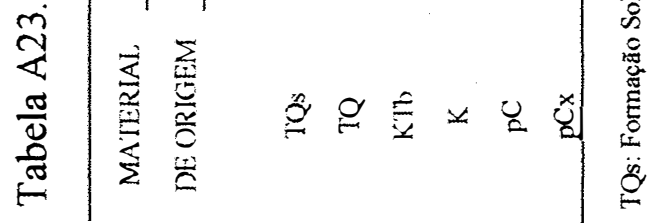



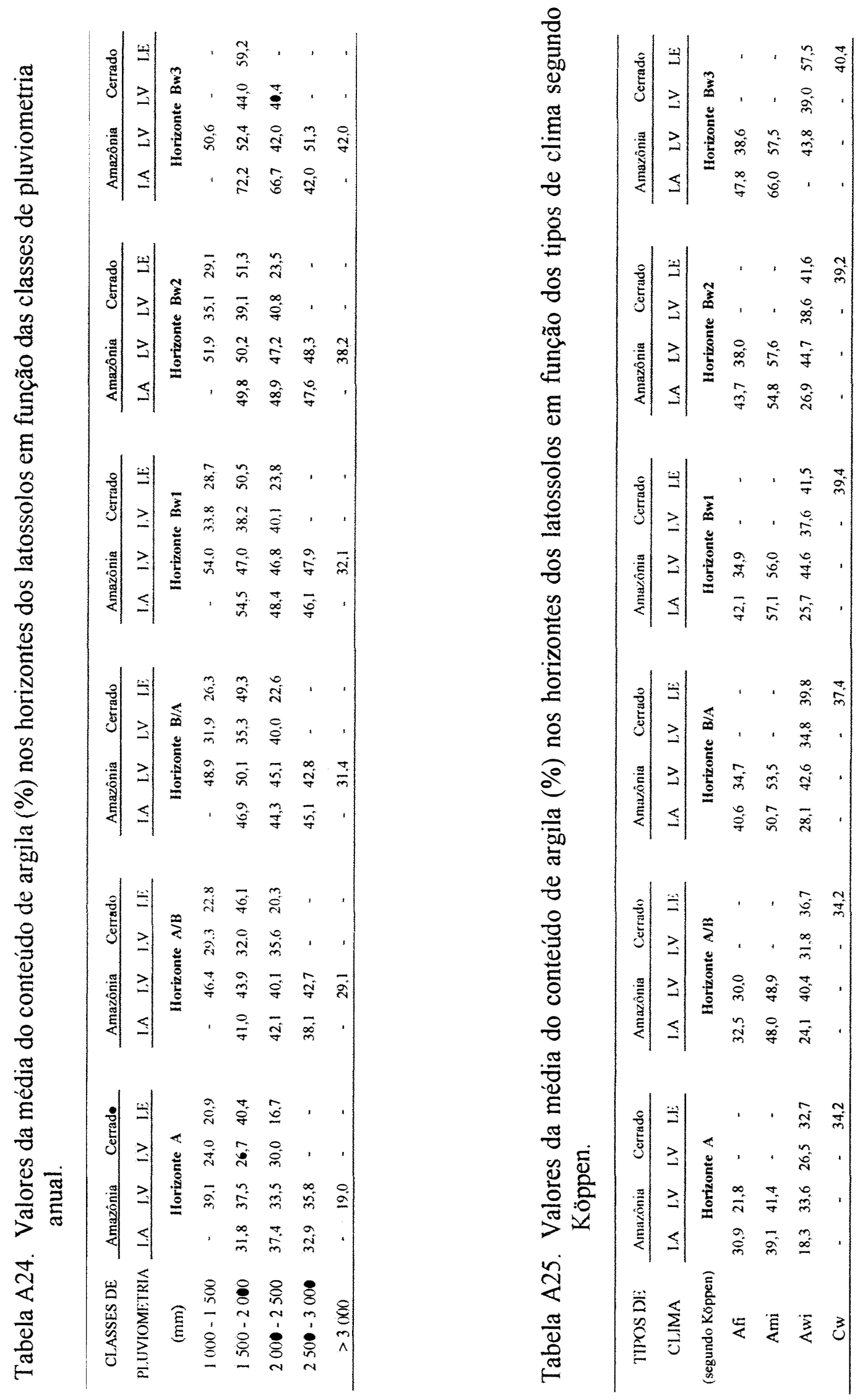

里 


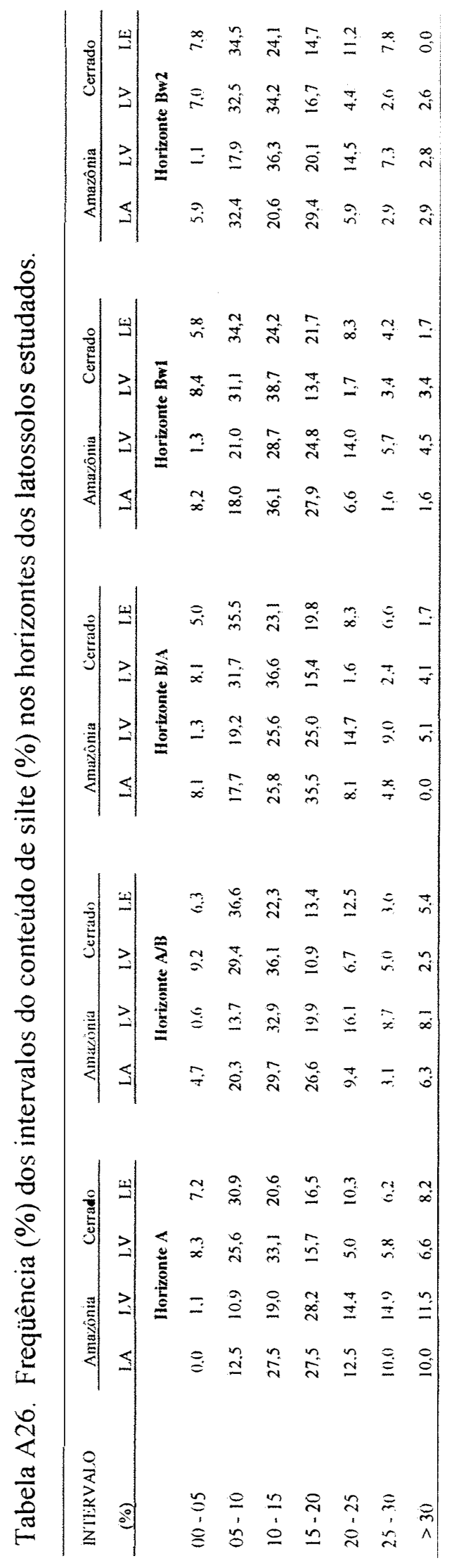

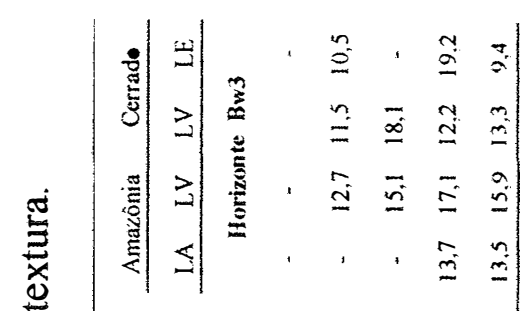

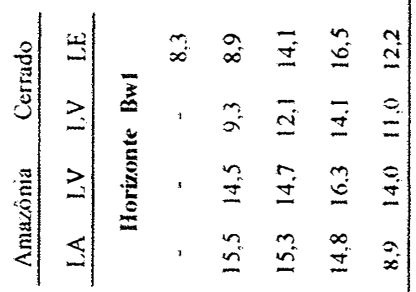

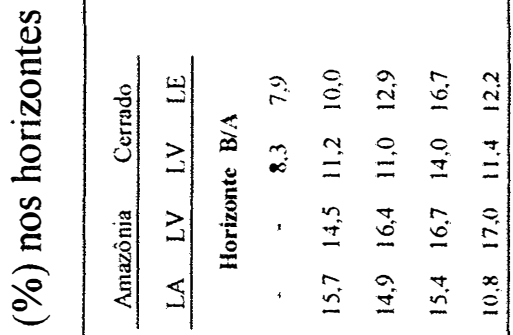

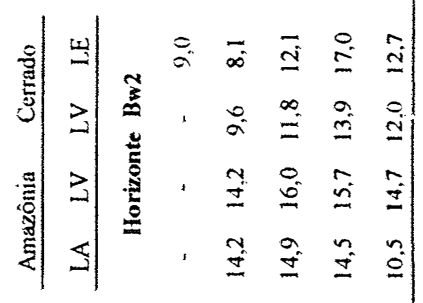

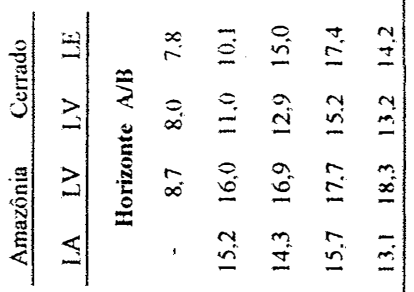

네

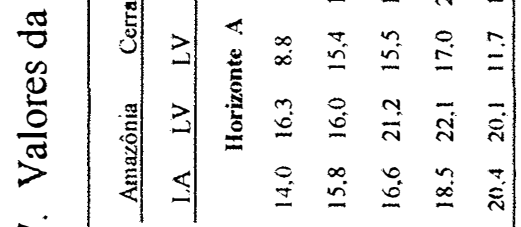

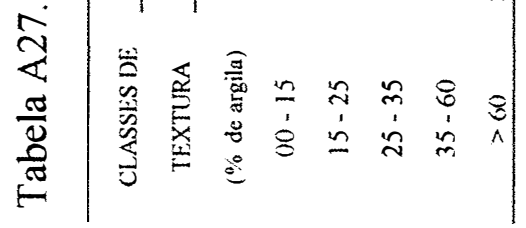



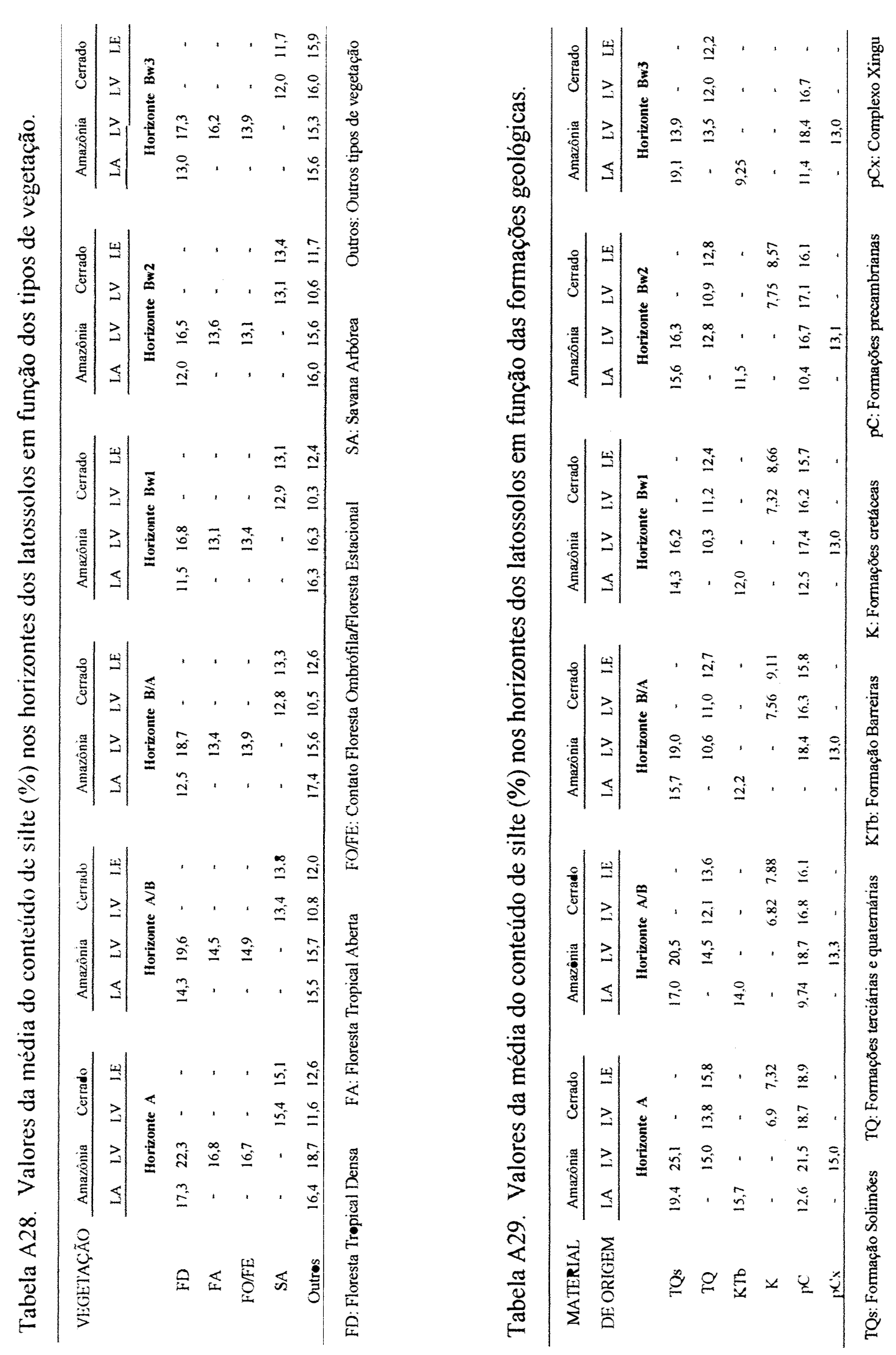

$\pm$ 

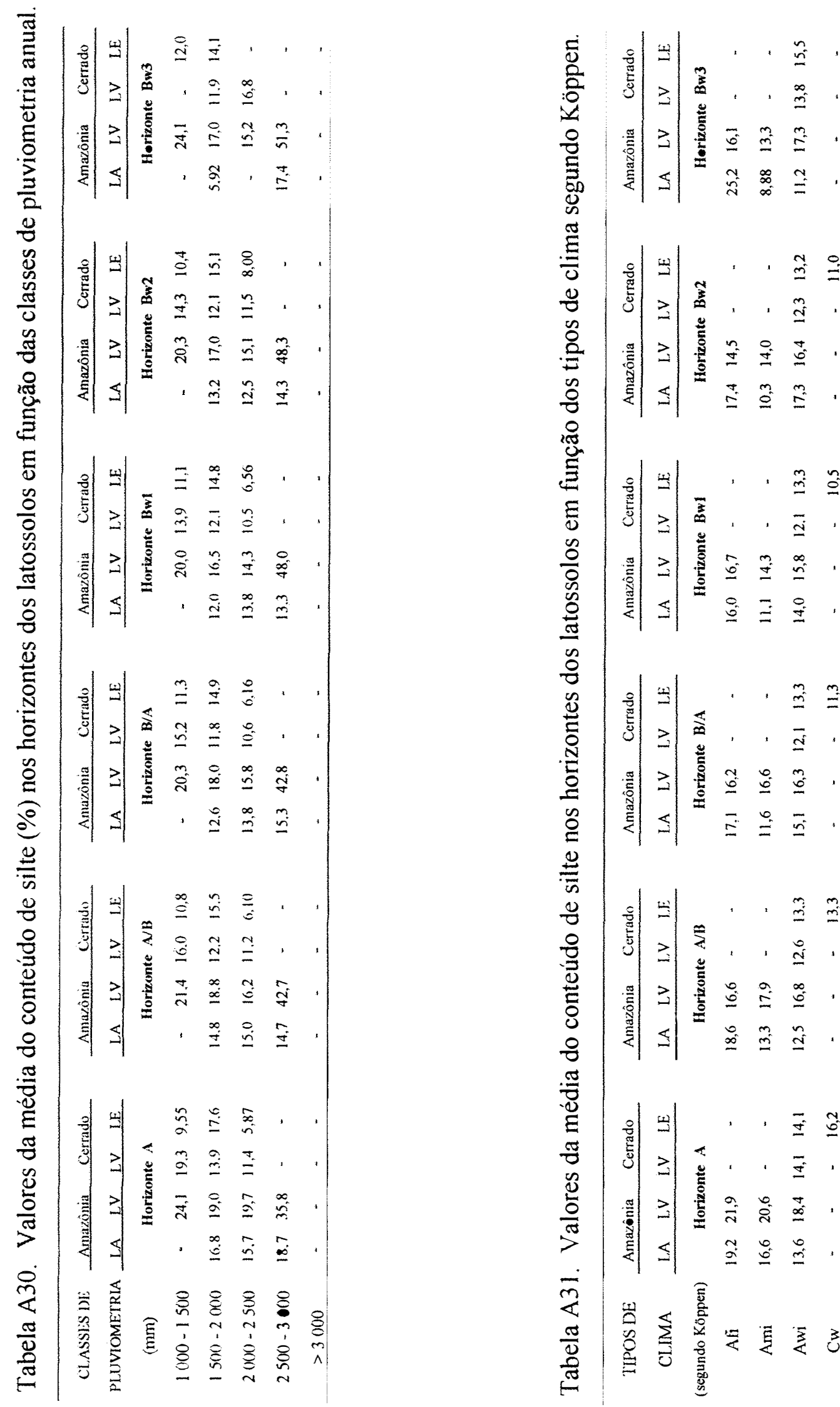

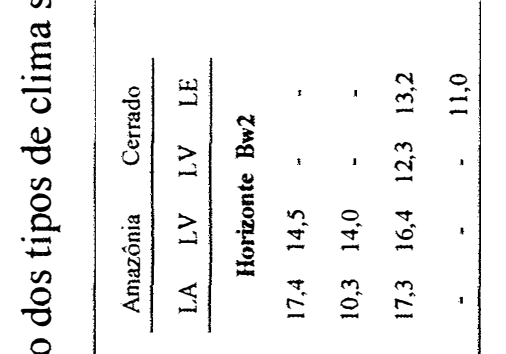

裉

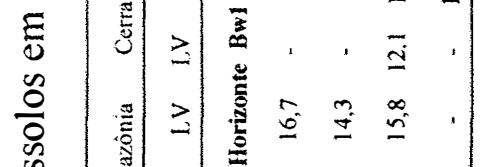

总

号

总

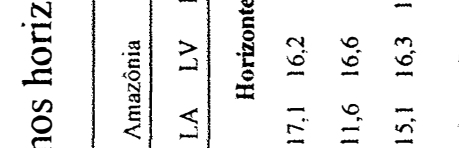

唄

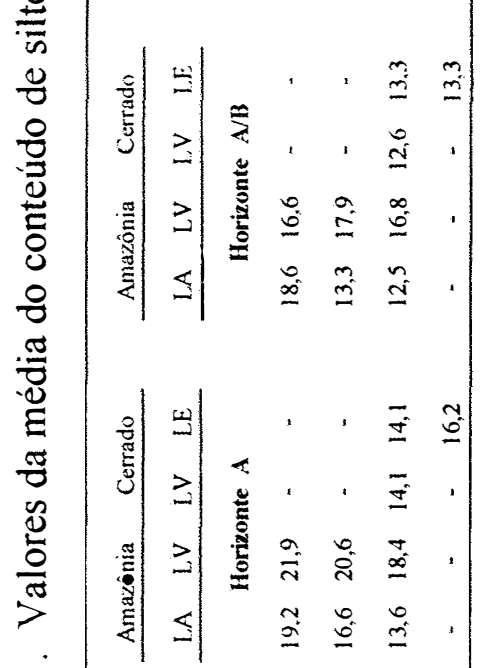

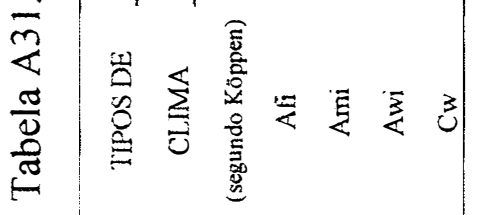



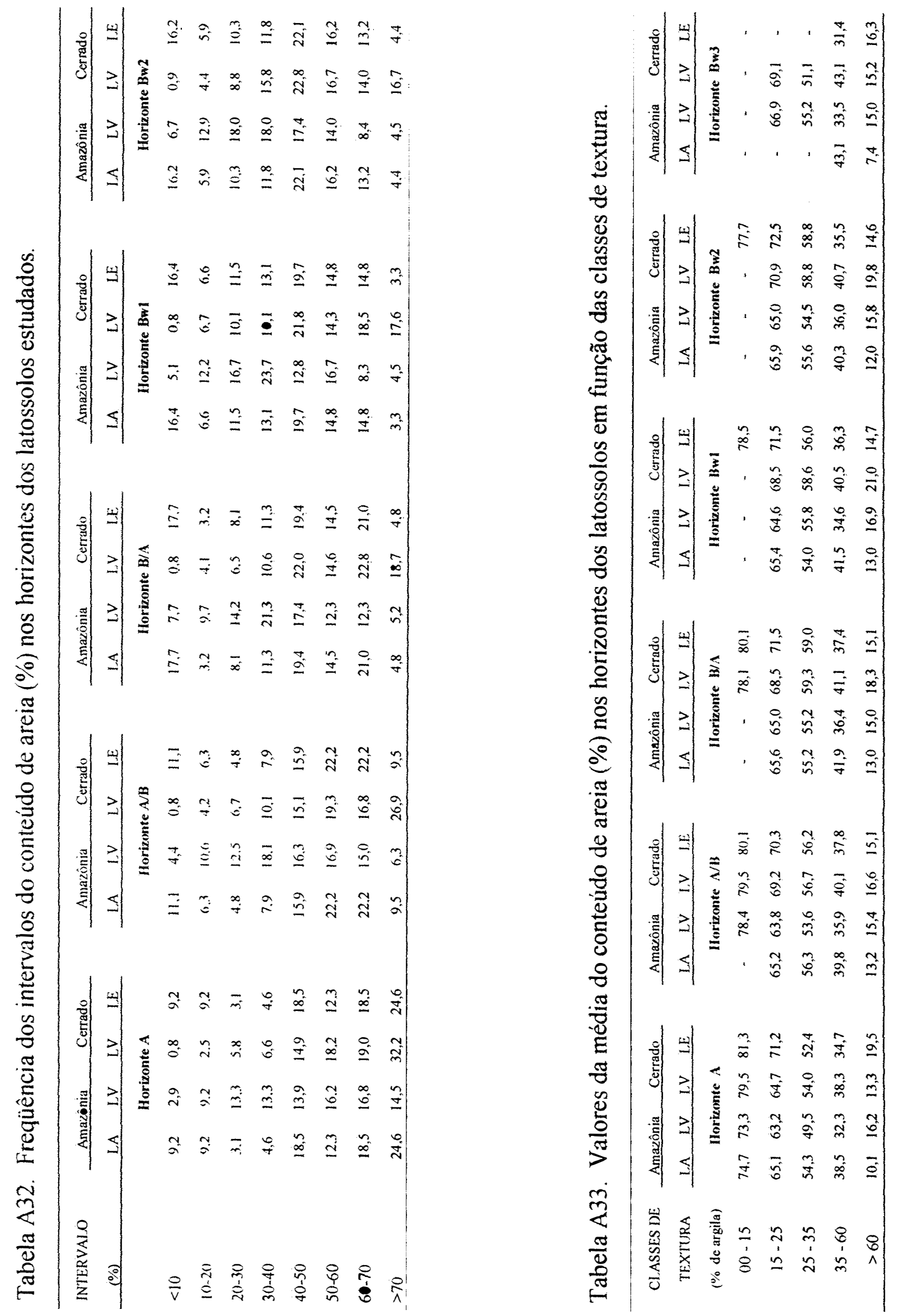

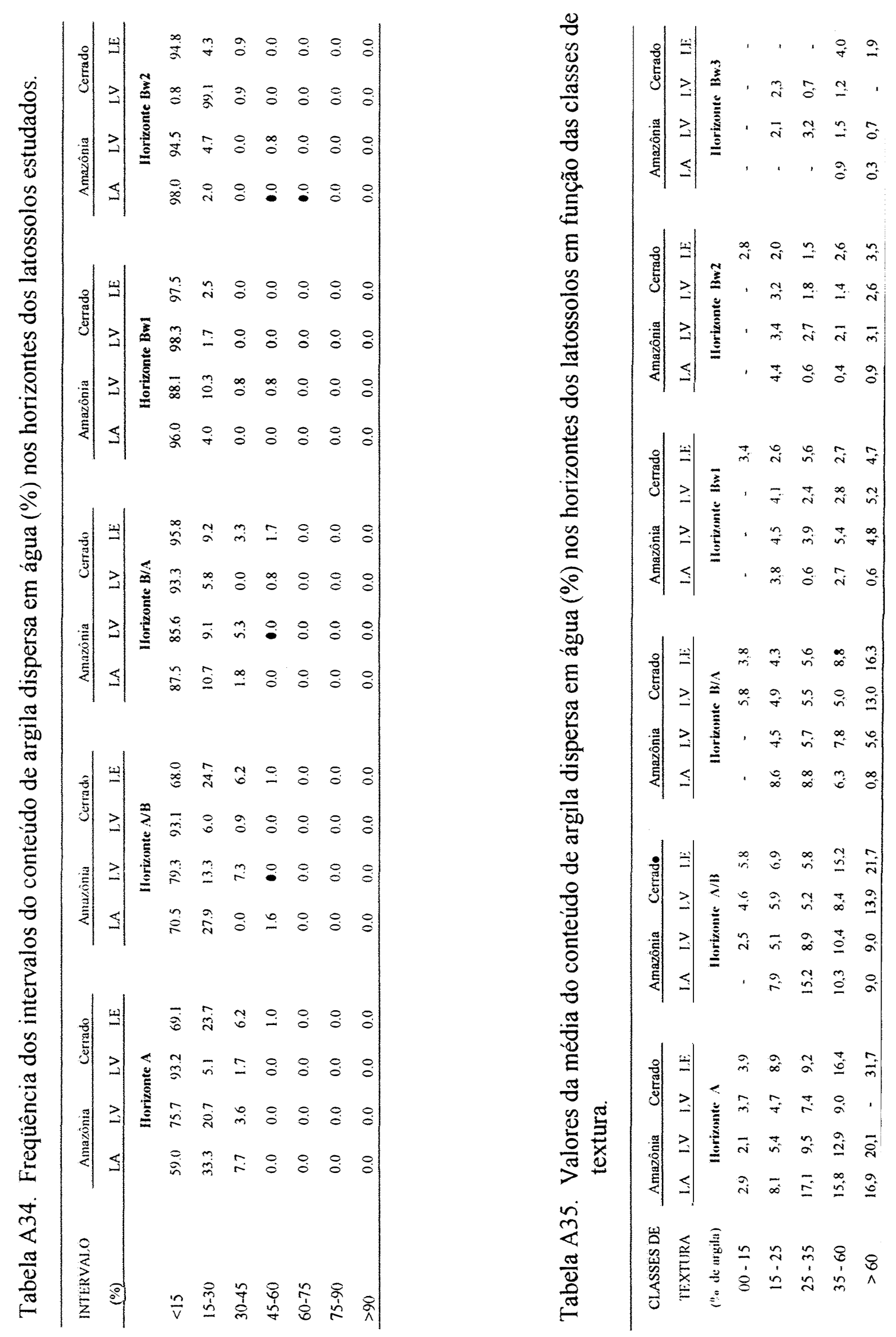


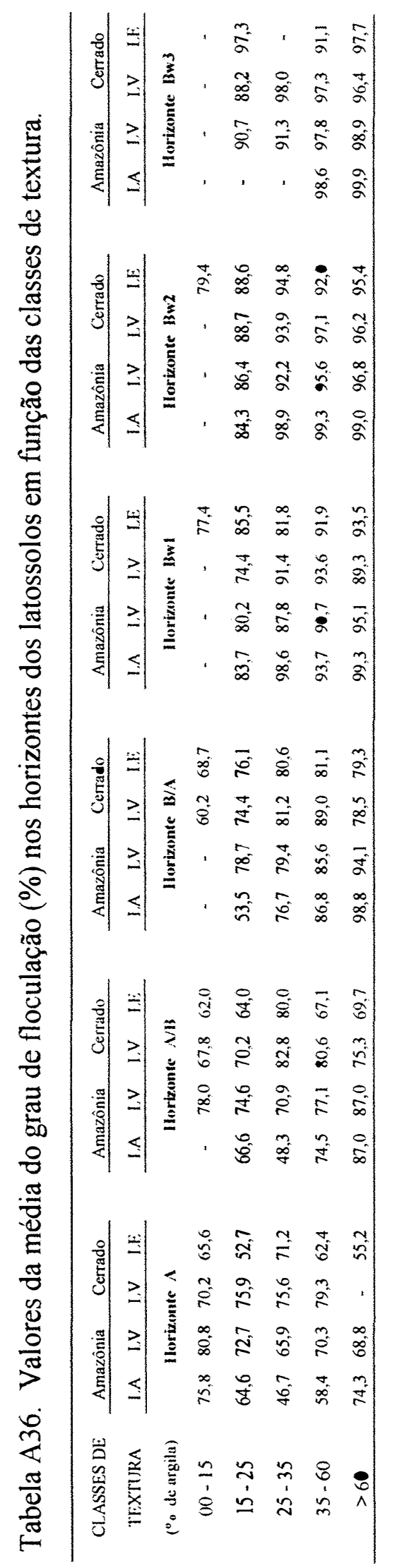



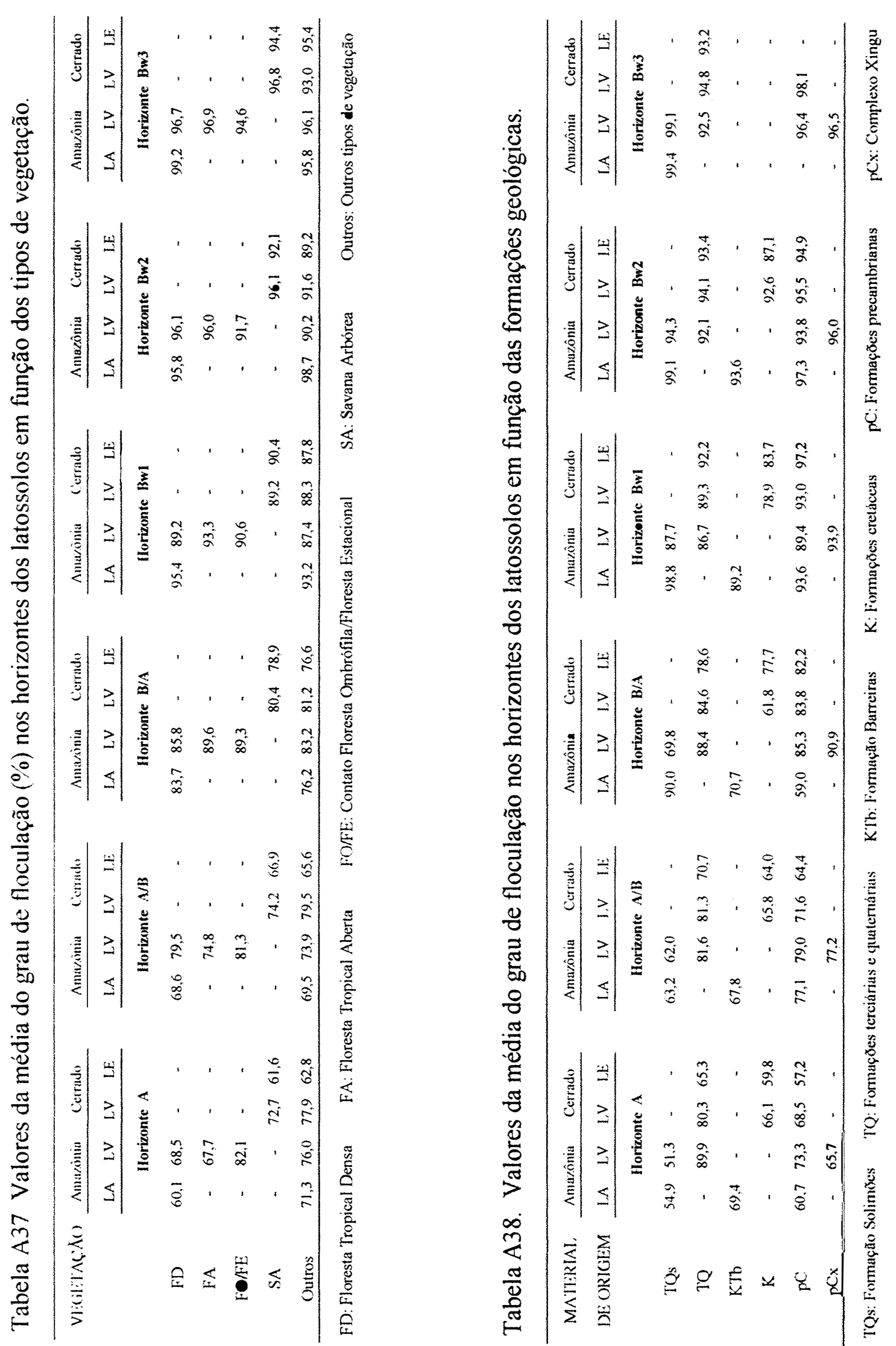

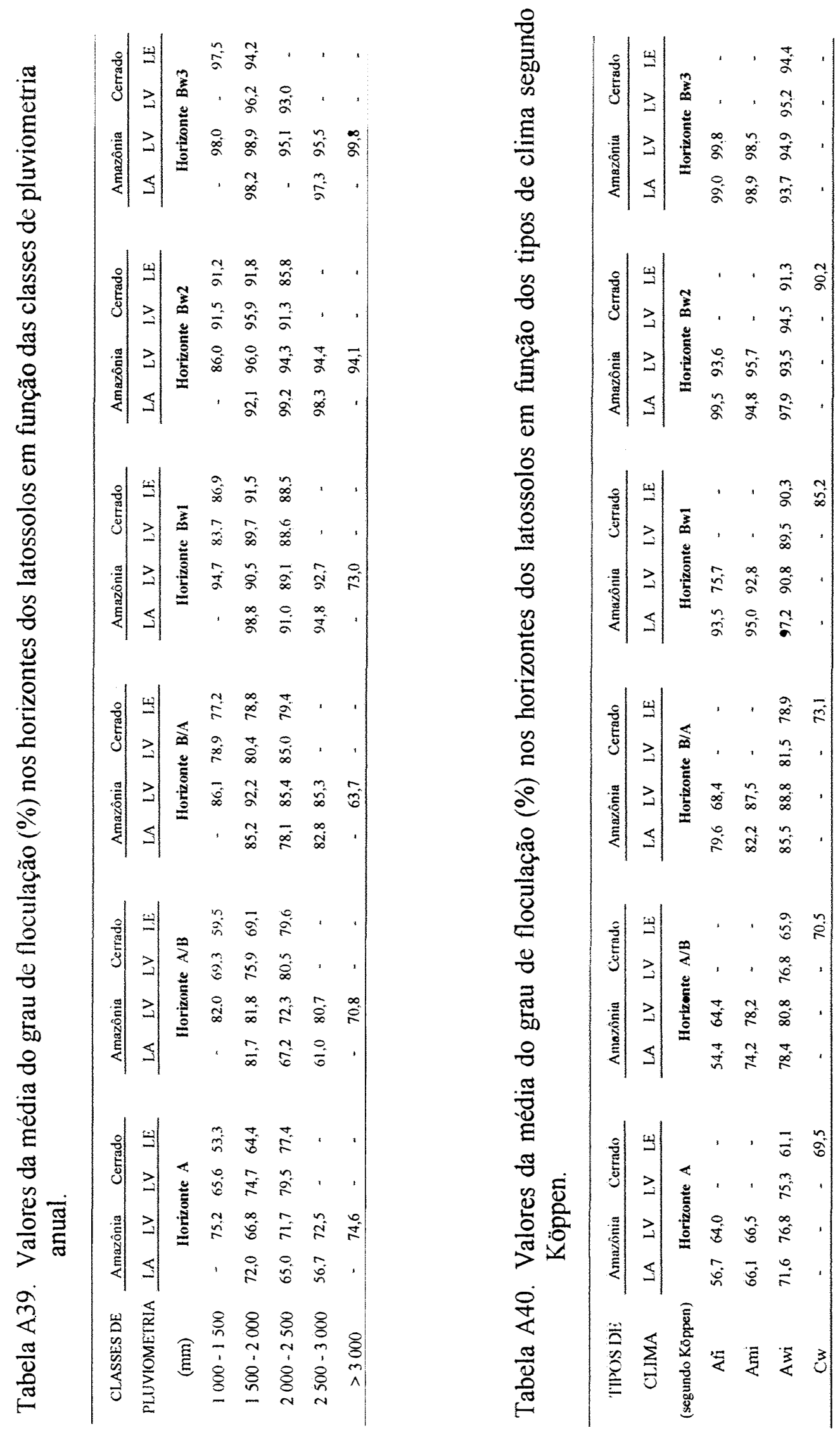

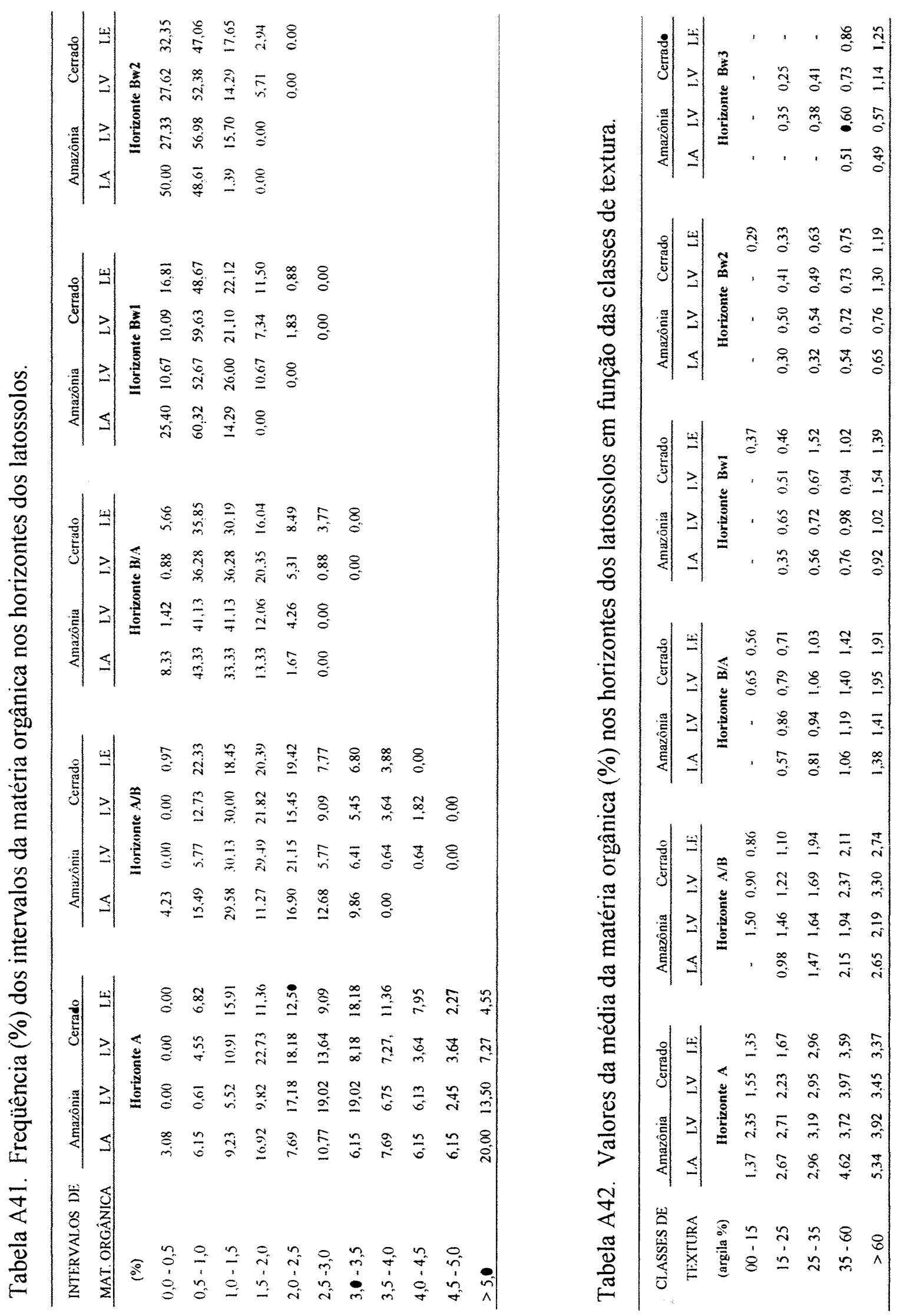

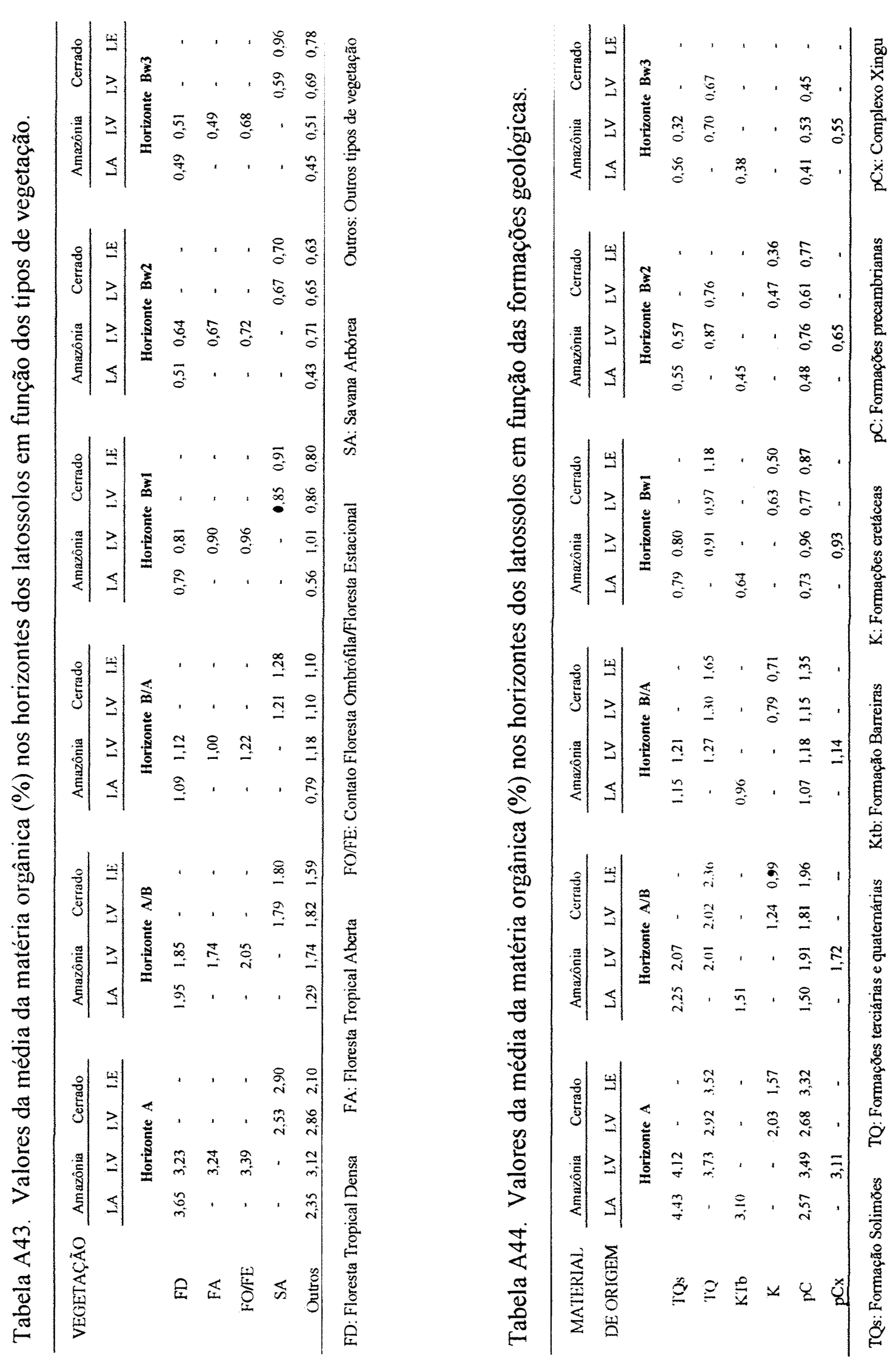

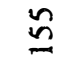



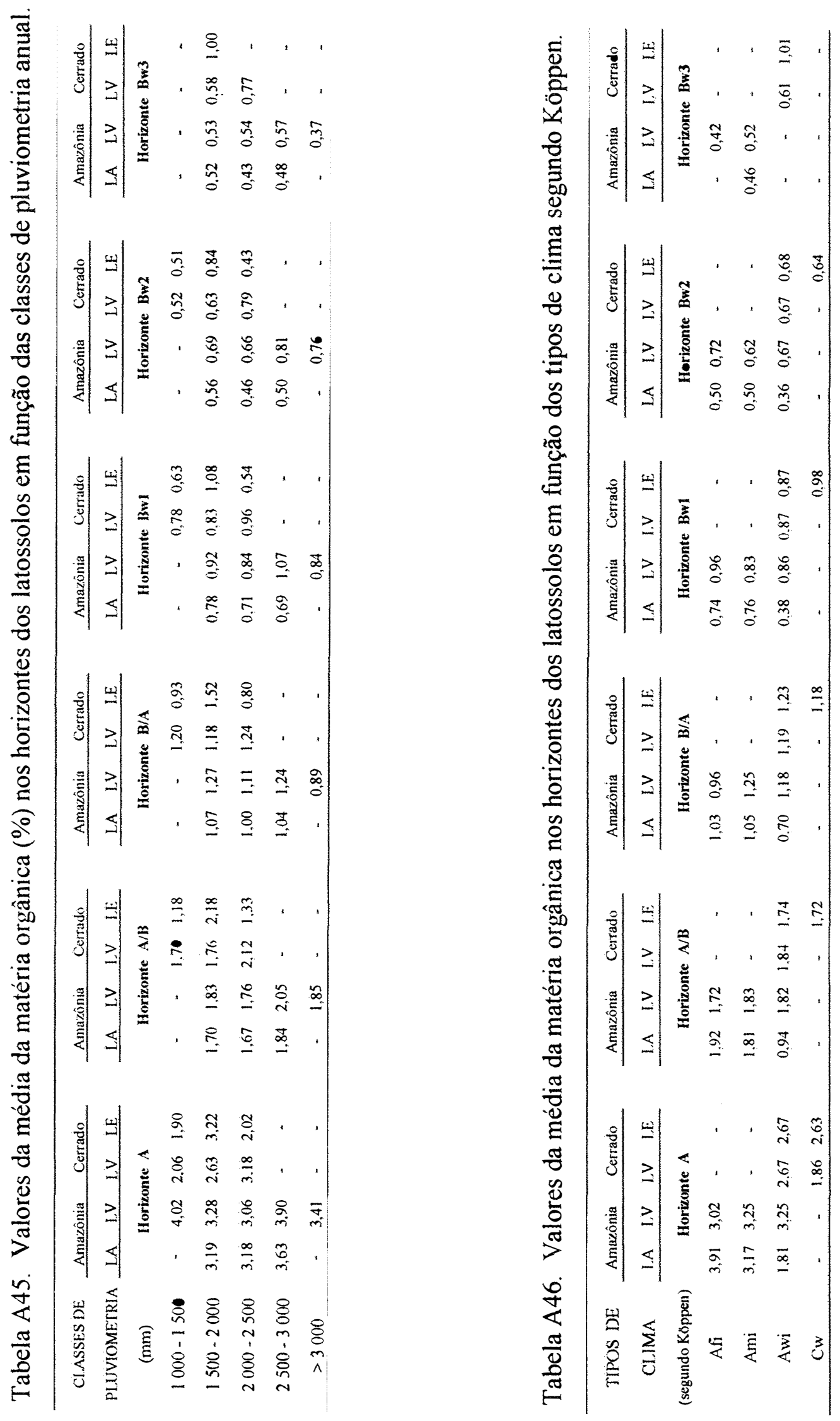

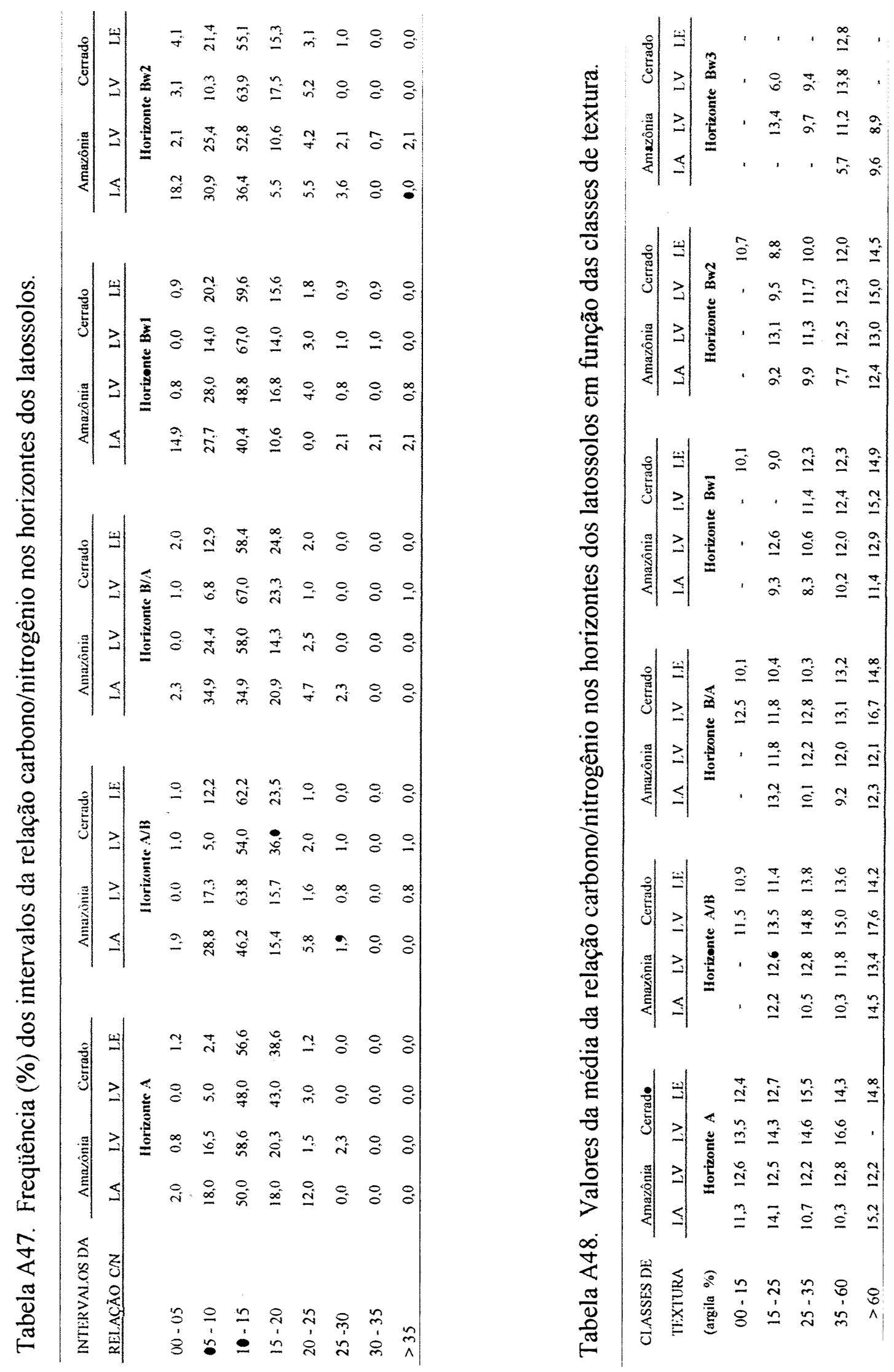

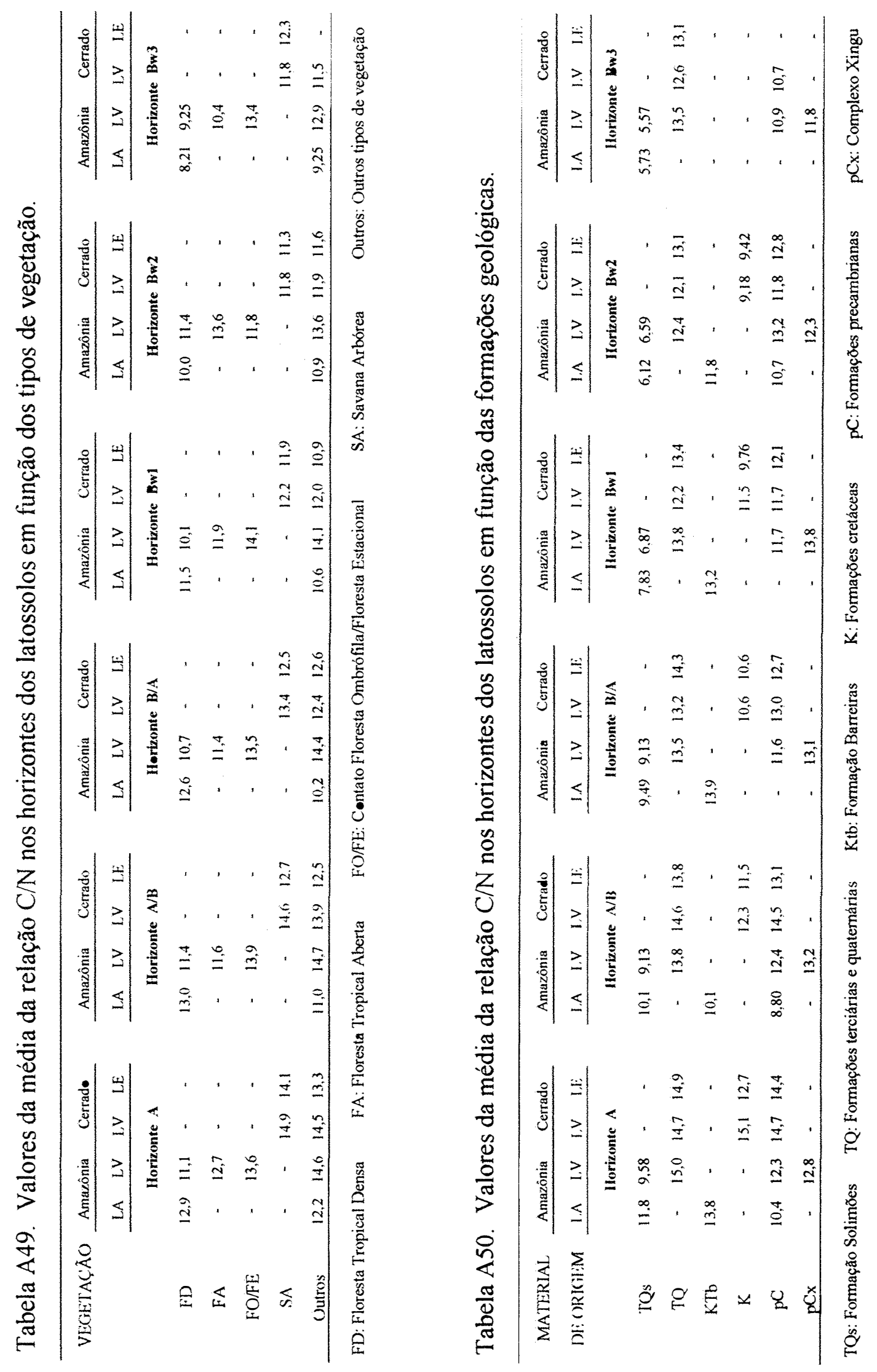

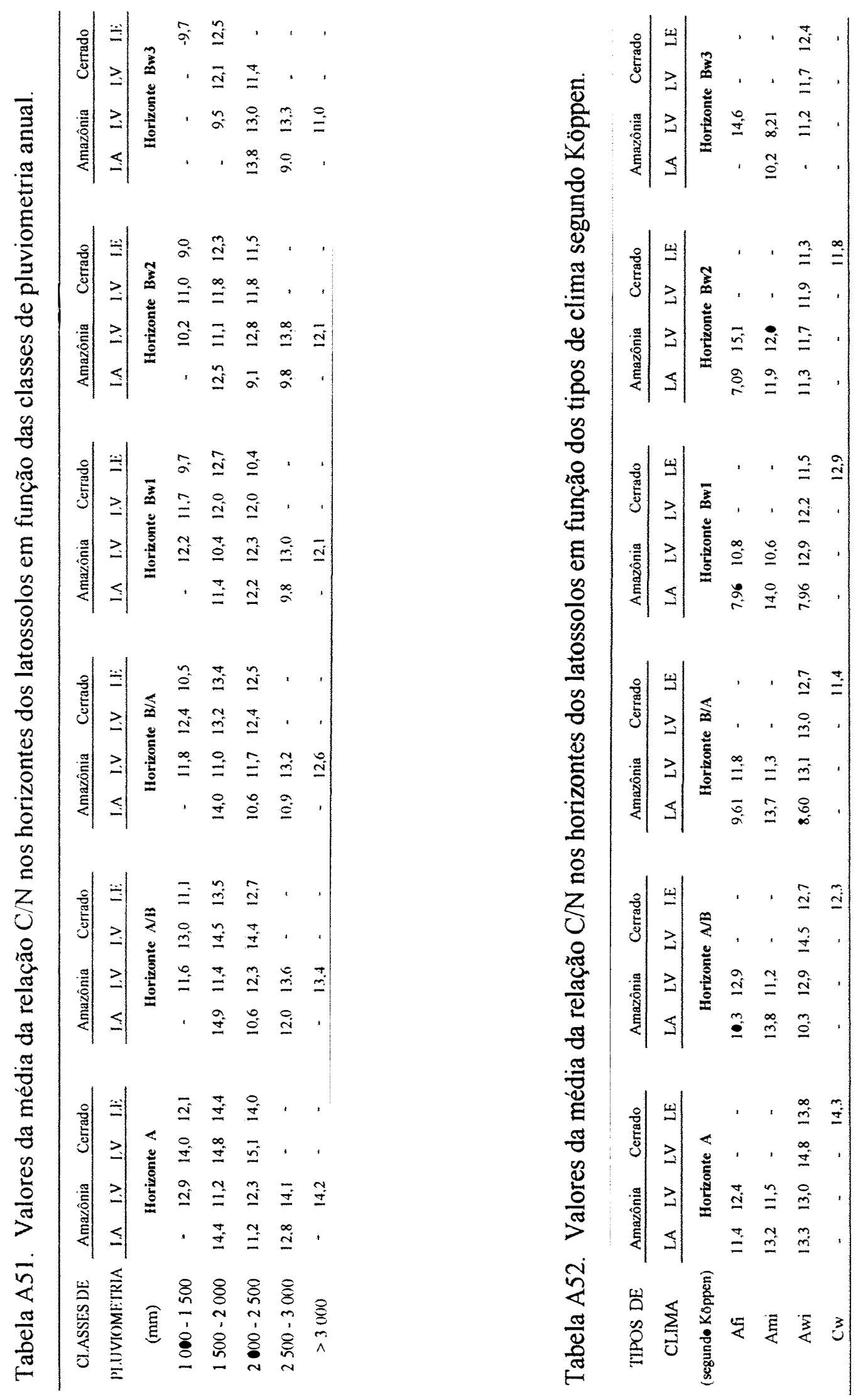

온 

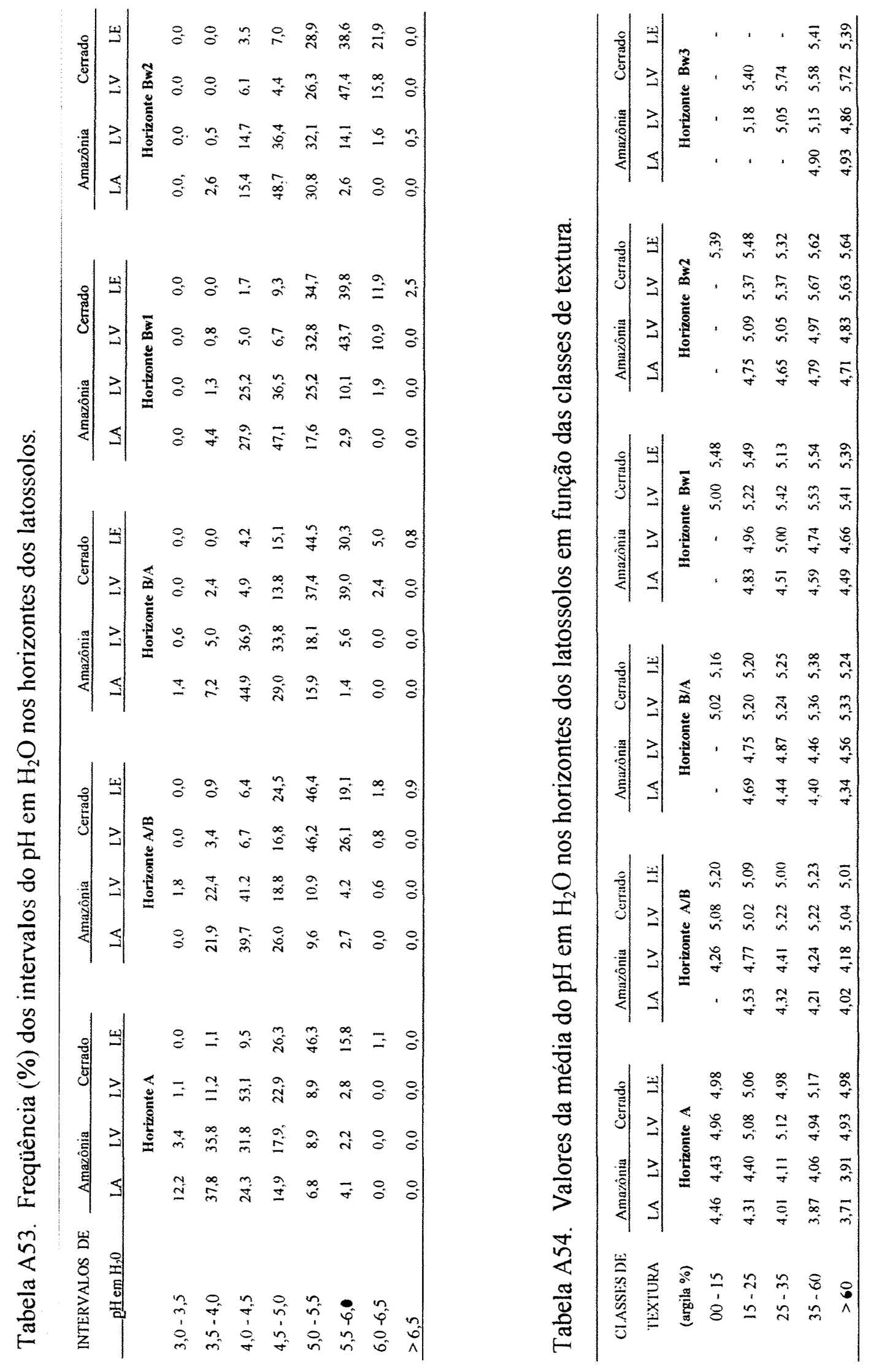

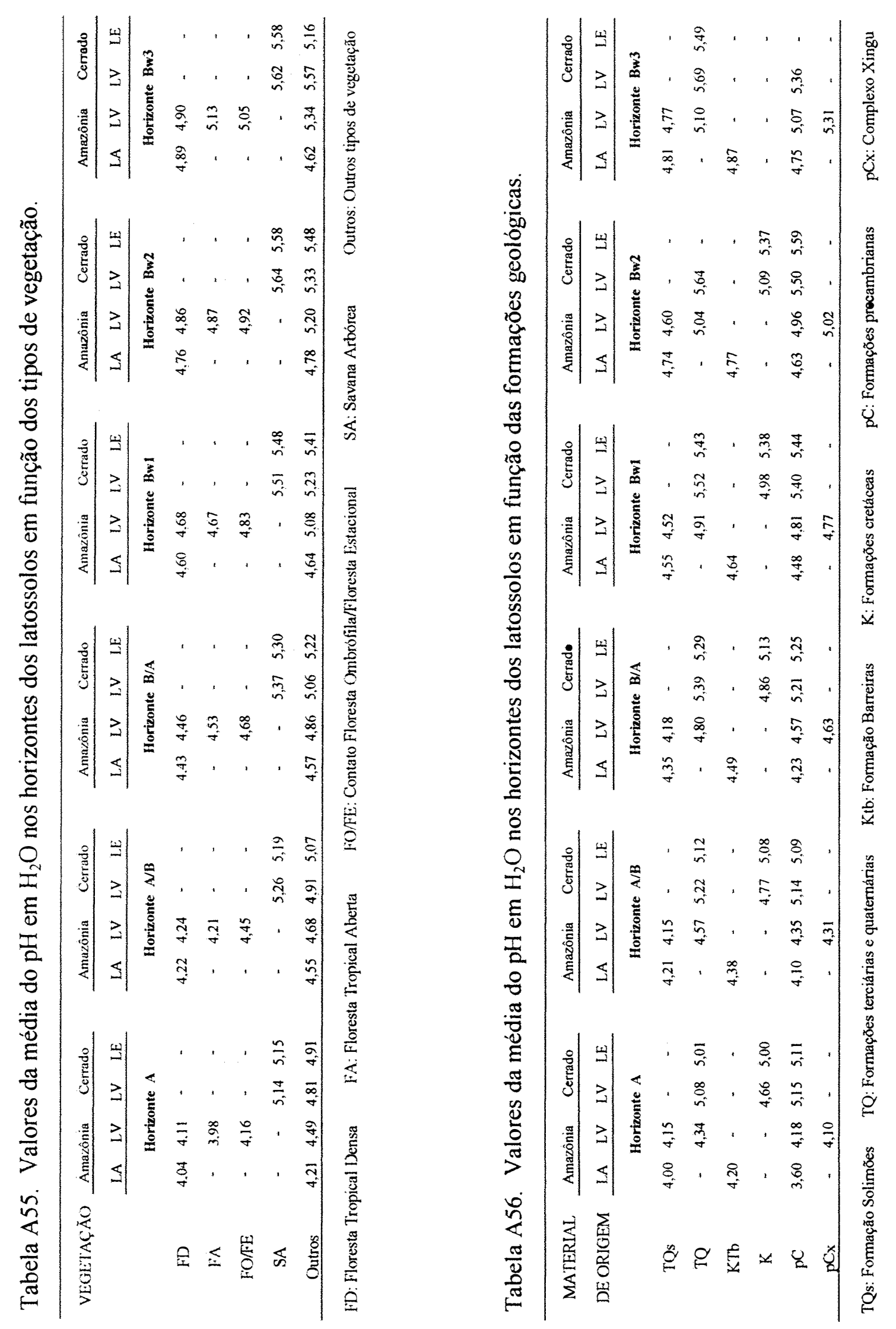


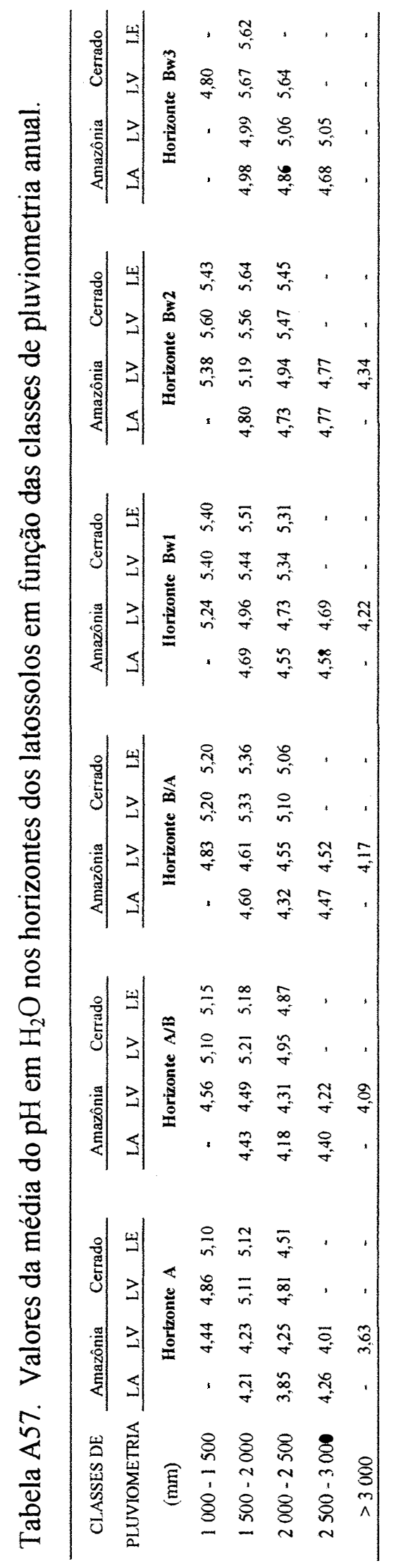



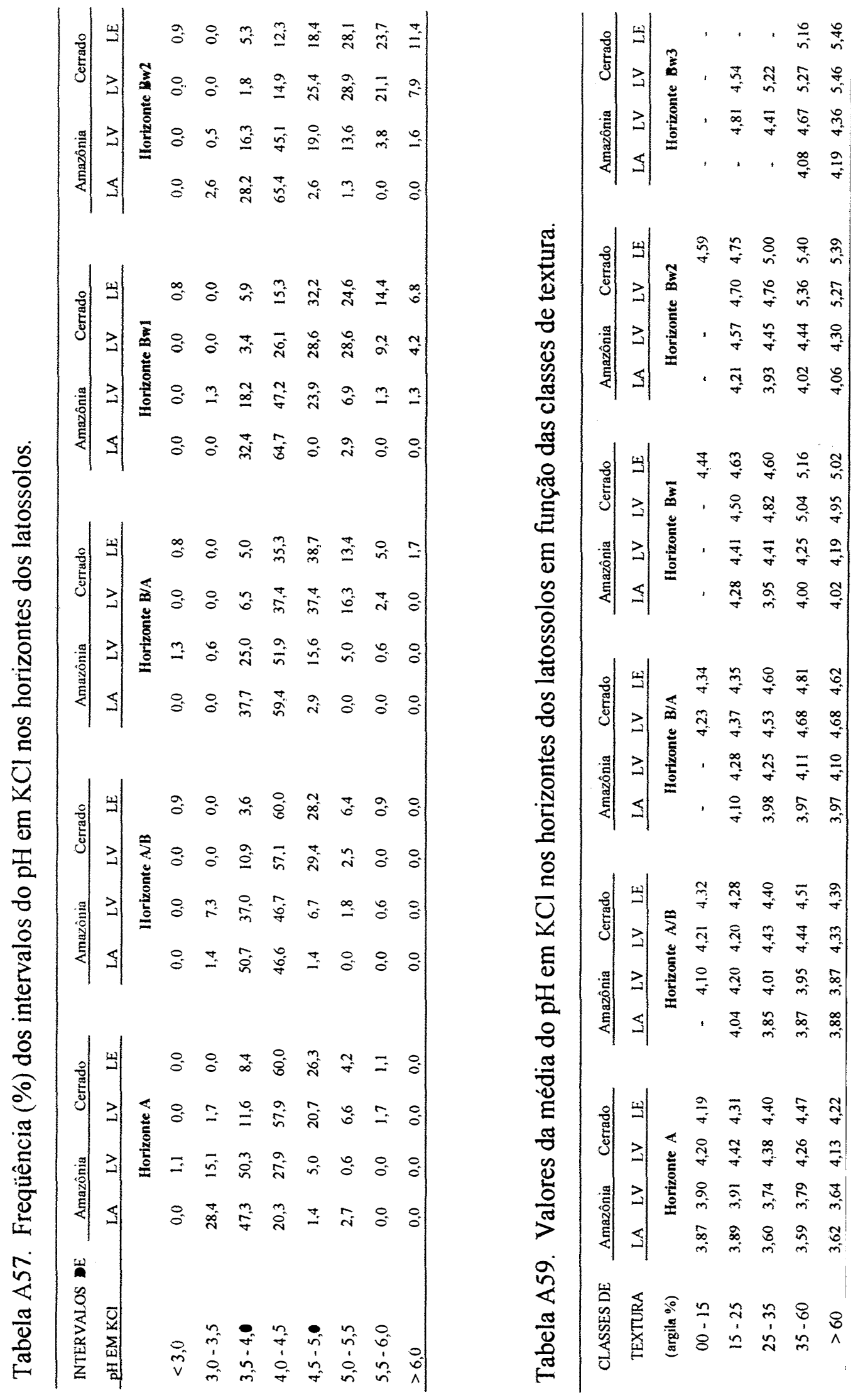

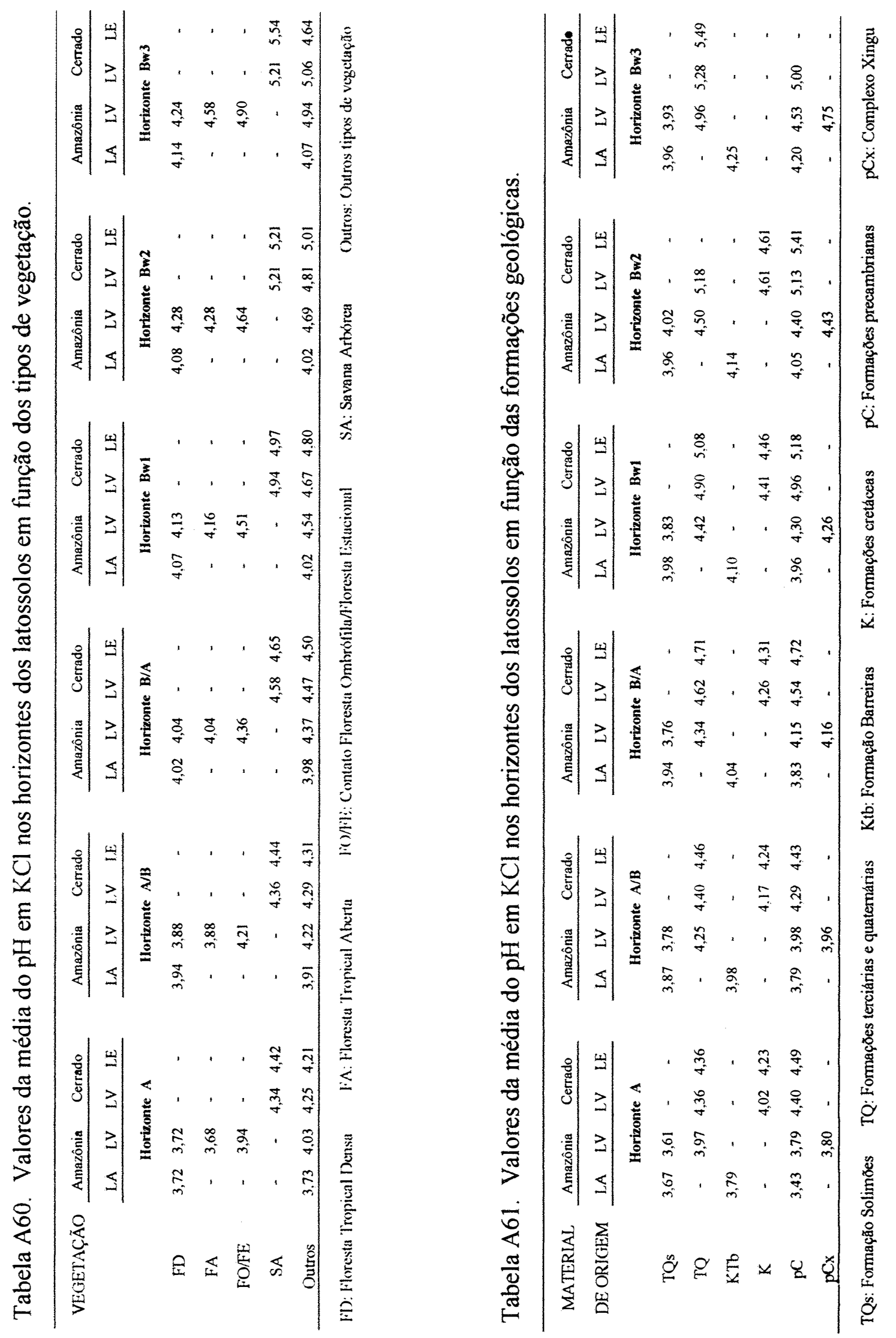

క్ర 

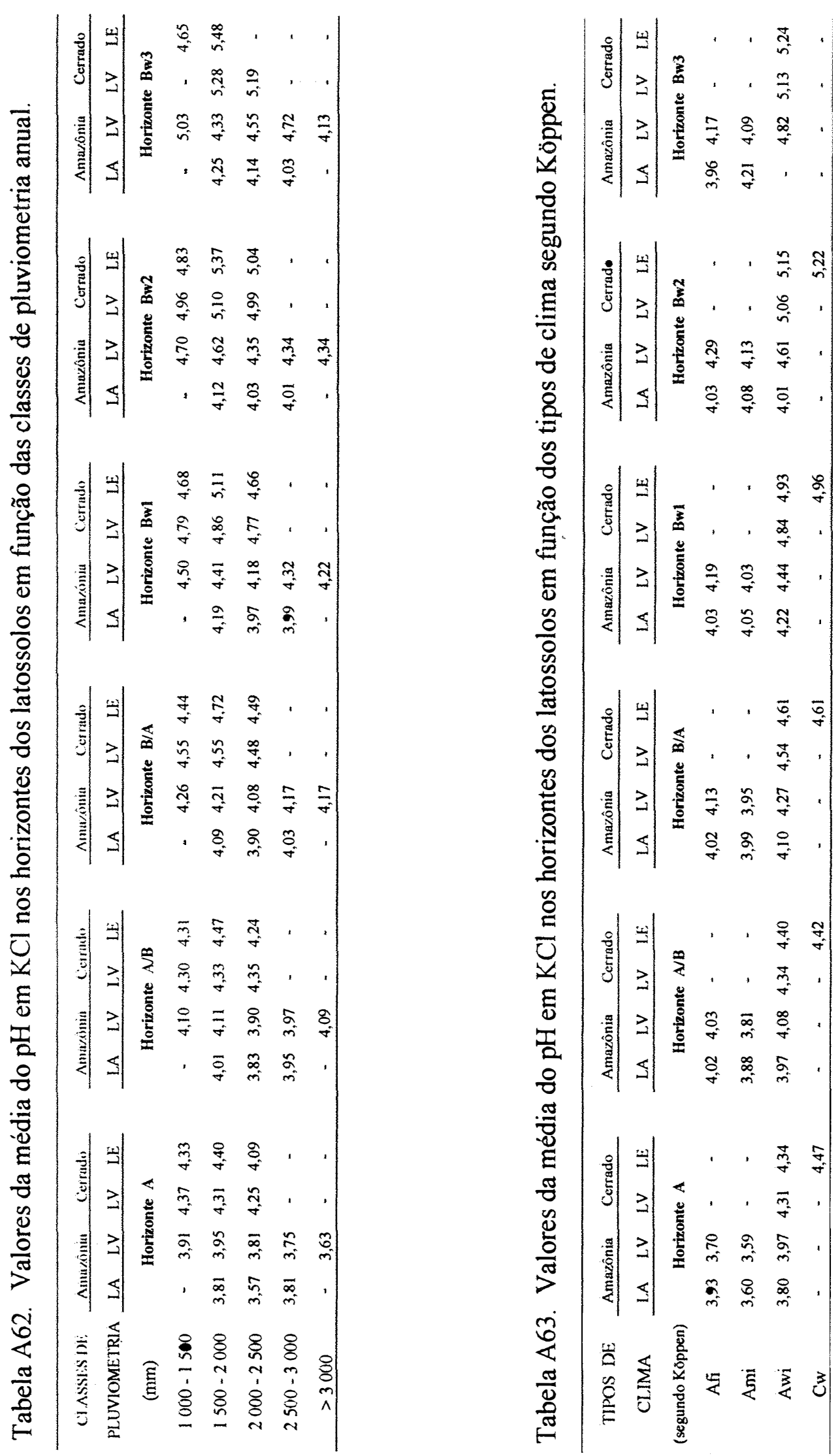

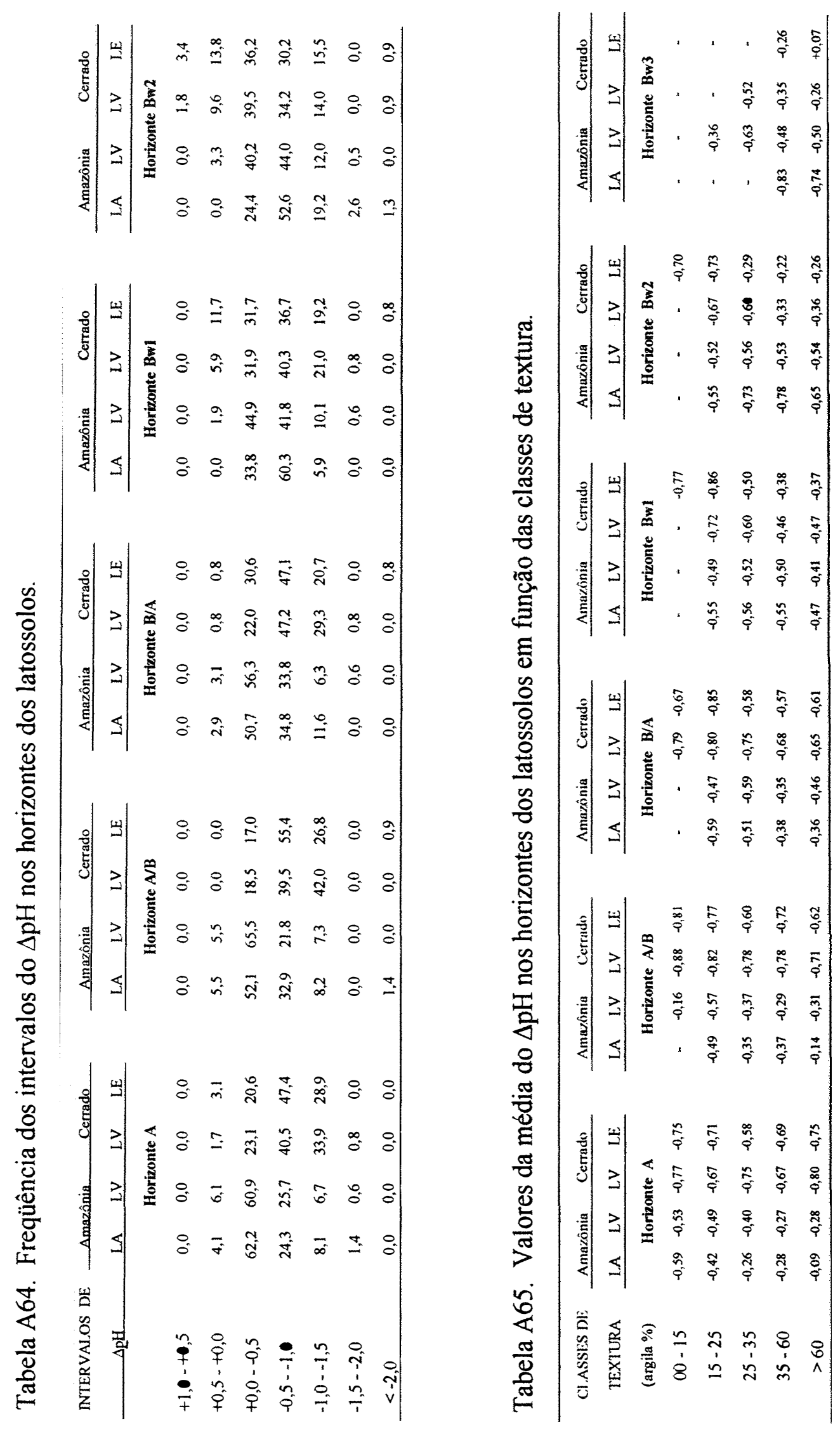

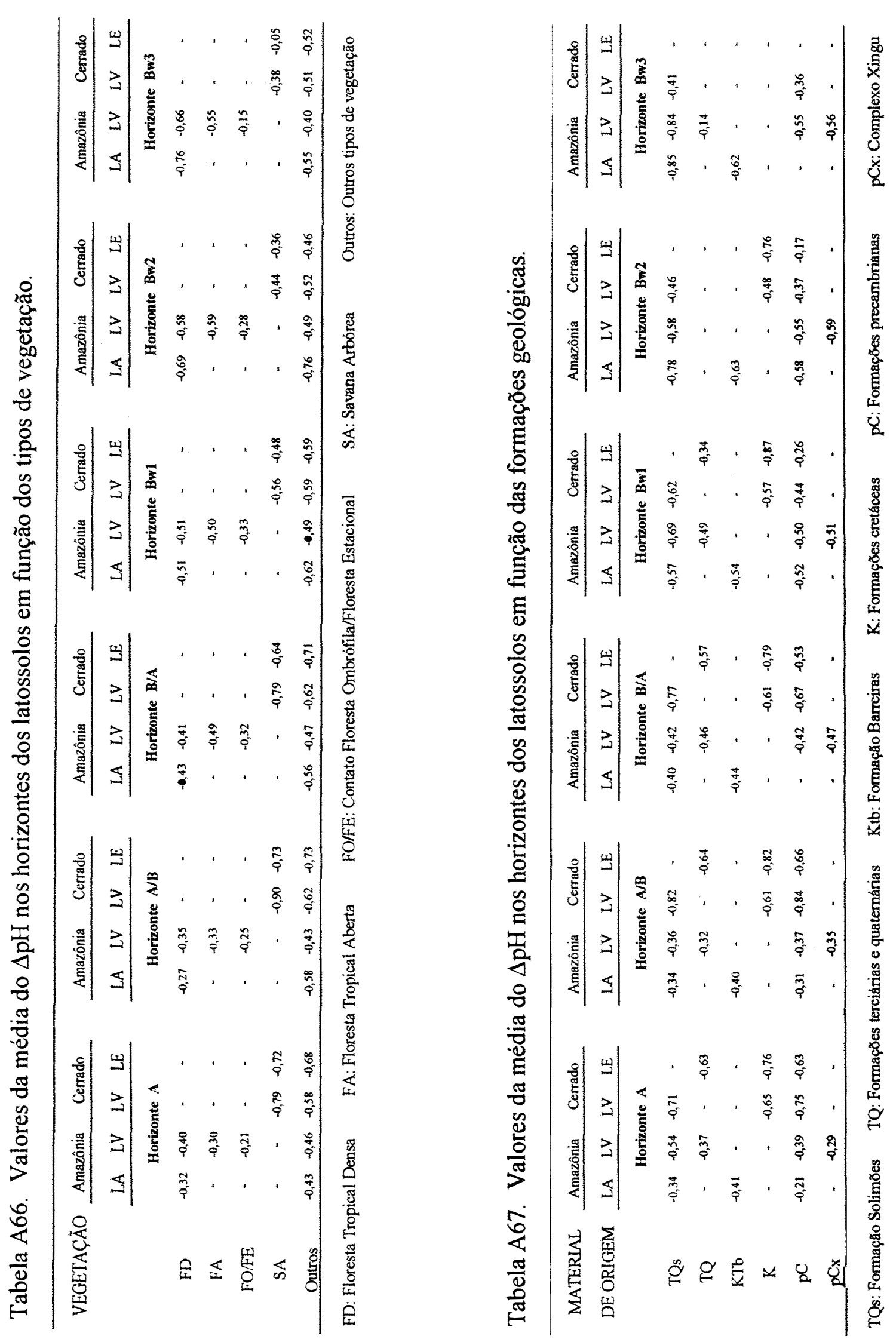

$\hat{\sigma}$ 

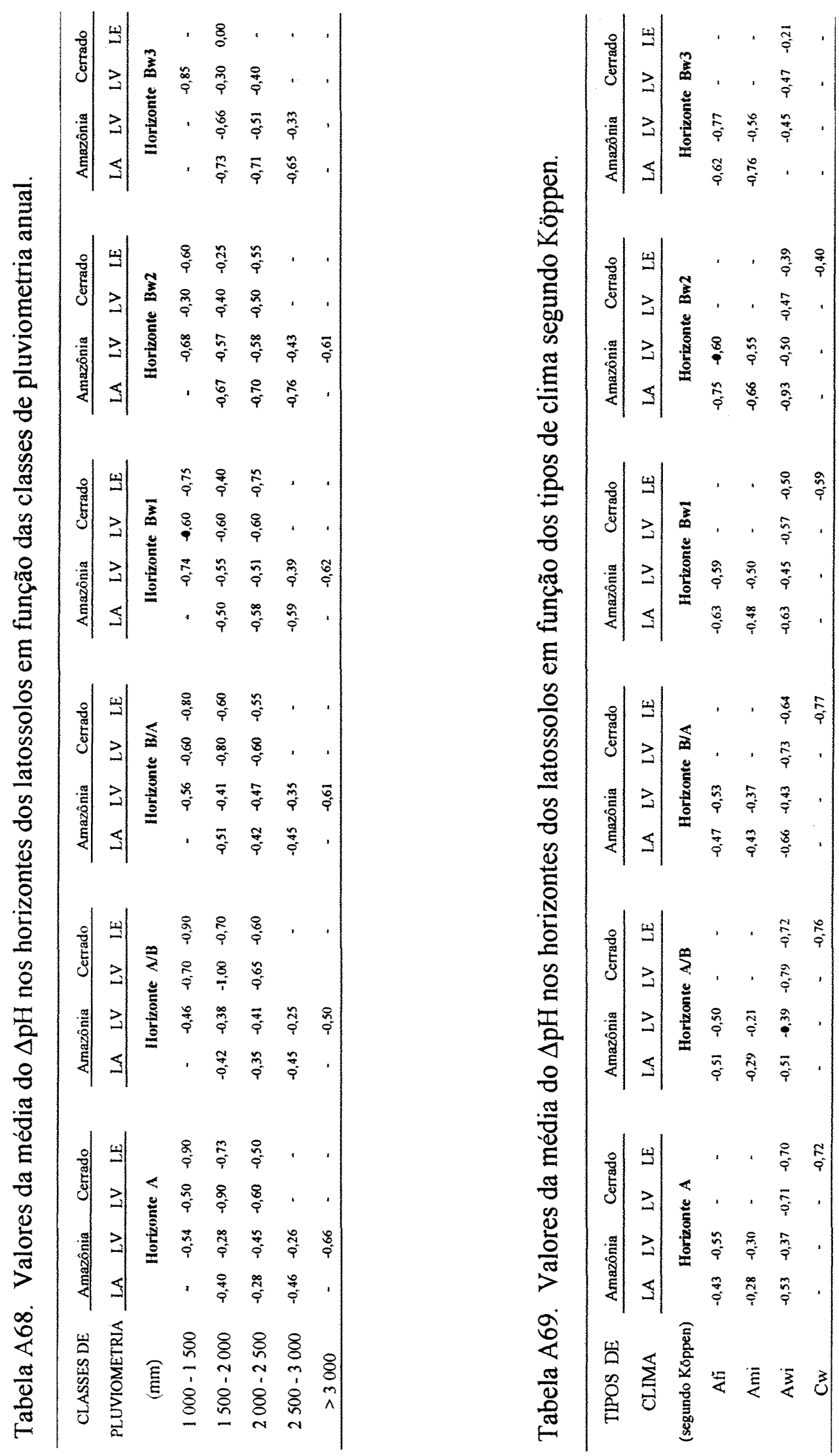

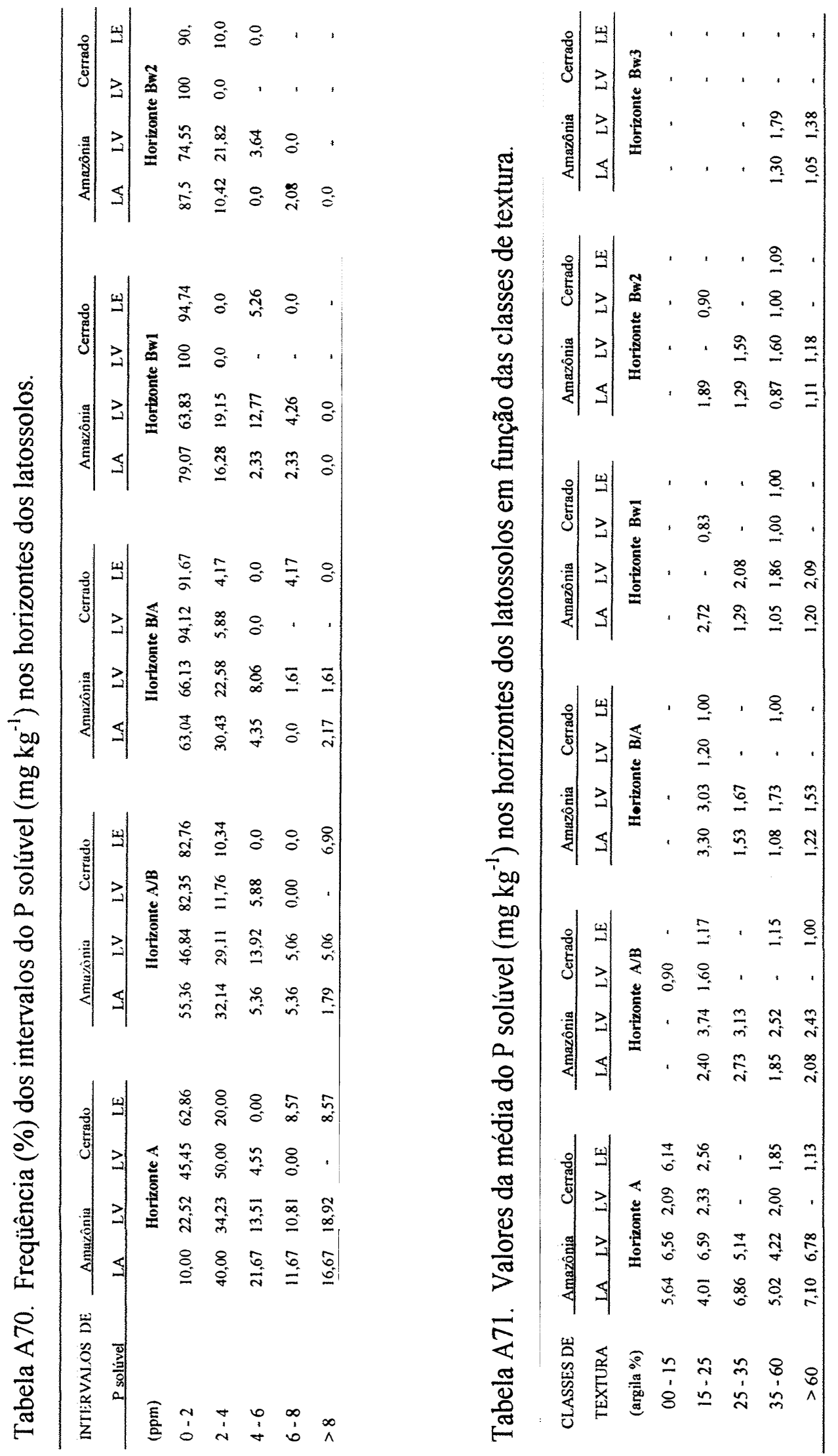

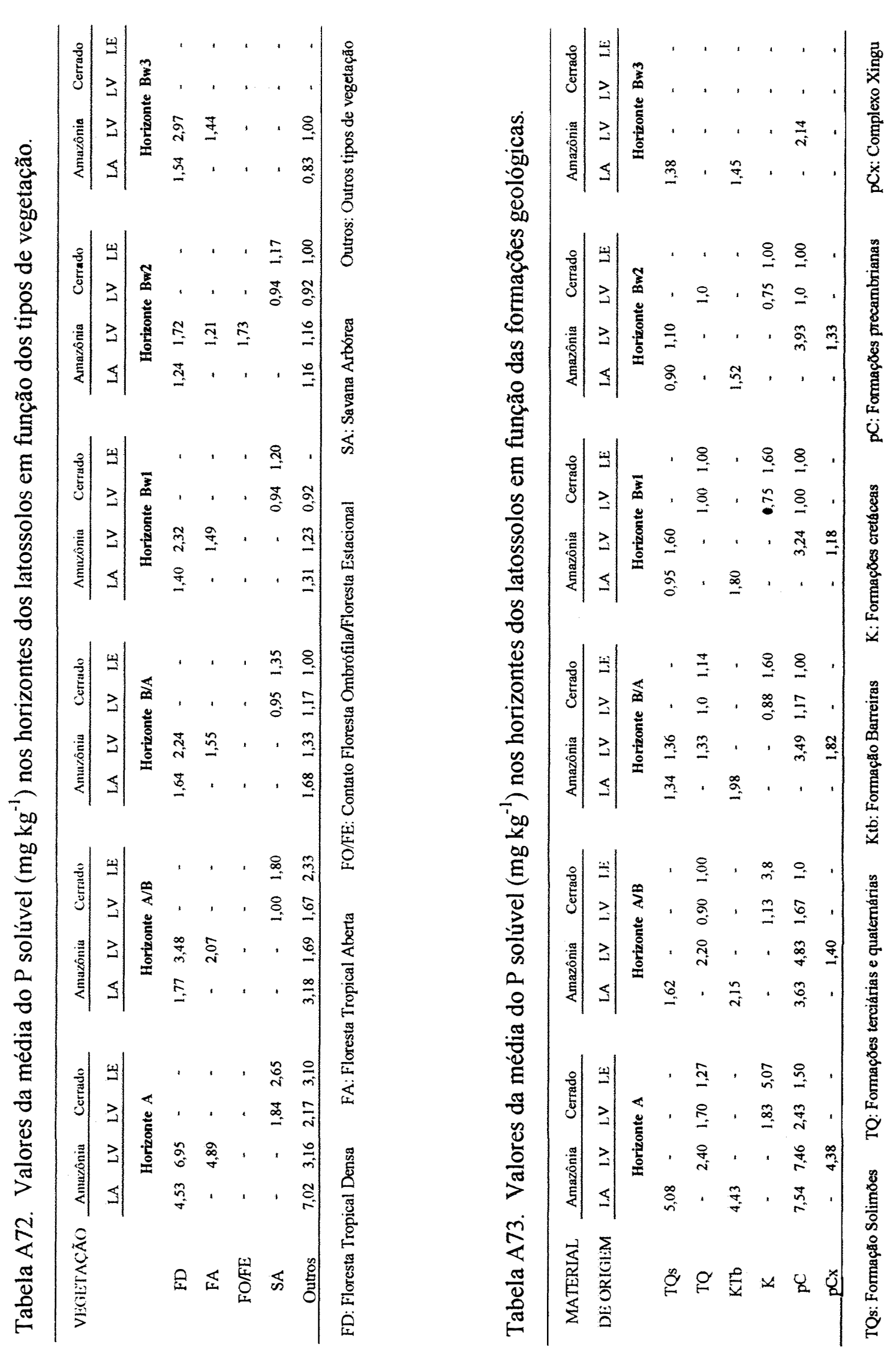

온 

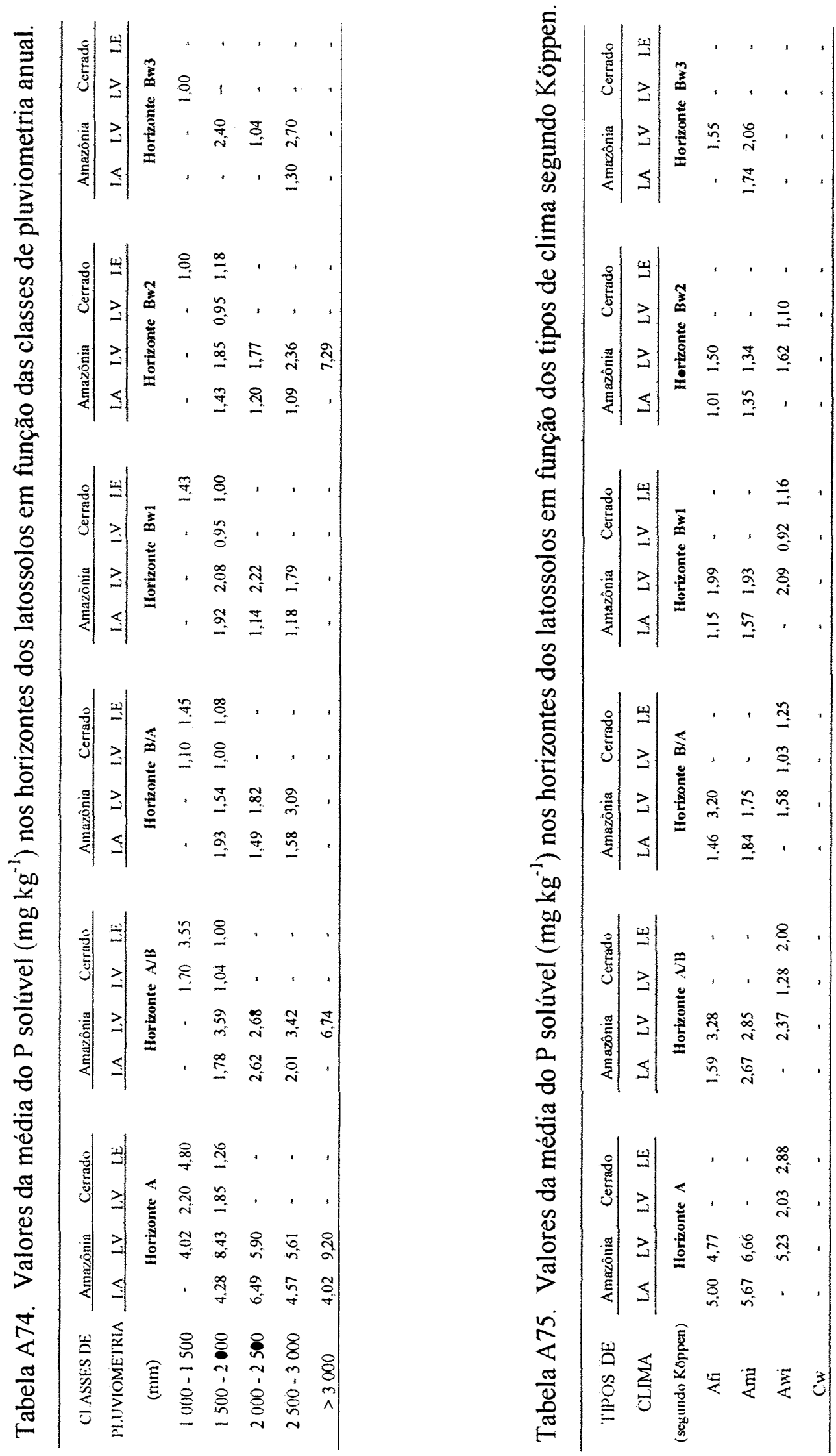

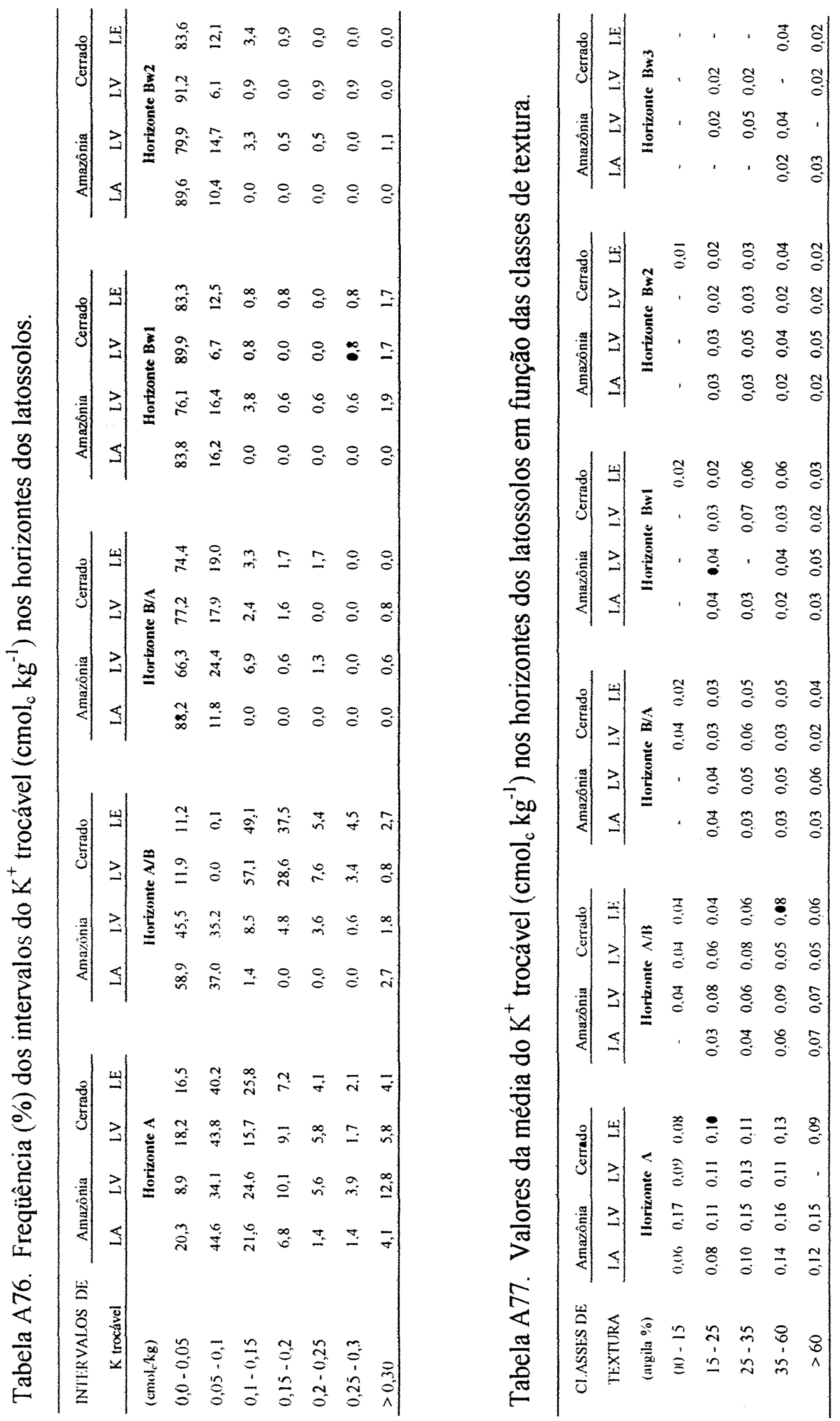

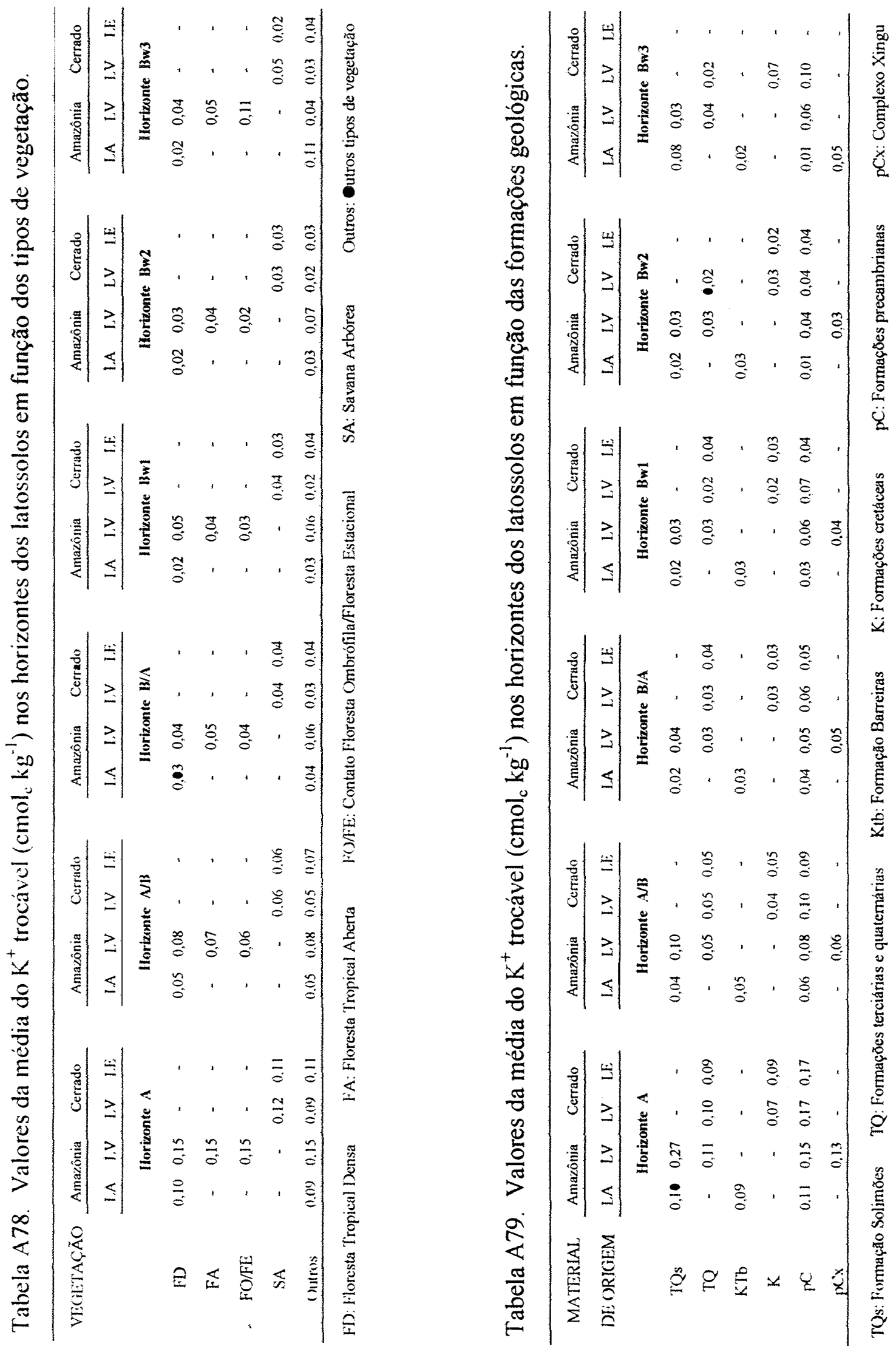

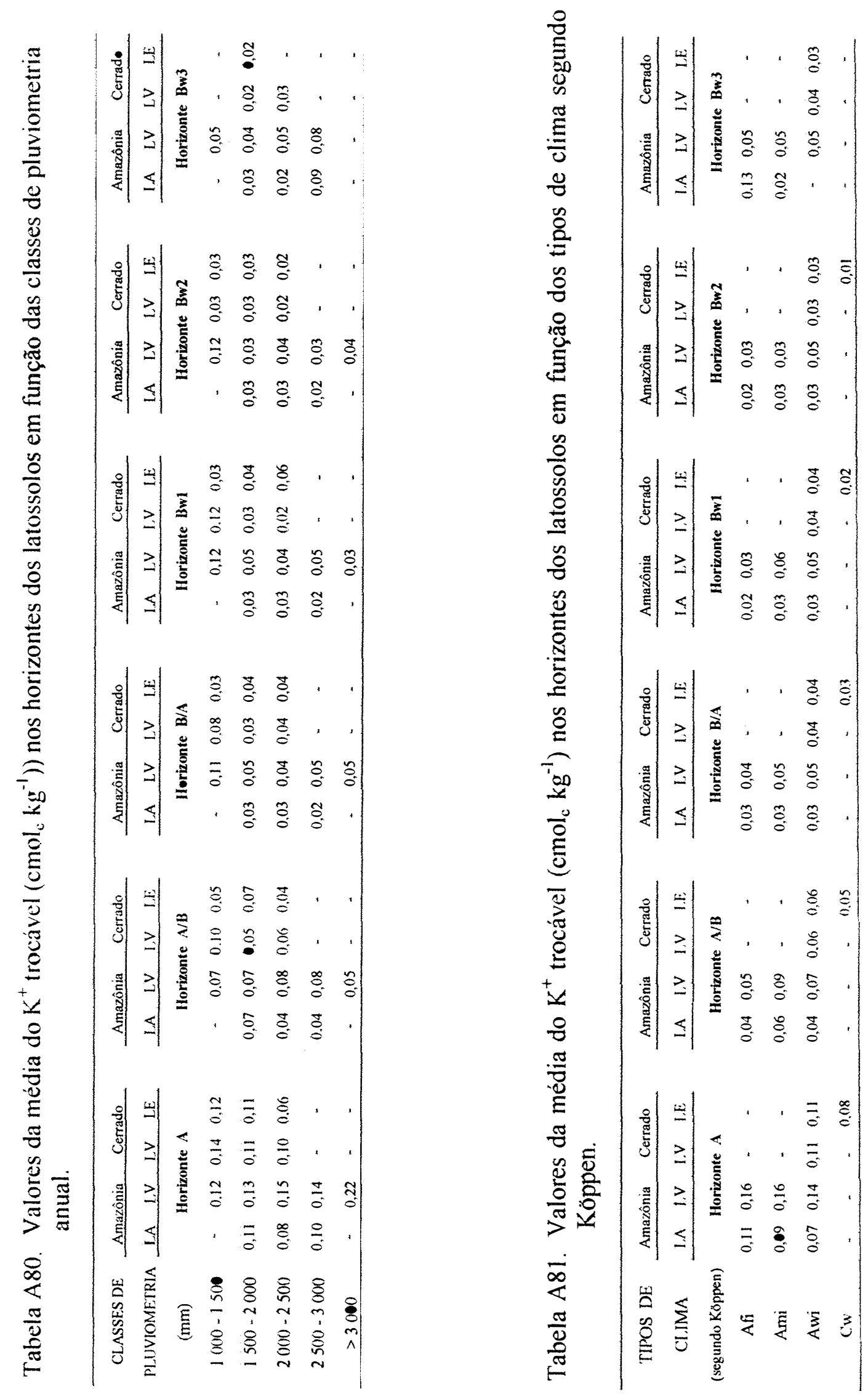

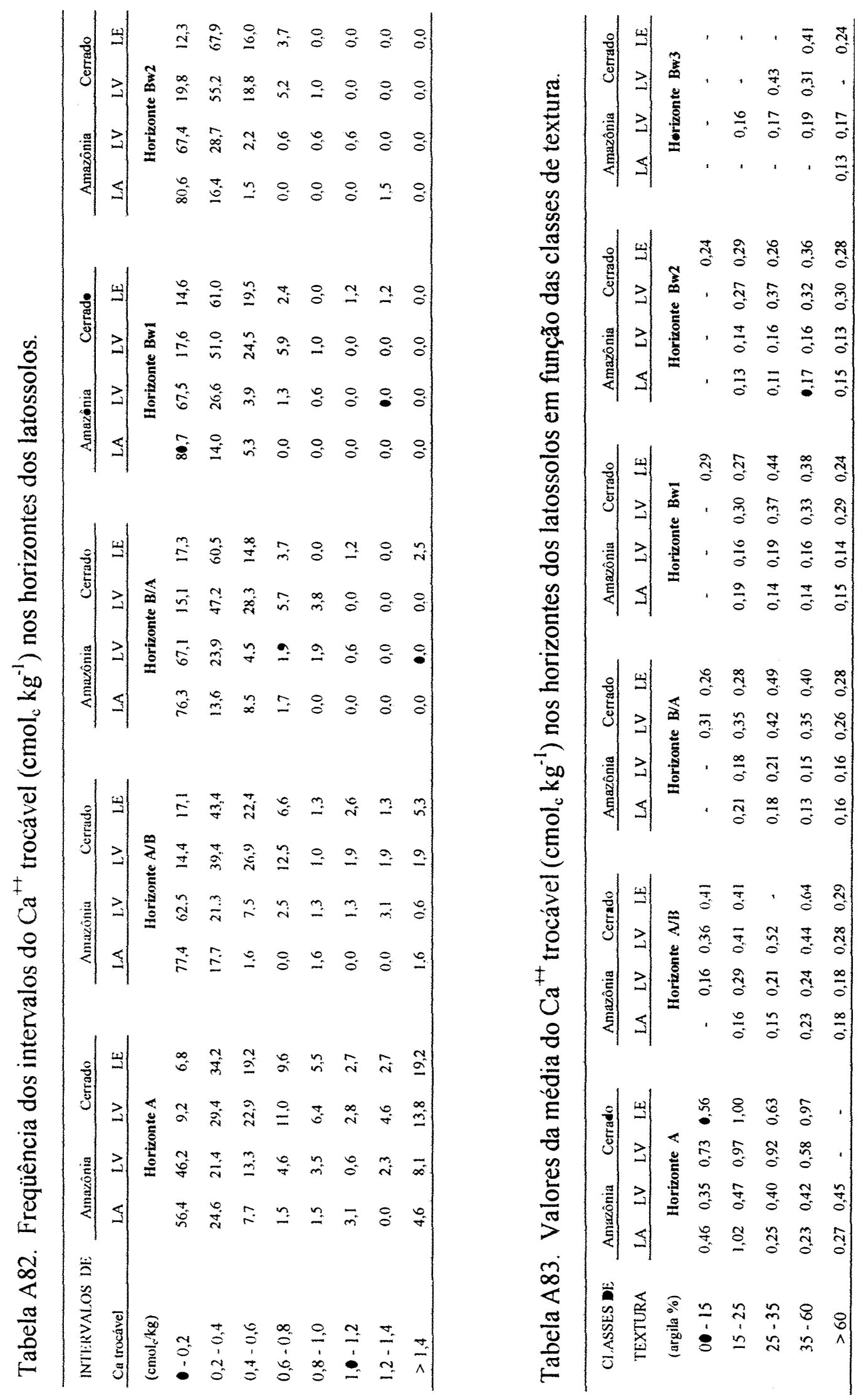

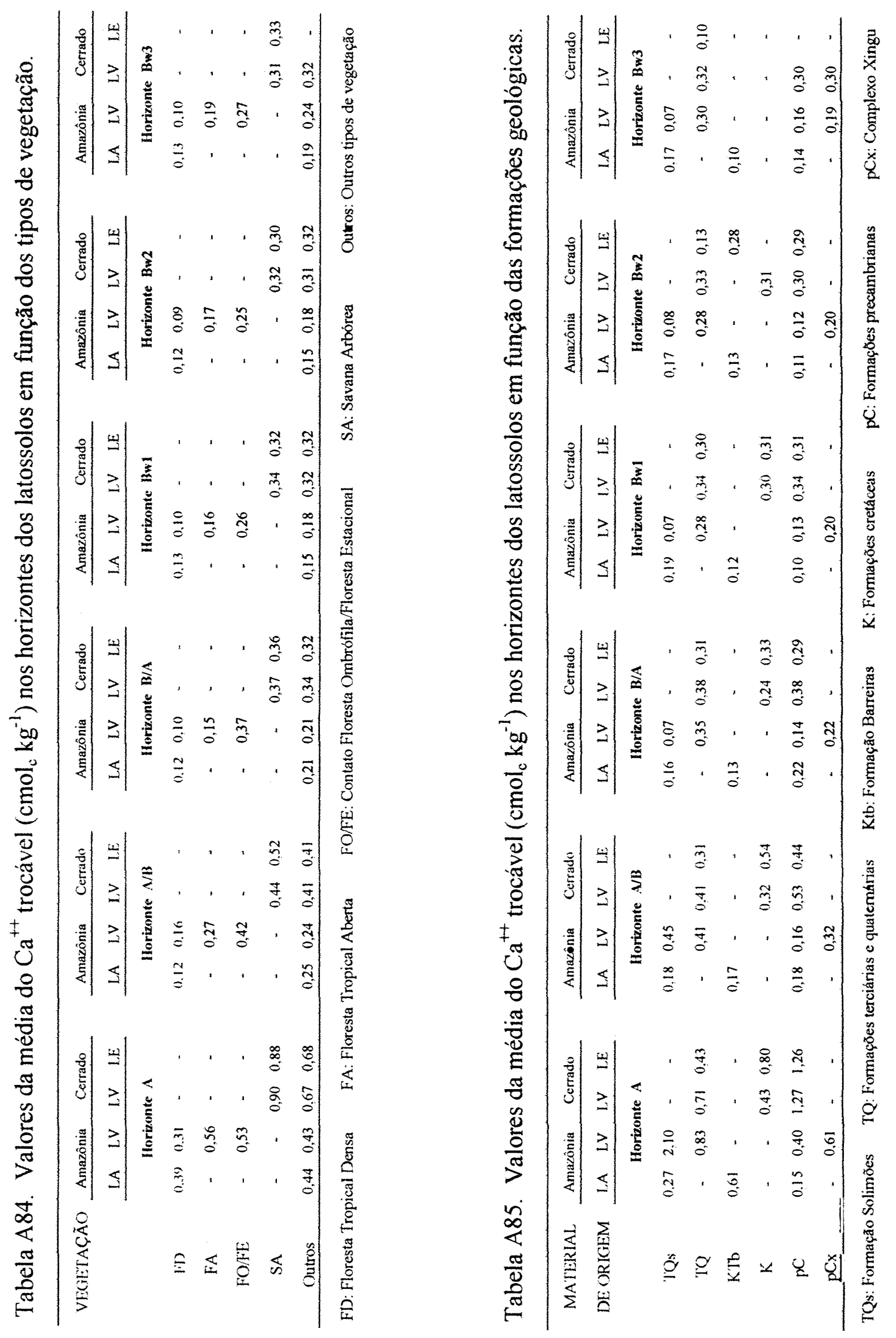

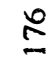



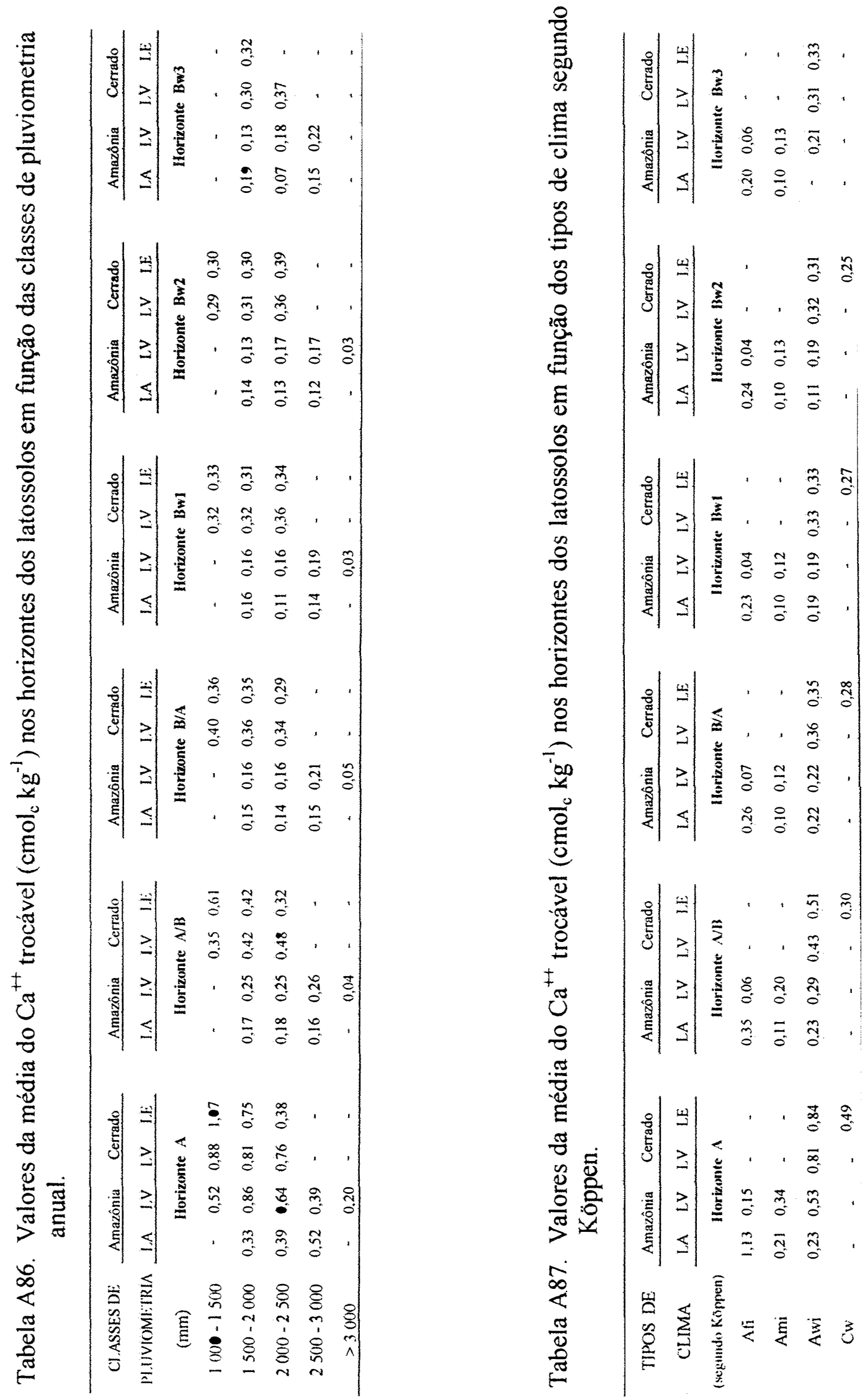

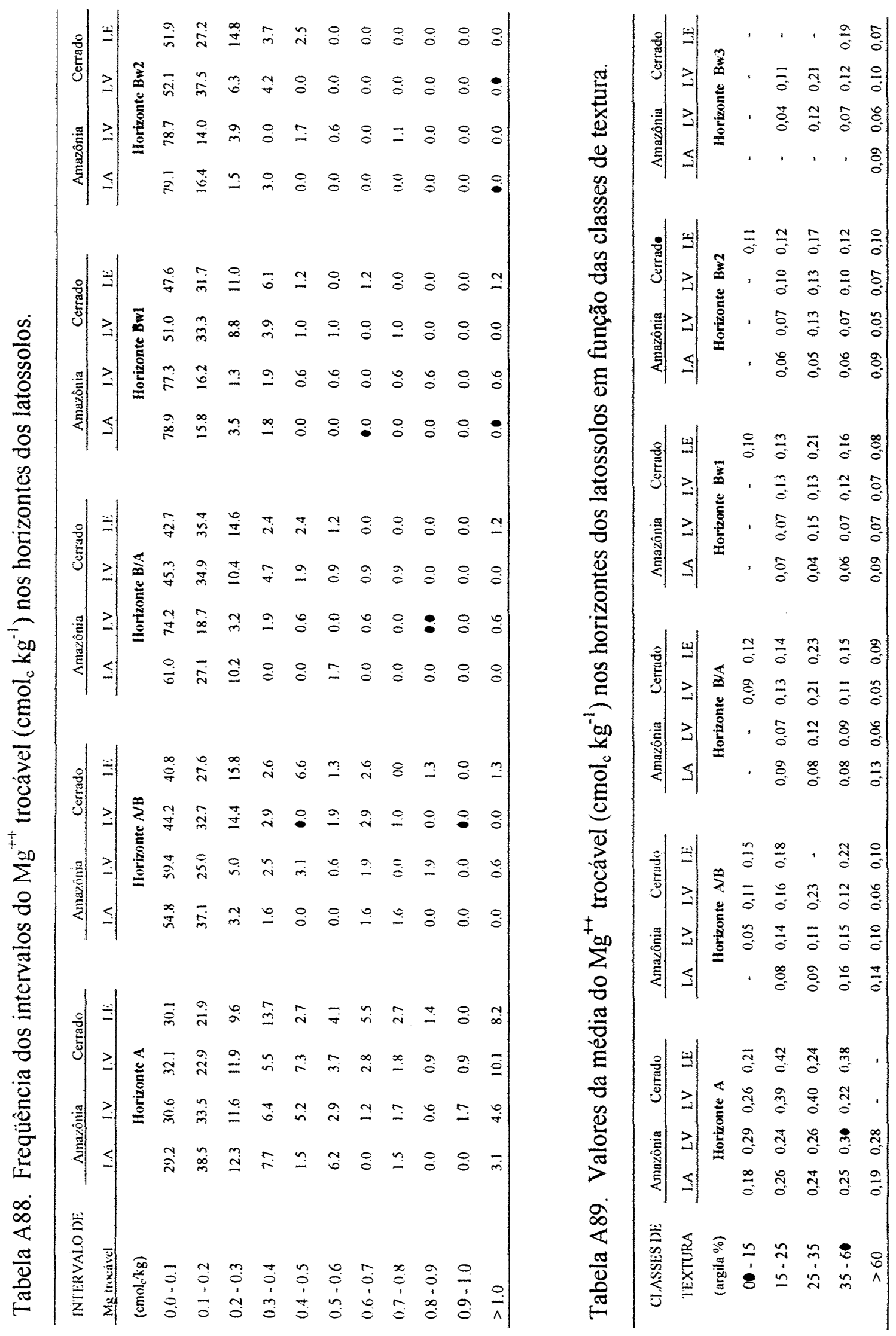

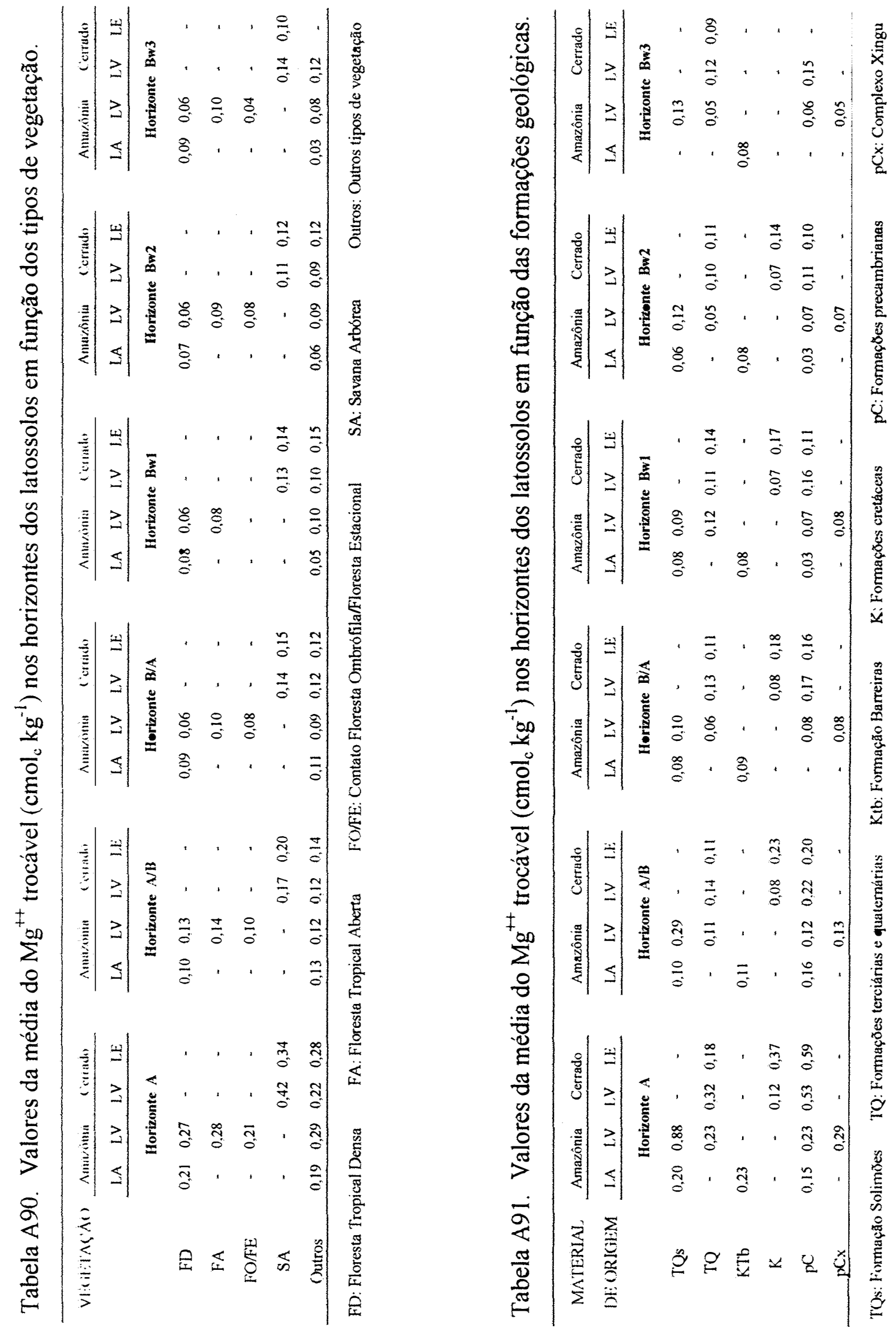

I 

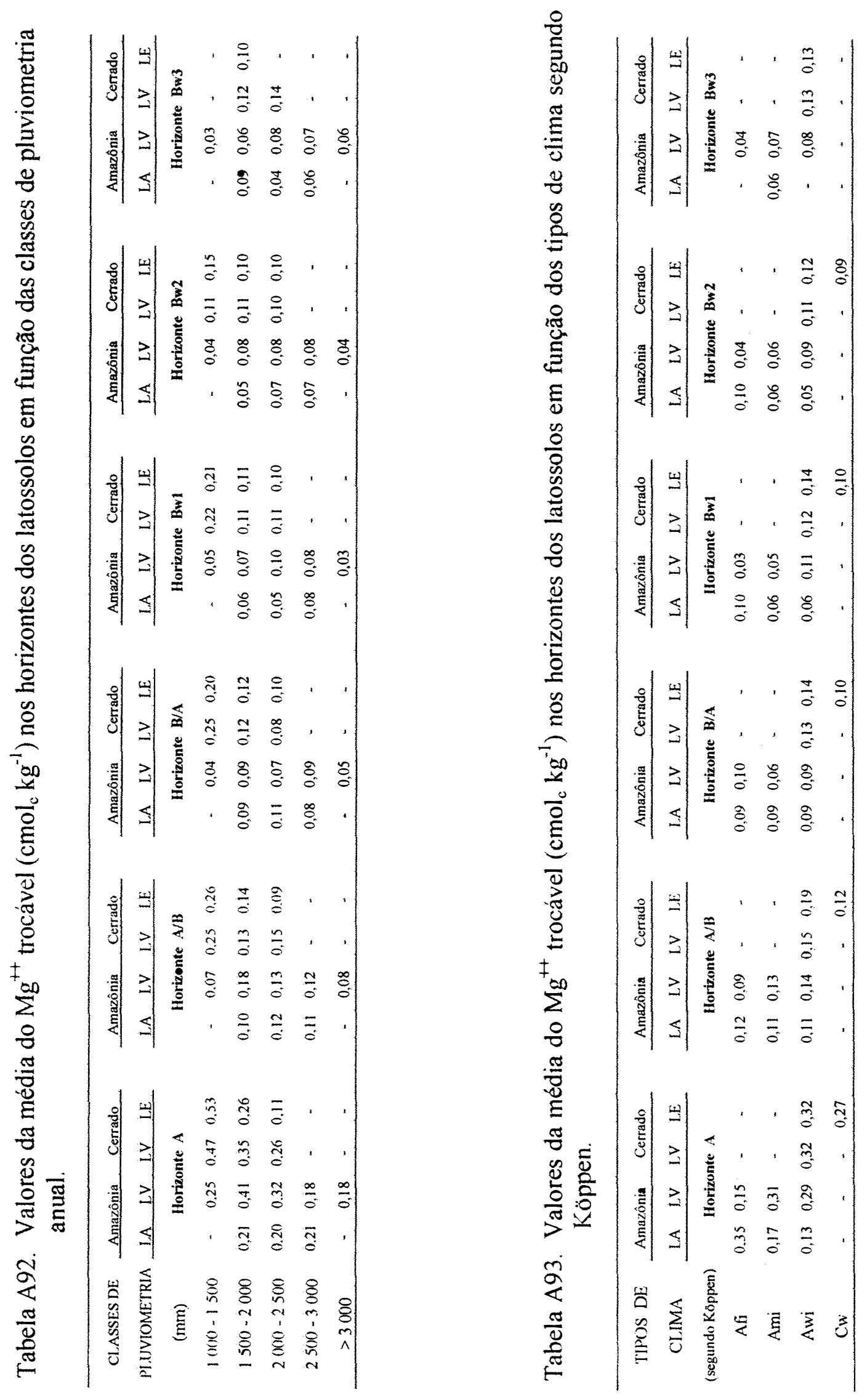

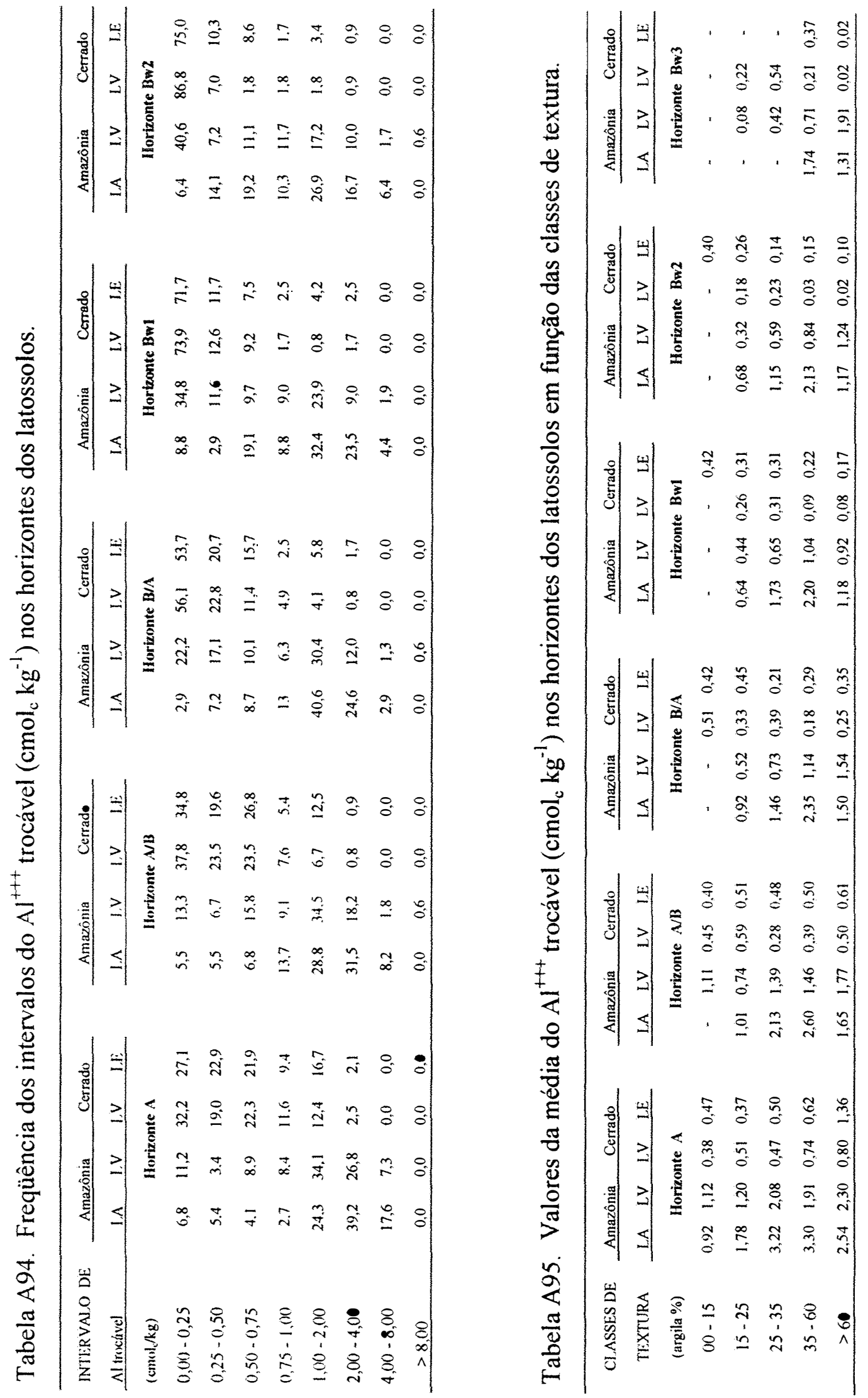

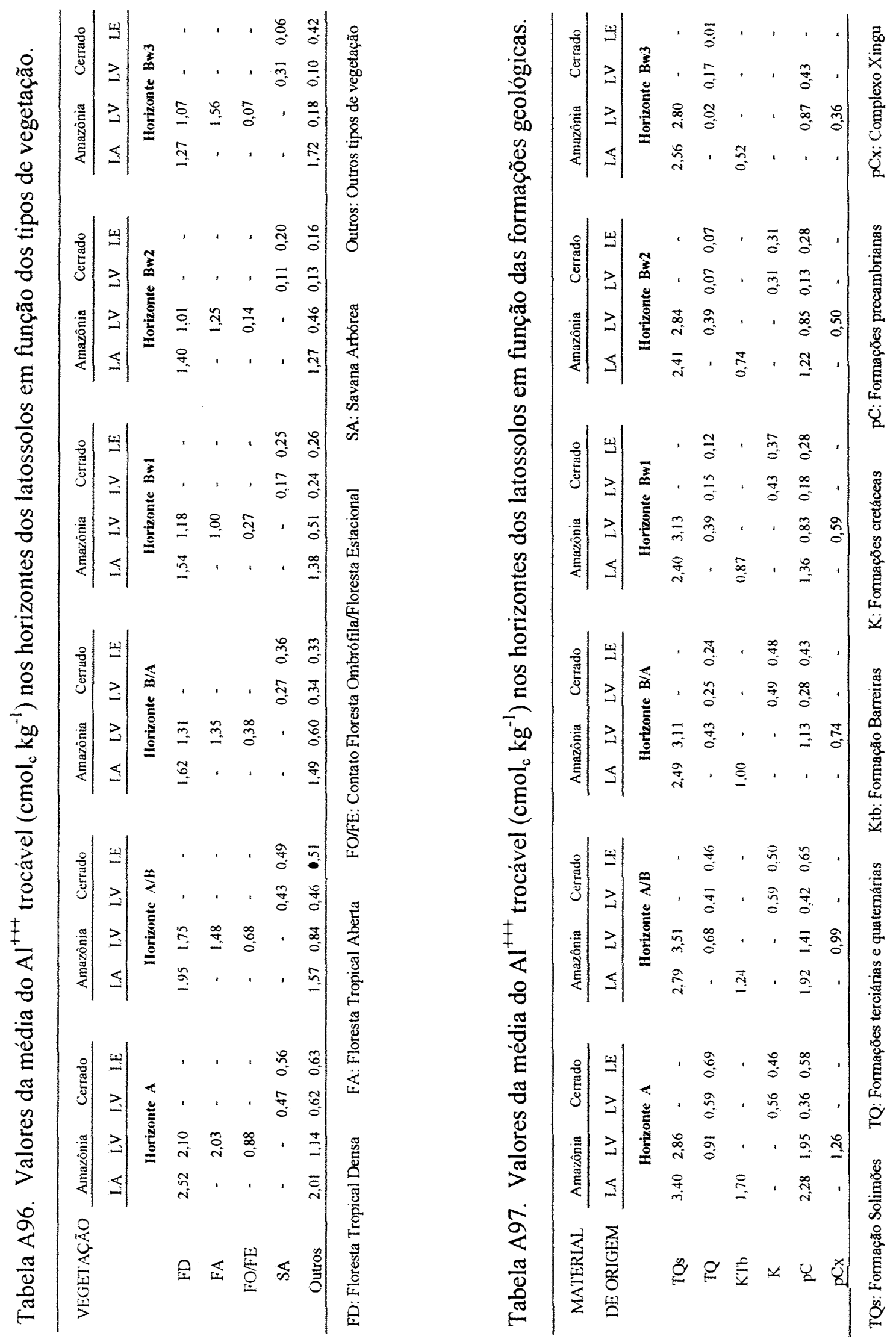

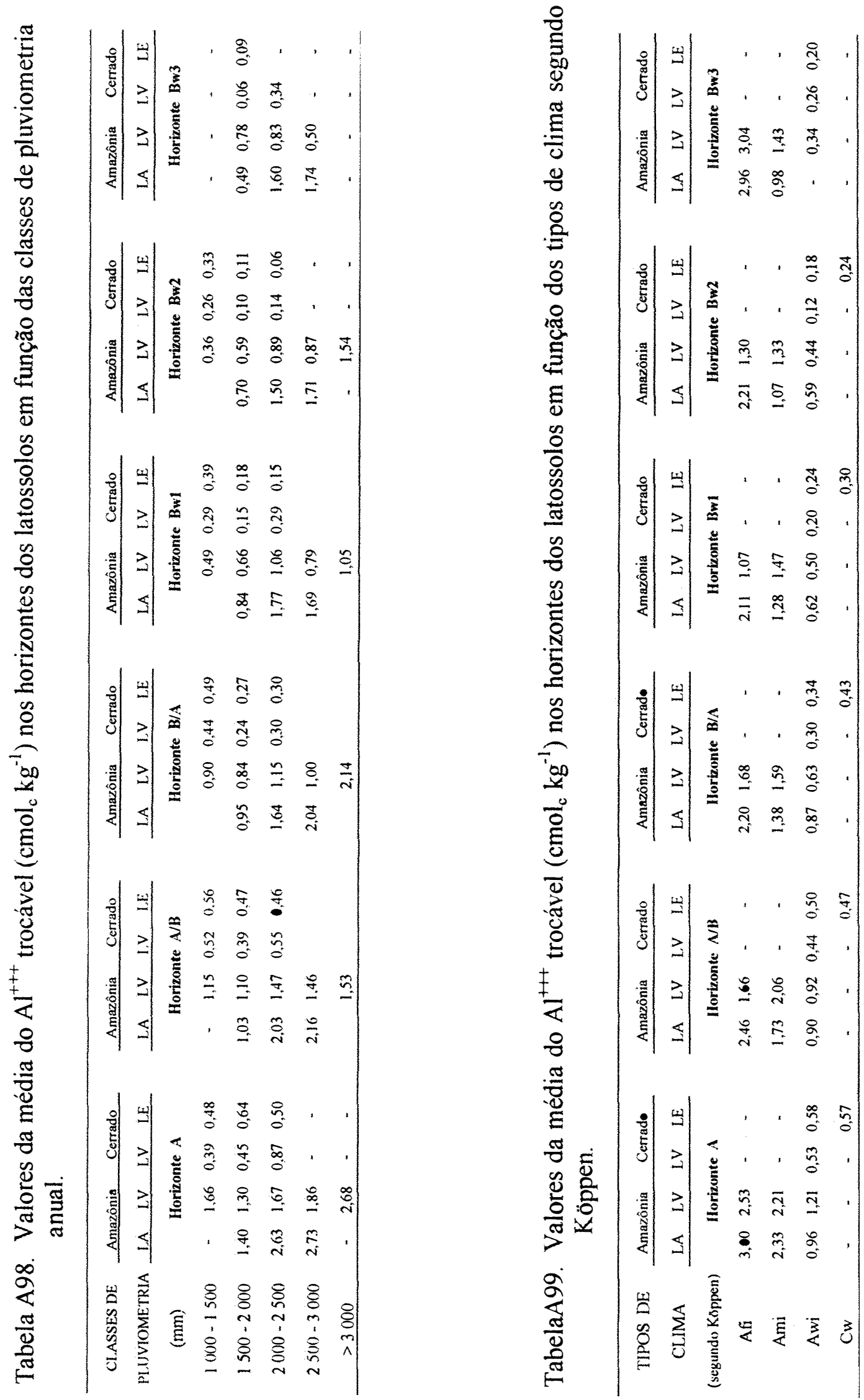

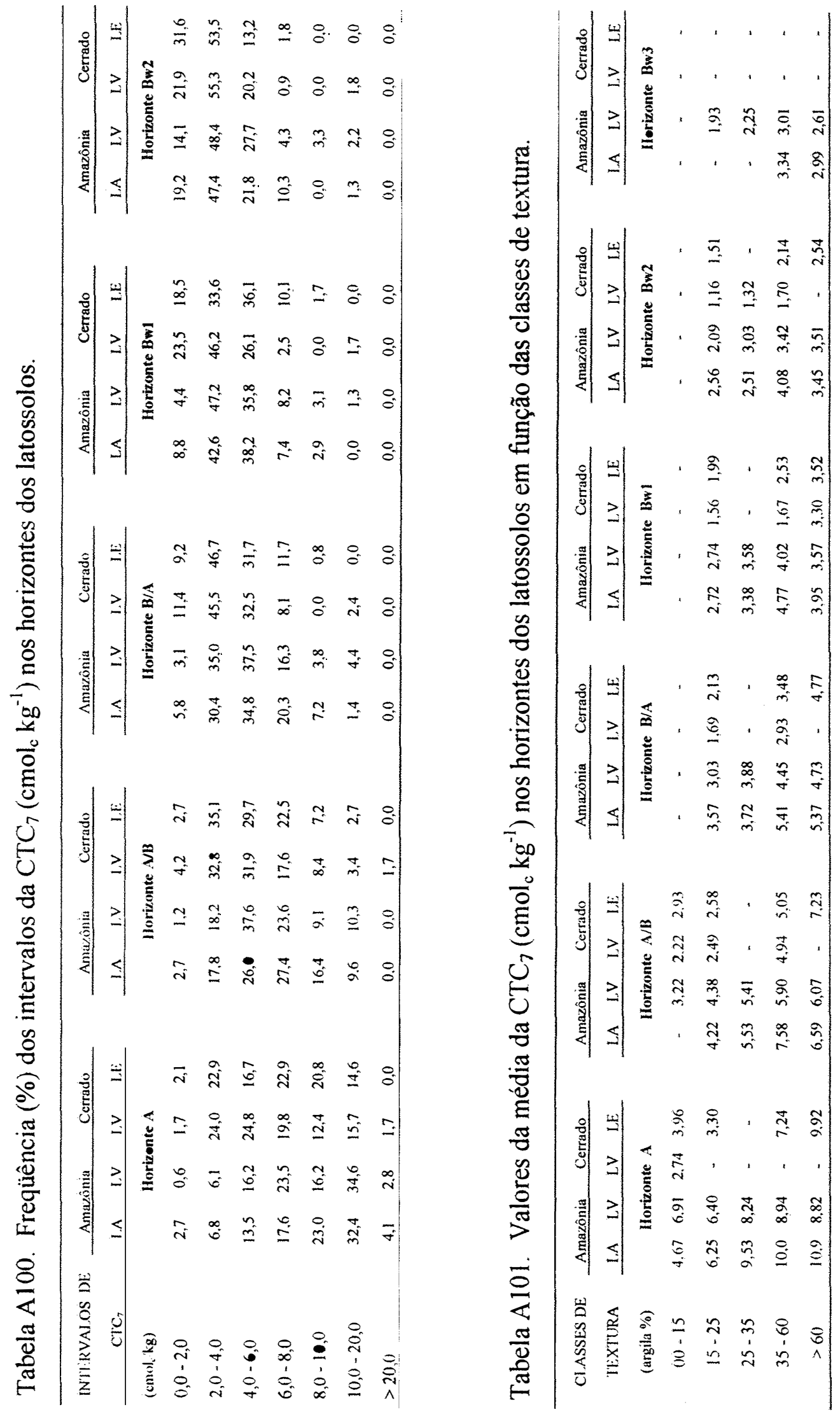

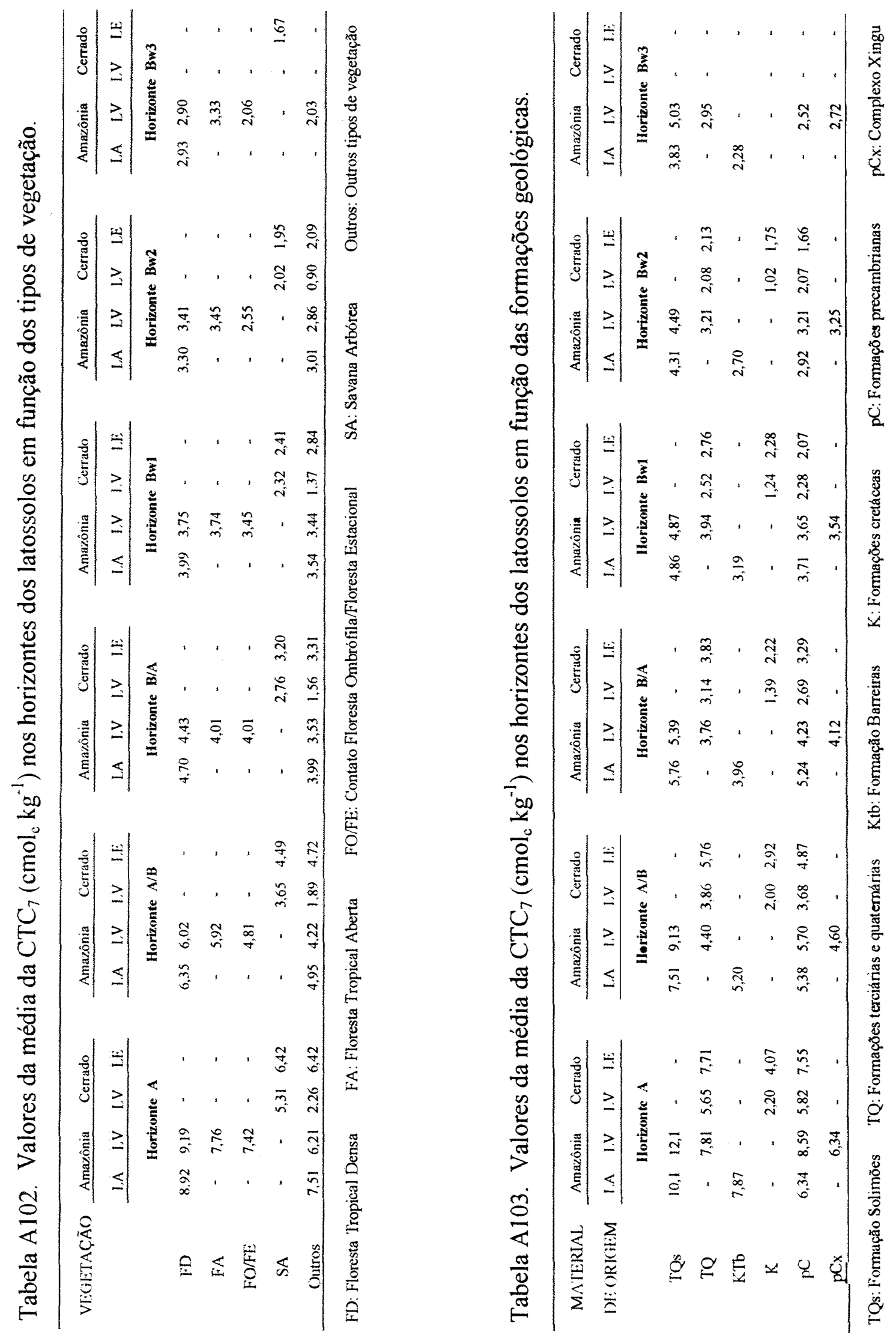

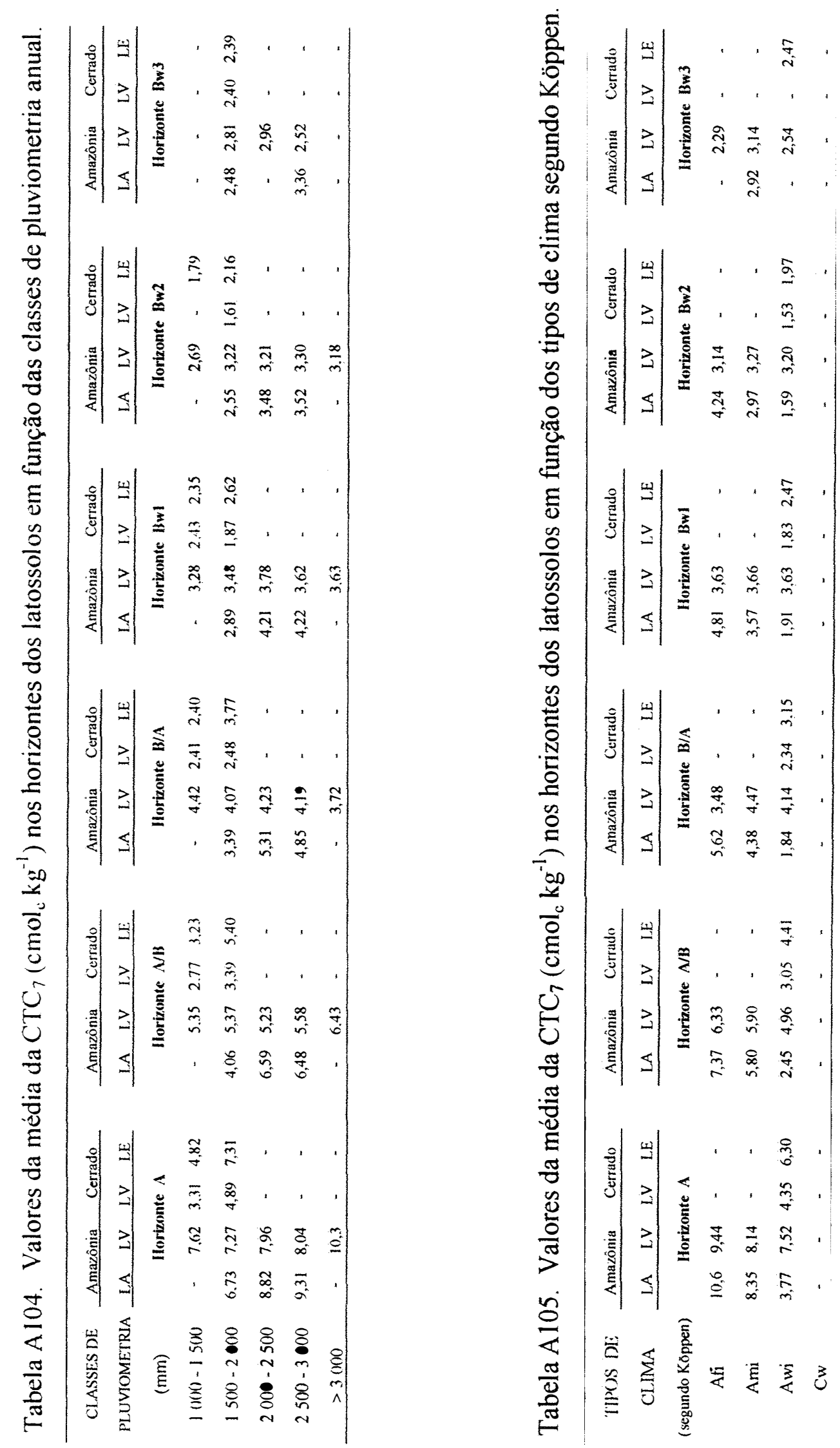


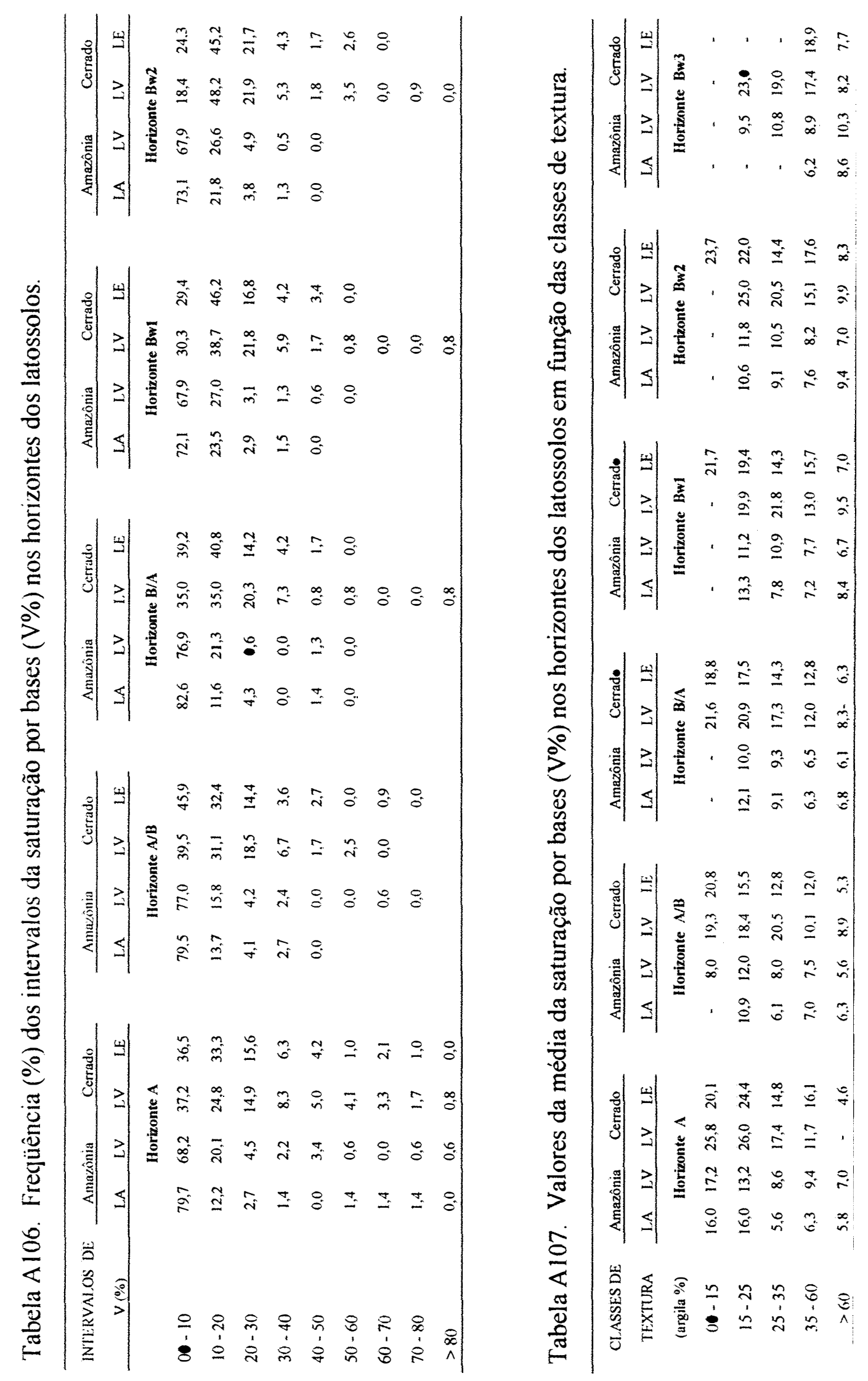




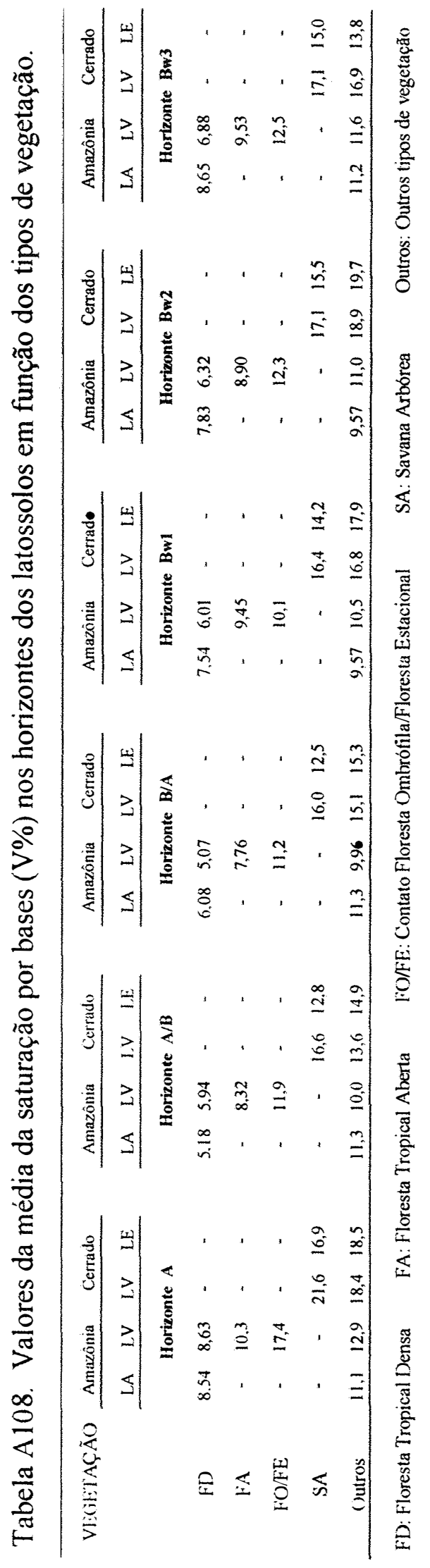

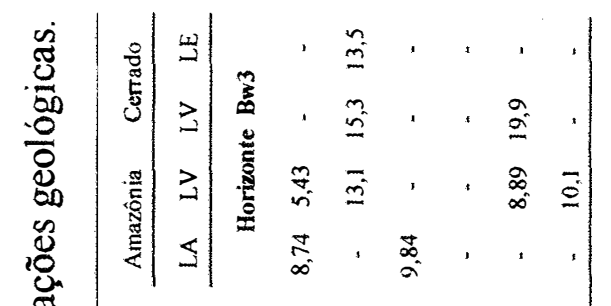

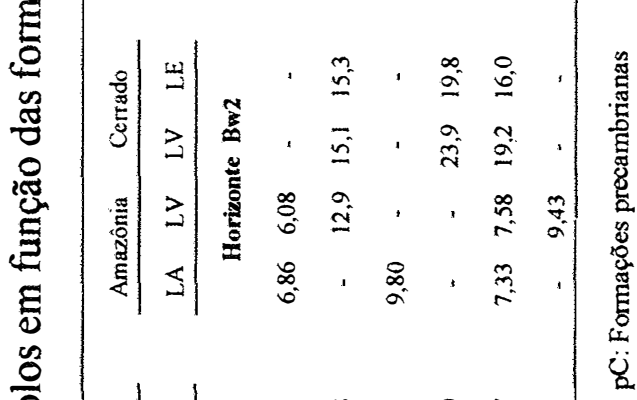

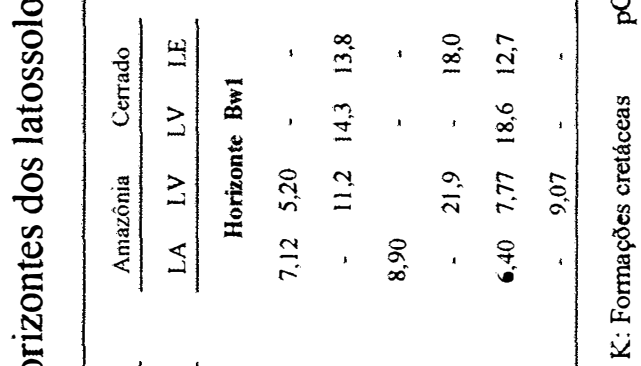

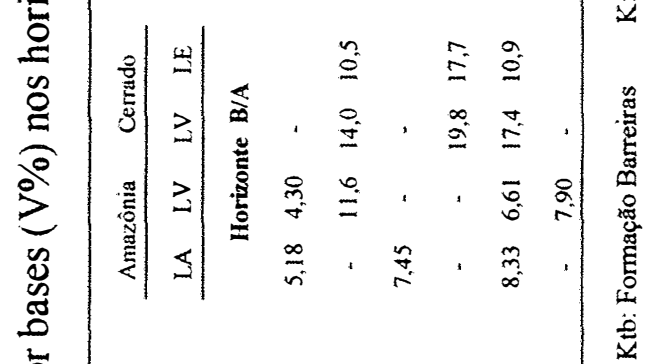

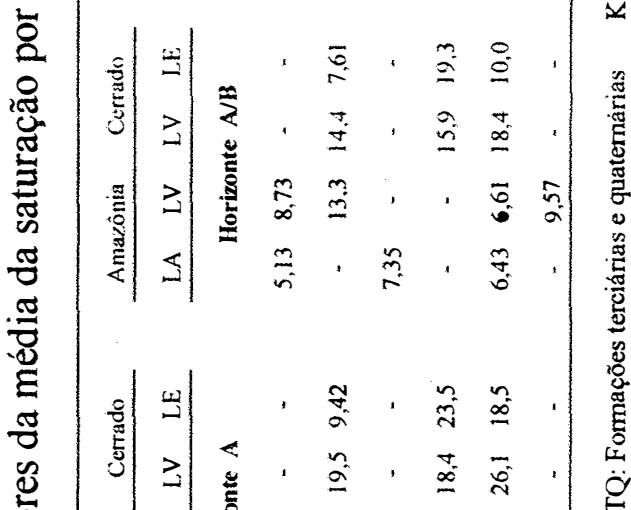

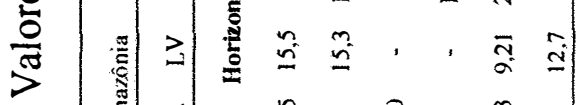

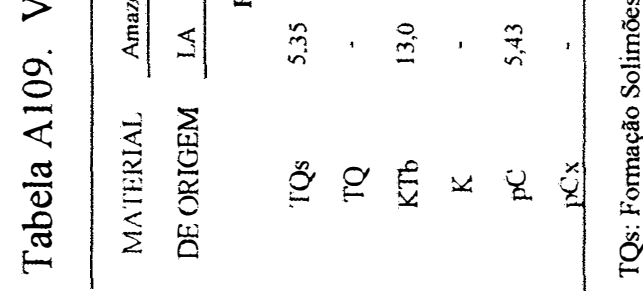



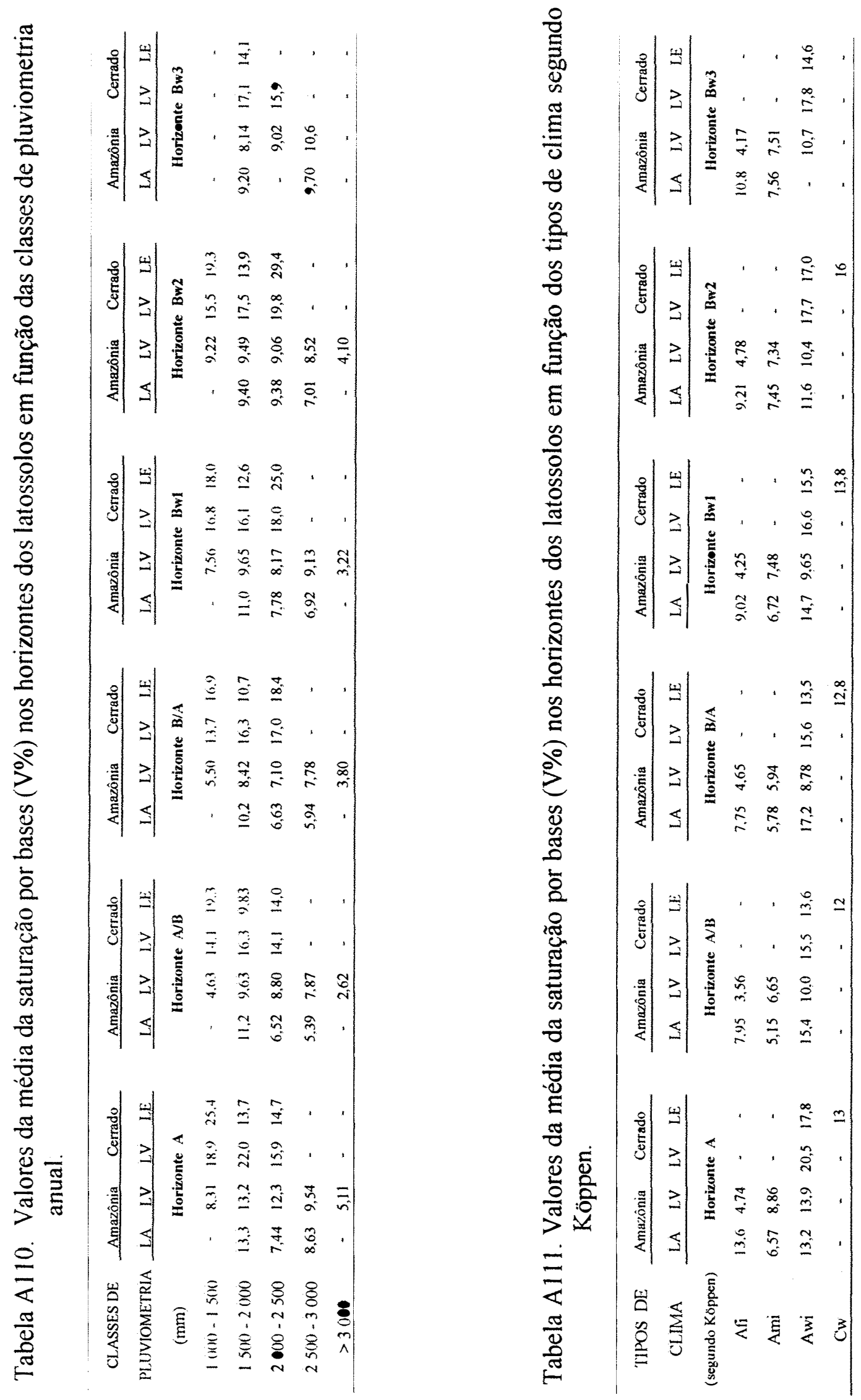


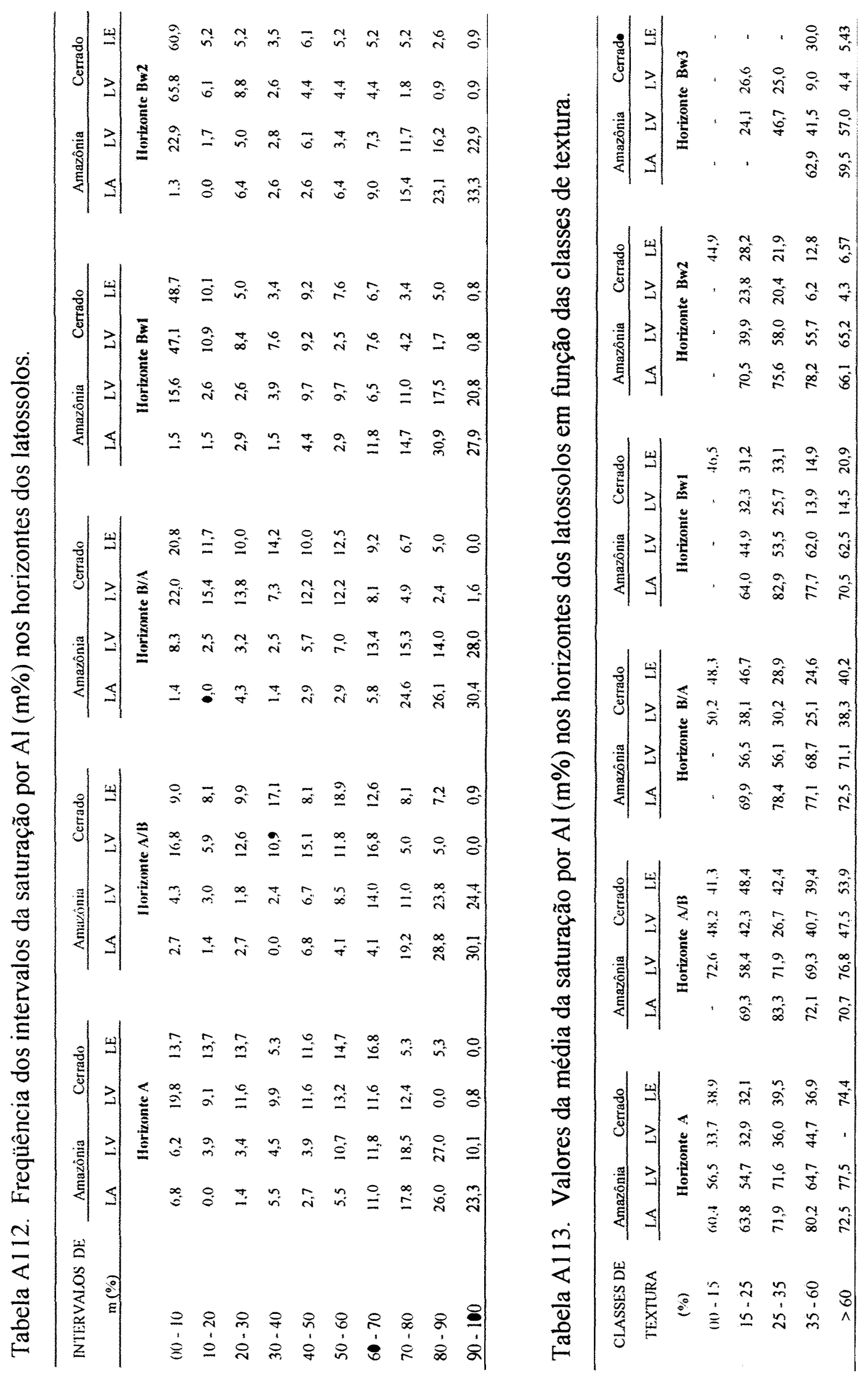



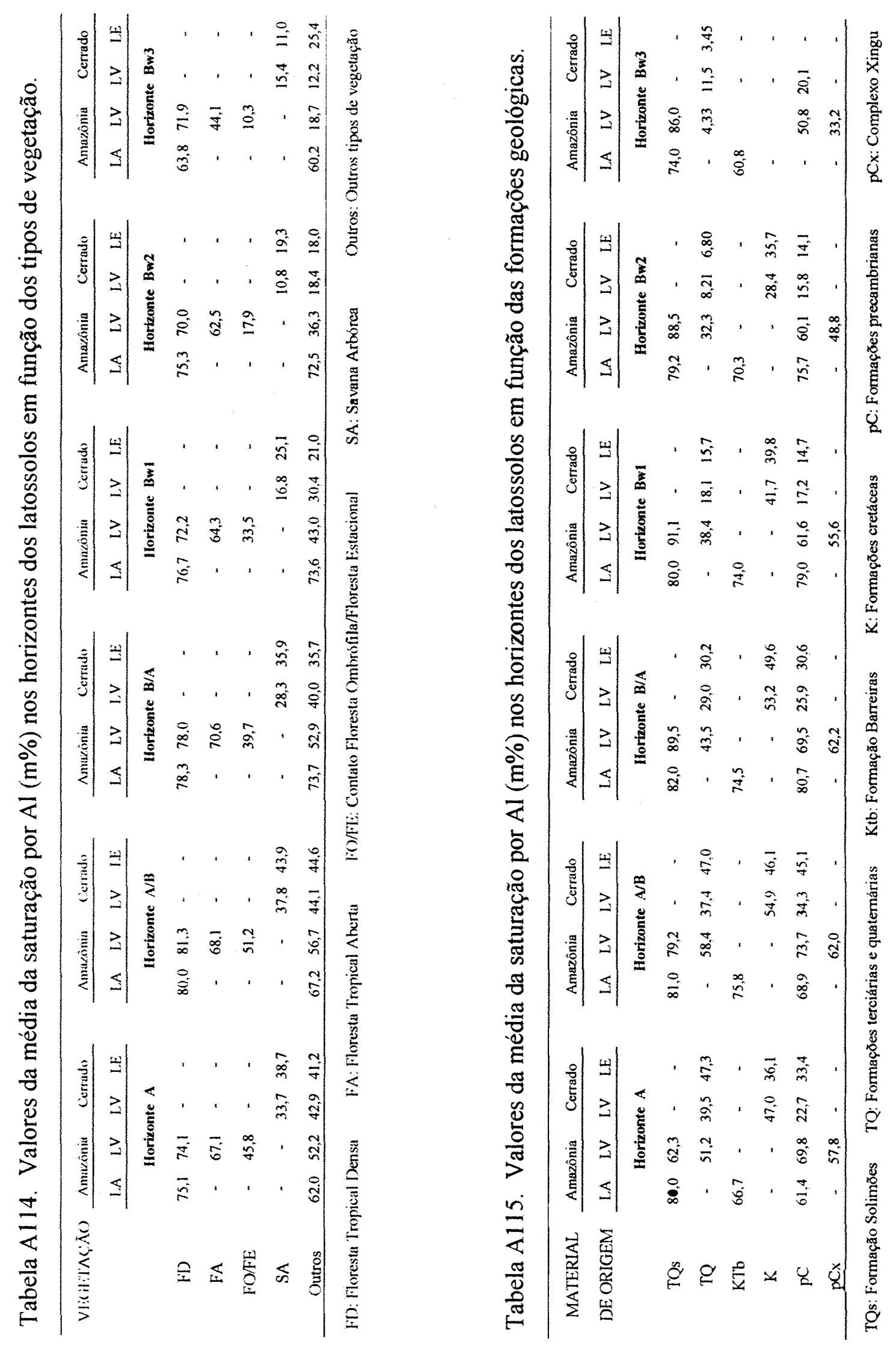

a 

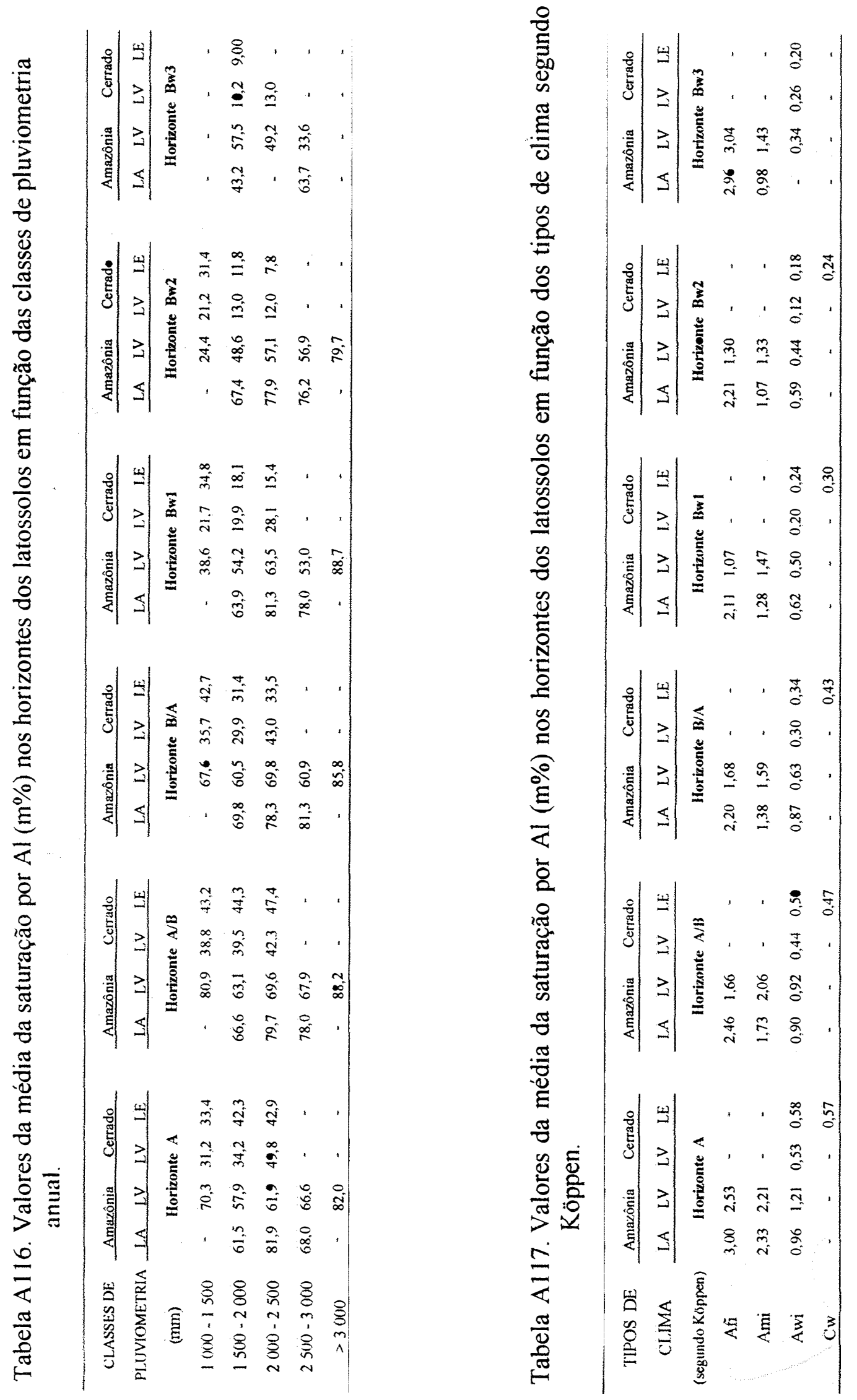

ล 